Illinois State University

ISU ReD: Research and eData

Theses and Dissertations

$2-24-2017$

\title{
Building Classroom Communities In A Pbis World: Voices Of Teacher Candidates As They Transition Into First-Year Teachers
}

Kira A. Hamann

Illinois State University, kiraannhamann@gmail.com

Follow this and additional works at: https://ir.library.illinoisstate.edu/etd

Part of the Education Commons

\section{Recommended Citation}

Hamann, Kira A., "Building Classroom Communities In A Pbis World: Voices Of Teacher Candidates As They Transition Into First-Year Teachers" (2017). Theses and Dissertations. 677.

https://ir.library.illinoisstate.edu/etd/677

This Dissertation is brought to you for free and open access by ISU ReD: Research and eData. It has been accepted for inclusion in Theses and Dissertations by an authorized administrator of ISU ReD: Research and eData. For more information, please contact ISUReD@ilstu.edu. 


\title{
BUILDING CLASSROOM COMMUNITIES IN A PBIS WORLD: VOICES OF TEACHER CANDIDATES AS THEY TRANSITION INTO FIRST-YEAR TEACHERS
}

\author{
Kira A. Hamann
}

\section{Pages}

For both beginning and veteran teachers, classroom management consistently ranks as one of their primary areas of concern (Hoy \& Woolfolk, 1990; Martin, Yin, \& Mayall, 2006; Oakes, Lipton, Anderson, \& Stillman, 2013; Veenman, 1983), and this concern is magnified in the early childhood years because these teachers are often the first service providers to interact with children exhibiting challenging behaviors (Powell, Fixsen, Dunlap, Smith, \& Fox, 2007; Tillery, Varjas, Meyers, \& Collins, 2010). Mixed messages in early childhood teacher preparation regarding the role of democracy and community in the classroom and the more behavioristic settings of field placements and first-year settings, such as in schools using the framework of Positive Behavior Interventions \& Supports (Sugai \& Horner, 2002), can contribute to this concern. Therefore, this qualitative study focused on exploring the perceptions and actions of early childhood teachers regarding their classroom management while teaching in schools using the PBIS frameworks, and as they graduated and became first-year teachers.

Using a collective case study (Stake, 1995; 2010) with ethnomethodological techniques (Garfinkel, 1967) design, 11 early childhood teachers were interviewed upon their graduation, and three were followed over their first year of teaching. Findings from this year-long study revealed a lack of classroom management preparation, feelings of unpreparedness, concerns of challenging student behavior, an overall mismatch in beliefs and experiences, and a persistent 
tension between classroom management practices, including PBIS, and feelings of community in early childhood classrooms. Findings also include yearlong impacts of school-wide attitudes and practices contextual factors, including administrative support, mentorship, and teacher selfefficacy on new teachers' ability to build classroom communities and establish strong classroom management practices.

KEYWORDS: Classroom Communities, Classroom Management, Early Childhood Education, New Teachers, Positive Behavior Interventions \& Supports, PBIS 
BUILDING CLASSROOM COMMUNITIES IN A PBIS WORLD: VOICES OF TEACHER CANDIDATES AS THEY TRANSITION INTO FIRST-YEAR TEACHERS

KIRA A. HAMANN

A Dissertation Submitted in Partial Fulfillment of the Requirements for the Degree of

DOCTOR OF EDUCATION

School of Teaching and Learning

ILLINOIS STATE UNIVERSITY 
Copyright 2017 Kira A. Hamann 
BUILDING CLASSROOM COMMUNITIES IN A PBIS WORLD: VOICES OF TEACHER CANDIDATES AS THEY TRANSITION INTO FIRST-YEAR TEACHERS

KIRA A. HAMANN

COMMITTEE MEMBERS:

Nancy Latham, Co-Chair

Amanda Quesenberry, Co-Chair

Beth Hatt

Sherry Sanden 


\section{ACKNOWLEDGMENTS}

This work has taken a career to create and has truly been a labor of love in its final days. It is imperative that I thank those who have helped me on my academic and professional journey and who have helped to make this work a reality.

First and foremost, thank you to the members of my committee. Without each of you, I would not be where I am today. To Dr. Latham, whose teaching in my undergraduate experience inspired me to become the best early childhood teacher I could become, and who welcomed me into my doctoral work with open arms, words cannot express my appreciation and gratitude for everything you have done for me, and the relationship we have built. Thank you for everything. An equal appreciation to Dr. Quesenberry who has been an ally, friend, and soul sister in her dedication to preschool, guidance, and social-emotional learning. Thank you for your wisdom, guidance, and friendship, and especially your support and feedback in the final hours of putting this piece together. To Dr. Hatt, taking your qualitative methods course was one of the best decisions I have ever made, as I have found in you a kindred spirit who sees the world through a similar lens as my own. Thank you for constantly supporting my work and vision for storytelling, as well as the endless hours spent reading and chatting about my process and writing over the years it has taken to complete this piece. With equal appreciation, thank you to Dr. Sanden. You have been a mentor to me in my work with teacher candidates since I began my program, and I have truly appreciated your grace, wisdom, and humor in all our work together, including this dissertation. Each of you has been a colleague, mentor, and friend to me, and to you, I will always be indebted.

I would like to acknowledge the love and support of my family through my doctoral process, especially the journey to complete my dissertation. While my family members did not 
always understand exactly what I was doing throughout the past six years of my program, everyone smiled while I tried to explain my work and supported me in their own way. My parents, especially, have always encouraged me to pursue my dreams, and they have cheered me on in every endeavor, including this process. From the bottom of my heart, thank you, Mom and Dad. I would not be who I am today without you both! I also want to thank my second family, my in-laws, who like my parents have offered words and actions of support since I was a teenager. I especially want to thank my mother-in-law, Connie, for her persistent words of encouragement and her willingness to drop everything and take care of John so I could write. This work is, in part, complete because of her! Also, I dedicate this work to my father-in-law, Ed, who also lived and within the world of academia, and who inspired and supported me in my decision to return to higher education. Countless times in writing these stories, I paused and thought through a conversation with Ed in my mind. While he is no longer with us today, I hope that this work is something of which he would have been proud, and in my heart, I know he would be.

A special thanks to all the teachers, teacher candidates, colleagues, and friends in the field who helped create the foundation for this study. To those from my first days in the field and with whom I currently work, without you, the fodder for this work would not exist. Also, thank you to my past young students for putting up with me as I worked through my own classroom management, especially in the first years, and to my current students for allowing me to hone my craft in teaching about classroom management as community-building over the past few years. To my colleagues within the School of Teaching and Learning at ISU, thank you for your endless words of support, guidance, and instruction in seeing this project and my journey to graduation through. To my doctoral classmates, huge thanks go out to each of you wherever you 
are across the country now, especially to Jay, Anni, Michael, Kristina, and Bre. Through smiles and tears, new learning, and great friendships, I have you to thank for helping me finally complete this project.

To my participants, especially "Molly," "Kristin," and "Vanessa," thank you for taking a chance and partnering with me over your first years of teaching. During this most vulnerable time, you allowed me to enter your teaching space and learn from you. Without you, this work would not exist, so from the bottom of my heart, thank you for your hospitality, as well as the hours and emotions you spent with me. I can never repay you for this kindness.

My final thanks go to my son, John, and my husband, Noah. John, while this "baby" of a dissertation began before you were born, it is for you, that I have persisted in this work. When you were born mid-study, it would have been all too easy to leave this work and spend all my time with you, as you filled my heart in ways that I never thought possible. However, I now realize that I have persisted in seeing this through because I need to help ensure your future classrooms are the kinds of places where I want you to learn and grow. You may have a new teacher in your first years of school like the participants of this study. Know that I will do everything in my power to help him or her feel confident in building a sense of community to ensure that you are supported, guided, and loved.

Noah, you have seen this project from the very beginning, on my path to become a teacher, to the very end, in these final days of editing. I cannot explain how much your words of encouragement, hugs through tears, insightful questions, well-played Dreikurs' jokes, persistence in the face of me giving up, understanding of the workload, and overall support of my "eggheaded-ness" have meant to me. Simply, thank you. 


\section{CONTENTS}

Page

ACKNOWLEDGMENTS

CONTENTS

TABLES - ix

FIGURES

CHAPTER I: INTRODUCTION 1

$\begin{array}{ll}\text { Statement of the Problem } & 4\end{array}$

$\begin{array}{ll}\text { Purpose of the Study } & 8\end{array}$

$\begin{array}{ll}\text { Research Questions } & 8\end{array}$

$\begin{array}{ll}\text { Significance of the Study } & 8\end{array}$

Definition of Terms $\quad 9$

$\begin{array}{ll}\text { Chapter Overview } & 11\end{array}$

CHAPTER II: SITUATING THE STUDY 12

Murkily Explained: Classroom Management 12

Teachers' Possible Pasts, Presents, and Futures with Classroom Management 14

Teacher Candidate and New Teacher Perceptions 14

Preparation for Classroom Management 16

Current Realities of Classroom Management in the Early Childhood Years 21

Positive Behavior Interventions \& Supports (PBIS) 21

A Sense of Community \& PBIS $\quad 24$

$\begin{array}{ll}\text { The "Two-Worlds Pitfall” } & 27\end{array}$

Studying Classroom Management 29 
As Lived Experience $\quad 29$

From an Integrated Perspective $\quad 30$

$\begin{array}{ll}\text { In Context } & 35\end{array}$

$\begin{array}{ll}\text { Through Theory: Interpretivism } & 36\end{array}$

Summary of Review of Literature $\quad 37$

CHAPTER III: RESEARCH METHODOLOGY \& DESIGN 39

Collective Case Study Using Ethnomethodological Techniques $\quad 40$

$\begin{array}{ll}\text { Design } & 41\end{array}$

Settings

$\begin{array}{ll}\text { Participants } & 43\end{array}$

$\begin{array}{ll}\text { Data Collection } & 46\end{array}$

Data Analysis $\quad 53$

$\begin{array}{ll}\text { Issues of Trustworthiness } & 57\end{array}$

$\begin{array}{ll}\text { Ethics } & 58\end{array}$

Summary of Research Methodology \& Design $\quad 67$

CHAPTER IV: AN “OVERWHELMING” TENSION: PRELIMINARY FINDINGS 68

$\begin{array}{ll}\text { Discussion of Themes } & 68\end{array}$

Lack of Preparation in Classroom Management 68

$\begin{array}{ll}\text { Varied Perceptions of PBIS Implementation } & 70\end{array}$

Anxiety in Balancing Classroom Management and Teaching 72

Entrenchment in the "Two-Worlds Pitfall"

A Tension Between Community, Classroom Management, and PBIS 76

$\begin{array}{ll}\text { Summary and Next Steps } & 80\end{array}$ 
The Path to Become a Teacher $\quad 84$

$\begin{array}{lr}\text { Student Teaching } & 84\end{array}$

On the Job Hunt $\quad 86$

The Context of Molly's First Year $\quad 89$

$\begin{array}{lr}\text { Molly's School Context } & 89\end{array}$

$\begin{array}{ll}\text { Molly's Classroom Context } & 98\end{array}$

A Year in Her Life as a First-Year Teacher 111

The Beginning of the Year: "I Came in Blind..."

In the Fall: "It's Been Kind of Difficult..." 121

The Middle of the Year: "Complicated." 130

Into Springtime: “I’m Moving Home.” 143

The End of the First Year: "I’m Just Glad I Did It." 153

Beyond the First Year: "Hopefully, It Will Be Different." 165

$\begin{array}{ll}\text { Molly's Year, a Metaphor } & 169\end{array}$

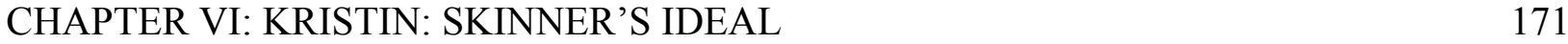

The Path to Become a Teacher 172

$\begin{array}{ll}\text { Student Teaching } & 172\end{array}$

$\begin{array}{ll}\text { On the Job Hunt } & 174\end{array}$

The Context of Kristin's First Year 176

$\begin{array}{ll}\text { Kristin's School Context } & 176\end{array}$

$\begin{array}{ll}\text { Kristin's Classroom Context } & 184\end{array}$

A Year in Her Life as a First-Year Teacher 199 
The Beginning of the Year: "In Every Classroom, There's a Clip Chart."

In the Fall: “...They Love Moving Up!”

The Middle of the Year: "Your Kids Are the Most Polite [sic]..."

The End of the First Year: "I Think the Color Chart Has Worked Wonders..."

Beyond the First Year: “What Can We Do Better, and What Do These Kids Need?" 260

Kristin's Year, a Metaphor

The Path to Become a Teacher

Student Teaching

On the Job Hunt

The Context of Vanessa's First Year

Vanessa's School Context

Vanessa's Classroom Context

A Year in Her Life as a First-Year Teacher

The Beginning of the Year: "My Head Is Above Water..."

In the Fall: "I Really Got to Step Away from Using These Kinds of Supports."

The Middle of the Year: "I Don't Mean to Toot My Own Horn..."

Into Springtime: “...Doing So Much More than Surviving.”

The End of the First Year: "It's Been a Good Year."

Beyond the First Year: "I'm So Excited!"

Vanessa's Year, a Metaphor 
Summary

In Sum, the First Research Question

In Sum, the Second Research Question

Reflection: My Dissertation Within the "Two-Worlds Pitfall"

Next Steps

Into the Future, the Third Research Question

My Next Steps

In Conclusion

REFERENCES 


\section{TABLES}

Table $\quad$ Page

1. Case Study Site Demographics 42

2. Focus Group Participant Demographics 45 


\section{FIGURES}

Figure $\quad$ Page

1. Data Collection Techniques 47

2. Molly: Classroom Map (9/14-5/15) 99

3. Molly: Bulletin Board Displays (9/14-5/15) 100

4. Molly: Alphabetized Name Display-Community Builder (9/14-5/15) 101

5. Molly: Daily Schedule (9/14-5/15) 107

6. Molly: Field's PBIS Rewards Chart (9/14-5/15) 113

7. Molly: Classroom Behavior Monitoring System (9/14-5/15) 114

8. Molly: Mrs. Thompson's Classroom Rules Poster (9/14-5/15) 116

9. Molly: Parent Communication for Classroom Management (9/14-5/15) 117

10. Molly: Rug Behavior Guidelines \& Reminders (9/14-5/15) 119

11. Kristin: Classroom Map (11/14-5/15) 187

12. Kristin: Kindergarten-wide Behavior Monitoring Clip Chart (11/14-5/15) 202

13. Kristin: Classroom Rules Posters (11/14-5/15) 204

14. Kristin: Classroom Attention-Getter Poster (11/14-5/15) 206

15. Kristin: Individualized Behavior Expectation Flashcards (11/14-5/15) 214

16. Kristin: Individualized Behavior Incentive Chart for Two Students (11/14-5/15) 215

17. Kristin: Individualized Behavior Expectation Visual on Table Spot (11/14) 216

18. Kristin: Calm-down Corner (11/14-5/15) 217

19. Kristin: Individualized "If-Then" Chart on Table Spot (1/15) 230

20. Kristin: Rug Behavior Guidelines Poster (11/14-5/15) 233

21. Kristin: Unused Behavior Guidelines Posters (11/14-5/15) 234 
22. Kristin: Literacy Small Groups Organizational Chart (3/15-5/15)

23. Vanessa: Classroom Map (11/14-6/15)

24. Vanessa: Sight Word Success Ladder-Community-Builder (11/14-6/15)

25. Vanessa: Classroom Photos (11/14-6/15)

26. Vanessa: Posted Daily Schedule (11/14-6/15)

27. Vanessa: Behavior Guidelines for Seatwork Chart (11/14-6/15)

28. Vanessa: Rug Behavior Guidelines Posters (11/14-6/15)

29. Vanessa: PBIS Student Incentive Tickets (11/14-6/15)

30. Vanessa: PBIS Expectations Anchor Chart (11/14-6/15)

31. Vanessa: PBIS Rules Class-Created Anchor Charts (11/14-6/15)

32. Vanessa: PBIS Student Incentive Ticket Storage System (11/14-6/15)

33. Vanessa: School-Wide Voice Level Chart (11/14)

34. Vanessa: Behavior Monitoring Clip Chart (11/14-6/15)

35. Vanessa: PBIS Whole-Class Rewards Charts (11/14)

36. Vanessa: Prize Box \& Class-Wide Incentive Pompom Jar (11/14-6/15)

37. Vanessa: Writing Guidelines for Kindergarten $\& 1^{\text {st }}$ Graders $(1 / 15-6 / 15)$

38. Vanessa: PBIS Incentive Chart-Community-Builder (1/15)

39. Vanessa: Individualized Behavior Contract (1/15)

40. Vanessa: Math Guidelines Chart (3/15-6/15) 348

41. Vanessa: Individualized Behavior Monitoring Charts (3/15-6/15)

42. Vanessa: Individualized Behavior Guidelines (3/15)

43. Vanessa: PBIS Cool Tool WBT Behavior Scorecard (3/15)

44. Vanessa: PBIS Cool Tools Friends Writing Activity (3/15) 
45. Vanessa: School-Wide End-of-Year Countdown Challenge (6/15)

46. Vanessa: Mini-Lesson Read-Aloud-Community-Builder (6/15)

47. Vanessa: PBIS Cool Tools Student Drawings (6/15)

48. Molly: Collection of Classroom Management Artifacts

49. Kristin: Collection of Classroom Management Artifacts

50. Vanessa: Collection of Classroom Management Artifacts

51. Contextual Influences on Classroom Management of Teacher Candidates $\&$ New Teachers 


\section{CHAPTER I: INTRODUCTION}

The perfect early childhood community: a warm, comfortable environment filled with bright colors, laughter, and play; children growing independently and collectively through engaging read-alouds, experiments, and songs... Of course, there would be no arguing, tears, or tantrums; everyone would be too engaged in meaningful learning to fall prey to social-emotional issues. Having heard messages supporting these images throughout my teacher preparation program, these were all ideas of the picture-perfect early childhood classroom that I envisioned as an early childhood teacher candidate. The realities of my first real teaching position painted quite a different picture. Demands on a new teacher working in an inner-city public pre-k classroom were varied and vast, the greatest of which was what I had predicted would be the least of my concerns: my classroom community. Surprisingly, no matter how much or how well I planned, organized, and prepared my teaching, my young students still seemed to struggle with getting along, working together, and staying on task. No amount of fantastic, creative lesson planning, brightly colored stickers, or well-crafted consequences/ punishments seemed to make a difference. My sense of self-esteem as a new teacher plummeted as I realized that despite being well prepared for the academic and developmental needs of my students, I had very little understanding of how to address their social-emotional needs. Thus, my overall classroom management suffered. I often questioned, “Why hadn't I learned this in college? What can I do now?"

For both beginning and veteran teachers, classroom management ranks as one of their primary areas of concern, and it is one of the major influences on student learning (Hoy \& Woolfolk, 1990; Martin, Yin, \& Mayall, 2006; Stough, Montague, Landmark, \& WilliamsDiehn, 2015). Like me, new teachers, especially, rate managing behavior as one of the most 
challenging aspects of teaching, and an area in which they feel the most unprepared (Hoy \& Woolfolk, 1990; Veenman, 1984; Oakes, Lipton, Anderson, \& Stillman, 2013). This worry carries over from their teacher preparation, in which a majority rank classroom management concerns as the most pressing (Cakmak, 2008; Chesley \& Jordan, 2012; Clement, 2010; Hoy \& Woolfolk, 1990; Kaufman \& Moss, 2010). Although my teacher preparation included no specific coursework or guidance in establishing strong classroom management, like within many teacher preparation programs, messages of establishing a classroom community through relationships and fantastic instruction were at the core of my early childhood program (Wisneski, 2005). These messages contrasted sharply with the dominance of traditional, reactive, and controlling classroom management that I had experienced growing up, both in the apprenticeship of observation (Lortie, 1975) of my K-12 years, as well as in the formal field placements of my preparatory experiences.

During my teacher preparation, I was lucky enough to be placed for a one-semester clinical experience in a very progressive school that used a specific humanistic approach to classroom management, Positive Discipline in the Classroom (Nelson, Lott, \& Glenn, 2000). At the time, this experience seemed out of place with the repetitive experiences of reactive and controlling classroom management I had observed in my own schooling and in my other clinical experiences. Thankfully, in the frustration of my first year of teaching in the Chicago Public Schools, I remembered that the cooperating teacher with whom I worked that semester had had a specific way in which she established her classroom community and the positive outcomes this created. Thus, with no real direction from my school or other easily-identified resources, I reached out to her. With her guidance and my own self-determination, I began to reflect upon my management practices, study theory and approaches, implement new ideas, and summarily 
improve my overall classroom management skills, while continuing to work through my first years of teaching.

Colleagues in my school and old friends from my teacher preparation program echoed my concerns with classroom management. Their stories highlighted children arguing, class time being interrupted, and an overall lack of cohesion throughout their days. Although problems with discipline are not the top anxieties for all beginning teachers (Ganser, 1999), studies consistently find discipline issues as one of the top reasons that new teachers leave the field within the first three years (Gonzalez, Brown, \& Slate, 2008; Kukla-Acevado, 2009; Lueckens, Lyter, \& Fox, 2004; Marvel, Lyter, Peltola, Strizek, \& Morton, 2006). Those that do not may spend an inordinate amount of time in the classroom establishing their classroom management (Evertson \& Harris, 1992). While not all my new teacher colleagues left the field due to classroom management issues, a few attributed this as to why they left the field quickly.

At the time, the topic of new teachers' classroom management struck me as problematic and led me to begin to share with other concerned teachers the new knowledge that I was learning about how to set up the classroom environment and my daily schedule, facilitate problem-solving, and focus on finding solutions with young children, among others. Because my skills in building classroom community were heading in a positive direction, my administrators began to ask me to lead professional development on this topic for both parents, pre-service, and in-service teachers, all while I was teaching full-time in my pre-k classroom. The participants of my professional development sessions consistently ranked classroom management as one of their top concerns. They reported to me that they felt as overwhelmed as I had been and attributed this to a lack of preparation in their own teacher education programs, which mirrored reports from research in the field that teacher candidates tended to be very 
underprepared for classroom management (Chesley \& Jordan, 2012; Clement, 2002; Kee, 2011; Liston, Whitcomb, \& Borko, 2006; Tal, 2010).

Although my frustrations with my own classroom management had dissipated by this point, my intrigue with the topic of classroom management preparation had grown significantly. What was taking place at the university level? Why were teacher candidates and new teachers continuing to feel under-prepared for establishing community? What impact did school-wide supports and programs have on this? These questions led me back to higher education to explore this topic more deeply.

\section{Statement of the Problem}

Whether the beginning is easy or agonizing, a feeling of survival tends to categorize the first year of teaching as teachers navigate discipline and management problems (Liston et al., 2006). Teachers in the early childhood years of education, including preschool through third grade, may be especially prone to classroom management stresses because they work with students who may enter school without the prerequisite social-emotional or behavioral skills needed to succeed and may be the first to recognize, work with, and screen challenging behaviors in young children (Powell et. al, 2007). As they attempt to stay afloat in the first year of teaching, many new teachers use strategies and behaviors that are damaging to the learning environment including those that are controlling and reactive in nature (Martin et al., 2006). Although many behavioral problems can be avoided by establishing a solid classroom management plan and building a strong classroom community at the beginning of the school year (Capizzi, 2009; Wolfgang, 2001), many new teachers are unprepared because classroom management preparation requirements and components vary from state to state (Freeman, Simonsen, Briere, MacSuga-Gage, 2014). Nevertheless, studies show that classroom 
management training in teacher preparation can positively impact teachers' attitudes towards classroom management and teaching in general (Christofferson \& Sullivan, 2015; Kaufman \& Moss, 2010; Putman, 2009; Tal, 2010).

When teacher candidates are prepared for classroom management in college coursework, they are often confronted with challenges to this preparation in their programs' field experiences. Many school districts want universities to more closely align their teacher training with the realities of high-stakes testing (Tellez, 2008), and cooperating teachers often see their role as the ones to initiate TCs into the real world (Clement, 2002). The expectation that teacher education programs are responsible for both promoting culturally-relevant, developmentally-appropriate instruction, and for being flexible to school settings, creates challenges for teacher preparation programs (Smith \& Avetisian, 2011).

Teacher candidates' developing beliefs become especially problematic when university teacher preparation messages of inclusion, community, and democratic values seem to sharply contrast with classroom and behavior management programs and frameworks that teacher candidates experience in their final field placements and first years of teaching. Historically, schools have played a critical role in bringing children from all walks of life together, helping to build a foundation of democracy and community (Serriere, 2010; Oakes, Lipton, Anderson, \& Stillman, 2013; Quinn, 2011). Simultaneously, efforts to control children's behavior have been present since the first American schools (Adams, 2011; Oakes et al., 2013). In the late 1800's and early 1900's, classroom management in schools modeled factory-like expectations and conditions (Kliebard, 2004; Oakes et al., 2013). This mentality persisted with an acceptance of Pavlov and Thorndike's promises of behavioristic rewards and punishments and now manifests itself in more recent promotions of behavior modification approaches based on the work of B. F. 
Skinner (Oakes et al., 2013). The mindset of control being akin to classroom management has persisted (Oakes et al., 2013).

Competing classroom management goals and practices can create a strong disconnect for teacher candidates between what they have learned in the university, and what they are experiencing in the reality of field experiences, especially in their visions and goals of the student teaching experience (Rajuan, Beijaard, \& Verloop, 2007, 2010; Smith \& Avetisian, 2011). Often referred to as the "two-worlds pitfall" as coined by the work of Feiman-Nemser and Buchmann in 1983 (p. 10), this influential part of a teacher's training can have serious consequences for later practice, both positive and negative (Anagnostopolous, Smith, \& Basmidjan, 2007; Hoy \& Woolfolk, 1990; Smith \& Avetisian, 2011; Zeichner, 2010). The setting of the placement is a critical context variable in teacher candidates' efficacy beliefs (Knoblauch \& Hoy, 2008; Putman, 2009). Teaching self-efficacy refers to the self-evaluations that teachers conduct in the process of teaching (Tschannen-Moran, Hoy, \& Hoy, 1998). Beliefs that are formed from these self-evaluations can have a tremendous impact on overall teacher persistence, motivation, and effectiveness (Hoy \& Woolfolk, 1990; Knoblauch \& Hoy, 2008). While my initial years were rife with these contradictory and competing messages, in the current stage of accountability, mandates, and requirements, the experience may be even more intense for teacher candidates and new teachers. One model that has been increasingly used in American schools is that of Positive Behavioral-Intervention Supports (PBIS). It was originally used as a preventative approach for students with severe disabilities as an alternative to punitive discipline measures, but it has since been transformed into a school-wide approach (Sugai, Sprague, Horner, \& Walker, 2000). To truly examine this framework, it is necessary to understand that there is considerable variability in how it is currently operationalized across the 
country (Center for Mental Health in Schools at UCLA, 2011). PBIS takes on different attributes and traits in different settings, which is often related to variations in understanding and implementation (Molloy, Moore, Trail, Van Epps, \& Hopfer, 2013). Molloy and her colleagues found that as with any innovation in school settings, focus on PBIS implementation is often underemphasized, but is truly necessary for change to occur.

Although some research has examined the social validity of PBIS (including teacher viewpoints) from a consumer-business standpoint and a quantitative research perspective (Miramontes, Marchant, Heath, \& Fischer, 2011), there is little to no research using qualitative methods to examine teacher candidate and new teacher viewpoints on PBIS and its effects on classroom community. The perceptions and actions of those who are using this framework is what the current research examining PBIS fails to address. While anecdotal evidence, including accolades and critiques from teachers, is found in online blogs and websites, within the extant literature, there seems to be a dearth of research examining PBIS from the perspective of those using it and affected by it, including teacher candidates and new teachers.

Moreover, PBIS has been noted for being very top-down and teacher-controlled (Adams, 2011; Bower, 2010). This may present specific issues for early childhood teacher candidates and first-year teachers placed in settings using this framework, especially if their classroom management preparation focused instead on democratic values and building community in the early childhood years (Boutte, 2008; NAEYC, 2009; Serriere, 2010). Additionally, although PBIS is being increasingly implemented across the country, little consideration has been paid to whether this framework contributes to strengthening or harming the development of classroom and school communities. This is especially true from the perception of the teacher candidate housed within these settings for field experiences and hired into these settings in his/her first 
year. Moreover, the impact of classroom management preparation and how teacher candidates and new teachers navigate this potential "two-worlds pitfall" has not yet been investigated.

\section{Purpose of the Study}

The purpose of this study was to develop a better understanding of how teacher candidates bridged their teacher preparation with real world practice in relation to CM. More specifically, this study explored early childhood teacher candidates' perceptions and actions in working within PBIS frameworks and university messages of building classroom communities and how these changed or remained the same into their first year of teaching. Through this study, the voices of these novice practitioners were revealed, hopefully filling a void in the research literature related to these practices.

\section{Research Questions}

The following research questions guided this study:

1. How do teacher candidates, through their last year of coursework and first year as teachers, experience, understand, and explain their beliefs and practices regarding classroom management?

2. How do the contexts of PBIS and participants' teacher preparation shape and influence the teacher candidates' beliefs and practices about classroom management?

3. Based upon the first two research questions, what are the implications for policy and practice both in P-12 settings and teacher preparation programs?

\section{Significance of the Study}

Viewing teacher candidate and new teacher perceptions of classroom management and PBIS from a lens of community opens areas that have yet to be explored within the literature on 
classroom management preparation, as well as on PBIS use within school settings. Findings from this study have several benefits for the field of new teacher preparation and novice teacher support for both university educators and school and district administrators. First, following participants from their student teaching semester and through their first year of teaching helps fill gaps in the literature related to tracking teacher candidates and their changing perceptions related to classroom management. Knowing how teacher candidates, transitioning into new teachers, navigate PBIS and build classroom communities can help universities reflect upon and potentially improve their own teacher preparation programs. Additionally, findings from this study provide voice to a group (i.e. teacher candidates and new teachers) that is often unrepresented within PBIS literature. Findings shed light on potential strengths or weaknesses of school-wide PBIS as it relates to classroom community. Also, because of this study, school districts may increase their own understanding of the new-teacher experience, which can impact new teacher professional development and mentoring. Ultimately, for my participants, this partnership provided them support and mentorship in an area in which they struggled in their first year of teaching, and which, in their words, created positive student outcomes and has had lasting impacts on their teaching self-efficacy.

\section{Definition of Terms}

Teacher candidate: Also, known as Pre-Service Teachers or Teacher Interns, this term refers to university students in an education major and taking courses to become a teacher.

New teacher: This term refers to teachers in their first year of teaching.

Early childhood education (ECE): Per the prominent professional educational organization, the 
National Association for the Education of Young Children (NAEYC), early childhood education refers to the care and teaching of children between infancy and age eight.

Classroom management: A critical dimension of a teacher's pedagogy, there is little consensus of its definition, as it refers to varied aspects of a teacher's practice and has different meanings for different users. While I will provide more details about the varied definitions of classroom management in the review of literature, for the purposes of this paper, the term "classroom management" will refer to more than just simple order and control in the classroom. I see this as leading and orchestrating in an aligned manner and coordinating everyone's needs to enhance student thinking and learning (Kaufman \& Moss, 2010; Tal, 2010).

PBIS: Positive Behavioral-Intervention Supports (PBIS), also called by other names including Positive Behavior Supports (PBS) and School-Wide Positive Behavior Supports (SWPBS) (Johnston, Foxx, Jacobson, Green, \& Mulick, 2006) has been defined as an implementation framework focusing on improving student behavior using data, resources, and evidence-based practices (Sugai \& Simonsen, 2012). For the purposes of this paper, I will use "PBIS" to represent PBIS, PBS, SW-PBIS, and SW-PBS.

Preschool: Referring to the time before a child is old enough to attend kindergarten, labeled a nursery school, pre-kindergarten, Pre-K, and typically serving 3-, 4-, and 5-year-olds. For the purposes of this manuscript, I will use "preschool" to represent all related labels. Community: Community as used in this dissertation refers to the essence of Tönnies' "Gemeinschaft," which refers to the experience of being in a community, that is, the sense of belonging, safety, and trust in others (1887/ 1957). Furman (2012) writes that 
the phrase to "create community" refers to efforts to foster these types of experiences for students and educators.

\section{Chapter Overview}

This dissertation consists of eight chapters. In the first chapter, I have explored the rationale and purpose for this study, as well as a background for how I came to my research questions. In the second chapter, I will review the current literature on the topics of teacher preparation and new teacher perceptions of classroom management, community, and PBIS through this lens. I will then outline the multi-theoretical framework that is guiding my work including a humanistic approach to classroom management, a sense of community, and teaching self-efficacy. This framework explains the epistemological and ontological stances with which I approached this project. I will provide background information on how these strands weave together to form the lens through which this study is conducted. Then in chapter three, I will

outline the methods of my study. To begin, I will summarize my research paradigm and explain the qualitative approach of collective case study using ethnomethodological techniques that I used to answer my research questions. I will provide a detailed description of the data sources, data analysis, positionality, trustworthiness, and ethics utilized in this study.

In the last four chapters, I will present the findings of this study. This will include data from the focus groups and an overview of the case study chapters within the fourth chapter, and the three following chapters each dedicated to one of the cases. In the fifth chapter, Molly will be introduced, Kristin in the sixth, and Vanessa in the seventh. In the final, eighth chapter, I will discuss these findings and detail the implications that this research has created. 


\section{CHAPTER II: SITUATING THE STUDY}

This chapter provides both a summary of the reviewed literature related to this study and a description of my conceptual framework. I will begin by describing the multiple facets of classroom management. Because both PBIS and building classroom communities stem from a focus on behavior and classroom management, it is critical that the classroom management attitudes, beliefs, training, and preparation that teacher candidates and new teachers receive related to classroom management be explored. Emerging themes from the relevant research centered on teacher candidates' and new teachers' classroom management preparation, and what they are seeing and learning about PBIS and building classroom communities. What follows will be the multi-theoretical/ conceptual framework that serves as a guide to this study and the methods it employs.

\section{Murkily Explained: Classroom Management}

Many studies define management as simply order and control, but the topic of classroom management is much more profound and complex, and there is little evidence that this basic definition is universal for all teachers and students (Kaufman \& Moss, 2010; Tal, 2010). CM is built upon an underlying continuum of teacher-student control ranging from all teacher power and control to shared power and control to all student power and control. This continuum illustrates three approaches to classroom interaction first identified by Glickman and Tamashiro (1980) as interventionist, interactionalist, and non-interventionist. The interventionist teacher uses a rules/ consequence philosophy. Per Wolfgang (2001), the interactionalist teacher's philosophy is a "confront/ contracting one," and the non-interventionist teacher utilizes a classroom management philosophy that is based on "relationship/ listening." All classroom 
management sub-approaches and programs fall under these three categories (Glickman \& Tamashiro, 1980; Wolfgang, 2001).

It can be said that classroom management is more than just structure and rules for student behaviors. Teachers' classroom management skills describe efforts to oversee a multitude of activities in the classroom, including learning, social interaction, and student behavior (Martin, Yin, \& Baldwin, 1998). Martin and her colleagues describe it as a multi-faceted construct consisting of three dimensions: instructional management, people management, and behavioral management (Martin, Yin, \& Baldwin, 1998; Martin, Yin, \& Mayall, 2006 \& 2007-2008). It is also a cyclical process that includes planning, implementation, assessment, and a final evaluation that considers factors related to the children and their environment (Tal, 2010).

Aspects of classroom management are wide and varied and include both conventional and dynamic measures of management. Marzano, Marzano, and Pickering (2003) identify four components of effective classroom management including rules and procedures, disciplinary interventions, teacher-student relationships, and appropriate mental set. Evertson, Emmer, Clements \& Worsham (1996) write that effective classroom management consists of organizing the classroom and supplies, choosing rules and procedures, managing student work, getting off to a good start, planning and conducting instruction, maintaining appropriate student behavior, having effective communication skills, and managing problem behaviors and special groups. Tal (2010) proposes a dynamic feature of classroom management that corresponds with having the ability to change course and be responsive to students' needs when necessary.

In sum, classroom management is a multifaceted, complex aspect of teaching. More than just simple order and control, it is also leading and orchestrating in an aligned manner and coordinating everyone's needs to enhance student thinking and learning (Kaufman \& Moss, 
2010; Tal, 2010). Becoming an effective teacher with strong CM rooted in conceptual frameworks and meeting all students' needs takes time and effort to achieve and is an area that consistently ranks the most troublesome for teacher candidates.

\section{Teachers' Possible Pasts, Presents, and Futures with Classroom Management}

The extant literature highlights themes related to teacher candidates' and new teachers' perceptions of classroom management and how they are prepared for classroom management. This includes field experiences and their university teacher preparation programs, as well as the possibilities that preparation experiences can and do offer.

\section{Teacher Candidate and New Teacher Perceptions}

Perceptions of worry, concern, and fear dominate teacher candidates' beliefs about future teaching. Classroom management concerns, specifically, rank high for teacher candidates (Cakmak, 2008; Clement, 2010 Fall; Hoy \& Woolfolk, 1990; Kaufman \& Moss, 2010). In Kaufman \& Moss's (2010) study of teacher candidates, most of the respondents' fears and concerns were grounded in student-teacher relationships, and they cited classroom management as a fear at least twice as often as any other response. Although teacher candidates are often prepared to start their careers with a constructivist, student-centered, albeit, somewhat idealized focus on quality lesson-plans, after their first teaching experiences, concerns about their own survival can increase (Cakmak, 2008; Hoy \& Woolfolk, 1990; Martin et al., 2006).

Studies have highlighted how teacher candidates can become overly concerned with controlling their students, diminishing prior beliefs about constructive practice they may have held (Kaufman \& Moss, 2010; Martin et al., 2006). Kaufman and Moss (2010) found that in their study of 42 teacher candidates, participants instead tended to stress the need to create rules at the beginning of the year and adhere to them consistently. The work of Marzano and 
colleagues (2003) highlights the optimal teacher-student relationship, consisting of equal parts dominance and cooperation, yet teacher candidates may perceive that it is the teacher's responsibility to organize and manage classroom functioning autocratically. Kaufman and Moss found this to be the case even when participants otherwise preferred a more student-centered approach (2010). Some researchers attribute this finding to teacher candidates' own lack of conflict resolution skills prior to entering teacher preparation programs (Liston et al., 2006).

An additional reason for these perceptions is the stress of the first few years of teaching. Conflict tends to be a constant both at the interpersonal and the public level (Veenman, 1984), and in many cases, the sting of conflicts with students, colleagues, or families catches new teachers off guard (Liston et al., 2006). Also, many new teachers have not yet realized that classroom organization is a tool that facilitates learning, independence, and creativity, and aids their classroom management (Kaufman \& Moss, 2010). Teacher candidates and new teachers tend to conceptualize management as a precursor to good organization and not the reverse. Kaufman and Moss (2010) found that teacher candidates appeared to view organization as a condition that arose out of strong behavior management, not one that promoted or resulted in good management. However, when teacher candidates are trained in strong organization, anxiety and confusion that contribute to student behaviors that new teachers most fear tend to be alleviated (Kaufman \& Moss, 2010).

Although many teacher candidates and new teachers struggle with this aspect of teaching, developing a strong sense of classroom management is not impossible. Good classroom managers are teachers who understand and use specific tools and techniques within a conceptual framework (Marzano et al., 2003; Tal, 2010). Awareness of and training in these techniques can 
change teacher behavior, which in turn changes student behavior and ultimately affects student achievement positively (Martin et al., 1998; Marzano et al. 2003).

\section{Preparation for Classroom Management}

For many, explanations for why the first year of teaching is so difficult for novice teachers are rooted in teacher preparation (Clement, 2005/2010; Liston et al., 2006). Criticisms stem from the arguments that teacher preparation programs devote too much attention to theory and not enough to practical skills of teaching or that the wrong theories are being taught (Chesley \& Jordan, 2012; Clement, 2010; Liston et al., 2006) and that they have typically not attended to this emotional dimension of teaching (Blum, 1994; Hammerness, 2011; Liston et al., 2006; Tal, 2010). While most states require that classroom management be addressed in teacher preparation, the implementation of this is spotty, at best (Clement, 2002; Freeman et al., 2014). In an update to Blum's 1994 study that highlighted how most teacher candidates in 226 NCATEaccredited universities were not receiving any comprehensive classroom management in their programs of study, Hammerness (2011) surveyed 31 traditional and alternative teacher preparation programs and discovered that fewer than half required any coursework in classroom management. Of those that did, the majority were for graduate training programs, not undergraduate TCs. In 2015, Christofferson and Sullivan conducted an even more updated study of 157 pre-service teachers from NCATE-accredited teacher education programs, and only a little over half reported that they were receiving classroom management training from a management-specific course.

Oftentimes, when it is not taught as a stand-alone course, classroom management is not completely absent in teacher preparation, but is instead embedded within coursework (Brophy, 2006; Hammerness, 2011; Landau, 2001; Oliver \& Reschly, 2010; Stough, 2006). The fact that 
classroom management is a complex, dynamic entity that requires more than a short chapter or weeklong view of it is often cited as the coverage of embedded classroom management in coursework (Landau, 2001). However, Landau argues that covering both course content, as well as the complexities of classroom management, in a single course is nearly impossible. When this happens, that which is taught tends to be behavioristic models of rewards and punishment because they are seemingly simple to teach and enforce, and Landau argues that this may not set future teachers up with the requisite skills for navigating the complexities of future classrooms and teaching for long-term learning.

This discrepancy suggests that universities and training programs feel that teacher candidates are receiving adequate training (Blum, 1994; Freeman et al., 2014; Stewart-Wells, 2000). The argument that is historically presented in teacher preparation programs is that fewer discipline problems result from better instruction, and so the primary focus in teacher preparation is on pedagogy and instruction, not on classroom management, specifically (Farkas \& Duffett, 2010). This belief holds that so long as teachers rely on engaging instructional techniques that tap their students' love of learning, behavior and classroom management will happen naturally (Farkas \& Duffett, 2010). However, it has been revealed that although effective pedagogy can reduce problematic student behavior, it cannot truly eliminate it (Emmer \& Stough, 2001). Given the importance that new teachers place upon preparation in classroom management and the current emphasis that school administrators and teacher evaluations place on teachers' classroom management (Bigham, Hively, \& Toole, 2014), overall, it appears that many new teachers may not be receiving the kind of preparation they may need to implement classroom management that supports classroom communities (Hammerness, 2011; Landau, 2001). 
The power of the field. While classroom management-related coursework is important, what teacher candidates learn about classroom management in field experiences is, perhaps as, or even more, important. In studies exploring where teacher candidates learn about classroom management, they rate learning about it in field placements most often (Christofferson \& Sullivan, 2015; Stough, Montague, Landmark and Williams-Diehm, 2015). In Christofferson and Sullivan's (2015) study, most participants responded that their classroom management training came from teachers with whom they worked in field placements. Stough et al. (2015) found similar results highlighting that the field was where graduates felt they had learned the most about classroom management. In cases where classroom management coursework is not being taught, the only classroom management beliefs, messages, and practices that teacher candidates receive may be from field experiences (Clement, 2002; Putman, 2009).

As such, some researchers argue that more attention should be focused on the role of the cooperating teacher in classroom management preparation of teacher candidates (Clement, 2002; Stoughton, 2007). When cooperating teachers implement best practices and articulate theories behind them, as well as provide related recommendations, teacher candidates develop what Clement calls a "much-needed foundation" for classroom management (2002, p. 59). However, concern exists that cooperating teachers may lack knowledge about classroom management (Clement, 2002). Clement in her survey of 48 cooperating teachers, found that most of them were not knowledgeable about specific classroom management theorists or approaches. She argues that if cooperating teachers do not have a working knowledge base about classroom management, they may be passing along a set of "survival skills" to teacher candidates (Clement, 2002, p. 59). 
Additionally, cooperating teachers' classroom management strategies may contradict the theories and practices taught in the university setting (Clement, 2002; Putman, 2009; Stoughton, 2007). Hoy and Woolfolk's seminal study on the socialization of student teachers in 1990 illustrated this concern. Their findings revealed that teacher candidates were often confronted with a custodial school culture, in which cooperating teachers pressed for order, control, and the accomplishment of instrumental goals, and teacher candidates responded by adopting this perspective (Hoy \& Woolfolk, 1990). Compounding this issue is the role of administrators, who tend to place classroom management at the top for teacher and teacher candidate performance evaluation ratings (Bigham et. al, 2014). Teacher candidates, who already have a limited understanding of this aspect of teaching, tend to feel deep-set apprehension about classroom management and often need strong support in this area (Stoughton, 2007). It is for these problematic reasons that Knoblauch and Hoy (2008) report that "teacher educators should do everything possible to ensure that each student teacher is placed with an efficacious cooperating teacher" (p. 176).

The role of teacher preparation programs. University teacher preparation programs can positively impact a teacher candidates' classroom management development through building it as a focus throughout the educational sequence. Tal (2010) argues that it is through explicit coursework, and then vicarious and mastery experiences in the field, that changes in classroom management beliefs can occur. Embedding classroom management courses in the educational sequence and following up with seminars during field experiences (Putman, 2009), partnering field experiences with classroom management courses where tensions can be discussed (Stoughton, 2007), and linking together the course, the field experience, and mentorship from the cooperating teacher (Christofferson \& Sullivan, 2015) are all ways that the 
university can address this area of concern for teacher candidates. When teacher candidates learn more classroom management content, one study of graduates from 21 different Australian teacher education programs highlighted that they identify an increased number of strategies they feel comfortable using and describe overall improved feelings of preparedness to work with students (O’Neill \& Stephenson, 2012).

Because classroom management is so complex, the training and preparation process must link well-established and researched theoretical concepts with real events in the field that enrich, modify, and validate these theories (Tal, 2010). Tal (2010) recommends supporting teacher candidates by using reflective practice to challenging their own beliefs when these beliefs contradict what they experience in the field. Liston and colleagues (2006) endorse preparing teacher candidates for the sting of conflict by explicitly enhancing conflict resolution skills, both as a tool to build learning communities in classrooms and as a professional skill needed to collaborate with others in school settings. Kaufman and Moss (2010) advocate that classroom management preparation in coursework and clinical experiences explicate that (a) control is only viable when it enhances other classroom conditions that lead to learning, (b) teachers work to help students develop self-control so they can take more ownership of their own learning, and (c) classroom management that supports learning may promote student movement as they take on more responsibility in learner-centered environments.

An individual course may not be the only, or best way to help teacher candidates achieve stronger classroom management skills (Oliver \& Reschly, 2007). A recent study by Stough and colleagues (2015) highlighted that even with a course in classroom management, experienced graduates still wished for more and still felt most concerned about this aspect of teaching. Although an entire course may provide enough time to cover the full breadth of classroom 
management, it may be conceived as distinct from other domains when not paired with concurrent field experience (Oliver \& Reschly, 2007; Tal, 2010). Despite this, a classroom management course should still be considered because of the complexity of this topic (Tal, 2010). Additionally, considerations for infusing consistent classroom management across all coursework in a preparation program need to be made to ensure greatest success (Kaufman \& Moss, 2010). Training on effective classroom management can give teacher candidates adequate conceptualization of the critical content—not as discrete skills, but as a complete approach to management (Oliver \& Reschly, 2007).

\section{Current Realities of Classroom Management in the Early Childhood Years}

Literature related to current classroom management theories, frameworks, and approaches highlight the realities that TCs and new teachers may be experiencing in their teaching, including Positive Behavior Interventions and Supports (PBIS) and the conflicts they may feel between this framework and classroom management messages from their teacher preparation programs. As early childhood teacher candidates work in their field placements and new teachers are hired into elementary schools, this may likely be a framework they encounter.

\section{Positive Behavior Interventions \& Supports (PBIS)}

PBIS is a framework that consists of a multi-tiered system of supports for behavior (Sugai \& Horner, 2002), in line with the Response-to-Intervention (RTI) approach (Adams, 2011; Sugai \& Simonsen, 2012), and its principles include arranging the environment to address student behavior, teaching and encouraging pro-social behaviors, and the continuous screening of students (Positive Behavioral Interventions \& Supports, 2012). When implemented at the school-wide level, Coffey and Sugai (2012) write that it unifies academic and behavioral approaches of supporting children within the school. 
The framework does not specify classroom management packages or approaches. Instead, the framework, "highlights specification and adoption of evidence- and research-based practices that characterize packaged programs" (Sugai \& Simonsen, 2012, p. 1), which means that districts and schools, while using unifying components of the framework, may interpret it differently (Molloy, Moore, Trail, Van Epps, \& Hopfer, 2013). The unifying components of the framework, as laid out in the PBIS School-Wide Evaluation Tool (SET), outline the definition and teaching of school-wide behavioral expectations, the implementation of both a reward system to acknowledge students for meeting behavioral expectations, as well as a violation system for correcting misbehaviors using a continuum of behavioral consequences (Sugai, Lewis-Palmer, Todd, \& Horner, 2001). Additionally, student behavioral data should be gathered and used to guide decision-making, and administrative leadership at the school and district levels in support of the framework are critical (Sugai et al., 2001). Defined as an implementation framework, not a curriculum (National Center for Mental Health Protection \& Youth Violence Prevention, n.d.; Sugai \& Simonsen, 2012), the framework is designed to enhance learning outcomes and is focused on improving behaviors in the classroom, leading to academic gains (Sugai \& Horner, 2002; Sugai \& Simonsen, 2012). However, its implementation mirrors the effect that a curriculum has on education, in that it can drive what it is done daily within schools, related to universal behavioral curricula and expectations (Bornstein, 2015).

Stemming from the world of special education, PBIS was created in the 1980's and with the passage of the Individual with Disabilities Education Act in the early 1990's, its use began to grow (Sugai \& Horner, 2002; Sugai \& Simonsen, 2012). In 2008, nationally, nearly 8,000 schools reported using the framework (Spaulding, Horner, May, \& Vincent, 2008), and by 2013, this number had grown to 18,000 (Molloy et al., 2013). Alone in Illinois, where this study took 
place, there are over 1,000 schools using this approach, which is over $30 \%$ of all school districts in the state (Illinois PBIS Network, 2013). Although the framework stemmed from behavioral interventions for students with special needs, it is now being used in school-wide, general education settings for all learners (National Center for Mental Health Protection \& Youth Violence Prevention, n.d.; Sugai \& Simonsen, 2012), in up to 18\% of U.S. schools (Molloy et al., 2013). This is in part due to the support of the federally-funded Technical Assistance Center, which many have criticized as solely endorsing PBIS, while other successful approaches are also available (Samuels, 2013).

Supporting research highlights that in schools with full implementation, PBIS has been attributed with improving discipline problems, school climate, academic achievement, student bullying behavior (Sugai \& Simonsen, 2012). The framework has also been credited with improving school safety, while lowering office discipline referrals (Horner et al., 2009), and it has been identified as being a solution to the school-to-prison pipeline phenomenon (Fowler, 2011; Fuentes, 2011). Because of its widespread and seemingly increasing use, some report that this model has found "undeniable success" (Johnston et al., 2006, p. 69), and many new teachers entering the field in Illinois enter an educational world where PBIS has become the norm.

Although some argue that this framework exemplifies a new discipline, theorists in the field contend that the PBIS theoretical base, its implementation, and related research are indistinguishable from applied behavioral analysis (Chitiyo, May, \& Chitiyo, 2012), and thus, within the theory of behaviorism, the framework is firmly rooted (Adams, 2011; Critchfield, 2015; Johnston et al., 2006). In the early 1900's, the learning theory of behaviorism in education provided the final foundations of the social efficiency model (Ornstein, 2011), and early social efficiency promoters, such as Bobbitt and Charters, based their work in the psychological 
theories of Thorndike, i.e. behaviorism (Kliebard, 2004). By the 1950's, this was one of most the dominant learning theories used in education (Freiberg, 1999). Even with shifts in thinking about learning, education today still reflects the strong influence of Skinner's behaviorism (Bruning, Schraw, \& Norby, 2011; Freiberg, 1999), as seen in PBIS and other aspects of education. Critchfield (2015) states, "PBIS arguably is our only existing model of the kind of society-wide behavioral engineering that Skinner (e.g., 1953) liked to envision" (p. 99). In the creation of the framework, Sugai and Horner (2002) made it very clear that this work was based on applied behavioral analysis, yet this connection is less evident in more recent publications (Johnston et al., 2006).

In a behavioristic model of education, educators focus less on the learner, and more on the stimuli causing the learner to change and its responses, manipulating these stimuli through rewards and punishments (Bruning et al., 2011; Schiro, 2008). While PBIS does not outwardly promote punishments, the PBIS School-Wide Evaluation Tool does include the requirement of a working violation system (Sugai et al., 2001). This violation system should be a "documented system for dealing with and reporting specific behavioral violations" (p. 3). The teacher's role is that of a manager (Schiro, 2008), which is the role that teachers may take when using PBIS (Bower, 2010). Two of the social efficiency model's top priorities are that all learning must be efficient and based in science (Schiro, 2008), and this undercurrent of PBIS expresses itself in its detailed tiers of support, intense focus on evaluation, evidence-based practices, and assessment (Adams, 2011).

\section{A Sense of Community \& PBIS}

While behavioristic approaches and frameworks, like PBIS, are being used in classrooms and schools across the country, there tends to be a humanistic undertone within all public 
education, focused on the role of school as "community" (Furman, 2012). Historically, schools have been places to foster and grow citizens for a democratic society (Quinn, 2011; Oakes et al., 2013). Additionally, because the educational system is based on historical and societal inequities, Meier (2009) argues that schools ought to be "schooling for ruling" (p. 46), instead of only preparing a few for the ruling class. Teachers play an integral role in creating these settings. Palmer (2011) defines good teachers as being able to "weave a complex web of connections between themselves, their subjects, and their students, so that students can learn to weave a world for themselves” (p. 65). He calls this “"community' of the highest sort” (Palmer, 2011, p. 65). Examples of locations and approaches focusing on building community democratically abound. The "small schools" movement towards smaller, more inclusive settings, provides an alternative to more behavioristic management and inequity through building community and allowing for democracy (Klonsky, 2011; Meier, 2009, 2011a; Scherer, 1994). In addition, restorative practices and approaches, including Positive Discipline in the Classroom (Nelson et al., 2000), Responsive Classroom (Rimm-Kaufman \& Chiu, 2007), and Circle of Courage (Rubin, 2011), among others, contrast with more behavioristic approaches like PBIS by providing democratic classroom practices that support children in developing autonomy, selfdetermination, respect, and responsibility.

Early childhood settings, specifically, are places in which children can first experience how their actions and decisions affect others and can create foundational opportunities for what society can become (Serriere, 2010). In these settings, children might be first exposed to positive values of a democratic society including autonomy, self-regulation, respect, and care and concern for others (NAEYC, 2009; Serriere, 2010). Preparation for building strong classroom communities is a hallmark of many early childhood teacher preparation programs as this tenet is 
a belief held by the larger early childhood field and is built into teacher preparation standards (Boutte, 2008; Goldstein, 1997; NAEYC, 2009).

In its 2009 position statement on developmentally appropriate practice, the National Association for the Education of Young Children (NAEYC), the professional organization of this field, writes that "in developmentally appropriate practice, practitioners create and foster a "community of learners" that supports all children to develop and learn" (p. 16). To create this community, NAEYC provides key components including making each member of the community feel valued, focusing on relationships, helping children develop self-regulation and responsibility, helping children in developing their own community rules for behavior, and ensuring that all members of the community feel psychologically safe, among others (NAEYC, 2009). Ultimately, early childhood teachers are responsible for creating these environments (NAEYC, 2009; Stone, 2001), which is why many early childhood teacher education programs include a focus on this as well. Although this is not always easy and requires time, experience, and patience, the goal of establishing and promoting a sense of community, stands in sharp contrast to the behavioristic mindset of classroom management as "managing" children's behavior (Freiberg, 1999; Oakes et al., 2013), which is at the root of the PBIS framework (Adams, 2011; Bornstein, 2015).

When reviewing studies that have taken a closer look at alternative perspectives about PBIS, there are some who criticize aspects of the framework, but still support it (Center for Mental Health in Schools at UCLA, 2011; Chitiyo et al., 2012; Critchfield, 2013; Johnston et al., 2006; Marshall, Caldwell, \& Foster, 2011; Northeast Foundation for Children, Inc., 2009; Tillery et al., 2010; Wilson, 2015), and some who do not support the PBIS framework at all (Adams, 2011; Rubin, 2011). Although supporters claim that the framework develops core values for the 
school community, to many, PBIS remains a top-down approach with a minimal focus on building mutual respect, developing democratic values, or true inclusion of all learners, which are hallmarks of a classroom community (Adams, 2011; Bornstein, 2015; Lagerwerff, 2016; Rubin, 2011; Wilson, 2015).

However, these voices seem to be trumped by the ever-expanding support base for PBIS. Relegated to personal blogs, websites, and discussion boards, parents, classroom teachers, and some educational consultants question the framework because of its controversial, disrespectful, and often-arbitrary use of rewards (Rubin, 2011), its similarities with the concept of "Big Brother watching" and another form of high-stakes testing (A Blog About School, 2009), and its potential long-term effects on children (Bower, 2010; Witz, 2011), amongst others. These authors criticize the PBIS model for perpetuating traditional top-down models, demeaning children, and treating them as animals (A Blog About Learning, 2009; Bower, 2010).

Additionally, there is a small, but increasing, camp of educators and researchers taking a critical look at the theoretical base and implementation of PBIS from a disability studies perspective (Adams, 2011; Bornstein, 2015). However, few of these perspectives come from educators or parents and seemingly none come from those most affected, including students, teacher candidates, or practicing teachers, especially within academic literature.

\section{The "Two-Worlds Pitfall"}

Ultimately, this PBIS world is the environment in which teacher candidates may be placed when conducting clinical field experiences and student teaching, and in which they may be hired in their first years of teaching. If the messages and practices of PBIS mesh with the sense of community framework that is espoused in early childhood teacher preparation programs, then it holds that teaching within the framework should be smooth and easy. If these 
two entities do not mesh, then what remains may be a "two-worlds pitfall" (Feiman-Nemser \& Buchmann, 1985, p. 59). This phrase, coined by Feiman-Nemser and Buchmann in the early 1980 's, refers to the place that student teachers can potentially find themselves when what they have learned in teacher preparation contrasts dramatically with the perspectives they encounter in the field from their cooperating teachers and the school setting. Smith (2007) writes that when caught between these two worlds, student teachers must "carve out their own space within it" (p. 100). Feiman-Nemser and Buchmann (1983) explain that pitfalls such as these disconnects can interrupt critical thinking and "mislead" student teachers into thinking that they have mastered teaching before they have (p. 16). They believe that this is because these perceptions are supported and rewarded by trusted cooperating teachers. When teacher candidates enter these pitfalls unknowingly and without support and mentorship, this can have great impact on their developing sense of personal teaching self-efficacy (Hoy \& Woolfolk, 1990).

While Feiman-Nemser and Buchmann (1983) and countless other researchers who have continued this work (Anagnostopolous, Smith, \& Basmidjan, 2007; Smith, 2007; Smith \& Avetisian, 2011; Zeichner, 2010, among others), have identified the "two-worlds pitfall" as residing in the field experiences of teacher preparation, the effects of experiencing the pitfall may have consequences for teachers' first years in the field. This may be especially true if teacher candidate perceptions and beliefs related to classroom management have been sharply influenced by living in this pitfall without strong support and mentorship to analyze these experiences during student teaching. Additionally, if the first teaching position is in a setting that continues to clash with university messages, the continuation of living within the "twoworlds pitfall" is a possibility. Feiman-Nemser and Buchmann (1983) write that "what makes them [pitfalls] even more treacherous is that they may not look like pitfalls to an insider, but 
rather like a normal place to be" (p. 16). It is because of this possibility that more exploration continues to be needed, and this study's focus helps to contribute to this exploration.

\section{Studying Classroom Management}

Previously, in the review of literature, I have attempted to provide a synthesized view of the murkily-defined topic of classroom management, reviewed studies exploring the pasts, presents, and futures of teachers and their management, outlined the current realities of PBIS and messages of community-building in early childhood settings, and detailed the outcome of the "two-worlds pitfall," in which novice teachers may find themselves. It is within this potential pitfall where this study is situated.

\section{As Lived Experience}

As important as methods may be, the most practical thing we can achieve in any kind of work is insight into what is happening inside us as we do it.

Palmer, 2011, p. 72

Exploring the perspectives of teacher candidates as they transition into new teachers and how they navigate building classroom communities within PBIS settings can cast a light into the depths or shallows of this pitfall. However, currently, the most meaningful perspectives on this topic are not considered; that is, the voices and lived experiences of these teacher candidates and new teachers. I believe that lived experiences are multifaceted, conflicting and best understood from the perspectives of those living within them. Thus, this study is grounded in the epistemology of interpretivism, which assumes that there is no true meaning of an event. As Stake (2010) writes, "there is only the event as experienced or interpreted by people" (p. 66), acknowledging multiple realities, viewpoints, and understandings. 


\section{From an Integrated Perspective}

For this study, I draw upon multiple theoretical and philosophical frameworks that allow me to explore these topics. I came to this research with certain assumptions about the nature of being, truth, and knowledge. These assumptions provided a way of seeing and inquiring into my world. Glesne (2011) writes that every research study is informed by higher-level theory. It is through my years of practice in the field with young children, teacher candidates, and new teachers, and endless sessions of self-talk and reading, that I emerged with an understanding of my ontological and epistemological views.

The following sections provide an outline of those perspectives that have guided my questions, methodology, analysis and understanding of PBIS and community from the perspective of new teachers in this study. This section of my literature review highlights my attempts to clarify the assumptions that I have brought to this study. Through reflection, I have realized that my assumptions do not fit tidily into any one theory, philosophy, or package. Nor, do I believe that by drawing on these multiple perspectives, I will create a more perfect approach or theory. Instead, I see my role as a researcher as an interpreter, someone who attempts to find a way to make new connections comprehensible to others (Stake, 1995). Because these topics have not before been linked, I find the need to acknowledge the complexities of the varied frameworks and perspectives that overlap and intertwine in telling the perspectives of these new teachers, including theories related to humanistic classroom management and a sense of community, as well as teacher self-efficacy.

Community and humanistic classroom management. I view classroom management through the lens of community. Schaps (2003) defines establishing a sense of community as "when a school meets students' basic psychological needs," and where "students become 
increasingly committed to the school's, norms, values, and goals" (p. 31). To Meier (2009) democratic values that educators should model in their community include evidence, viewpoint, connections and cause and effect, conjecture, and relevance, amongst others. Classrooms that embody this, and thus establish a sense of community, have been shown to lead to a decreased numbers of problem behaviors (Battistich \& Hom, 1997; Oakes et al., 2013) and an increase in levels of academic achievement and levels of social and emotional skills (Schaps, 2003). Democratic classrooms are those that treat all stake holders equitably, including students, teacher candidates, teachers, and teacher educators (Farmer, Leonard, Spearman, Qian, Rosenblith, 2016).

Although far from perfect, classroom communities can and should embody both the values of mutual respect and social interest as well as the existence of conflict and tension (Blank \& Schneider, 2011; Oakes et al., 2013; Wisneski, 2005). Blank and Schneider (2011) describe how conflict in the classroom can and should be desirable as it encourages new ideas and language learning, and that mediating conflict takes time and teachers must be selective of when they step in to mediate. However, the promotion of an idealistic view of classroom communities, typical in early childhood education (Blank \& Schneider, 2011; Souto-Manning, 2014), dismisses the realities of multiple perspectives and lived experiences, and presents a sense of community that is only a charade (Wisneski, 2005). A more realistic stance recognizes and acknowledges the tensions inherent within a community and addresses them head-on through communication and dialogue (Blank \& Schneider, 2011; Oakes et al., 2013; Souto-Manning, 2014; Wisneski, 2005).

Viewing classroom management through this lens requires an understanding of its theoretical foundations. The approach of seeing the purpose of classroom management as for the 
common good is indicative of a humanistic approach to education. Humanistic approaches to teaching are student-centered and place a heavy emphasis on recognizing individual students, respecting their differences, and seeing their social-emotional well-being at the center of all learning (Walker, 2009). The work of Carl Rogers (1961) first brought the humanistic approach to the forefront and explored its sharp contrast with behaviorism, the approach of the times.

The learning theory of behaviorism was built on the theories of Pavlov (classical conditioning) and Bandura (social learning), and is most closely associated with the works of B. F. Skinner (Freiberg, 1999). Per behaviorism, only observable behaviors should be studied as internal states, such as cognitions, emotions, moods, and free will (choice), are too subjective. However, research shows that this is one-dimensional and too simplistic a view (Bruning et al., 2011). There is much more that makes up the human experience than just observable behavior. Additionally, behavioral theory does not account for learning that takes place without reinforcement and punishment, nor does it recognize the power within learners to control their own learning (Freiberg, 1999; Rogers, 1961). Moreover, in the dominant view of a progressive early childhood classroom, punishment, which is an integral part of the theory, has no place (Gartrell, 2001; Mosier, 2009; NAEYC, 2009, 2011). Using punitive consequences, such as time-outs or worse in response to misbehavior, has been shown to do little to teach children appropriate behaviors (Gartrell, 2001; Mosier, 2009).

Diverging from this perspective, in the humanistic style, the focus is on the whole child and is very person-centered (Walker, 2009). Classroom management that embodies a personcentered or humanistic approach focuses on what Doyle (2009) calls the "important work of building context" (p. 58). He argues that without this, a well-managed classroom can not emerge (Doyle, 2009). A humanistic classroom has shared responsibility, embodies mutual respect, and 
values and promotes self-regulation of behavior (Brophy, 1999). I see classroom management through this humanistic paradigm that places more importance on person-centered management, in which leadership is shared as much as possible, and management is a form of guidance.

While behavioristic theory is still prevalent in education today (Freiberg, 1999), and especially within the PBIS framework (Sugai and Horner, 2002), many more humanistic theorists' work is emphasized in the field of early childhood. Specifically, those that have guided my conceptual framework center on the tenets of Adlerian theory as elucidated through the works of Rudolf Dreikurs. Dreikurs, a student of the social psychologist Alfred Adler, came to the U.S. from Austria in the mid-1900's and with him brought with him Adler's theories of individual psychology to American parents and teachers (Croake, 2011; Dreikurs, 1987; Shulman \& Dreikurs, 1978). Dreikurs developed Adler's theory of individual psychology into a pragmatic and usable method for understanding what motivates and drives children's behavior without rewards or punishments (Nelson, Lott, \& Glenn, 2000). At the root of this work is the belief that encouragement is the foundation of all human behaviors and relationships, and that we, as humans, are all searching for significance and belonging. To achieve this significance and belonging, Dreikurs promoted the use of democratic classrooms in which mutual respect and social interest were practiced, versus classrooms that embodied rewards and punishments, which he felt offended and humiliated students (Dreikurs, 1987).

Although I did not learn of Dreikurs' and Adler's work in my teacher preparation, I was prepared in an early childhood teacher program that placed a heavy emphasis on the construct of building a "sense of community" within my classroom. Without explicit instruction in classroom management or knowledge of how to build this community, I heard vague messages throughout my teacher preparation that democratic, constructivist classrooms in which mutual respect was 
fostered were necessary. Ultimately, these early childhood messages resonate with Dreikurs' depictions of classrooms and relationships, in which mutual respect is fostered, mistakes are seen as wonderful opportunities to learn, and children are supported in independent problem-solving (Croake, 2011).

Despite this, through my work with new and veteran teachers, I have experienced very behavioristic, teacher-centered practices that have created strife for educators and have not helped to build mutual respect nor a sense of community for children. These practices have been contradictory to messages of democracy and community that early childhood preparation programs espouse. Ultimately, using teacher self-efficacy as a guide for exploring these tensions can do much to bring community and humanistic classroom management into perspective for the participants of this study.

Teacher self-efficacy. Rooted in social cognitive theory, "teacher efficacy is the teacher's belief in his or her capability to organize and execute courses of action required to successfully accomplish a specific teaching task in a particular context" (Tschannen-Moran et al., 1998, p. 233). How teachers self-evaluate has a tremendous impact on their teaching and interactions with students (Tschannen-Moran et. al, 1998; Knoblauch \& Hoy, 2008). Efficacy beliefs have been shown to have a powerful impact on behaviors, persistence, and level of success achieved (Bandura, 1997; Hoy \& Woolfolk, 1990; Bruning et al., 2011). Hoy \& Woolfolk (1990) identified two forms of assessment that teachers conduct when self-evaluating, including teaching efficacy that focuses on the belief that the process of education affects students in important ways, and personal teaching efficacy in which teachers believes that they can enact significant change for students. Teachers evaluate themselves along these two lines of thought, which can then impact their interactions with students. 
When a teacher has a strong sense of personal teaching self-efficacy, many positive outcomes have been found, including an increased willingness to work with struggling students (Gibson \& Dembo, 1984), a decreased concern with the risk of failure (Ross, Cousins \& Gadalla, 1996), and a decrease in the tendency to criticize student mistakes (Ashton \& Webb, 1986). Research reveals that students of teachers with a high sense of personal teaching self-efficacy exhibit higher levels of student achievement, motivation, and their own self-efficacy (Bruning et al., 2011; Knoblauch \& Hoy, 2008). Because this theory posits that teachers' beliefs and feelings influence their behavior, this theory seemed a logical framework to apply to exploring teacher candidate and first-year teachers' perceptions and behaviors related to PBIS and their classroom communities.

\section{In Context}

Stake (2010) writes that "context and situation are background" (p. 50), and this background is critical. I view all learning as taking place within a social context, and that we create our own understandings within this. In describing person-centered, humanistic classroom management, Doyle (2009) writes, “contexts are, in important ways, jointly constructed by participants and depend on the willingness of participants to cooperate in creating order together" (p. 158). The contexts of teacher preparation, the first year of teaching, PBIS, public schools, and individual classrooms overlap, and while in the background, each plays a heavy role in impacting the lived experiences of this study's participants. My second guiding question, "How do the contexts of PBIS and participants' teacher preparation training shape and influence the teacher candidates' beliefs and practices about classroom management?" gets at the root of exploring how the various setting and contexts in which these novice teachers live impact who they become as educators. The best vantage point to explore these teacher candidate and new 
teacher perspectives about classroom management, PBIS, and community is within these various contexts.

\section{Through Theory: Interpretivism}

This multi-theoretical framework, viewed as contextual and grounded in a sense of community, humanistic classroom management, and the importance of teacher self-efficacy, lent itself nicely to being analyzed from an interpretivist paradigm. Within qualitative research, the term "interpretivism" is used, and within teaching philosophies, the term "constructivism" is used. The interpretivist and constructivist frameworks are often used interchangeably (Glesne, 2011), because at their roots, unlike from a positivist approach, these approaches assume that reality is always socially constructed and is rooted in context (Glesne, 2011). My background as an educator prepared me to view the world from a constructivist lens, and from a qualitative researcher standpoint and for the purposes of this study, I used an interpretivist frame. In this collective viewpoint, there is no one truth or reality; instead members are constantly constructing it (Glesne, 2011). Within this mindset, I see learning as wholly subjective, where I cannot take myself out of the context and be objective because the influence of my own experiences and knowledge will be forever impacting that which I am seeing. Stake (1995) writes that constructivism, "is the belief that knowledge is made up largely of social interpretations rather than awareness of an external reality" (p. 170). Within this paradigm, it is logical to observe knowledge from the inside out, as opposed to from an external positivist perspective.

Exploring lived experiences from within illustrates multiple perspectives and lived experiences. Crotty (1998) explains that, "in this understanding of knowledge, it is clear that different people may construct meaning in different ways, even in relation to the same phenomenon" (p. 9). Eisner (1997) writes that constructivism makes the behavioristic viewpoint 
of the world less relevant as, "humans live in a contingent world and form purposes that shift and alter depending on the meanings those contingencies have offered." For this study, I attempted to explore possible alternatives to the behavioristic view to which Eisner (1997) alludes. My first guiding question, "How do teacher candidates, through their last year of coursework and first year as teachers, experience, understand, and explain their beliefs and practices regarding classroom management?" is grounded in the belief that there is no reality outside of oneself, i.e. that people construct all knowledge as they are living. Each of the themes of humanistic classroom management, community, and teacher self-efficacy are examined through the lens of the teacher candidates, as they become new teachers.

This interpretivist paradigm recognizes that variables are at once "complex, interwoven, and difficult to measure" (Glesne, 2011, p. 9). Most important is how one interprets or makes sense of these variables. Thus, the situated role of the researcher is critical. Employing qualitative methods served best for revealing the voices of those living within these contexts.

\section{Summary of Review of Literature}

After reviewing the current related research, a better understanding of what is classroom management specifically, and the related attitudes and beliefs that teacher candidates and new teachers have emerged. Research has shown that preparation and training in this area are lacking, and this negatively affects teacher candidates' attitudes and beliefs about classroom management (Clement, 2002; Freeman et al., 2013; Hammerness, 2011; Landau, 2001). This is further complicated by field experiences and new teaching positions in settings that use PBIS, which may conflict with messages of building classroom community that candidates have experienced within their teacher preparation. Further research into how teacher candidates and 
new teachers negotiate this was warranted, which led to this study's focus, and the framework that guided it. In the next chapter, I will discuss the methods used to conduct the study. 


\section{CHAPTER III: RESEARCH METHODOLOGY \& DESIGN}

By exploring the potential "two-worlds pitfall" resulting from competing messages from university programs to "build a sense of community" and more behavioristic classroom management messages of the PBIS framework, I hoped to tell the story of how teacher candidates built classroom communities within PBIS settings. Qualitative methods proved best for telling their stories and revealing these voices. Stake (2010) defines those studies with a focus on personal experiences in described situations as qualitative. To explore this, I used the following questions as a guide:

1. How do teacher candidates, through their last year of coursework and first year as teachers, experience, understand, and explain their beliefs and practices regarding classroom management?

2. How do the contexts of PBIS and participants' teacher preparation shape and influence the teacher candidates' beliefs and practices about classroom management?

3. Based upon the first two research questions, what are the implications for policy and practice both in P-12 settings and teacher preparation programs?

To search for a deeper understanding of the perspectives and practices of teacher candidates as they became new teachers, with these guiding questions, and situated within an interpretivist paradigm (Glesne, 2011), I chose to use a collective case study method with ethnomethodological techniques (Denzin \& Lincoln, 2011; Garfinkel, 1967). In this chapter, I will describe how the researched topics, conceptual framework, and purpose coalesced in this research design. Additionally, I will explain my own positionality in approaching this work, outline my methods including the research setting, participants, and data sources, and explain the 
stages of my data analysis. I will conclude this chapter by examining issues of validity and exploring the ethical considerations that were taken.

\section{Collective Case Study Using Ethnomethodological Techniques}

The specific qualitative method used for the present study was collective case study (Stake, 1995/ 2010) using ethnomethodological techniques (Garfinkel, 1967). Because I was looking to tell the stories of these TCs as they became new teachers, using a collective case study approach was appropriate. The case study approach fits within the larger umbrella of ethnography. Ethnography consists of describing a people or cultural group (Glesne, 2011), and ethnomethodology, specifically, focuses on specifically uncovering the everyday practices in which people construct their reality and make sense of their world (Garfinkel, 1967). Ethnomethodology hones in on how members of a group construct their own experiences and what they do in their practical actions, including the nuances of their language, behaviors, and beliefs (Denzin \& Lincoln, 2011). Both related approaches are addressed using collective case study (Stake, 1995; 2010) in which participant-observation, in-depth interviewing, and artifact collection takes place (Emerson, Fretz, \& Shaw, 2011).

The nature of the case study approach (Garfinkel, 1967; Glesne, 2011) allowed me to enter the research setting and spend an extended period of time capturing the experiences of my participants and then interpreting their constructions of reality. I explored in-depth multiple cases that were within a "bounded system" (Creswell, 2012, p. 465), connected by the frame of teaching within PBIS school settings. Analyzing and comparing each within the larger group to provide insight into this problem was best accomplished through collective case study (Stake, 1995/ 2010). Initially defined by ethnographer Louis Smith, the idea of cases as "bounded systems" refers to the fact that each case has boundaries and working parts functioning in an 
integrated system (Stake, 1995, p. 2). Studying multiple cases of new teachers in context allowed me to find distinctions, as well as patterns, across teacher characteristics and experiences about PBIS and its connection to communities in schools and classrooms.

\section{Design}

To explore my guiding questions, I chose to use a multi-leveled approach beginning with focus groups and moving to collective case study (Stake, 1995; 2010). I conducted focus group interviews at the end of the student teaching semester and then followed three participants from the focus groups into their first years of teaching.

\section{Settings}

The first phase of this study began within one ECE program at a large, public, Midwestern university, Midwest State Teacher's College, "MSTC" (pseudonym). Founded as a "normal" school, this university has a deep history in teacher preparation. Because one in four new teachers in the state of Illinois graduates from this institution, this seemed a fitting setting to conduct the study and achieve a representative view of early childhood teachers within this state. Graduating from the same teacher preparation program ensured that the study participants had the same coursework and were subject to the same state-level requirements for teaching preparation and standards for teaching.

The National Council for Accreditation of Teacher Education (NCATE)-accredited early childhood program of this institution prepared teachers for licensure serving children from birth to age eight or third grade. At the time of the study, there was no classroom managementspecific course within this program's plan of study, nor were there CM-focused courses offered as electives, as noted by the university's course catalog. CM topics were infused across courses, such as in previously-researched teacher preparation programs (Brophy, 2006; Hammerness, 
2011; Landau, 2001; Oliver \& Reschly, 2010; Stough, 2006). It is from this setting that the participants were recruited, and where two of the focus group interviews were conducted.

In the second phase of the study, the classrooms and schools of the new teachers became the settings of the study. The setting of each of the three cases were public schools housed in Illinois, and each school used the PBIS framework, as verified by the Illinois PBIS Network's list at the time (Illinois PBIS Network, 2013). The three sites of Smith Elementary, Monroe Elementary, and Field Elementary (pseudonyms) will be described in more detail in the case study chapters of this manuscript. Commonalities across the three sites included grade level spans and number of students. Additionally, in the year of the study, each served more students who came from lower-income backgrounds, as well as who had special needs, than other schools within their respective districts. Two of the three sites, Monroe and Smith, served more students who were English language learners than others within their respective school districts, as well.

Table 1

Case Study Site Demographics

\begin{tabular}{llll}
\hline School & Field Elementary & Monroe Elementary & Smith Elementary \\
\hline School Type & Rural & Rural & Large Suburban \\
Grade Spans & PreK-6 & K-5 & K-6 \\
Student Population & 549 & 609 & 591 \\
Racial Make-Up & $93 \%$ white, 4\% & $86 \%$ white, 14\% & $25.4 \%$ white, 40.8\% \\
& Hispanic, 3\% other & Hispanic & $\begin{array}{l}\text { Hispanic, } 8 \% \\
\text { African-American, } \\
\end{array}$ \\
& & & $22 \%$ Asian- \\
& & & American \\
SES Levels & $28 \%$ low-income & $81 \%$ low-income & $45 \%$ low-income \\
English Learners & 0 & $17 \%$ & $28 \%$ \\
Exceptionalities & $16 \%$ & $21 \%$ & $11 \%$ \\
Average Class Sizes & 21 & 23 & 22 \\
\hline
\end{tabular}




\section{Participants}

Participants for this study were also grouped based on the study's two phases: the first for the focus groups and the second for the case studies. Specific sampling strategies were used for each.

Focus groups. I used concept sampling (Creswell, 2012) to identify 10-12 early childhood education teacher candidates in their final semester of the ECE program at this institution. Concept sampling is used when a researcher samples individuals because they can help generate or discover a specific theory or concept (Creswell). Because I was interested in examining how teacher candidates transitioning into new teachers negotiated building classroom communities and PBIS, this was appropriate.

In the spring of 2014, after securing a list of current ECE student teachers, I sorted possible participants into those who were student teaching in schools identified as using the PBIS framework, and those who were not. Out of 27 ECE student teachers this semester, 19 were placed in PBIS settings. I confirmed this by checking the placement site's school and district websites, as well as the Illinois PBIS Network's list at the time (Illinois PBIS Network, 2013). While teacher candidates from this program have the option to complete their student teaching semester in locations outside of Illinois, in this semester, the only participants who fit the criteria of having been in a PBIS-setting were placed in Illinois public schools. A recruitment email was sent to the 19 eligible participants, and of these, 11 agreed to participate.

Of these 11, all were female, which was representative of their cohort of ECE graduates (as all were female), and all, but one, who identified as African-American, considered themselves to be White. These demographics were representative of the larger institution, in which there was a predominance of White and female students in the year of the study (over 
$70 \%$ ), as well as the field of education, with $82 \%$ of teachers in the U.S. being White and female (U.S. Department of Education, 2016). Most of the participants ranged in age from 22-24, with one aged 39-years-old. Grade level opportunities for student teaching in this program were from kindergarten-3rd grade, and the participants' placement grade levels demonstrated this range. This ECE program offers candidates two options for student teaching. The first is a traditional 16-week student teaching experience that takes place the final semester of their program. The other option is a full-year placement in a local Professional Development School (PDS) site housed within one local school district, where they complete both a fall-semester clinical experience and their 16-week student teaching placement within the same classroom. While exploring the differences in student teaching models was not the focus of this study, half of the potential participants in this semester were placed in PDS sites, and because every one of these sites used the PBIS framework, more teacher candidates who had been in a PBIS site were invited to participate. Seven of them agreed, making this experience a dominant preparation feature of the sample. 
Table 2

Focus Group Participant Demographics

\begin{tabular}{lllllll}
\hline $\begin{array}{l}\text { Teacher } \\
\text { Candidate }\end{array}$ & Sex & Race & $\begin{array}{l}\text { Type of ST } \\
\text { Placement }\end{array}$ & $\begin{array}{l}\text { ST Grade } \\
\text { Level }\end{array}$ & $\begin{array}{l}\text { PBIS } \\
\text { Setting }\end{array}$ & $\begin{array}{l}\text { Focus } \\
\text { Group \# }\end{array}$ \\
\hline 1 & Female & White & PDS & Kindergarten & Yes & 1 \\
2 & Female & White & PDS & $2^{\text {nd }}$ & Yes & 1 \\
3 & Female & White & Traditional & Kindergarten & Yes & 1 \\
4 & Female & White & Traditional & $2^{\text {nd }}$ & Yes & 1 \\
5 & Female & White & Traditional & Kindergarten & Yes & 2 \\
6 & Female & White & PDS & $3^{\text {rd }}$ & Yes & 3 \\
7 & Female & White & PDS & $1^{\text {st }}$ & Yes & 3 \\
8 & Female & African- & PDS & $2^{\text {nd }}$ & Yes & 4 \\
& & American & & & & \\
9 & Female & White & PDS & $3^{\text {rd }}$ & Yes & 4 \\
10 & Female & White & PDS & Kindergarten & Yes & 4 \\
11 & Female & White & Traditional & $1^{\text {st } / 2^{\text {nd }} \text { Split }}$ & Yes & 4 \\
\hline
\end{tabular}

Case studies. From this sample, and in the summer following their graduation, I used opportunistic sampling to identify three teacher candidates to follow for the yearlong case studies. Opportunistic sampling refers to purposeful sampling that takes place after a research study has begun to take advantage of events that unfold during the study (Creswell, 2012). I did not target a specific gender, age, race, ethnicity, or language background. To investigate their perceptions, beliefs and practices in PBIS ECE settings over the first-year of teaching, case study participants needed to be employed in an early childhood setting that used PBIS. As such, criteria for recruitment included full-time employment in a public school, early childhood setting, in which the PBIS framework was used, and which I could access the following year. I did my best to ensure that this smaller subset was as diversely represented as possible (i.e. showing a range of gender, age, race, ethnicity, native language), but I was limited by 1) the number of participants who initially participated in the focus group; 2) the diversity that this 
group represented; 3) the diversity of participants who were hired in a teaching position in a school using the PBIS framework after graduation, and 4) the permission of their school district.

At the time of the study, PBIS was primarily being used in Illinois public schools, which ruled out consideration of participants who found first-year employment in childcare settings. Of the 11 focus group participants, three qualified to participate based on these criteria, and two agreed to participate, Vanessa and Molly. An additional ECE graduate who had been eligible, but unable, to participate in the focus groups, expressed interest in participating in the yearlong study and fulfilled the case study criteria. Thus, Kristin became the third case study participant. All three were hired across the state of Illinois in public elementary schools. I will provide much more detailed profiles of each of these case study participants in chapters five, six, and seven.

\section{Data Collection}

Data for the study was collected throughout the summer of 2014 and across the 20142015 school year, which allowed each case to develop as the teachers grew and provided a more well-rounded picture of their experiences. The use of semi-structured interviews, participantobservations, and artifacts allowed for data to come from the participants in an open-ended fashion and provided triangulation, which helped me feel, "more confident that we have the meaning right” (Stake, 2010, p. 124), when analyzing my findings. These tools provided a window into participants' beliefs, feelings, and classroom practices.

Over the year, I conducted focus groups with the teacher candidate participants and fourfive semi-structured interviews, three full-day observations of their classroom practice, and multiple points of artifact collection spaced every few months from the beginning to the end of the school year with each of the case study participants. Due to the extensive amount of data collected, I used a data accounting log (Miles, Huberman, \& Saldana, 2014). See Appendix A 
for the schedule of the data collection. Additionally, I developed a table of sources and organized each type of data into files. Creswell (2012) writes that this organization is critical when large amounts of data are acquired. Figure 1 provides a visual representation of the data collection techniques used in the study.

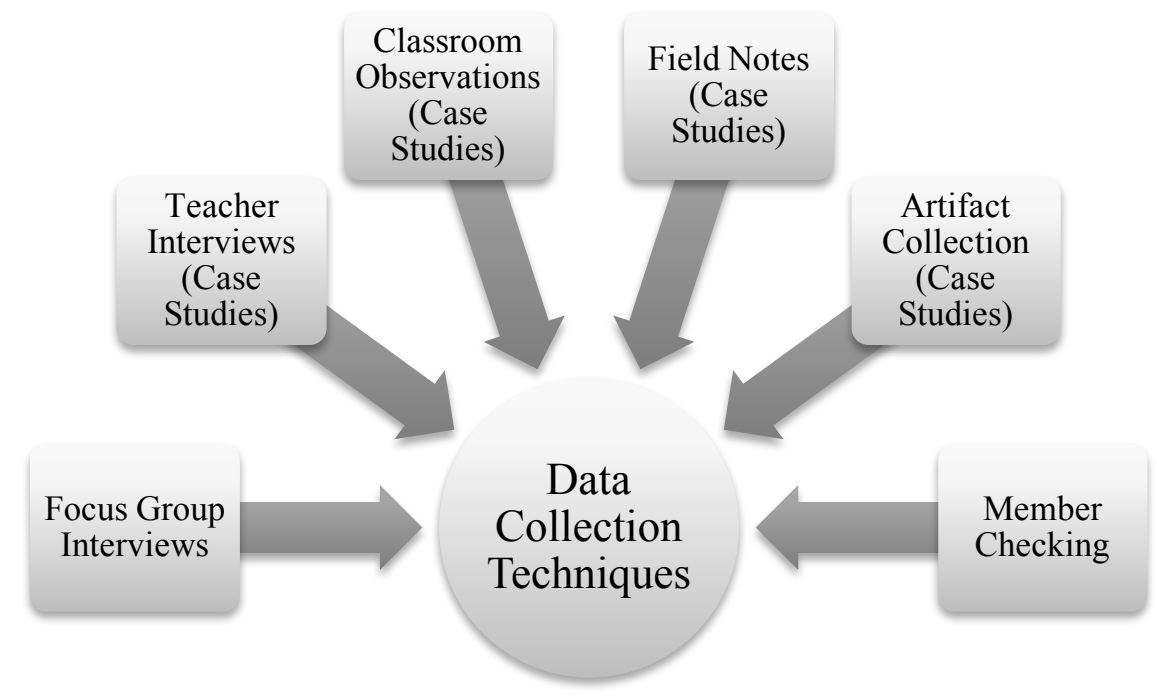

Figure 1. Data collection techniques.

Focus group interviews. Because participants tend to feel more comfortable in groups, focus groups "often produce data that are seldom produced through individual interviewing and observation" (Denzin \& Lincoln, p. 559). For this reason, I chose to begin the study with focus groups. Bringing participants together at the end of their student teaching experience to discuss their perceptions of CM, PBIS, and their preparation was, in a way, a cathartic reunion of sorts (i.e. because they had been separated for at least one semester in the field student teaching). There were lots of hugs and "how's it going" kinds of comments when the groups met. The relaxed format also encouraged them to debrief about their perceptions and beliefs more deeply, 
because ideas were spurred by others (Denzin \& Lincoln, 2011). An example of this was when two participants realized that they had completed clinical placements at the same site. One exclaimed to the other, "Wow, I did one of my clinical placements at that school too! I also didn't know it was a PBIS school because that's how little I saw too!" Discussing their experiences together pushed them each to reflect in ways that they may not have done individually.

Slated to take place towards the end of the student teaching semester, I decided to conduct two face-to-face focus groups with the participants during the week of their graduation, yet scheduling made this challenging. Consequently, a total of four focus groups took place following their graduation, between the months of May and July 2014. After receiving consent, two were conducted in-person, one on the university campus, and one on at a partner district's office several hours away, near where several participants lived. All four participants scheduled to participate in the on-campus focus group did so on this date. However, three of the four candidates scheduled for the suburban focus group were unable to attend at the last minute, which forced this focus group to become a one-on-one interview. Because these three nonattending participants were still interested in participating in the study, and additional participants who had agreed to participate were located far and wide, an amendment was made to the IRB protocol to conduct two additional focus groups online; one with two participants, and one with four. Each was approximately 60 -minutes and was audio-recorded and transcribed. The interview protocols consisted of 13 broad, open-ended queries based on my research questions and refined through pilot studies. See all interview protocol attached in Appendix B.

Teacher interviews. I engaged in multiple interviews with each of the case study participants to explore how they were making sense of PBIS while building their classroom 
communities in the first year of their careers. Stake (1995) cites the interview as the "main road to multiple realities" (p. 64). With these interviews, I intended to carry over questions and findings from the focus groups to continue exploring the study's guiding questions. By September 2014, Molly, who had participated in the first focus group had gotten a full-time teaching position in an early childhood PBIS setting and had consented to participate in the yearlong study. In October 2014, Vanessa, who had participated in the fourth focus group and Kristin, who had been unable to participate in a focus group, also joined the yearlong study. With my son's birth that fall, Kristin's and Vanessa's first interview and classroom observations scheduled for late September and early October were postponed. By year's end, with each participant, I conducted four to five semi-structured interviews, spaced every few months from the beginning to the end of the school year. Meeting one-on-one allowed each participant to share experiences and words that told the story of her year, and the conversational stance (Stake, 2010) with which I approached the interviews brought out meaningful emotions and reactions over the course of the year. Each semi-structured interview lasted approximately 60-minutes and took place at a mutually agreed-upon location that varied from my university office to the participant's classroom after school and was audio-recorded and transcribed.

Hollway and Jefferson (1997) describe the need to be cognizant of the "function of the gender, age, and other power-laden dynamics inherent in all social interactions, as well as the manner of framing questions" in the interviewer-interviewee context (p. 68). Thus, the interview protocols consisted of 12-14 broad, open-ended queries based on my research questions and refined through the two pilot studies and the focus group. As the year went on, additional clarifying probes were used within the semi-structured interviews to expand on the observation data, and other ideas that had been revealed. The responses from these open-ended probes 
helped add meaning and relevance to the understanding of the central phenomenon. The goal was to gather these participants' stories to illustrate their perspectives on this important topic.

Classroom observations. To triangulate the data from the new teacher interviews, I also conducted full-day classroom observations of their classroom practice over the course of the year. Participant-observation refers to the act of learning firsthand that which members of a group experience through observation and interaction (Glesne, 2011). There is a long history of participant-observation in qualitative research (Glesne, 2011), as it “...is the heart, and heartwood, of all qualitative inquiry" (Wolcott, 2002, p. 101). Even though one may engage in everyday casual observations of daily happenings, participant-observation differs in that I, as a researcher, carefully observed, while systematically experiencing, and consciously recording what took place in these classrooms.

Spending time in each classroom allowed me to observe each participant's classroom management style, as well as how she embedded PBIS and built classroom community within her setting. While my goal had been four to five classroom observations, due to the timeline of when I received participant consent and district approval, as well as the birth of my son, some of the observations were postponed. By year's end, I spent three full days in each of the participants' classrooms. The one-on-one interviews were paired with these days of observation when possible. Spending this time in these new teachers' classrooms and schools provided what Emerson and colleagues (2011) describe as "access to the fluidity of others' lives" (p. 3). This access enhanced my sensitivity to interactions and processes within the participants' daily lives that without observation would have been inaccessible (Emerson et al., 2011). Following each interview and classroom observation, I used a contact summary form (Miles et al., 2014) to reflect on the interaction and make analytic memos. 
Through my prolonged, full-year engagement, I gained access as a "trusted person" (Glesne, 2011, p. 63) in each of the participant's classrooms, and for the purposes of this study and my researcher role within it, I took more of a participant-as-observer role. Because of my positionality, which I will expand upon later in this chapter, I was at times brought into the activities of the classroom. When children would ask me questions and invite me to participate, I happily and respectfully participated, but for the most part, I attempted to remain in the background, so as not to disrupt the natural flow of the classroom. I used my field journal to capture the experiences of the day with a focus on the behaviors and language used by the new teachers. When dialogue with children was captured, I assigned them pseudonyms.

I used a field journal to collect my observations and on it noted everything from details about the classroom environment, to language samples, to observations of teacher and student behavior. I often wrote my field notes while sitting in my car outside the schools after classroom observations, or I dictated them onto my phone during the drive home to keep my memory fresh. Because talking to others about what I had observed before writing it down "can rob note writing of its psychological immediacy and emotional release" (Emerson et al., 2011, p. 50), I waited to relive the experience later with my husband. These field notes helped inform my analysis.

Artifact collection. Providing a third form of triangulation within these case studies, I also had four points of artifact collection related to PBIS and community across the year with each participant. Glesne (2011) reasons that artifacts/ documents can raise additional hunches and new questions, thus guiding future observations and interviews. Miles et al. (2014) argue that good ethnographers have always captured visual data, but with the media advances of today, there are more ways of capturing and using visual data than ever before. Because there are often tools, manipulatives, and other hands-on artifacts that are used with CM and PBIS, taking 
photographs, scanning in materials, and writing detailed descriptions of these involved another layer of exploration. This technique provided another perspective to the study and visually painted the picture of how these teachers navigated these complexities. These artifacts provided a third form of triangulation within the case studies, helping to round out the participants' stories. Artifacts were both self-selected by the participants and curated by me. They included hand-outs, posters, student work, and photos of classroom design, amongst others. I photographed, scanned, saved, and drafted analytic memos of these visuals. Although images of the classroom management and PBIS artifacts may on their own have represented significance, until I interpreted them through description and reflection, they did not carry meaning for the purposes of this study and the participants' stories. These memos represented ideas and thus allowed the collection of these documents to be coded (Miles et al., 2014). Data was stored in my password-protected computer that was backed by a Carbonite subscription.

Member checking. I utilized member checking to increase the trustworthiness of this study by allowing my participants to help me represent them in as accurate a description as possible (Glesne, 2011). Providing my focus group participants and the three case study participants the opportunity to review my transcripts and notes ensured that reciprocity was met and that their voices were truly represented. Stake (1995) likens participants to actors and explains that "actors play a major role directing as well as acting in case study" (p. 115). I encouraged these actors, my participants, to provide feedback and their own hunches in the hopes that this could provide more insight and detail than I was uncovering myself. By returning to them with data, I attempted to respect their interpretations and understandings of the experience. I hoped that member checking might also provide reflective support for my participants as they considered their previous words and actions, providing the possibility of 
feedback for improving their practice and craft as an early childhood educator. Member checking took place throughout the yearlong process. While the participants rarely found areas of concern or edit, the fact that they read through the transcripts surfaced in follow-up interviews and revealed that they were processing the data.

\section{Data Analysis}

Because I conducted a collective case study using ethnomethodological techniques, it was fitting that I use qualitative forms of analysis. Wolcott (1994) writes that there are three major modes of data collection in qualitative research including "participation observation (experiencing), interviewing (enquiring), and studying materials prepared by others (examining)", and as such, there are three ways to "do" qualitative analysis (p. 10). These include description, analysis, and interpretation, and they served as a fitting form of analysis for this study's data. I found it helpful to also infuse analytic techniques from Miles et al. (2014) throughout. I will describe each of these modes of analysis below.

Description. Once data collection began, I started the coding process. Coding refers to the process in which the researcher makes sense of the data, dividing the text into segments, labeling segments, looking for overlap and larger themes (Creswell, 2012; Stake, 2010). Coding followed a multi-step and iterative process, as it was done concurrently with data collection. I began by using "open coding” (Emerson et al., 2011, p. 174) in which, I noted my reactions and thoughts in the right margin of the transcripts and read them in their entirety.

Upon learning of patterns in experience, I used Wolcott's (1994) descriptive tool of the Rashomon Effect, in which the researcher attempts to describe data by telling participants' stories through storytelling from different perspectives. This effect coined from Akira Kurosawa's 1950 film, Rashomon, in which a crime witnessed by four individuals is described in 
four mutually contradictory ways highlights the subjectivity of experiences. Kurosawa's film emphasizes that there is never one account of an incident, but as many versions as there are spectators (Wolcott, 1994). Wolcott (1994, p. 21-22) writes that with the Rashomon effect, ....as a story telling technique, any descriptive account can be related through the eyes of different participants, seemingly freeing the researcher from having to disclose his or her own view-except for the presence of the authorial hand that has guided each viewer's recounting.

For my study, this strategy was useful for depicting the feelings, experiences, and beliefs of different early childhood teacher candidates who had all been in PBIS student teaching settings. While they did not all experience PBIS in one specific school, each of the participants was prepared in the same teacher preparation program and placed in an Illinois public school using this framework for student teaching and their first years in the field. Highlighting stories and perceptions across these similar, yet distinct, experiences proved helpful for analyzing the data from these interviews. Additionally, I sought patterns across these stories, and I revisited them throughout the study, as they aided in the next stage of overall data analysis.

Analysis. I then employed line-by-line coding. By coding each line, I sought to find redundancies and cohesion in ideas. I read the transcripts, memos, and my field journal multiple times. The areas of overlap and cohesion combined and illustrated larger patterns within the data. Miles et al. (2014) write that, "the human mind finds patterns almost intuitively; it needs no how-to advice." I used a coding matrix (Miles et al., 2014) to note these larger themes. This visual display assisted me in seeing initial themes, which I used to create categories and a concept map to highlight them. Additionally, I used factoring by comparing and contrasting cases of the focus group participants and the case study participants (Miles et al., 2014) to 
illustrate unique findings from within the data. Next, I plugged lines and quotes from the data into these themes to identify larger connections to my research questions. I also examined the patterns revealed in the story memos using the Rashomon Effect (Wolcott, 1994). I was ready to see these patterns emerge; yet I remained open to disconfirming evidence when it too emerged at this stage of overall data analysis (Miles et al., 2014).

In Wolcott's mode of analysis, evaluating findings against a standard is a helpful technique (1994). Each of the participant's settings utilized the PBIS framework, and extant literature had indicated that there may be variability in this implementation (Center for Mental Health in Schools at UCLA, 2011; Molloy et al., 2013). Also, my research questions aimed to explore what the participants were learning about PBIS in their settings. For these reasons, it was helpful at this stage of analysis to evaluate their understandings and reporting of PBIS against a standard. For PBIS, the standard outlining required components of the framework is embodied in the PBIS School-Wide Evaluation Tool (SET) (Sugai et al., 2001). Thus, I used the SET to identify components of the PBIS framework that I observed in practice and that participants described. An alternative to assuming the role of an evaluator is to investigate how those immediately involved or affected evaluate what is going on (Wolcott, 1994). Because my role in doing this was not as an evaluator of PBIS implementation, and instead it was to gauge participants' perspectives about the framework, I assumed the role of an "information processor" (Wolcott, 1994, p. 34) in conducting this analysis.

Interpretation. In the final mode of analysis: interpretation, I dove into what was to be made of the data (Wolcott, 1994). By year's end, it was clear that the best way to tell the stories of these three case study participants was using Wolcott's descriptive technique of telling a "day in the life" of each participant (p. 19). The nuances of their daily routines, behaviors, and 
interactions reveal themselves so perfectly in this format. However, with so much data, a more global interpretation of the case study findings was to tell the story of a "year in the life" of each. Wolcott (1994) writes that "day in the life need not be taken too literally" (p. 19). Instead, the goal of this technique is to provide the reader with what Wolcott calls "the feel" of the setting through a reconstruction of what I experienced as the researcher, and which each participant lived (p. 19). Through examining the first year of teaching from a year in the life of each of these new teachers, the results of the study manifest themselves in the language, behaviors, and raw emotions that each experienced with the passage of time.

Additionally, fully interpreting the data to identify implications from it related to my third research question. To do this, I employed the use of metaphors (Miles et al., 2014). Miles et al. (2014) state that metaphors are useful for connecting findings back to theory. Pink (2005), writes that "if a picture is worth a thousand words, a metaphor is worth a thousand pictures" ( $p$. 50). Through comparing two things via their similarities, metaphors illustrated larger connections to be made across the three participants' experiences. Crafting metaphors allowed me to condense my data into manageable chunks and revealed a deeper understanding of the research problem. As my work over the course of the year was aimed at telling these teacher candidate/ new teachers' stories, using these tools did much to highlight themes from the data.

Because this was a longitudinal study with multiple sources of data, coding was an iterative process. As I came back after each set of interviews and observations, I went through the first mode of overall data analysis, and as it progressed, I found myself moving through the modes of description and analysis repeatedly. By the final round of interviews and participant observations, the final stage of interpretation was truly attainable. 


\section{Issues of Trustworthiness}

Because of the qualitative nature of this study, it was critical that I establish trustworthiness measures to ensure the credibility of my work. Glesne (2011) illustrates the quandary that qualitative researchers are in when asked to establish the "validity" of their work, because all interpretivist, constructivist work is socially constructed; as such, it is always true and valid for those living it. At the same time, it was critical that I establish "verisimilitude" or a sense of authenticity for my readers (Glesne, 2011, p. 48). Because of my researcher roles within this study, this was even more necessary so that others could find their own understandings of the stories I hoped to tell here. Thus, I established trustworthiness by using several validity techniques, including triangulation, prolonged engagement, thick description, and member checking as explained earlier.

Triangulation. Researchers use triangulation to "minimize misperceptions" (Stake, 1995, p. 134). Triangulation refers to the use of multiple data-collection methods, or multiple sources (Glesne, 2011). In this study, each of the various data sources layered in a more richly detailed example because each provided a different perspective of these participants' realities, which would have been lost if I had only conducted interviews or observed in classrooms. Additionally, triangulation allowed me to cross-reference findings and hunches throughout the year to confirm and/or dispel patterns and overall findings that emerged.

Prolonged engagement. Carrying over the conversations from the focus groups at the end of the student teaching semester to the whole first year for these three participants ensured that I could form relationships and develop trust (Glesne, 2011), learn the culture of these teachers, their schools, and practices (Creswell \& Miller, 2000; Glesne, 2011), and truly allow my understanding to grow and develop. Creswell and Miller (2000) write that prolonged 
engagement helps to build a "holistic case" (p. 128). I realized this because the longer I was in the field, the more my understanding of their daily practice, and their beliefs and feelings related to these topics grew.

Thick description. Immersing myself deeply into the school setting allowed me to garner detailed field notes based on classroom observations and document collection that were enmeshed in the context of that local setting (Emerson et al., 2011). Being able to write and expand upon this immersion is what Clifford Geertz, quoting Gilbert Ryle, termed "thick description" (Geertz, 1973, p. 312). When used, thick description aids in the trustworthiness of qualitative studies by leading readers directly into the experience (Geertz, 1973; Glesne, 2011). Using my participants' language and layering in rich, context-laden details allowed me to truly tell the participants' stories, and thus, permits readers to enter the classroom and school settings in which these new teachers lived. Weaving the details of the environment, the artifacts utilized and displayed, the overt and covert behaviors of each participant and her students, the ambiance of their exchanges, and the participant's reflective language in the interview following the observation allowed me to provide a thick description of the experience to future readers and interpreters of this research.

\section{Ethics}

As with any study involving human subjects, there were ethical considerations that I made in advance and then during the study (Glesne, 2011). These participants and I entered a relationship that, for some lasted just an hour, but for three lasted over a year. It was critical that I protect them, their students, and myself in this research. To be fair and responsible, I considered the privacy of my participants and offered full disclosure throughout the study. I also 
attempted to remain ethical throughout the study by examining my own positionality and practicing reflexivity and reciprocity.

Privacy and full disclosure. This study received approval from the university institutional review board, as well as district approval for each of the case study participants. Each of the participants signed a consent form to participate in the focus group interviews, and the three participants in the collective case study also signed an additional consent before our work together began. The principal at each of the case study sites also received an informational letter that included an introduction to the purpose and scope of the study and detailed information about the procedures for data collection, transcription, analysis, and dissemination. Furthermore, the letters outlined the potential risks and benefits of participation in the study and communicated the voluntary nature of the new teachers' participation.

There were privacy considerations that I made for both the focus group interview and the case study participants. The distribution of trust in focus group interviews not only embodies the power of this format, but also belies the dangers of anonymity (Denzin \& Lincoln, 2011). There was a remote risk that some participants may breach confidentiality and share what had been discussed in the focus group. However, the knowledge and experience of this format made it worth pursuing. The feeling of comfort that being in a group provides diminished the possibility of personal vulnerability and risk (Denzin \& Lincoln, 2011). Additionally, I reminded all participants to respect the privacy of others and to not repeat what had been said in the focus group discussion. Also, I kept all notes and transcripts on my password-protected computer, where participant responses were kept confidential. I used pseudonyms for individuals and schools and removed all identifiable information. 
A professor, supervisor, mentor, researcher? Researcher positionality. Stake (1995) writes that interpretation is a major part of all research, especially qualitative because of the constant need in this line of research to be maintaining "vigorous interpretations" (p. 9). No research is conducted without researcher subjectivity whether it is qualitative or quantitative (Peshkin, 1988). Who I am, my history, my beliefs, my perceptions, my relationships, and my "me-ness" are all things that I carry around with me every day. I acknowledge within my epistemological beliefs that from an interpretivist perspective, data reflects not only my participants' historical, social, and situational locations, but also my own as the researcher (Denzin \& Lincoln, 2011). To feign objectivity towards this research or my potential participants would have been ludicrous. The fact that as a qualitative researcher I am the instrument of data collection and interpretation impacted this study in multiple ways. To make assertions about what I was encountering in the study, I drew from understandings within me about the nature of PBIS, sense of community, and new teachers. These understandings stem from personal experiences, scholarship, and others' research (Stake, 1995).

Solely looking at the personal experiences influencing these understandings, I recognize that my background as an early childhood alumni of the study institution, as a teacher candidate, a new teacher, an early childhood educator, a coach of early childhood teachers, an instructor and supervisor of early childhood teacher candidates, and a researcher all impacted the way that I viewed and interpreted the cases that presented themselves in this study. I have lived many of the same experiences that my participants were living during this study. I have felt the excitement of young children purposefully and happily engaged in play, as well as the frustration of a room erupting in turmoil and chaos. I have felt the push-pull of professors giving me one perspective and cooperating teachers in the field telling me otherwise. I have also witnessed the 
power of emotions displayed by teacher candidates and new teachers discussions about classroom communities, the teaching of pro-social skills, and frustrations of not knowing or understanding school-wide classroom management policies. I could not disassociate myself as a researcher from these experiences, and doing so would have prevented me from bringing the insider perspective that I brought to this study. I recognize that this closeness at times presented issues that had to be addressed. However, this closeness also brought an insider's perspective that was richer and more detailed than an outside researcher could acquire (Glesne, 2011).

Ultimately, the goals of case study research are to paint the picture as those experiencing it see it (Stake, 1995), so I tried my hardest to preserve the multiple realities that the teacher candidates and new teachers described, so that their cases alone illustrated responses to the research questions. I recognize that because of my passion for this subject, I took on the role of advocate in interpreting and preparing my work for viewing. When case researchers take on the role of advocate, they attempt to discover the best arguments against other assertions and provide data to counter them (Stake, 1995). Because of the relative abundance of current research promoting PBIS in elementary schools, I recognize that I sought out opportunities to illustrate another side of this approach. As I was viewing this work through a lens of community and humanistic classroom management, I was confronted with many teaching practices that were contrary to this guiding belief.

Additionally, there was the possibility that because of the nature of this topic and my background with it that I would also take on the role of mentor within this study's framework. A major reason for this was because with each of the participants for both the focus group interviews and the case studies, I had been in previous relationships with them in which I served as a guest lecturer, course professor, and for some, a university supervisor. Through the 
yearlong relationship in which I interviewed and participated in their classrooms as a new teacher, I predicted that they may still perceive me in this university role, which happened with each one as I will explain more in the case study chapters.

Knowing myself as an educator, I predicted that it would be nearly impossible for me to ignore their pleas for support and mentorship. Although I recognize that some may see this as problematic, I believe that engaging in relationships with participants is a critical component of qualitative research (Emerson et al., 2011; Glesne, 2011). Inherent in this type of qualitative work, I was brought close to my participants' lives by actively participating in their classrooms and spending time engaged in deep conversation with them (Emerson et al., 2011).

Emerson et al. (2011) acknowledge that the goal in ethnographic research should never be to be a "fly on the wall" (p. 4). Even without a prior relationship, there was no way that I could ever be completely neutral. Thus, I believe that knowing my participants before the study yielded a stronger rapport and increased the overall trustworthiness of the study by allowing them to trust me more than an outsider, and thus be more open with me. Before beginning, I also predicted that my previous relationships may lead these participants to be more willing to open their classrooms and their vulnerability for a year of participating in this study, and as I will later explain, I found this to be true.

Despite the strong relationships that formed, I recognize that I was never truly an insider for these participants. I was always still "at least something of an outsider, and an extreme, a cultural alien" (Emerson et al., 2011, p. 5). The tension between our pasts and presents together surfaced, especially when their confidence wavered or they were confronted with stressors and challenges in their daily practice. To offset this, I worked harder to protect my participants' vulnerability and engage in reflexivity and reciprocity. 
Reflexivity. As I acknowledged in the above section on my researcher role and positionality, I fully embraced my subjectivity in this study. Denzin and Lincoln (2011) write that, "the way in which we know is most assuredly tied up with both what we know and our relationships with our research participants" (p. 123), and this is what provides validity in the ethical relationship. Because of my background as a university instructor and supervisor at the same institution as the participants, I waited to begin the study until they were no longer students of mine in either of these roles. I believe that doing so helped eliminate worries of retaliation, but may not have fully addressed their desire to provide pleasing responses to my interview questions. Conducting multiple interviews and prolonged engagement helped address these concerns in the case study year, and even then, at times, I was left wondering if they were giving me the answers they thought I wanted to hear. At a few points, they even commented on this, and we discussed it in the moment.

Additionally, because of my layered background experiences related to classroom management, as I predicted, I did encounter teaching practices and other interactions that, at times, made me unsure and uncomfortable. For the purposes of the study and to protect my participants' vulnerability, I did not offer feedback that ran directly contrary to the messages that they were hearing or experiencing in practice, even when I felt this discomfort. Each of the participants reached out to seek feedback related to classroom management and other aspects of their teaching at various points throughout the yearlong study. These questions always made me pause and contemplate my next words. Seidman (1991) explains that while sharing one's own experiences, "may contribute to building rapport, it can also affect and even distort what the participant might have said had the interviewer not shared his or her experience" (p. 74). Thus, in each scenario, I responded in what I hope was a professional manner, attempting to push each 
participant towards a deeper understanding and realization of next steps on her own. I would be remiss to not acknowledge that this created tension and was difficult for me on both professional and personal levels, especially when participants experienced intense stressors and challenges and reached out for help. However, I feel that it was essential that I not disrupt the realities they were experiencing, as new teachers navigating the bridge between teacher preparation and the real world and dealing with the highs and lows of their first years of teaching.

Throughout the year, I kept an audio-recorded and written researcher journal where I noted these tensions, my reactions, and reflections. This tool helped me monitor myself: my reactions, my beliefs, and my attitudes that grew, shifted, and changed throughout the course of this year and half. Peshkin (1988) writes that through doing this, "I can create an illuminating, empowering personal statement that attunes me to where self and subject are intertwined" ( $p$. 20). Getting so close in qualitative research comes with its inherent benefits and challenges. As a researcher sifting through this very close material, I was confronted with discomfort myself and on behalf of my participants because multiple perspectives and priorities surfaced (Emerson et al., p. 174). My goal was not to determine one single "truth," but instead to reveal the multiple realities in which these participants lived (Emerson et al., 2011 p. 4).

Reciprocity. Glazer (1982) writes, "The threat of the stranger is a double-edged sword with ominous implications for both respondents and researchers. The enactment of reciprocity shows each side the goodwill of the other and the actual or potential benefits of the relationship" (p. 28). Out of deep respect for my participants and the practice of qualitative research, I worked to establish reciprocity with my participants. "Cultural thieving" is the process of solely conducting research to publish without benefit to the participants (Glesne, 2011, p. 177). 
Because this was not my goal, I considered how much I was asking from participants versus what benefit they were receiving at each stage of this yearlong study.

I attempted to be clear and transparent regarding participation throughout the study with each of my participants. For the focus group participants, I shared my gratitude for their participation. It was important that I emphasized how important their perspectives were for illuminating the TC and new teacher perspective in an area of research that before this was not considered. At the end of each focus group interview, I made sure to express my appreciation and offered continued communication and support as these participants began their first year of teaching, and several stayed in touch to let me know how they were doing. Glesne (2011) writes that the interview process in and of itself can offer reciprocity. In the interviews, I listened closely and seriously to the points my participants raised, which I hope gave them a sense of importance and validation. As they expressed frustrations with their preparation for classroom management, several commented how it was nice to be talking about this topic with the focus group members. A few also commented that it was interesting to hear their classmates' perspectives that they otherwise would not have heard.

After spending so much time with Molly, Kristin, and Vanessa over the course of the year, the responsibility of providing recompense for their time, commitment, and participation in the study was even stronger. Each of these new teachers opened her classroom, her hopes, dreams, and fears, and more with me throughout the year. Glesne (2011) states, "The closer the relationship between researcher and research participants, the more special obligations and expectations emerge" (p. 179). Every time we connected, not only did I share my gratitude and appreciation for everything that they were putting into participating, but I also offered my time to volunteer in their classrooms the following year. About this, Molly replied, "Yeah. I would love 
that! I might be calling you, like, 'Kira, what do I do? I need advice.'” As an example of this, Kristin reached out the following year through Pinterest to share classroom management ideas she was interested in trying out.

More helpful in the moment was the positive effect of the interviews that Glesne (2011) alludes to, as this surfaced with each participant over the course of the year. The prior relationships I had with each, and the relationships that grew as their first year and the study progressed, allowed each of the participants to relax and share in ways that they may not have otherwise. Towards the end of the year, Vanessa reflected that talking to me about her CM had made her, "confront my inner beliefs, Kira. I mean it." When I asked Molly at one point near the end of the year, what I could do to help, her response was "just being able to talk to you helps." For her, she explained that because she was so uncomfortable in her own classroom, "...it was more a comforting thing..." to have me come and observe and talk with her. She felt validated by my presence in that she saw me as an ally for developmentally-appropriate practice, which she had learned from me and others in her teacher preparation, and which she did not feel was being practiced in her classroom. She explained that this comfort came from feeling, "where...you know what I know." Additionally, through member checking, I asked for participant feedback, and I offered to share materials when they pointedly asked, such as Vanessa asking for reading suggestions when thinking about removing her clip chart. Vanessa expressed interest in co-presenting with me about the topic of co-teaching, which was a theme that emerged across the year of data. So, in her second year of teaching, she and I co-presented at a new teacher's conference held back at the university. I will continue to look for ways to collaborate with each of them in the years to come. 
Although all of this cannot make up for the time that these participants spent participating in the study, it has hopefully offset the dynamic of the power of the researcher and the researched. Furthermore, to offer reciprocity to the school districts that allowed me to work with teachers in their respective districts, I plan to offer transparency in my findings and a narrative summary of findings with suggestions that can potentially be used to affect district changes when the dissertation is complete.

\section{Summary of Research Methodology \& Design}

In this chapter, I have discussed the real work of the study. Identifying the research paradigm of interpretivism as my guiding force laid the groundwork for the selection of collective case study methodology using ethnomethodological techniques to explore the lived experiences and stories of early childhood TCs as they transitioned into new teachers. Through examining the sites and participants of the study, along with the steps and tools of data collection, the path that this yearlong study took is revealed. By explaining the steps of data analysis, I have set the stage to discuss the results that surfaced. The attention to trustworthiness measures and ethical considerations provide context for understanding this work and the care that went into it. In the following four chapters, I will outline the results of this inquiry. 


\section{CHAPTER IV: AN “OVERWHELMING” TENSION: PRELIMINARY FINDINGS}

The results of the focus group semi-structured interviews highlighted themes related to classroom management, PBIS, and classroom communities for these teacher candidates, nowturned new teachers. All participants experienced the context of the PBIS framework in a public-school setting within the seminal experience of student teaching. This chapter includes the results from these interviews, which set up the foundation for the case study and the subsequent chapters of this dissertation.

\section{Discussion of Themes}

Across descriptions of participant experiences, multiple realities were revealed within the context of being placed in a PBIS setting, that in all effects, should have been more similar. These patterns highlight how these teacher candidates, through their last year of coursework, experienced, understood, and explained their beliefs and practices regarding classroom management. Themes included an overall lack of preparation in classroom management, varied perceptions of PBIS implementation, anxiety in balancing classroom management and teaching, a mismatch in beliefs and experiences leading to entrenchment in the "two-worlds pitfall," and a persistent tension between classroom management practices, including PBIS, and feelings of community in early childhood classrooms.

\section{Lack of Preparation in Classroom Management}

At the time of the study, no classroom management course was offered in the ECE program at this institution, so none of the participants reported having received extensive coursework on this topic. Outside of a few guest lectures that I presented on the topic, they reported learning most of what they knew about classroom management while in the field. One shared, "the only time we talked about classroom management at all was with you, with the 
workshops." A few recalled learning about attention-getters, forming relationships, and setting up the classroom environment, "like putting...quiet areas not by the loud areas obviously," but outside of planning dynamic, engaging lessons, they had little other formal training in this critical aspect of teaching. One participant's description exemplified the typical university perspective that once a teacher has great lessons, "you are more ready to go into the classroom and be like, 'Ok, classroom management, let's do this!" Several concurred with this perspective due to the unpredictable nature of student behavior. Even if they were not fully confident in their own lesson planning skills, they felt they could control the instructional planning aspect of their teaching.

Additionally, specifically related to preparation for the PBIS framework that was present in each of their schools, they were similarly unprepared. None of the participants received formal training related to the various components of the framework in either their teacher preparation, nor while student teaching within their school sites. A few were paired with cooperating teachers who sat on school-wide PBIS committees, and they described somewhat learned about the framework from them. All others learned of the framework from what their cooperating teachers shared with them, which varied from positive reviews to downright dismissal of the framework. One explained, "she [cooperating teacher] is like, 'this is Kindergarten, and this is how they're expected to act'... They're gonna start expecting this [rewards] and then when they get older and if they don't get that, there will be issues.'" Another, whose cooperating teacher was on the school-wide PBIS committee, reported that her teacher disregarded all aspects of the framework and used what she wanted throughout the year. 


\section{Varied Perceptions of PBIS Implementation}

Thus, their perceptions of PBIS represented a pieced-together interpretation of this framework, and how it interplayed with a teacher's classroom management skills. Their descriptions of the components of PBIS and the other classroom management approaches that were used at their schools illustrated incomplete, and at times, inaccurate understandings of the framework. Their descriptions did not highlight an understanding of the tiered aspects of PBIS, but they described components that were clearly connected. An example of this was from one participant who stated that her cooperating teacher "did not really use PBIS," but then she went on to describe her cooperating teacher's use of school-wide rewards and the teaching of behavioral expectations with the "8 Keys" program. Upon analysis, she was most likely describing Tier 1 supports related to the framework. Another example was when another participant described the Check In/ Check Out program being used at her site. Although this participant admitted knowing nothing about the program, it is typically implemented as a PBIS Tier 2 student support.

That which they did describe illustrated wide variability in how the framework was implemented across their school sites and within the classrooms of the same school. In part, this was because many teachers added PBIS components onto behavioristic systems that they had been using before the framework was applied at their schools. As such, candidates struggled with deciphering which aspects of their cooperating teacher's classroom management approach related to PBIS, and which related to her own strategies. This led to many labels of various monitoring systems as being a part of the framework when possibly they were not. Participants described behavior monitoring systems ranging from stoplights, to the Class Dojo program, to clip charts, to cards that were flipped. Rewards varied from Lion Loot, to Lightning Tickets, to 
other rewards tickets, to "warm fuzzies," to "bucket-fillers." Some described Check In/ Check Out, referral systems, and many explained the multiple layers of consequences and punishments at their sites, with most centering around the removal of recess. A few described the teaching behavioral expectations and prosocial curricula such as the Second Step Social-Emotional Program and the 8 Keys to Excellence. What stood out was the sheer number of different strategies being used in each classroom and across the classrooms of these participants, even when they were teaching within the same school. One explained, "And the classroom next door, it was like seeing what a classroom can become when it's not controlled. It was like, 'oh wow!'” Another prominent feature was the variability that their descriptions of the components of PBIS included. Each described pieces of the framework, but none were able to fully elucidate a complete framework being implemented at their school, highlighting incomplete understandings on the part of the teacher candidates, and possible incomplete implementations on the parts of their schools.

The participants' interpretation of PBIS implementation at their schools was framed by their background experiences and their personal reactions to its components in practice. The one constant component across their school settings was the use of a behavior monitoring system. Some participants related this to the PBIS framework at their schools, and others were unsure. Their reactions to these systems highlighted the newness they felt in analyzing them from the role of a teacher, as they were very familiar with what it felt like to experience them as a student. Each described growing up with some sort of behavior monitoring system in their own classrooms. In the new "teacher" role, they described observing a variety of student outcomes from the use these systems in their classrooms, which varied from glee, "especially when they get the prize," to sadness, such as for one student who was described as, "crying every time he's 
on yellow." Several commented on how they noticed the same students receiving consequences and punishments each week, and this led to a few candidates sharing anecdotes of being similarly punished from their own pasts. One participant presented a contrasting perspective, as she commented, "I just don't remember being so difficult." Several other participants agreed. They described feeling astonished that a move down of a clip, a removal of recess, a "dong" on Class Dojo, were actions that did not seem to affect their students as much they had remembered being affected by a similar consequence as a child.

\section{Anxiety in Balancing Classroom Management and Teaching}

While a few participants felt strongly prepared to take over during student teaching, as compared to other teacher candidates whom they had met from other teacher preparation programs, many expressed feelings of being unprepared for the various aspects of teaching they encountered. One explained, "I did not know how much work it would be! I am so tired." Others concurred and stated that they now understood why some teachers relied heavily on worksheets, because as one exclaimed, "they're so much easier!" A few remarked at how unprepared they felt to take over teaching responsibilities during student teaching. One described this by stating, "I said to her [the cooperating teacher] all the time when I had full-time takeover, 'I don't know how you do this by yourself!'” Despite several semesters of prior field experiences, the shock of the roles and responsibilities of a classroom teacher were fully realized during their student teaching semester.

This feeling was especially strong when related to classroom management. Many of the participants expressed that they felt overwhelmed at times balancing cooperating teachers' expectations and the use of various classroom management systems, all while teaching new content. One explained, "I mean kids over here need your help and over here, and you're trying 
to work at the guided reading table...you couldn't get anything done." Another asked the group, "how do you find that perfect combination of everything?" It was clear they had begun to realize the comprehensive nature of classroom management, and how it affects every aspect of one's teaching. Teaching new content, along with the range of systems they were managing magnified their feelings of being overwhelmed. The total number ranged from three to over six different, and at times, competing classroom management systems, approaches, and components, which were significant to manage. One exclaimed, "I was a lot of times getting behind saying, 'Remind me to give you a good Dojo,' because I couldn't get to go to the SmartBoard, and teach a lesson, keep everyone involved. It was so much at once!” A few participants connected their own reactions to student responses, describing how they felt that the systems were also overwhelming for their students.

A few described that they observed their cooperating teachers feeling similarly overwhelmed. One shared, "but even, I saw my CT [cooperating teacher] have issues with just keeping up with it [Class Dojo]." Another explained, "I think that my CT was very stressed out throughout the year, and it was hard for her to stay positive a lot of the time." Several described how their cooperating teachers struggled with figuring out what worked best with students, and so they observed these teachers trying multiple strategies and programs across the semester. One exclaimed, "Then we developed another system! Because we had to do something!” While varying strategies gave them perspectives about being responsive to students' needs, doing so highlighted the fact that in many classrooms, cooperating teachers were also trying to make sense of classroom management, potentially making the modeling of best practices less likely. 


\section{Entrenchment in the "Two-Worlds Pitfall"}

Through the focus group conversations, many participants raised points that illustrated a mismatch or disconnect between what they previously knew or were learning in their teacher preparation program, and what they were experiencing during student teaching. One of the biggest mismatches was the frustration that many expressed at how their two worlds of the college classroom and the field had not been aligned. One explained, "I loved my school, don't get me wrong, but it was just like everything that we were taught was supposed to come full circle, but I never saw that piece of it." What they were observing in their final semester of the program was not matching what they had learned in prior semesters. Another stated, "So I think that's been my biggest challenge is just that you can't necessarily bring in everything that we've learned." Trying to find their voice in general was challenging, as one stated how challenging it was with competing voices, stating, "Even though our CTs [cooperating teachers] are doing this, or even though you guys [university faculty] are telling us this, or you know edTPA [final statelevel performance assessment] wants this." Another raised the concern of cooperating teachers wanting the teacher candidates to use approaches that they saw the teachers themselves struggling to use. Several described how this was difficult for them.

Others described aspects of classroom management practices that were problematic because they contrasted with how the teacher candidates had been prepared. One described a situation where her cooperating teacher verbally shamed a child to the point of tears. About this, she admitted, "I don't know what to do. I'm just in the background letting her do this; it's her classroom, you know. It was just the way she did it, but I don’t necessarily agree with it." Another explained, "It [Class Dojo] was kinda demeaning to a kid," and still one more, "And for me personally, doing the whole Dojo thing was a disconnect because of everything that we were 
taught at MSTC." This contrasted with their preparatory experiences that focused on building relationships with students. One participant explained, "But I think that teaching the kids was everything that I ever thought it would be." Another stated that when she felt she had taught a good lesson, "or I could tell that they got it, it was just such a confidence-booster for myself, and kind of like, 'Oh I don't need her [cooperating teacher] assurance, because, you know, I know what I'm doing!'” Their favorite part of teaching was working with and forming relationships with their students.

Only one described regularly implementing classroom management-related ideas that were her own. She described being encouraged by her cooperating teacher to "jump in and just try a few different things of her own." Others felt expected or were told to follow along with the practices in place, whether they agreed with them or not. One participant expressed how she wanted to try out classroom management approaches that she had learned about in teacher preparation, but she encountered a set-back when her cooperating teacher resisted this initiative. She explained, "she kind of just didn't want to deal with adding a new system and didn't really want my input. And so, I kind of just went along with whatever she thought was the best idea, while still trying to make it as positive as I could." When other teacher candidates were given the opportunity to teach, they realized other mismatches. One explained, "But for your lessons you're like, 'Oh I have this down pat!' And then you get to the behavior, and you're like, 'uh-oh,' my lesson did not go how it should have."' Many of the participants were emotional in describing their feelings related to the push and pulls they felt.

Several described how their cooperating teachers encouraged them to become "meaner," saying, "Good job! Good job," when the participants punished students. However, this led to confusion. One participant illustrated this, stating, “Okay, what do you want from me?" One 
participant shared a sentiment that highlighted the lasting impact of the dominance of behaviorism in the field, stating,

I think MSTC told us, 'No there's better ways to do classroom management. You really need to whatever...' but then every single real classroom I went in has had some kind of behavior system. A stoplight, a clip chart, something in every classroom that I observed...

Each of these examples illustrated that these participants were firmly situated in the "two-worlds pitfall" of competing messages.

\section{A Tension Between Community, Classroom Management, and PBIS}

An important finding from the focus groups was highlighted in the participants' responses regarding the sense of community they felt in their classrooms, and how the classroom management practices and PBIS-components of their school impacted it. Each time I raised the question of community within a focus group, the atmosphere of the room changed. Having just discussed their classroom management practices and the PBIS components at their schools in very problematic and somewhat intense ways, when asked about their classroom communities, the participants' moods shifted. In each group, they became upbeat and excited. Comments such as, "we are a family," and "everybody gets along” were common. One participant described how her cooperating teacher had the classroom rule, "Just be a kind Kindergartener," even though the only kindness in the room was expected for the teacher. In the moment, comments like these contradicted other examples they had provided of students consistently missing out on activities for specialized services and punishment, of being consistently being blamed, or of being shamed, demeaned, and bullied by their cooperating teachers. 
The contradictory practices they described were most commonly related to the PBIS Tier 1 behavior monitoring system used in the classroom, such as Class Dojo, a color clip chart, or a stoplight. Additionally, the models that some of the cooperating teachers offered of snarky, unsupportive behaviors did not help these TCs learn that adults also contribute to the development of the classroom community. Across focus groups, several participants commented on the toxic environment of adults at their schools. This ranged from "my teacher was the lone wolf," to "...but there was still...talking about each other behind their backs among the teams, the grade level teams too," to "Honestly I enjoyed being with them [the kids] every day. I didn't necessarily enjoy being with some of the adults every day." The adult community at each of their schools presented mixed messages to these novice teachers about establishing a sense of community.

Participants' descriptions revealed a deeper belief that for many of them, a classroom community only existed when everyone was getting along, and another belief that contradicted this: that it was possible for a classroom community to exist when members were excluded. Both were problematic. Early childhood classroom communities are messy; not everyone gets along; problems arise. It is what teachers and children do when problems arise that determines whether a community builds up or brings down its members, and many of the participants' descriptions highlighted the bringing down of members. They casually described feelings of community in their spaces, in the same breath where they explained that students were "shamed," "demeaned," "left out," and "missing out." Some teacher candidates seemed to sense the tension inherent in this, as they spoke about teaching approaches that focused on prosocial skills, even while they talked about very punitive measures in their classrooms. However, these ideas only surfaced when I asked about the feeling of community in their spaces, not when 
discussing their classroom management. They raised ideas about the Second Step Program, class rules, Cool Tools, and bucket-fillers, but they did not point these out when I asked about their management. Those who used these approaches and strategies at their sites explained that they were often cast aside. One explained how much she loved how the Second Step program because it focused on discussing emotions and problem-solving and incorporated books, but, she explained, "my teacher never did it!" Another described how the "bucket-fillers," meant to be a format for giving and receiving compliments, were dismissed because her students had written mean comments on them. As such, these prosocial ideas were less common in their experiences. This finding illustrates that most of the participants did not see how their classroom management decisions affected or correlated with the feeling of community in their classrooms.

Two participants described looking deeper into these connections. One felt that her cooperating teacher modeled management strategies that contributed to building a sense of community, and while the other participant did not, she was critical in analyzing the effects that her cooperating teacher's classroom management decisions had on the sense of community in her space. One of these teacher candidates explained, "Whether it was trying to earn lightning tickets as part of the PBIS program, or when they were just trying to work and learn up to my expectations, they were constantly trying to do that as a team together and help their peers do the same thing." These two candidates felt strongly about choosing classroom management strategies that worked to build up their future classroom communities.

Where the perspective shifted for some of the other teacher candidates was in talking about their plans for their first year of teaching, where they alluded to ways in which they planned to establish their own classroom communities. One described being inspired by her students' reactions the few times she taught the Second Step Program, and she was excited to 
incorporate social-emotional learning through literacy, stating, "Like in Lilly's Purple Plastic Purse, because you can relate it back to them!" Others shared that after realizing how overwhelming it was to teach with so many competing systems, they now knew that simple acknowledging students could be enough of a reward without any tangible item. One described this, stating, "It was so much at once, umm, where sometimes it was just easier to say, 'Hey...great job,' or 'I like the way you're doing this,' kind of thing." Others shared ideas for using more humanistic tools such as a peace table, calm-down area, and other problem-solving tools in the future. Comments like "I feel like the first couple weeks are... what sets the tone," and "So, just teaching them that at the beginning of the year that they can be independent and take charge of their learning. I believe that is really what my goals will be," displayed a real sense of hope on their parts.

However, without consistently seeing these models in action or practicing them in course or fieldwork, many were honest that they were less than certain in regards to their future plans. For several, they described that in the future, their default behavior would be to use a behavior monitoring system, even if they did not want to. One exclaimed, "I've seen it [a clip chart]. I've used it, so I'm like, 'Yeah...I'm gonna do that.' But do I think it's the best thing? No! I don't think so!" Another shared, "At the end of the day, I need something like that [a stoplight behavior monitoring system]. It's the backbone, and honestly as a new teacher, since I haven't seen anything else, it's better safe than sorry." Yet, she immediately paused, turned to me, and asked my opinion, ultimately unsure. All of the participants described feeling less than certain, and a bit exhausted at having had to navigate the difficult place of being a teacher candidate when their two worlds did not easily align, without someone to consistently help them analyze their experiences related to classroom management. However, each described new knowledge 
they had gained. Only time would tell if they would be able to better entwine the seemingly disparate domains of their teacher preparation and the field, or their classroom management and the task to establish a sense of community within their classrooms.

\section{Summary and Next Steps}

Participants from the first stage of this larger study demonstrated beliefs and attitudes that were in line with current research, as related to a lack of classroom management preparation for teacher candidates (Blum, 1994; Hammerness, 2011) and in their feelings of unease with relationships with cooperating teachers and his or her practices (Kaufman \& Moss, 2010; Putman, 2009). They also realized questions related to seeing classroom community in the lens of "the perfect ECE family," in line with the works of Blank \& Schneider (2011), SoutoManning (2014), and Wisneski (2005). They were firmly situated within the "two-worlds pitfall," between what they were learning in the classroom and the field as others in the field have highlighted (Feiman-Nemser \& Buchmann, 1985, p. 59), especially with classroom management messages (Anagnostopolous, Smith, \& Basmidjan, 2007; Smith \& Avetisian, 2011).

The voices of these teacher candidates highlight a markedly different experience within the shared context of PBIS and illustrate a perspective of one set of PBIS-users that is currently not represented in the extant literature. In their placements, these teacher candidates observed PBIS being implemented with less fidelity than one would hope, or has been seen in other studies (Horner, Sugai, \& Anderson, 2009). The inconsistencies they observed across their settings, within their school across classrooms, and within their own classrooms presented a lessthan-ideal image of how the framework was being interpreted. With little to no guidance about PBIS from their teacher preparation, nor the field placement itself, they were left to make sense 
of the various systems and components of the framework being applied. Here, the "two-worlds pitfall" was elevated as tensions rose, ghosts from their own apprenticeship of observation surfaced, and less than concrete plans for their futures emerged.

The disconnect they described between PBIS and other classroom management practices of their classrooms, and the often harsh, punitive, and un-community-like descriptions they provided of their own experiences was disheartening to listen to as an early childhood educator and as a preparer of future teachers and aligned with the outcries of parents and educators on-line and in other formats (A Blog About School, 2009; Bower, 2010; Rubin, 2011; Witz, 2011). Comments related to a sense of community highlighted that for these teacher candidates, most did not see how their classroom management decisions, whether they be PBIS-related or otherwise, correlated with a sense of community within their classrooms. In many ways, the very behavioristic methods of the rewards-violation systems they described being used within the PBIS frameworks at their sites contradicted the traditional ECE mindset of everyone belonging that these teacher candidates espoused.

These participants were one sample of the larger study. While these data highlight preliminary findings, at this point in the study, they helped to inform the larger case studies that began the following school year when these teacher candidates became first-year teachers. The themes that surfaced from the focus groups were predictive of later findings in the case studies, and they also set the stage for the case study participants, interview protocol, and the course of events that followed.

The following three chapters will outline the continued development of two of these participants, Molly and Vanessa, and add in the third, Kristin. Like any new professional, these new teachers grew and developed in their skills, knowledge, and practice over the course of their 
first years in every aspect of teaching, including building classroom communities and their classroom management within it. Pulling from all data sources, each of their chapters presents their first year in a holistic sense and is divided into four sections: a description of the participant, the contexts of her first year, a year in her life, and an interpretation of her first year, as a metaphor. These metaphors entitle each chapter and represent the images that I have created to encapsulate the multitudes of their first year within a single phrase. The subheadings of the year-in-her-life section of each chapter, written in each participants' own words, will help to better illustrate each metaphor. The presentation of the chapters will follow a progression related to the big idea of building classroom communities within PBIS worlds and will center around whether these two entities and the first-year teacher's classroom management decisions within them intertwined or not. Starting with Molly, moving to Kristin, and finishing with Vanessa's chapter, readers will find a progression of experiences that range from a sense of community not realized within the PBIS framework to one where the two were intertwined tightly. The final chapter of the dissertation will serve to synthesize findings across this yearlong study, weaving together the perspectives from this chapter with the data revealed within each case. 


\section{CHAPTER V: MOLLY: THE FIRECRACKER TO THE "BLACK SHEEP”}

Molly Daley was a 22-year-old, spirited, petite woman with long and thick red hair. Her pale white skin was sprinkled with light brown freckles, and she admitted that many mistook her for someone younger because of her small frame, explaining, "I look younger than most people." She had a bubbly, sweet personality and was very quick to smile. I met Molly as her university supervisor for two clinical courses, and I also served as her professor for the early childhood social studies methods course in the semester before her student teaching. In class, she was a "good schoolie," insightful and willing to participate. Molly rarely shied away from sharing her opinions, and she often delivered them in a humorous way making her classmates and others laugh; her giggle was infectious. At the same time, she was very demure. Having been raised in a large Catholic family and within Catholic schools until she entered the university, she had a strong sense of what was right and wrong, and she was very respectful and humble in relationships with cooperating teachers and others in authority. Always responsive to feedback in class and the field, she demonstrated the behaviors of a responsive and thoughtful teacher.

Molly grew up in a small suburban community on the edge of Chicago, Illinois. She described her hometown as feeling like a small town, but with the benefits of being right next to a major metropolis. Her family was a big part of her life, and her mother's career as a teacher had the opposite effect on Molly than most might guess. She explained, "She's a teacher, so I originally didn't want to be a teacher!" As a child, she remembered loving school, but getting in trouble there because she talked too much. Despite this, teaching was ultimately the path she found herself on because she was drawn to working with others. Molly was the oldest cousin on one side of her family and the second oldest on the other. She shared, "It just seemed like my cousins would come back from school and I would ask them what they learned and work with 
them, doing puzzles and things like that. That was so interesting to me." These interactions laid the groundwork for her future career.

\section{The Path to Become a Teacher}

Molly started her path to becoming an early childhood teacher as a native student in the university's early childhood program, entering directly out of high school. Instead of returning to live with her family for student teaching like many teacher candidates do, Molly decided to stay in the campus community and rented an apartment with her boyfriend, Will. Will, who was also an education major at MSTC, was one year behind Molly in his teacher preparation.

\section{Student Teaching}

For student teaching, Molly was placed in a kindergarten classroom at Jefferson Elementary, a public school in the university's suburban community. Molly chose the traditional student teaching track of 16-weeks at the end of her program. This was in part driven by her desire to continue working in her part-time job at a local childcare center, The Learning Center, where she loved to work, and which she needed in order to pay rent. Choosing the Professional Development School (PDS) model of the full-year internship would have prevented her from doing this. Molly expressed appreciation for her experiences while student teaching kindergarten at Jefferson. The school utilized the PBIS framework and was a part of a much larger district in the community that is known for diversity of all kinds across its schools, yet not as much within them. Molly noticed this and described, "It was racially diverse, but not really socio-economically at all."

In recalling funny stories that she experienced with her students, she reported being pleasantly surprised at how much kindergartners knew, stating, "Kids are underestimated $100 \%$ !" She acknowledged that she had questioned whether teaching at the kindergarten level 
would be a good fit for her. She lamented that her young learners were not very confident in themselves, and she wished their confidence levels would be higher. However, after completing student teaching, she knew that teaching at the lower grades was the best fit for her.

Overall, by the end of student teaching, Molly's confidence in her ability to work with young learners had grown significantly. Still at times, she described feeling caught off guard by the sheer responsibility of the 'teacher' role. With a thoughtful expression, she explained, "Quite honestly, teaching doesn't become real until you're actually doing it." She revealed that she sometimes struggled with knowing just what to say at the right moment, stating, "I can rattle off things. I memorized information, but when I'm right there in the classroom, I'm not like, 'Okay, wait! Hold on! Let me process this for a minute!'” Until student teaching, Molly felt that her "classes didn't really prepare you for the entire day, each day, every aspect of teaching." She described feeling somewhat overwhelmed by the many nuances of teaching, and she connected this to how her young students must feel when she was teaching, stating,

It's hard to put the pieces together. (laughing) I'm not good at puzzles at all. We're [teacher candidates] like preschool students! (laughing) It's hard to put it together like this with that daily routine. It's a lot in one day. It's a lot for us. So, I imagine how much it is for the kids to actually be introduced to, learn it, and do each day!

Molly was prone to laughing when she seemed stressed, and she dramatically shared this poignant realization in the focus group interview, which brought on giggles and approval from the other participants. With this mindset, Molly graduated. Because her boyfriend, Will, had another year at the university, she decided to also stay in the area, and she began her job hunt. 


\section{On the Job Hunt}

Immediately following graduation, Molly was hired as the head teacher of a two-year-old toddler classroom in a local, subsidized daycare center, serving at-risk students. She rationalized that taking this position quickly was because she wanted to experience teaching at the younger ends of her certification for one year, to see if this was a good fit. After one year, which coincided with her boyfriend moving back to the suburbs to student teach, she planned to look for a school-age teaching position. Molly strongly felt that if she first looked for school-age positions in a public school, she would most likely never again explore teaching the lower range of ages. She attributed this to the low pay that she believed to be standard in childcare, "because financially, that's how it is." While she seemed happy to have this position, her experiences teaching at this childcare center ended up being less than ideal, as she stated, "it was a really jumbled up kind of mess there." With mobility in staffing, Molly was often moved around to teach in different classrooms. Spending more time teaching in the center's preschool classroom, she realized that this level was where she wanted to be. Thus, she continued to hunt for the perfect position.

Later that summer, one such opportunity did arise, and it came through me. The director of student teaching in my department often sent me early childhood job postings knowing that I would forward them to my large listserv of old early childhood teacher candidates. One such email came through my email, the position: a one-year preschool maternity-leave position at Field Elementary, a small, rural elementary school in Central Illinois. I immediately thought of Molly, the petite firecracker, whom I knew was still in the local area and searching for a position. I responded to my director recommending Molly for the position, and I then forwarded the email on to my listserv and wrote Molly specifically about it. Intrigued, Molly immediately responded, 
even though the position would only be for one year. She later explained, "I knew that going in," as a one-year commitment had been her plan all along.

She responded to the posting from the school's principal, Mr. Paul Anderson, immediately. Since she was currently employed, she felt she had nothing to lose. Mr. Anderson called her back for an interview the next day. As the start of the school year was only weeks away, this process was expedited with her first interview taking place at 8:30 p.m. at the school a few nights later with both Mr. Anderson and the district's superintendent of special education, Mrs. Stinson. Molly expressed surprise at the timing, but reasoned that it was most likely at this odd hour because, "they needed somebody. I was a late hire in the year." In the first few weeks of the school year, she would come to learn that she was the second substitute hired for this position, after the first one quit, due to the working conditions. However, at the time, she was just excited to get the interview.

In describing her feelings about the interview, Molly stated that it had seemed "somewhat awkward" because she was unfamiliar with the school, and it was so late at night. However, she felt, "real calm about it because I wasn't expecting to really get it." She shared that the interview "was very loose in general," and although they only asked her a few questions, she thought these were pretty "standard." She did not remember them asking her anything related to her views on $\mathrm{CM}$ or how she would establish her classroom community, but instead "how I would set up a classroom." Molly was confident responding because of her experiences in the preschool classrooms at the childcare center, as well as her college job at The Learning Center.

Molly explained that she had attempted to prepare herself for the interview by researching information about the school online. She was especially interested in what curricula the school used and whether they implemented the PBIS framework. She was most interested to 
learn how they infused the Common Core State Standards (CCSS) because this was an area in which she felt most confident upon completing student teaching. However, when she searched the school's website, she found that it included little information about any of this. Additionally, because the posting had not included many specifics about the position, and they did not share more information with her in the interview, when given the opportunity, she planned to ask about the specifics of the position including how many staff worked in the preschool classrooms, what the daily schedule looked like, and what kinds of specific curricula were used. When given the opportunity in the interview to ask questions, she had these questions ready to go. However, in response, she received what she perceived as very unclear and evasive answers. Although in retrospect, this murkiness should have raised a red flag for her, as it hinted at a disconnect between these administrators and preschool that would later surface, at the time, she did not see their responses as problematic. Instead, she felt that the short interview had been "more of a conversation," and with this, these administrators must have gotten a good feeling about her.

Two days later, she received a call back offering her the position at another odd hour, 10:00 p.m. She recalled getting the call while in bed after what felt like a long time since her interview. Excited to be teaching in a public school, she immediately accepted the position and turned in her resignation at the childcare center the next day. Molly described being very uncomfortable with quitting and explained, "I was not used to it. I worked at Penney’s [J.C. Penney, a past part-time job] for three and a half years! So, for me to just quit a job is kind of a big deal." Despite this, her bosses at the center demonstrated understanding, and she explained that she felt she could return later if she desired. 


\section{The Context of Molly's First Year}

As such, Molly was set up to begin her first year as a teacher in a one-year, full-day maternity-leave teaching position at Field Elementary, teaching both morning and afternoon sessions in the at-risk preschool. She would be the permanent substitute for Mrs. Thompson, who would be on leave for the year. While taking a long-term substitute teacher's position had not been Molly's initial plan, she felt good about this decision. She believed this to be a smart career move putting her within a public-school setting, and providing time to try out being a preschool teacher. She explained, "I knew that I wanted preschool. I knew that I wanted to do the younger kids." Molly had entered student teaching ready to take on the world, and because of her experiences at Jefferson, she remained excited, yet a bit wiser and more cautious at semester's end. For a novice teacher, I knew her to have a passion for creative and interesting teaching practices that engaged young learners and demonstrated good insights about children's needs. From a coach's perspective, she seemed primed for coaching and mentorship, eager to learn and open to feedback. On her way to becoming a great teacher, she was filled with fire and fun. It seemed like this acceptance of a one-year position would be the perfect trial run.

\section{Molly's School Context}

Field Elementary was a preschool-6th grade school that was housed in a one-story, square red brick building tucked into a neighborhood of small ranch houses and sidewalks. Located in the quiet, close-knit town of Field, it was the one elementary school in a town of just under 3,000 people, and it was part of a two-school district, Field Community-Unit School District \#32. The other school in the small district was the junior-senior high school that was just down the road from the elementary school. Surrounded by corn and soybean fields, the town of Field was about a half hour's drive from nearest bigger town. Much of the parking for the school was painted on 
the side of the streets surrounding the school. Two parallel streets perfectly flanked the school giving it a square appearance. There was a large fenced-in, open grassy area and wood-chipped play lot that was contained by railroad ties off one side of the building. The play lot contained several climbing apparatuses including a jungle gym and a hexagon-climbing dome, as well as a large swing set. Driving by, one would often see a mixture of students walking and riding bikes up to the school. Although there were a few bicycle racks near the main entrance of the building, many students' bikes lay in the yard around the school throughout the day. Crossing guards stood alert on every corner, as most of the student population walked or biked to school. See the specific demographics of the school in Table 1 of the third chapter.

The year that Molly was hired at Field, there seemed to be significant changes at the preschool level. There were three early childhood, preschool classrooms at the school. One of these classrooms was an early childhood blended special education class, which the school called "ECE," one an at-risk classroom, and the other a new tuition-based classroom. This third classroom had been added that year due to the overwhelming numbers of preschool students, and was being filled in a half-day capacity by the school's speech pathologist, Rachel. Rachel had an advanced degree in speech pathology that included teaching, and which licensed her to work with students preschool-21. However, she had no specific background or coursework in early childhood education. Both teachers of the other two classrooms went on one-year maternity leaves at the start of the year, which meant that the school needed to hire two full-year substitutes for these classrooms. One of those substitutes was Molly for the at-risk preschool position, and a young woman named, Allison, who was also an MSTC alumni, filled the other position. Allison, while new to Field like Molly, was not a first-year teacher and had been teaching in a Head Start setting for three years prior. Both teachers on leave were slated to return the following year, yet 
it was not until the spring that Molly knew with confidence whether, her teacher, Mrs.

Thompson, would be returning. Another new hire that fall included a second-grade teacher.

Otherwise, much of the staff had worked at the school for more than 10 years.

Community, classroom management, and PBIS at Field Elementary. At the school, like in the town, there was a close-knit community of people. Much of the town's population remained in the community after graduating from the high school, and many of the students at Field were third and fourth generation students of the elementary school, making families very well known to the school staff and amongst the community. This was exemplified when, near the beginning of the year, a local high school student was killed in a car accident right outside of town. Several of the Field teachers had close relationships with his family as he had been one of their students, and they currently taught several of his siblings and cousins. The ripple effect of his death on the elementary school was palpable. Molly was called into an impromptu meeting the morning after his accident, and she observed many distraught staff members when Mr.

Anderson announced the news. Additionally, there were events at Field throughout the year that worked to bring the larger community together, including a hoe-down event for the staff and a large end-of-the-year concert and celebration in the spring. Upon entering the school, the main lobby was always decorated in a theme with a laptop displaying a loop of school photos on a small table in the center. Display cases held years of trophies and awards won by students. One lobby theme that generated much discussion at the school was the circus theme where the lobby's ceiling was transformed into a circus tent.

However, for a newcomer, like Molly, this close-knit community was not as welcoming as one might expect. With a school website that was only a few pages on the district's website and elusive responses to her questions about daily functioning in her interview, Molly entered 
the Field community curious and excited to learn more. Her curiosities were left unfulfilled when within the first few weeks, she seemed to be just as confused about specific details related to the school as when she started, stating, "I feel very out of the loop." She attended one districtlevel new-hire meeting in August. After this, neither did she mention, nor did I observe, anything being done at the school specifically for the three new Field teachers by the ways of mentorship, collaboration, meetings, or professional development. While both she and Allison were in substitute positions, these were for the full year, and they were new teachers to the school. Yet Molly did not indicate that their newness bound them together in a lasting way. As a substitute teacher in a grade level that is not always included in regular elementary school events, by the middle of the year, Molly felt very isolated at Field. She quickly learned that "PreK is kind of its own separate thing! Not a lot of interaction." She explained that she did not know how to enter the larger school community because the preschool classrooms were often not included "with a lot of other school-wide things going on." She was unsure of whether this was because the larger school community was unwelcoming to the preschool classrooms, or if staying isolated had been an intentional preschool decision in prior years, or if this was considered normal for preschool classrooms in public schools, as this was her first teaching experience. Enhancing her feelings of isolation was the fact that she was not provided with a teacher mailbox in Field's main office until January. This meant that for over half of the year, she had to gather important information such as fundraisers and other school events from her teaching assistant, and from her students' parents, which embarrassed her greatly. Even after she got the mailbox, she still rarely received information, as she explained, "they just like to skip mine." This led to countless examples of miscommunication and embarrassment across the year for her. Additionally, Field had a cross-grade book buddies program, and Molly's class was 
partnered with a second-grade classroom. Although this presented a great opportunity for Molly to connect with another teacher, every time the classes were set to connect, the second-grade teacher happened to be absent. Molly described liking the program, and I overheard her students happily reuniting with their second-grade "buddies" on the playground, yet she described never feeling connected to this teacher.

The confusion that Molly felt regarding her position at Field included her lack of understanding about the school's use of PBIS. While she described knowing that Field used the framework, there few mentions of this on the school's or district's web pages, and throughout the year, Molly struggled with explaining how the framework was implemented at Field. This was in part because she received no formal training about PBIS. On the website, the only mention of framework was of a prior year's calendar announcement for a PBIS event. Additionally, very little on the website hinted at the sense of community that the elementary school fostered to create for its students and families. The school's web pages did include a student handbook written for parents that included extensive details relating to behavior management, discipline, and consequences and punishments, but no mention of PBIS. This included details relating to playground/ school grounds safety rules, digital/ technology acceptable-use policies, a participation code for extra-curricular activities, and a student code of conduct for various behaviors such as cell phones, gym behavior, dress code, and discipline on school buses. Under the "DISCIPLINE" heading in the school's handbook, 26 different misbehaviors and corresponding consequence/ punishments were listed with a description of the "Delegation of Authority," which explained that any school personnel could "authorize" any disciplinary measure, could use force to ensure safety, and could remove students, both in school and on the bus. Tucked into the handbook was the "Elementary School Behavior Matrix" with three 
headings "Respect Yourself, Respect Others, Respect Your Environment." While these three responsibilities seemed to be a nod to school-wide behavioral expectations with PBIS Tier 1 universal supports, no other mention of prosocial teaching or the PBIS Tiers was included in the handbook.

Although the preschool wing being connected to the rest of the building, Molly was told in her interview that the PBIS framework at Field was not integrated into the preschool classrooms. Throughout the year, she struggled with explaining whether the program was a part of the larger school's PBIS framework. Despite emphatically exclaiming, "I love this school," at the beginning of the year, by year's end, she shared, "I felt more welcomed as a student teacher, than I did as a first-year teacher at this school." The school context of Field and the adults there played a huge role in her feelings.

Molly's co-workers. Although Molly taught on a classroom team with another adult, and on a grade level team with several others, Molly rarely referred to these adults as her "team members," as these relationships were filled with tensions and issues. Her primary co-worker was the teaching assistant assigned to this classroom, Mrs. Susan Lewis. Susan, a white woman, was a well-established member of the Field community. She had worked at Field for 17 years along with her husband, who was Field's custodian. She was proud to tell me that her children had also attended Field, and they were now about Molly's age. Despite working in the preschool for this length of time, she had earned a bachelor's degree in elementary education, and Molly explained, "She's really an elementary teacher." Many of the students' parents knew Susan well, as she had been working at the school when some of them were students, themselves. Molly believed her to be very close to Mrs. Thompson, “they're best friends.” Molly described that while many people in the school revered her, she frightened many others. 
A tall woman, Mrs. Lewis had a somewhat stoic personality and was very "by the books." Molly described that Mrs. Lewis would often explain things about the classroom to her as, "this is the way we've always done it," and as the year progressed, Molly learned that this would be her motto. She was committed to keep the classroom, both in its physical and curricular sense, the way that it had been in prior years. She expected Molly to come in and follow along. Importantly, "the way we've always done it," did not mean that what had always been done was in line with best practices in early childhood education today. From harsh tones with students, to multiple missed learning opportunities, to a dominating presence regarding basic functioning in the classroom related to the schedule, the thermostat, and even the classroom layout, working with Susan was a job for which Molly felt unprepared. Her relationship with Susan, while positive in the beginning, ebbed and flowed as the year progressed, and Molly felt passionate that I use a pseudonym for her in my writing, stating, “...I know she will never see it, but I don't want her to know." This relationship would prove to be one of Molly's biggest challenges.

Other adults with whom Molly worked regularly included the school social worker, Mrs. Wilson, who came in twice a month to work with small groups of her students on social skills. Molly only ever spoke of her positively, albeit rarely. Molly also was a member of the larger early childhood team at Field, which included Allison, Rachel, and the para-professionals who worked within their classrooms. At times, Molly described feeling a sense of camaraderie amongst these adults, such as when Allison was also confused about school-level miscommunications in the beginning of the year and they commiserated together, or when she chatted quite a bit with Rachel mid-year, "because I can really vent to her." She appreciated that 
Rachel, in her role as the speech pathologist at Field, would at times, advocate for Molly's students on her behalf, saying, "this isn't fair what Molly's going through..."

However, despite the similarities between Molly, Allison, and Rachel: the fact that they were all teaching preschool and were all new to their positions this year, or that two of them were in maternity-leave positions, or that two of them were graduates from MSTC, these commonalities did not seem to consistently unify the three of them. At no point did Molly refer to them as a "team" or use the term, "we," when describing her interactions with them. She expressed that there seemed to be pressure from Field's administrators for each of the preschool classrooms to stand out and be "the [emphasis added] PreK program at the school," but she confessed, "nobody really knows for sure." In the beginning, she had high hopes for working with them, stating, "I had such an expectation coming in thinking, 'oh, you're new to PreK. I'm new to PreK! We can plan together! We can do things together. And that has not been the case." Instead as the year progressed, she felt that because Rachel and Allison shared teaching assistants, they also shared resources, and practices, and she felt left out of this.

Molly's administrators provided me with easy access to work with her, but I rarely saw them when I visited the school, and their presence in Molly's life was spotty. Mr. Anderson was someone whom Molly looked up to in the beginning. Throughout the year, she sought him out for support, but in her opinion, he seemed to say one thing and then do another, often leaving her without support, especially with challenging behaviors in her classroom. Overall, he seemed very clueless about the needs of the three preschool classrooms and had a very hands-off approach to what happened in them, which was exemplified in countless anecdotes that Molly shared in frustration. In November, Mrs. Stinson, the special education director with whom Molly had interviewed was assigned to oversee the preschool classrooms. Thus, Molly and the 
other early childhood teachers were responsible for reporting to two administrators for most of the year. About this, Molly reported, “I feel like they're not really on the same page, and so I don't really know how to feel about it. I just know her expectations are different than the principal's. It's driving me nuts!" In many ways, Molly's first-year experiences illustrate the incalculable ways that administrators contribute to new teacher retention and attrition, as a year in her life will elucidate.

Mentorship for Molly was a slippery and elusive aspect of her first year. Although she was a substitute, she was also a new teacher to the field and in need of support, which she expressed by reaching out to her co-workers repeatedly, especially in the fall months. Throughout the year, she expressed questions, concerns, and points of introspection, concerns with which a mentor or coach, whether assigned or self-identified, could have helped her. While it seemed that she was seeking one out on her own in the beginning, this attempt fell away as the year progressed, and she began to feel more isolated. When her relationship with Susan was new in the beginning, it seemed that Susan fulfilled this role for her, as Molly stated early on, "I really look up to her as... a mentor." However, as their relationship became strained with passing months, Molly no longer considered Susan in this role. Also, while she formed a camaraderie with Rachel by mid-year, this teacher was also new to preschool. She lacked a background in early childhood education and the ability to provide Molly with the guidance and support she needed. Molly, with more experience in preschool settings, also often disagreed with her classroom practices. At a low point, mid-year, Molly expressed that she felt that she had no one to turn to for support. 


\section{Molly's Classroom Context}

Molly's classroom was down a main hallway that was covered with student work and posters. Throughout the year, the student work on display tended to be craft-based, productoriented, one-size-fits-all, matching examples of student work. Typical of displays across the year, for example, at one point in the year, I passed 20-some dinosaur crafts all looking very similar and 15-some writing prompts of "What Should David Do?" inspired by the text, No David, hinting at the crafty, product-based nature of teaching there. Down the main hallway of the school and to the left, Molly's classroom was situated off to the side within the preschool wing. A large rectangular room with low ceilings, tiled floor, and no windows outside of the sidelights by the classroom door, this classroom was filled to the brim from the start of the year.

I quickly learned from Molly that she had walked into a space that was exactly as Mrs. Thompson had left it the year before. Although Molly would be taking over the lead teacher position in this classroom for the entire year, early on, she did not believe that she had permission to make physical changes to the room. This belief was fostered by Susan, who consistently expressed to Molly, "that Mr. Anderson loves our PreK and wants everything to stay the same." In the beginning, she explained, "I came in blind. I didn't know that everything was going to be put together, and I was going to have to follow the routines." However, this was not the impression she had taken away from her interview with Mr. Anderson. Even so, because the administration did not state otherwise, she deferentially accepted Mrs. Lewis' wishes and decided to "not rock the boat." Even when she later learned that Susan's statements about Mr. Anderson's wishes were untrue, she felt powerless to make changes. Thus, the classroom I observed at the beginning of the year was the same one I saw at the end, with very little change. Figure 2 illustrates an aerial view of her room arrangement. 


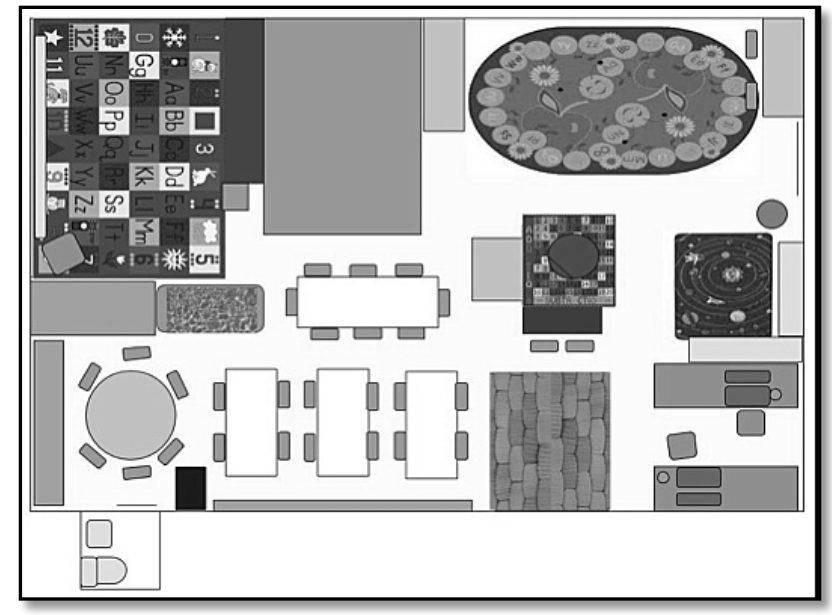

Figure 2. Molly: classroom map (9/14-5/15).

Mismatched furniture pieces designated centers around the room and brightly colored, teacher-store materials hung from every wall and the ceiling. There were shelves, materials, and objects everywhere, and this, combined with the low ceilings and lack of windows, gave it a very cluttered and somewhat claustrophobic feel. The room was kept at a chilly temperature throughout the year, as Molly explained, "she [Susan] has hot flashes," and thus, Susan controlled the classroom thermostat. I often overheard students complaining of the cold, and Molly always wore a sweater. She exclaimed, "sometimes we keep this room so cold that I'm wearing my jacket!" A small bathroom with a dim light was attached to the back corner of the space, and a little wooden house that a prior parent had built for the students' dramatic play sat on the other side of the room, although it was rarely "open" for play on days that I observed due to poor student behavior in it the day before.

Every wall held multiple large bulletin boards, and each was covered in competing colored butcher-block paper and border and teacher-store materials, but little to no student work throughout the year. One bulletin board held the behavior monitoring system of a giant paper 
frog with lily pads, explained more below in a "Year in her Life..." Another long bulletin board displayed the "Reading Rewards Display." Next to this, a "Star of the Week" bulletin board, hung that occasionally had images of students on display (Figure 3). Along the opposite wall of the classroom, a giant bulletin board was hung displaying football helmets that stated the students' birthdays, along with a life-sized Chicago Bears football player poster. Multiple clotheslines were hung from corner to corner of the room, and at times across the year, I observed student art projects hanging on them. Near the door, there was a large papier-mâché giraffe positioned in the corner above a seldom-used writing center.
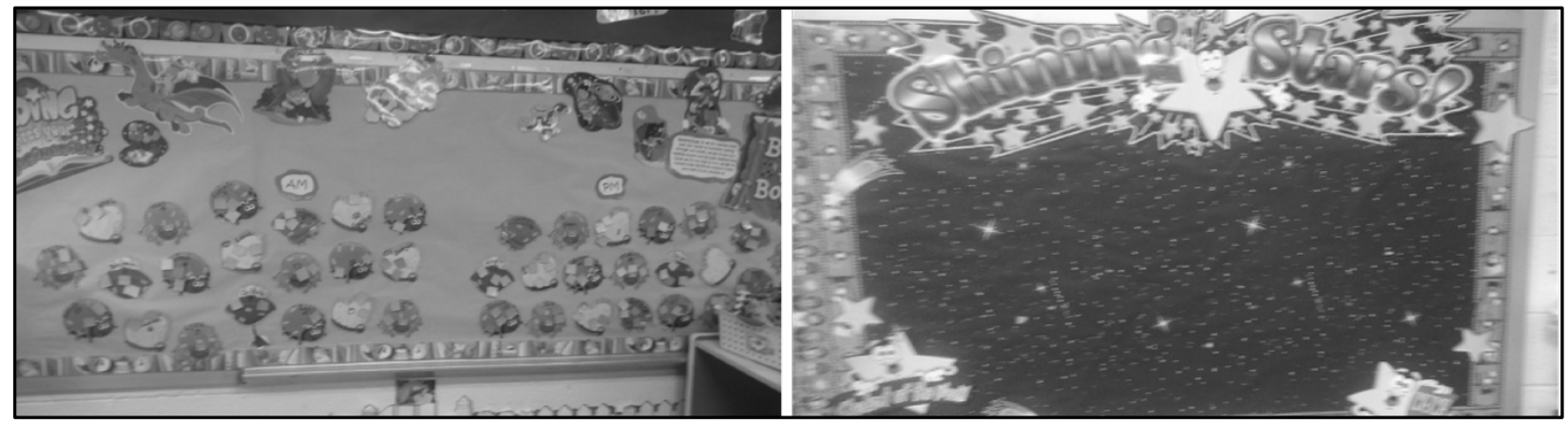

Figure 3. Molly: bulletin board displays (9/14-5/15).

Five rectangular tables were arranged on one side of the room with three parallel to each other and two arranged perpendicularly to the others. Rugs designated specific activities in the classroom, including an oval-shaped rug which served as the spot for read-alouds, mini-lessons, and independent reading, a smaller rectangular rug where manipulative play took place, and a large patterned rug near the SmartBoard, which is where the students started and ended every session. On the wall shared with the SmartBoard was a large calendar display including a calendar poster, a weather poster, and a class jobs display. Hanging above this space was a word 
wall of student names (Figure 4), which Molly felt contributed to a sense of community within her space because students could see their names and faces represented in a prominent space.

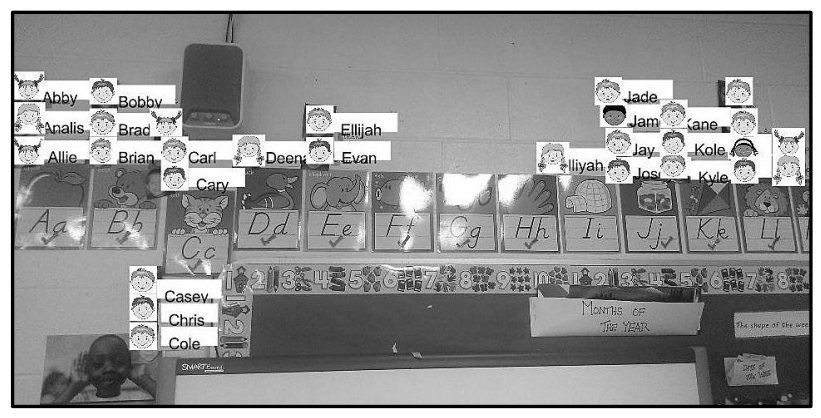

Figure 4. Molly: alphabetized name display-community builder (9/14-5/15).

Shelves were filled with bins and baskets of manipulatives near the smaller rug. There were a limited number of books in the classroom, and those that were accessible to students were stacked in a vertical display case off to the side of an even smaller library rug. Shelves lining one wall of the classroom were filled with stacks of paper, bins, boxes, art supplies, snacks, and more. Interestingly, there were no unit blocks in the classroom, even though they are typically a staple material in most preschool classrooms.

A homey touch in the room, a royal blue valence covered the sidelights that surrounded the room's doorframe. Outside of this feel of comfort, there were a few floor pillows, some small soft chairs, and a papasan chair positioned next to a hand sanitizer dispenser affixed to the wall. Still, this was the limit of soft, home-like materials. A class turtle, "Lightning," lived in a glass tank on one of the shelves. Molly explained that he was a class pet purchased the year before with Mrs. Thompson, and that one of the students' families cared for him over the 
summer. Very rarely, did I observe Molly or the students talking about him or interacting with on the days I was present.

In this classroom, students were assigned spots for almost the entire day, including their where they should stand in the line, sit at the tables for snack, and sit on the multiple rugs in the classroom when they were at circle time or mini-lesson/ independent reading time. These nametags were a point of contention for Molly and Susan all year. Susana and the prior teacher had affixed symbols to each students' name tag hung around the room that ranged from small boats to clouds to basic shapes because they believed that students would learn their names more quickly by identifying the symbol. However, Molly wholly disagreed, expressing, "I hate those symbols! Can I just say that?" She believed that the students could learn their names by teaching them their names instead of the added step of learning the symbol.

The teacher spaces of the classroom highlighted an unwelcoming environment for any substitute, including Molly. In one corner of the room there were two desks with personal computers situated so that their backs were to each other. The one against the back wall was designated Susan's, and the other was the lead teacher's desk. At the beginning of the year, the drawers of this desk were still filled with Mrs. Thompson's things, as though she had gotten interrupted mid-thought and had left, leaving everything behind. Additionally, across the classroom, there were references to Mrs. Thompson/ Mrs. T. as though she were still present. Unsure if leaving a classroom like this when going on a planned leave was typical, Molly asked her mother, a teacher, for her opinion. She shared that her mom was shocked that Mrs. Thompson had not cleared out some of her things, but Molly reasoned, "she [her mother] comes from a different environment. She's not in a smaller town like Field, where you know, 'and it'll be there when I get back." Molly understandably expressed discomfort with the multiple 
references to Mrs. Thompson and the lack of space provided to her. However, she felt very restricted in making changes by Susan.

In moments across the year, I saw Molly's fiery personality shine through. At the beginning of the year, about Mrs. Thompson's materials, she shared mischievously, "I already took a few things down." These changes included taking down a photo of Mrs. Thompson near the door and hiding it from Susan by putting it behind a shelf. Although Susan disagreed that it made a difference to the students, she also removed several of Mrs. T.'s nametags within the room. She explained, "I just told Susan, 'oh, I took the signs down because I think the kids might be confused because I know some of them had her...they might think that she's still here and think she's the teacher." Despite these few changes, for the entire year, the nameplate to the side of the door stated Mrs. Thompson and Mrs. Lewis' names, not Molly's. Also, it was not until January that Molly felt comfortable or angry enough to clear out Mrs. Thompson's personal items in the desk so that she could have a space for her own teaching materials and personal items. She shared, "I also need a personal space, and doing this took a long time." She described her desk as unorganized and "always messy," without space, her materials were spread around the desk. From observation, I would agree.

Throughout the year, the classroom varied in its tidiness and cleanliness. On one date of observation, I noticed that the room was very dirty. Considering many of the environmental rating scales that are typically used to assess early childhood classrooms, I believe that the space on one day of observation, specifically, would have earned a very poor rating, as there was dirt on the floor, a layer of crud and old messes on the tables, flecks of paper and materials on the carpets, and dust on the shelves. Throughout the year, the tables did not seem to be consistently wiped between the morning and afternoon classes, and sadley, it seemed that the whole room 
would have benefitted from a deep scrubbing. Molly recognized this when she admitted midyear, "Everything just seems so old, and we just need to clean the room." There were other days of observation when the room seemed more wiped down, but old layers of dust on materials prevented it from ever feeling truly clean.

Another new teacher may have made more changes including turning up the thermostat, rearranging furniture that was awkwardly placed, emptying out a drawer (or two or three), taking down all of Mrs. Thompson's name tags, and removing the countless materials that cluttered the classroom and did not contribute to her teaching. However, Molly, in the tenuous position of being a substitute and new teacher, and, at least in the beginning, believing that she was not allowed to, made very few changes. At no point in the year did Molly take down or edit any of the displays on the walls or other materials in the room. Not wanting to step on any toes or offend anyone, she said nothing about the room design that was already set in stone.

Molly's students. As a first-year substitute teacher in this classroom, Molly worked with two groups of students, one in the morning and the other in the afternoon. While she described that her room had the capacity to hold 20 students in each section, neither her morning nor afternoon group ever reached that number. At the beginning of the year, her morning class consisted of 17 students, 12 boys and five girls, of mixed ages, 3-, 4-, and 5-year-olds. Two more students, another boy and girl, joined the group by the end of the year, making the total 19 . All morning students were white and from the local community. Her afternoon group was smaller and stayed consistent throughout the year. With a total of 14 students, eight boys and six girls, 12 were white and two were multi-racial. They were additionally an older group than the morning one with more 4-, and 5-year-olds. Molly explained that most of her students came from lower-income households. To qualify for Molly's state- and federally-funded preschool 
program, students had to be considered "at-risk" for later school issues, and her students met these requirements. Molly described issues throughout the year that spoke to the challenging home environments in which some of her students lived including homelessness, abuse, and neglect, such as repeatedly coming to school hungry, wearing shoes on the wrong feet, dirty clothes, or a lack of underwear, having weird marks on their bodies, and other examples. Additionally, from the start, Molly described student behavioral issues that surfaced in the classroom, such as stealing and self-harm.

Despite these and other challenges, the students were the one aspect of Molly's first-year experience that consistently lit up her face, and her relationship with them grew daily. In my first interview, she exclaimed, "I love working with the kids. The kids are fun!" Throughout the year, Molly took the time to fully realize the range of abilities, interests, and needs of each student in her sessions. I often observed children running up to give her hugs, and I noticed her demeanor changing when she greeted them at the start of the day, and when she was reading aloud or connecting with them, especially when using her own ideas and materials to teach.

She often attributed differences she noticed in her students to their varying ages. Typically state-funded, at-risk, preschool programs like Molly's serve students who have turned either 3- or 4-years-old by a cut-off date that aligns with the same date for kindergarteners. However, because of low enrollment at Field in the first few months of the year, the administration decided to extend this cut-off and allow some families whose children did not qualify for at-risk services to pay tuition and enter later in the year. Consequently, Molly had some students who were significantly younger than others. With some students having just turned three in November and others who turned five-years-old in August, this created a vast developmental range. She described one of her youngest, stating, "We have a little girl who just 
turned 3-years-old, and she's not on the same level as the others. Not many of the things we do are developmentally appropriate for her at all." Meeting the needs of such a young learner, as well as her older students moving on to kindergarten, meant that Molly's teaching and management were stretched. She felt this impacted all the students.

Although much of my last interview with Molly focused on the challenges she felt over the year and was feeling at the end, the one shining light in the interview related to her relationship with the students. She easily described the many new skills that her students were demonstrating, and she was proud of their growth. I pushed her to consider from where and how her students had learned these many concepts and skills. After a few pushes and prods, she gave me a small smile and pointed to herself. She exclaimed, "I just love my kids!" Despite feeling stressed by so many aspects of her daily practice, Molly's students could consistently get her to smile and laugh. She rarely described the rapport she had with her students as a part of her classroom management, the sense of community in her space, or the PBIS framework at Field, when I would ask her about it after observing positive interactions between them, she always agreed that she and her students had a positive relationship. Throughout the year, I heard several students randomly call out, "I love you Miss Daley!" She shared that she had been called "mom" a few times, and this made her smile. Working with the students was one of the best parts of her first year.

Molly's daily schedule. Molly's daily schedule was split into two blocks. Her morning and afternoon sessions were two hours and forty minutes each, and she had an hour and a half break in between them. The content of both sessions was very similar. Like the arrangement of the classroom environment, about this content, Molly felt that she had very little control to make changes. After she realized that a lack of control would be her reality, she explained, "I just 
didn't have much say in anything." The year of the study, her daily schedule was created the year before by Mrs. Thompson and was reinforced by Susan upon Molly's arrival. Molly described this by stating, "The procedures and routines are exactly the same." While this schedule was shared with parents, it was never posted in a child-friendly way for the students, nor consistently reviewed (Figure 5).

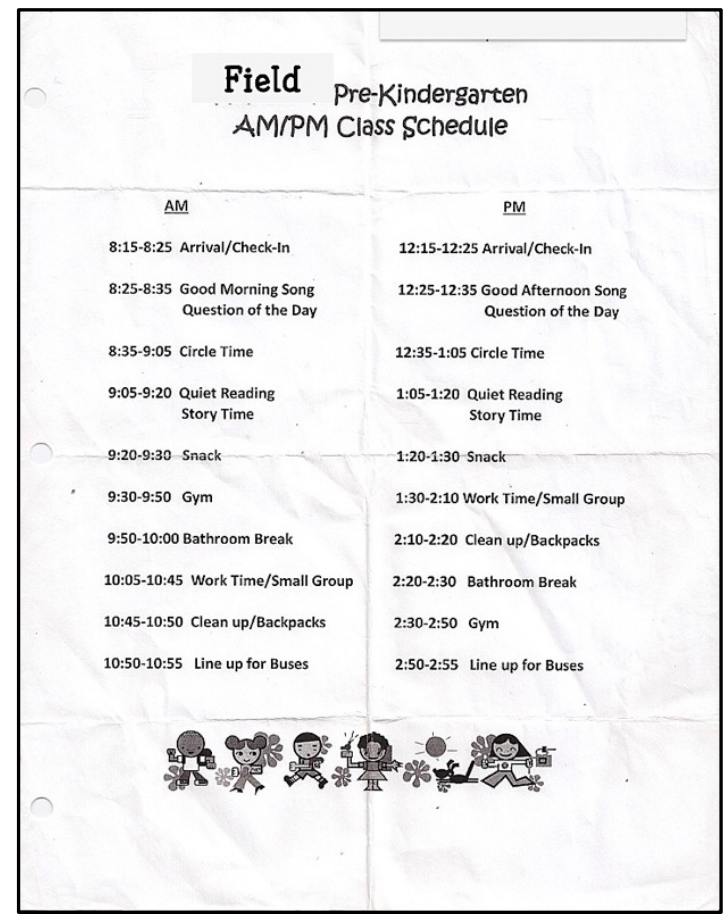

Figure 5. Molly: daily schedule (9/14-5/15).

Because Molly was hired at the last minute, in the beginning of the year, she expressed appreciation that the routines of the day had already been established, stating, "Phew, okay! At least there's a routine that works, and they like it, so I can build upon it." However, as the year went on, her opinions about the daily schedule changed, and she would later describe it as developmentally-inappropriate and cause for struggles for her students. From my observations, I 
concurred. There was little to no choice in the day, and students sat in large group rituals for extended periods of time, i.e. upwards of 40-50 minutes in one block of sitting on the same rug for "arrival," the "good morning or afternoon song," and "circle time." Transitions within the sessions seemed choppy and disjointed. Molly saw that there were times where more appropriate blocks of time and activities within these blocks could be infused, but about altering the routines in any substantive way, she felt powerless.

Molly's teaching. Having observed Molly as a teacher candidate both teaching and learning and from listening to her describe her teaching goals, it was clear she had very high and appropriate expectations of preschoolers' capabilities. However, she explained that in her first year, Susan did not share these expectations. The types of activities that Susan encouraged her to use to stay consistent with Mrs. Thompson's practices were not what Molly expected. She explained, 'They were projects, 'cutesy,' 'we all made it.' That's the vibe I'm getting that what was done in the PreK before." Molly she quickly learned that this type of teaching was pervasive in the school. Walking down hallways and seeing displays of learning at Field highlighted to Molly that the philosophies and practices that she had learned at the university and practiced within student teaching related to meaningful, rigorous teaching would not be the norm for her here. She saw the approach at Field as very "crafty," stating, "Every once in a while, that's fine. But in order to have your walls decorated seasonally each month, how do you have time to do all of that?" She questioned whether teaching at Field aligned to standards and was meaningful for students. Also, in the fall, when her students were learning about apples, she noticed that other grade levels had similar displays of learned content for their older students. This lead her to worry that the teaching there was repetitive, which she viewed as problematic. 
Molly's concerns about a teaching style and philosophy disconnect were confirmed at a faculty meeting early into the year, where the CCSS were first being introduced to the Field staff. She was astonished that the teachers there were unfamiliar with the standard set because she had been fully prepared to use them. She explained, "Everyone was like, 'we don't understand that! We don't understand why we're doing this kind of thing,' But it's simple!' Understanding academic language and infusing it into her teaching with the CCSS was one area in which Molly felt very confident all year. Even though there were no CCSS for the preschool level, she still felt that she could layer her knowledge of these standards into her teaching.

While she did not feel that she could change the room arrangement or daily schedule in the classroom, the one area in which she tried to apply her teaching skills was during story time and work-time, which was just a small group activity she led during this playtime. Molly's comfort with using the CCSS and her focus on intentional planning for those for students who would loop the following year impacted the types of activities she designed. She focused on connecting math and literacy games to children's literature, and she created meaningful related activities. However, she quickly got the impression that Susan disapproved of this style of teaching because it was markedly different from Mrs. Thompson's. Molly explained, "I don't think Susan is very happy when I do counting and stuff. But I don't want to do projects all the time, so we're going to sit and do this activity." Having worked in preschool classrooms before, Molly described that she had observed lessons that were craft-focused, "and it was okay because it worked on fine motor and gluing skills, and you could make it academic-based to talk about colors." She felt that Nancy disapproved of even these types of activities because of the academic connection. 
Although she felt limited by what curricular choices she could make, and despite the lack of rigor in the curriculum, she saw gains with her students because she was naturally engaging and planned moments of meaningful teaching all year. In the fall, after seeing students make math take-away connections between what she had taught in small group and when they shouted "pop!" and took a cookie away at snack, she said, "Those are the lessons that I want to do instead of the others!" To Molly, what made this application of her teaching even better was that the students did this independently, highlighting that they truly understood the content. Throughout the year, Molly found that meeting her students' needs was where she felt most confident in her teaching. She explained, "Seeing where they are struggling...that's how I'm basing my planning for what activities we'll do." However, without a coach or mentor, and in her attempts to establish her own teaching identity, I observed Molly at times employing teaching strategies that were less developmentally-appropriate or meaningful. An example of this was when Molly introduced letter books into the weekly schedule. Even though she knew that Susan did not want her to focus on alphabet instruction, she felt that these photocopied books brought rigor to her classroom practice. Yet upon observation, I noticed many students bored with these books, as they could easily identify each week's letter on Monday, making this activity less than necessary for them. Possibly, with a mentor or coach, Molly would have also realized this, and she would have been encouraged to explore alternative ways to infuse learning about the alphabet in a preschool classroom. Despite this, any time she had a chance to try out a teaching idea, her sense of ownership and teaching self-efficacy grew.

One of her favorite aspects of teaching was seeing when students understood a new concept she was teaching, and I often observed "a-ha!" moments in her teaching. To Molly, the best parts of the day were when students struggled with a concept, "and, all of a sudden, they get 
it!" She explained, "Seeing them get excited about something and learning about it is great!" At another point in the year, she explained:

I love to see them learning because there is one girl in my P.M. class who when she came in at the beginning, she didn't know how to count. You know, she couldn't do it! And then, she could slowly do up to four, and now she can do all the way up to 20 !

Across the year, describing her students' gains brought animation to her face and excitement to her voice, even when other aspects of her practice were not as positive.

\section{A Year in Her Life as a First-Year Teacher}

The context of the last section provides a foundation for Molly's first year in the field. Many of the highs, lows, stresses, tensions, and moments of confusion and clarity that surfaced across Molly's year were highlighted in the ways in which she built her classroom community and established classroom management within Field's PBIS framework. The next section of her chapter illustrates these changes.

\section{The Beginning of the Year: "I Came in Blind..."}

Before Molly understood how limited her actual role and responsibilities would be at Field, her initial reactions to starting her school year at Field were very positive. She described her first few weeks as "going very well," and she bubbled up with excitement in telling me about it. She exclaimed:

I just love being in this school! It's so exciting, just the whole atmosphere, and the kids are excited. So, when they're excited, and especially at the PreK level, when they don't know the content that you're teaching, and they get it, I think that's great!

She attributed this in part to the fact that she was working with Susan, who she saw in a mentorship position due to her veteran status and strong personality in the beginning. "Having 
another teacher is actually the best feeling in the world," was Molly's perspective after having often been left alone with two-year-olds in her prior job.

Beginning of the year classroom management. Within a few weeks, Molly began to realize how dominating Susan's personality was and how little control she would have in this position, and the feeling that she was "so out of the loop" at the school had started to set in. When I asked about her reactions to PBIS at Field, confused, she paused and stumbled in responding, "...nobody told me about it." At the beginning of the year, it was clear that she did not have a clear understanding of which components at the school were related to PBIS, nor specifically how the classroom management pieces of her classroom were related. After asking Mr. Anderson in her interview about how PBIS was infused in Field's preschool classrooms, and receiving a murky response from him, she admitted knowing very little about the framework. She felt confident that it was not very integrated into the preschool classrooms there. Although there was a third-grade classroom across the hall, the only adults she interacted with daily were the other early childhood staff, leading her to have a limited understanding of the contexts of the larger school. She continued, “but as far as kindergarten, it's in its own wing. So, I don't even see it [PBIS]. It's kind of like if you don't see it, it's not there, but that's not true." Despite not "seeing" PBIS, Molly was quick to explain that she had not seen anything "negative" at Field, hinting at an implication that she associated PBIS with negative aspects of teaching practices.

To aid her in pulling out specifics of the classroom management she was using in this classroom and seeing within the larger school, I rephrased my question and asked her to compare PBIS here to the framework in her student teaching placement at Jefferson. With this rephrasing, she had a much easier time pulling out specifics. She described learning from others that the school's mascot was the Giant Grasshoppers, and a school-wide rewards system was related to 
this mascot. For good behavior, students could earn "Hopper Hearts," which were small paper tickets, from teachers across the school, including while walking in the hallways. These tickets were similar to rewards she those she had used in student teaching. When the Field students earned these school-wide rewards, they were stored on a "Respect Bingo" board in each classroom, which in turn led them to win prizes, such as special lunches. Because preschool students rarely traveled through the hallways, nor did they participate in the larger school's lunches, Molly explained that they did not use the Hopper Hearts rewards in the same way as the rest of the school. She continued, "It's not like we are secluded, but we are. So, we'll just use it in class." Despite this, there was an old Respect Bingo board in the classroom, and Molly mentioned that they may use it in the future (Figure 6).

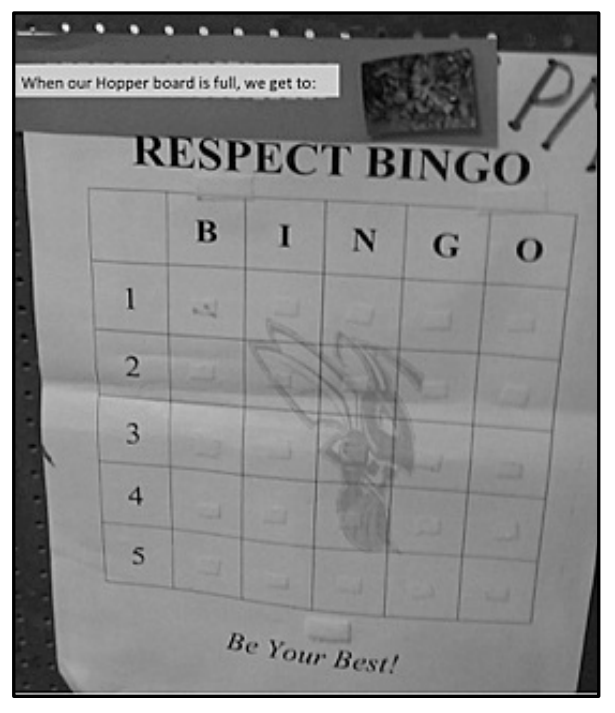

Figure 6. Molly: Field's PBIS rewards chart (9/14-5/15).

Although Molly had asked about "a stoplight in the PreK class, from before I stepped into the room," she had not received a firm response about whether there was a behavior monitoring 
system like this in each classroom from the Field administrators. Thus, she had no idea that there would be a stoplight-like, behavior monitoring system in this classroom. Instead of a stoplight image, theirs was a large bulletin board display near the main rug of the classroom that Mrs. Thompson had used the year before, titled, "Hoppy Helpers" (Figure 7). The "hoppy" adjective in the title referred to a frog theme, instead of the school-wide Giant Grasshopper theme. On the display, there were large cut-outs of a frog and red, yellow, and green lily pads. Students had small frog cut-outs labeled with their names. All of the frogs started on the green lily pad each day, but teachers could move them to another color from green-yellow-red based on students' behavior. This display served as the system that Mrs. Thompson and Susan had used to monitor students' behavior the year before, and Susan expected Molly to again use it this year. Time spent between the morning and afternoon sessions was spent removing the morning students' frogs and adding the afternoon frogs.

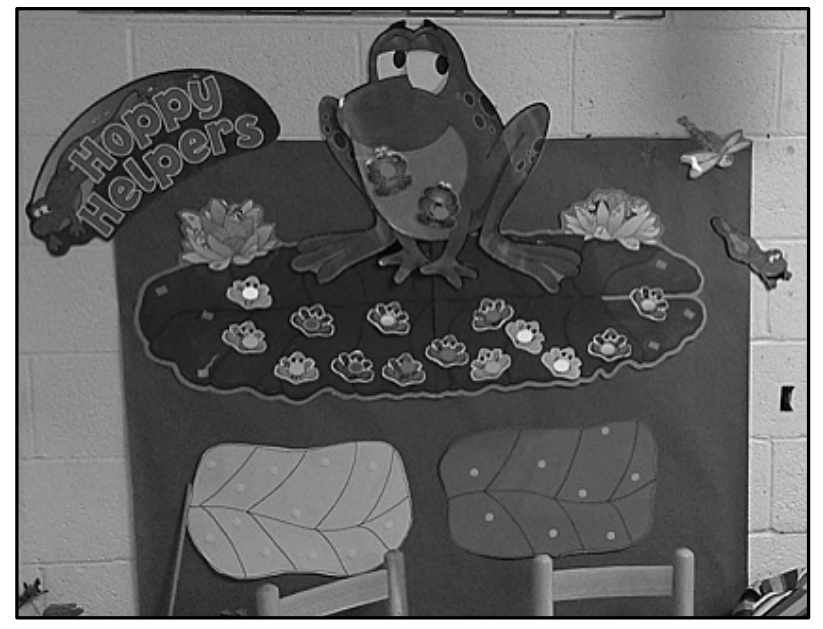

Figure 7. Molly: classroom behavior monitoring system (9/14-5/15). 
Susan described this board and the rewards system as being a part of Field's PBIS framework, but Molly disagreed. She felt that Susan did not fully understand PBIS at Field, although admittedly, she did not either. She explained:

She [Susan] said most rooms use the stoplight too, but I'm not sure that's so accurate. I was in one of the second-grade rooms, where there's a new teacher too, and I didn't really see a specific stoplight. I feel like Susan might have been confused about PBIS because it doesn't really reach out to PreK, so if it doesn't reach out to PreK, it doesn't concern her.

She further rationalized that their system was not a part of a school-wide system because the Hoppy Helpers board was only used in the preschool classrooms at Field. Yet while knowing it was present in each classroom, she was unsure how the other preschool teachers used it.

What constituted appropriate and inappropriate behaviors and warranted a move to the yellow or red lily pad was also unclear at the beginning of the year. A poster titled "Class Rules" near the Hoppy Helpers display could have explained this (Figure 8). This was a poster of rules that Mrs. Thompson had created in years past and left up for the year. Molly desperately wanted to remove it because she felt the rules were inappropriate and excessive. She explained, "It's a list of all these rules that we have never even told the kids. So why is it even up there? I want to take it down so bad." Molly felt frustrated by the fact that these were not the same rules that she believed in, highlighting the fourth rule specifically, "For me, 'you get what you get, and you're okay with it.' That's just my personal belief." She expressed how she had wanted to co-create a rules list with her students this year, "but not this one-they can't even read it." Here she was referencing the fact that it was too high for the students to reference if they were seated on the rug, where they were for an extensive portion of their half-day. She felt that co-creating a new 
list of rules would benefit her classroom management from the beginning and prove helpful for students transferring in later. Despite expressing interest in doing so, she did not indicate when she would remove the poster and replace it with something more meaningful for the students, and by year's end, it was still hanging in the same spot.

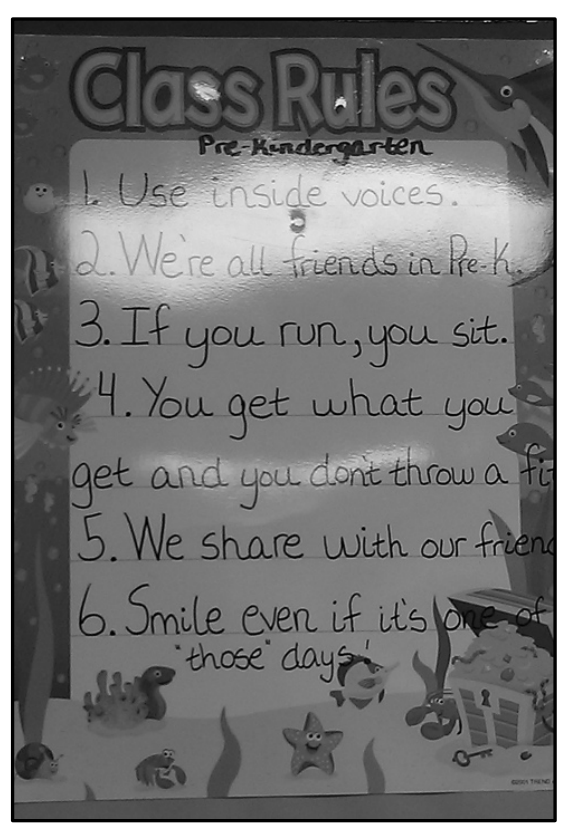

Figure 8. Molly: Mrs. Thompson's classroom rules poster (9/14-5/15).

Related to the classroom's Hoppy Helpers board, Mrs. Thompson and Susan also used a ticket system to communicate with parents about children's behavior. In the beginning, Molly was unsure whether this ticket system was affiliated with the larger PBIS framework at Field, or just something that this classroom used. At the end of each day, Molly was supposed to send students home with a red, yellow, or green ticket that corresponded with their final placement on the Hoppy Helper board, explaining, "If you stayed on green, you get a green note." Molly and Susan would write in the behaviors that warranted the change in color on the yellow and red 
sheets, and it was expected that parents would sign these and return them the next day. In the beginning of the year, Molly admitted that almost every student went home with a green ticket because she was not moving their frogs on the pads, but this changed over time (Figure 9).

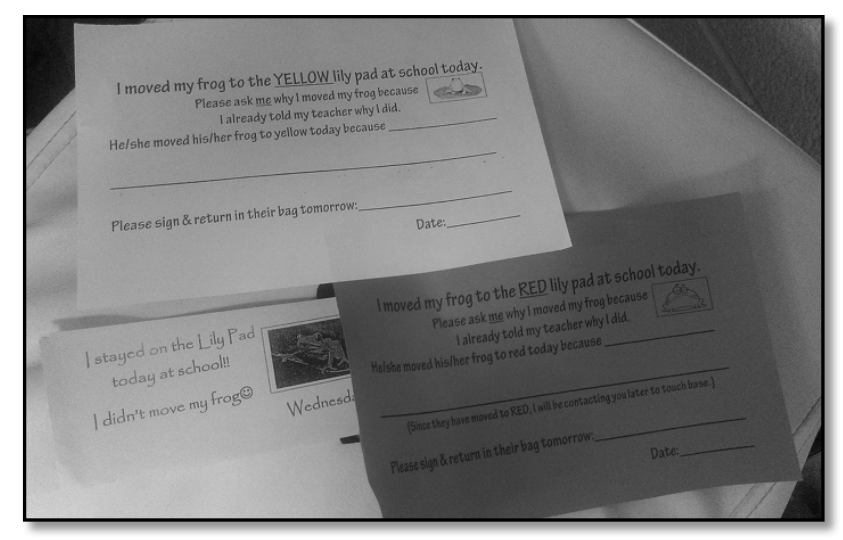

Figure 9. Molly: parent communication for classroom management (9/14-5/15).

Ultimately, Molly went along with Susan's wishes to use these pieces of Mrs.

Thompson's teaching because she did not feel that she had a say in any of the "green frogs or red tickets." About these various components, she expressed worry, stating, "I feel like there's [sic] so many different pieces of the classroom management, like the Hopper Hearts and the frogs, and having two teachers in the room." In many ways, whether she and Susan were on the same page regarding expectations for and reactions to behavior was a bigger concern for Molly than the various systems, themselves. While she appreciated Susan's strong personality, she questioned many of her interactions with students, explaining, "She can be a little harsh on the kids, but then I don't know... because they seem to really respond to her.” In our conversations, Molly always seemed uncomfortable describing this, worrying that she was painting Susan in a bad light, stating, “Oh no, I'm making her seem mean!” However, she described, and I 
observed, very strict, punitive interactions between Susan and the young students, which contrasted sharply with Molly's upbeat and caring personality.

Molly gave an example of this concern by describing a scenario where Susan reprimanded a student for moving wood chips from one side of the playground to another. Molly later observed him continue to do this, and instead of undermining Susan's prior reprimand, she told him, "I'm going to bring you to Mrs. Lewis because I don't know what she already talked to you about with this." Even though she felt indifferent about students moving wood chips on the playground, to her, "it's the little things like that that we need to be on the same page about." She felt strongly about not stepping in to guide or redirect behavior if Susan was already addressing it, even if she disagreed. She believed that by not stepping in or disagreeing with Susan's behaviors, they would have a stronger relationship, stating, "because we're all on good terms. It's easier to be open with someone when we're agreeing and going along." To Molly, classroom management success was found when she and Susan were on the same page. She described this by stating, "She [Susan] does the same thing, like 'Oh, Miss D. told you.' It's just a very simple thing that we all have to be on the same page. It's helpful too because sometimes we reiterate each other." Molly felt that when they backed each other up, the students would know that the teachers were serious.

Outside of the school-wide pieces of PBIS, of which Molly was aware, and the set-instone classroom practices that Susan made clear, Molly was excited by a few plans of her own for this classroom and her management within it. She explained that soon after the year began, Mrs. Wilson, the school social worker, started coming in to lead small groups focused on teaching pro-social skills with her students. The approach she used was not the Second Step approach, which Molly was familiar with after using in student teaching, but it still "focused on 
social skills." After observing students being chatty on the rug during whole group times, she worked with Mrs. Wilson to create photo cards to serve as guidelines for rug behavior that showed children what they should be doing with their bodies during this time (Figure 10). This was a much more proactive approach than the reactive Hoppy Helpers behavior monitoring system. One was an image of a boy with his finger in front of his face as if to say, "sh." She explained, "Since we've used the 'no talking' visual, now we just say their name, and we point, where before we had the visuals, we just would say it again and again." She believed that these changes were very beneficial for the classroom community.

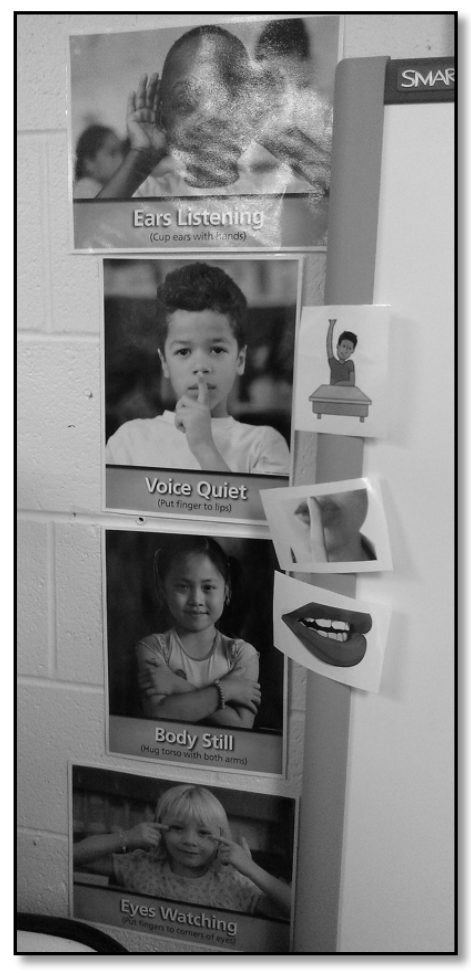

Figure 10. Molly: rug behavior guidelines \& reminders (9/14-5/15). 
In describing her classroom management at the beginning of the year, Molly explained that she was noticing that several of her students struggled with the routines of both the morning and afternoon sessions. She observed students calling out, hitting, lying, and throwing tantrums, but as an observer in her space, I was surprised that she did not have more students acting out. This was because her young students spent a significant amount of time sitting and as a large group, which typically leads to behavior issues. Molly shared that her afternoons were the tougher time of day because she had one young 3-year-old, Zack, who regularly displayed challenging behaviors, and she did not know what to do for him. She explained that he was very fidgety, stating, "He tries so hard, but he just can't. He'll jump on the trampoline for a while, but we feel like that just makes him feel like, 'Oh yes! I'm going to go more!' We are like, 'oh no!" For him to be moved into Allison's blended preschool classroom where he would receive more adult support, Molly and Susan needed to document the challenging behaviors he displayed. Days that he was absent changed the classroom atmosphere. Early into the year, the administration assigned a one-on-one aide to work with him, as he was quickly processed in order to receive instructional supports at Field. However, this aide was only assigned for part of the afternoon, and Molly found that Zack was often without one-on-one support, which she felt both she and he desperately needed.

About working with students and her classroom management at the beginning of the year, Molly was thoughtful. She reflected upon the fact that when she was a teacher candidate, she had been judgmental of other teachers' management styles and how they responded to behavior, for example, "Why isn't she doing that? Why isn't she doing anything?" However, she explained that now that she was teaching, she was realizing that "you can't catch everybody!" Molly also realized that the nature of behavior interpretation is subjective, stating: 
It's funny to see because everyone has their limit of what they find annoying. If a kid is tapping like Zack, oh, that gets me! But some of the things he does, I'm like, 'he's a part of our classroom.' The kids are learning... and I'm learning to work around it.

She explained, "I give him more leeway," but she felt that a substitute in her place might move his frog in response to his challenging behaviors.

In sum, Molly's beginning. Ultimately, Molly was unsure about how many classroom management changes she could implement in this setting, elaborating, "We'll just have to wait to see how the year goes." She blamed this on the unpredictability of her students' behavior on any given day based on which students were present. She expressed a lack of certainty that what she was doing was working for all her students, stating, "It's really up in the air about what works and what doesn't." At the time, I wondered if this sentiment was also because she had so little control over the many aspects of her teaching.

\section{In the Fall: "It's Been Kind of Difficult..."}

Into the fall months, Molly's upbeat and smiling outlook on her position at Field had begun to change. When I asked her how things were going at our fall interview, she responded, "Uhh, it's going...It's been kind of a difficult time since you last saw us." Unable to identify anything positive when asked, Molly described feeling very limited in her teaching because of Mrs. Lewis. Her positive feelings about having a co-teacher in the beginning had changed dramatically. Throughout the day, she saw opportunities for more meaningful and rigorous teaching, with which Susan disagreed. Thus, Molly shared, "Susan's just not helping me." On days that I visited in the fall and onward, I observed Susan on her computer at the back desk or out of the room, while Molly was left to manage all the students' behavior on her own. This 
presented a serious challenge to Molly's classroom management and strained her efforts to establish a sense of classroom community.

Unsure of whether my presence caused Susan to be absent, I asked Molly, and she responded that the days that I observed were like all the others. She explained that she felt very disappointed because she wanted to do so much more with her students, "but my aide won't help them play a game. I can't even put a color puzzle out and have her sit there and do it with them. She's always on her computer." At various points in the year, I would observe Susan leaving Molly alone with the children during center-time and in the gym for 30-40 minutes at a time with no acknowledgement or explanation. This left Molly's classroom out of compliance with state preschool requirements of the child to teacher ratio of ten students for every one adult. Additionally, it was wholly unsafe.

Classroom management in the fall. When asked about whether she felt any successes with her classroom management in the fall, Molly paused and exclaimed, "I'm drawing a blank right now!" She found it challenging to talk about her management because she felt so limited by the practices in place that were not her own. She described both of her classes, but especially the morning section of younger students, as very "wiggly!" She was experiencing more and more disruptions with them as the months progressed, which she felt was "weird to say" because she had expected disruptions to decrease over time. While disruptions could have been due to the extensive amount of time students were expected to sit still in large group activities, or the fact that Molly was self-managing the classroom, she attributed this behavior to the fact that, "It's just over for them. They've been in school for so long now. They've gotten comfortable with the environment and with the kids in the classroom." However, it had only been a few 
months, and Molly's expectation that students should have been showing more appropriate behaviors as they got to know the routines, environment, and procedures, not less was accurate.

In Molly's opinion, another reason for the behaviors she was observing was the differences in age and abilities between her morning and afternoon groups of students. As in the beginning, she felt that the young age of her morning students contributed to many more behavior issues during this session. She compared their behavior to her afternoon group of older students', stating, "however in my PM, there are no disruptions at all." This was in part because her afternoons had gotten a bit easier to manage as Zack, the little boy she had expressed concerns about in the beginning of the year, had been moved to Allison's blended ECE classroom. Now her afternoon students were all 4-and 5-year-olds, which she felt contributed to smoother days. When asked if she might alter her management style or choices for the two different groups because of their differences in age and abilities, Molly responded that she had, which she later explained.

To Molly, a big reason she connected to the behavior issues she was experiencing in the fall was the fact that she felt little ownership of the practices in the classroom. She explained, "Since I use the routine that was already in the classroom, I don't think I can have as much fun. And I don't know if the kids can really have as much fun too." She truly believed that if she could redesign the schedule and make her own curricular choices, she would be able to make the learning more fun and interesting. Molly astutely believed that if her students were more engaged, she would be able to hold their attention better, and their behaviors would improve. She continued, "I try to make the best of it, but knowing that it's not mine, and it's, 'Oh, I have to do this,' kind of thing, it's a little frustrating." Ultimately, she revealed that it was difficult to use approaches that were not hers. 
Despite this, in the fall, I observed Molly's classroom management skills improving as she was quickly learning how to identify when and where she needed to step in with student behavior. She explained that not everything ruffled her, stating, "A lot of their jumping around - honestly, I can handle it!" For the more extreme and persistent behaviors, she was quickly becoming adept at using redirection to get students on track during activities like circle time and the quiet reading time, as well as at work-time and within transitions. She shared that she had decided to move the assigned spot of one little boy who was consistently touching others when sitting on the rug during circle time. He was now sitting in a little chair in the corner of the rug by himself, and Molly believed that this was helping him greatly. However, she felt torn by somewhat removing him from the group, stating, "But I just hate that he's over there." She explained that when redirecting him she had not wanted it to be a negative experience, but instead a learning one, "not 'you need to go sit there! Instead, it's 'oh, this is your new special spot! I think your body needs room!'” While she felt badly about his individual spot, she found that he was more focused when sitting there, so this management decision was beneficial to him and the rest of the class. Throughout the year, I often observed Molly infusing teaching of prosocial skills into her explanations about consequences and planning for her classroom management.

On multiple occasions, I noticed Molly pausing as an activity ended to quietly follow-up with students whose behavior she had redirected during the activity. These subtle redirections included noticing a student, Nate, kicking vigorously under the table at snack, and her guiding him to a new spot to eat, or overhearing Nate say an inappropriate word, and acknowledging this, "Nate, please don't say that again." Because Molly was often alone in the classroom, redirection during work-time was a constant, as many issues surfaced during this time of play. Work-time 
was the time of day where she led a small group that followed up on the mini-lessons she taught just before, while other students continued to play around the room. This was one of her favorite activities to do because she controlled the planning and implementation. Intentionally making these activities meaningful and rigorous, she observed her steadily making gains.

For her to be able to lead this small group, she needed a co-teacher who could help manage the rest of the students. Typically, in preschool classrooms, when one teacher leads a small group like this, and the other teacher assists the remaining students, this is called the "one teach-one assist" co-teaching model. However, without Susan's presence in the room, Molly was understandably and consistently interrupted by arguing, loud noises, tattling, and chaos somewhere else in the room. In one example, she noticed students getting off-task and out of control in the playhouse. She walked over, identified the one boy throwing toys back and forth and asked him to come and work with her on the activity at the tables. While working with another student, she noticed one of her students crying on the rug. I observed her walking over and bending down to process what had just happened with him and the others near him. She redirected this crying boy by asking, "Why don't you take a break? Let's all do it." Another example during this time was with boys using their Lego blocks to make guns and shooting them at various people in the classroom. From her spot at the tables, Molly saw this and immediately popped up and walked to them. "Remember, we don't play guns in here" she said as she bent down and quietly redirected them to make their guns into another object before returning to her small group.

I was impressed observing her intuition and composure in handling these little fires of misbehavior and conflict in her classroom, as she was doing this single-handedly. However, day upon day of managing this time by herself was wearing on Molly's spirit and her ability to 
effectively resolve and prevent student issues, and problems persisted. For the little boy with the Lego gun, the minute Molly walked back to her small group of students, he returned to his Lego gun and shooting it at students, quietly exclaiming, "Put your hands up!" At the same time, another little boy walked up to Molly at the table to tattle about another child's behavior. In the middle of her response of, "Well, what could you do to let him know you're not happy about that..." another little girl ran up to tell Molly her that someone was cutting the letter paper and they were not supposed to. These small fires and redirections took away from Molly's teaching and stretched her patience, but she tried to be consistent with follow-through. With the Lego gun issue, specifically, during clean up that day, I noticed her pausing next to that little boy and again asking him, "What could you have done instead of that?" He shrugged his shoulders and continued to toss Legos into a bin, and Molly walked away. While she knew to address the troubling behaviors that surfaced during this time, she either did not know how or did not have the energy to see the consequence through with this child or plan for a solution for him to prevent the problem from happening again.

In the fall, Molly was still using the behavior monitoring system of the frogs and lily pads, although I did not observe her using this tool during the "fires" of the work-time or at any other time in the day. She explained that she did use the system, albeit rarely, and "some kids get it, and some kids don't." The Respect Bingo chart for collection of the school-wide rewards still hung empty near her circle time rug. About this, Molly shrugged her shoulders and stated in a deflated voice, “Well, it's just something that's gone to the wayside because I don't have the other board that the school uses, and I still never made one, and I'm thinking, 'Oh I'm going to make one,' but I never do.” She did not express any consequence she experienced for not using the chart or school-wide rewards. 
Instead, Molly explained, "I've been trying different things on the fly." With her morning class that she had described as "wiggly," she tried having the students bring chairs to the rug to sit on them during circle time, but "they just ended up on their heads and bottoms over to the next kid!" Additionally, she noticed that her students were leaving the classroom very messy after work-time and were unmotivated to pick up. To address this, she decided to reward those who were cleaning up the room with stickers. She explained, "I think it's time to start doing something to give them more incentives." She described working harder to use "just little things like that." She explained that she was using more positive reinforcement as well, "especially, 'you're having a great day!'” Highlighting correct behaviors from students as an example to encourage/ coerce others to follow suite was also something she had built into her repertoire of classroom management strategies.

Molly reported finding bits of success with the combination of verbal praise and stickers. In one example that I observed, while seated on the rug, I overheard Molly using this demonstrative verbal praise. She announced, "I love the way that Ashley and Abby are sitting," while she walked to a little box behind her chair at the head of the rug. She pulled out a sleeve of star stickers and gave one to each of these girls. Their faces beamed as she placed it on their hands. It was clear Molly intended this demonstration to positively influence the other students' behavior. However, the goal of others listening and being motivated to mimic the two girls was not achieved, as the others failed to notice. In other examples, I heard Molly dangling the reward of the stickers to promote positive behavior, such as, "I'm going to read this book, and if you're sitting nicely—everyone else, then you'll get a sticker too!"

Often, I observed her using verbal praise and stickers with specific students, highlighting how she was tailoring her classroom management within the two groups. Without calling it this, 
she was developing informal and impromptu individual behavior plans for students who needed them. Nate, who was one that Molly redirected consistently, received more stickers than any other student. I observed an example of this when the students were lining up to go to gym class. Seeing that Nate was standing properly in the line, Molly loudly announced, "I'm going to give Nate a sticker for standing such a long time in the line so nicely!" She gestured demonstratively as she handed it to him, and several students standing nearby seemed interested. Another little boy cried out, "Me too, Miss Daley!” However, Molly did not seem to hear him and instead walked to the head of line. Another example of this took place later that day, again with Nate. Standing at the front of the line, he excitedly told Molly, "Miss Daley, I'm so happy that I got a sticker today, and I am not on yellow today!" She responded positively, and another little boy standing near them chimed in dejectedly, "But Miss Daley, I didn't get a sticker today." She turned to him and replied, "Ryan, yesterday you did, and maybe you will later today too." Despite this, at no point that day did I observe Ryan receiving a sticker. Tailoring her use of the rewards for specific students highlighted that she understood her students to be unique learners and that her management should be differentiated because of this, but she failed to notice the effect this had on her other students.

In some ways, it seemed that Molly was clawing at ways to create a teaching identity in the fall. While confined by the classroom management practices of the classroom, she was trying a variety of strategies to different effects. The simple addition of Susan back into her schedule would have helped with most of the behavioral issues that Molly was encountering. However, without her presence, teaching and managing behaviors was a challenge. Without a mentor, coach, or team to turn to, trouble-shooting these issues was a challenge. 
In sum, Molly's fall. The disconnection that Molly felt with Susan was magnified by how "out of the loop" she still felt within the larger school. Changes from the administrative team, a lack of mentorship, and competing voices magnified these feelings. In disbelief, she explained that in a staff meeting, she had been "bombarded" by the administration when she was told that they wanted her to overhaul Mrs. Thompson's status quo within the classroom in front of others. In exasperation, she reiterated earlier messages of Susan's insistence that the administrators had wanted the classroom environment and daily practices to remain the same in the room. She explained,

And I was like, 'Okay, if that's what Mr. Anderson wants,' but then later on, I'm finding out that that's not really accurate info! She [Susan] said that Mr. Anderson loves our PreK and wants everything to stay the same, but then I was told by another administrator that he doesn't!

She described feeling betrayed in learning this because overhauling the status quo had been all she had wanted to do from the beginning. More like the fiery Molly whom I knew before, she sassily stated that if the administration had an issue with what she was doing, "You can come speak to me and talk to me. I would love to accommodate that!” Because I knew of Molly's deference for authority, I did not believe that had said this. However, she did go directly to Mr. Anderson to politely raise her concerns and ask him to weigh in on her trying new things out in the classroom and moving away from Mrs. Thompson's old practices. In disappointment, she shared, "But nothing has happened...He's just not umm, confrontational. He has a lot on his plate." With this, she was catapulted back to the status quo.

Despite some initiative with starting new things in the fall, for much of her second interview, we discussed challenges Molly was facing. Taking over most of our conversations, 
the pieces that she was identifying as exciting and positive were marred by frustrations, confusion, and disappointment. About this, Molly apologized profusely, stating:

I apologize that this came off kind of vent-y. I just honestly felt like once I was out of student teaching, I thought, 'Oh when I'm a first-year teacher, I'll feel confident and feel more qualified,' and all this stuff, and now that I am a first-year teacher, it's really tough because I'm the lowest on the totem pole! I feel like I can't state my opinion as well as others because I feel like I don't have as much credibility, and it's really frustrating. Comparing Molly's first year to traversing a deep ravine, at this point in the year, she was slipping down into the depths, trying to keep a foothold, but slipping. Her giddiness and quick dismissal of discomfort at the beginning of the year made way for the realization that this was her first-year reality, which provided her little hope as months continued to pass.

\section{The Middle of the Year: "Complicated."}

Molly described the school year in January in one word, "complicated." In quiet hushes when I visited her in January, she shared that she felt very unhappy at Field and was considering leaving the field of teaching, stating, "I love the PreK classroom, but I'm reevaluating..." In the minutes before the start of the day, she whispered to me that she was "miserable." Issues within the preschool program at Field, including a lack of a substitute for Susan over the several weeks she was absent due to surgery in December, tensions related to enrollment competition from another childcare center in town, the forced implementation of a new assessment system without related professional development, and continued uncertainty regarding whether Mrs. Thompson was returning at year's end, all created surface-level stresses for Molly. Drama within the larger school and district with the hiring and firing of another new teacher at the local high school due 
to criminal drug charges, along with these other issues, seeped into Molly's day-to-day interactions.

Classroom management in the winter. Molly's relationship with Susan and the larger early childhood team at Field was also fraught with stresses and tensions mid-year. She explained that, "sometimes, I throw Susan a bone," referring to the fact that she would build in cutting and arts and crafts activities that she knew Susan preferred, "to appease her." However, more than anything at this point in the year, Molly expressed frustration and sadness about her interactions with Susan. With a lack of literal and figurative support from her, she was additionally growing frustrated by some of Susan's specific behaviors, especially related to parent communication. Molly expressed being most uncomfortable by the fact that Susan often sent notes home with students or emailed parents without letting Molly know she was doing this, especially related to student behavior; whereas, she always cleared emails with Susan before sending them. Without notice of Susan's emails, Molly often felt blindsided. She explained, “Sometimes I'm okay with it, but it really depends on what it is." In January, Molly received multiple negative pieces of parent feedback related to Susan's emails. She worried about sharing this parent's concerns with Susan, but felt an obligation to let her know, stating, "I just worry that she's a very strong-willed person, so I don't want any bad blood... and just so she knows that I'm not doing that. So, she doesn't retaliate, which sounds bad." Her worry about Susan's reactions in part stemmed from feedback she had received about her from Field administrators.

In hushed conversations, mid-year, Mr. Anderson and Mrs. Stinson had apologized to her for how challenging they knew it was to work with Susan, saying things like, "I know that this has been a really difficult year for you," and "we completely understand." Molly admitted that hearing messages like this from administration made her feel good, and "it makes me feel like 
I'm not crazy." However, these words of support sharply contrasted with the lack of support she felt from them especially related to specific behavior issues and substitutes for Susan when she was absent mid-year. She also felt extremely frustrated because when she asked for guidance in how to better communicate with Susan, their response was "kind of like, 'oh, that's how she is,' which is frustrating and makes me so angry." She explained that Mrs. Stinson's response to her pleas was to appease her by saying, "Well, did I tell you about my first year of teaching? I had an aide that tried to get me fired!" Molly was stunned and unsure how to respond to this.

Without prompting, Molly provided numerous examples of students with challenging behaviors and extenuating issues that were impacting her classroom community in January. She described a little girl, Crystal, who had joined their class in October as one that she was giving lots of extra attention mid-year. She explained, "Oh, she just turned 3-years-old in October, and we were forced to take her." Molly quickly made accommodations and modifications for her, such as having her sit in a plastic cube chair while they conducted their beginning of the day routines. Because she was prone to distractions, Molly felt that doing this helped her focus and engage. Additionally, Molly was seeing issues with several of her male students. She explained, "I feel like a lot of the boys in my classroom aren't getting home-discipline. There's really no connection between school and home." She described behaviors from two boys specifically, such as showing their private parts to others in the bathroom, climbing on furniture, and being aggressive. In response, Molly sent multiple notes home with the boys, but she felt that they were not making a difference. She explained that she was at her wit's end, stating, "At this point, I wanted to try anything. It's these two boys, and they would push somebody or do something to somebody." She had already tried talking to her administrators about the boys' behavior to no avail. In troubleshooting, she landed upon the idea of connecting them with the 
principal, and she went to talk about this with Mr. Anderson. When she explained the issue and how she felt he might help (i.e. by being a strong male role model for them), Mr. Anderson agreed to talk to them, but then never came down to her room. Disappointed, she waited until she had coverage in her room, and she took the boys to him, but she was disappointed in his reaction when they arrived.

She was also disappointed with the boys' parents' responses. In talking about one, she described this by stating, 'Mom has been like, 'oh, what should I do?' and I'm not a parent, so I don’t know!" Molly felt very uncomfortable by being asked by a parent how to handle children's behavior. She explained, 'I don't feel like it's my place because I see them for three hours of the day..." Despite this, she shared advice with his mom to celebrate when he received green notes, which indicated that he had displayed appropriate behavior all day, and to focus more on these. She reported that the mother used time-out as a punishment, and Molly shared that she encouraged her to keep doing this, or "at least just talking to him about this." However, she quickly deflected ownership of this punitive comment, reiterating, "but I'm not a parent!" When I asked her why she thought his mother asked her for advice, she replied, "She doesn't know what to do. If I had to go to my principal for two hours because I'm not sure how to handle his behavior, I can't imagine managing his behavior at home!" Throughout the year, she experienced several parents searching for behavioral answers. Each time, she seemed flummoxed.

These students, whom she lovingly called her "high-fliers," challenged Molly's classroom management skills in the middle of the year, and in response, I observed her grasping at very behavioristic ways to control their behavior. This contrasted with earlier observations and discussions about her management. In talking about the day that I had observed mid-year, 
she reflected, "I feel like my management was terrible." About this, she shared, "I feel like I do a lot of stopping and starting. It's frustrating, but I do know it's PreK." She explained that with her morning group, “it's very hit or miss. There are just days that I feel like, 'wow!' I can't really get a grip on them!" In describing the sense of community in her morning class, she said, "ehhh because we have some really big high-fliers in that class. Some really interesting kids." To Molly, these behaviors prevented a real sense of community within that group.

After introducing the stickers as motivators in the fall, her use of them increased until they became a regular part of her practice in January. She explained that she had not used the stickers more in the beginning of the year because she knew that Susan did not like them, "but then when she wasn't there for a week, I was like, 'Stickers! Oooh, you're standing nicely...' " She felt the stickers helped to motivate her morning students to behave appropriately, even if it was just in getting them to quietly transition to the hallway. Here, she recognized that she was tailoring her classroom management and stated, "I try to give them to my high-fliers. Sometimes I will just go over to them and kind of prompt them, 'look at so and so,' but most of the time I only need a few." She admitted to trying to highlight different students each time.

Conversely, with her afternoon class, she shared that she did not use the stickers often. Instead, she said, "I feel like we have a really good community." Again, she attributed this to the fact that the group was older in age. She provided an example related to teaching about good choices with the Elf on the Shelf, a trendy holiday tradition of an all-knowing elf messenger who reports children's behavior to Santa. She explained:

We were talking about 'if you make good choices, I can bring you a treat.' So, we brainstormed good choices. 'What are the choices we can make so that he can go back and tell Santa?' And they gave lots of great ideas. We talk about good choices all the 
time, and I talk individually with certain kids about, 'What good choices can we make to this next transition?'

She explained that she only felt she could do this activity with her afternoon class. Teaching about making good choices, which is an appropriate topic for all preschoolers, was from Molly's perspective, something that only these older, more well-behaved students could learn. Mid-year, this illustrated a change in the high expectations I knew Molly to have for her young learners.

Along with the stickers, Molly found herself increasingly using the frogs and lily pads regulation system. Although she rarely moved students' frogs as punishment in the beginning of the year, by mid-year, she was doing this more and more, and thus sending home more yellow and red notes to parents. At the same time, I observed her having one-on-one follow-up conversations with students whose frogs had been moved. She would quietly talk with them, "Okay, so today you made some choices that were not good choices. What will be better choices tomorrow?" Despite using punitive measures like the red and yellow notes, Molly's behavior in following up with students to focus on solutions highlighted a humanistic side to her classroom management. Dismissing her earlier comments related to behavior challenges in her morning group of students, Molly strongly explained that this system was working to positively change the behavior in the majority of her students. This contrasted with the frustrations she felt related to the behaviors of her morning students, where the use of the system did not seem to positively impact their behaviors.

She shared an anecdote with me about a boy, Colin, playing pretend guns in her afternoon class. From my prior observation, I had learned that playing pretend guns was a big no-no in this classroom. It was a big deal that she moved Colin's frog to yellow in response because in this class, she rarely moved students' frogs. She explained, "I wasn't fully intending 
on having him stay on yellow at all! I said, 'that's not safe buddy. That's not really a game for school." She thought this warning was enough, but soon after, he did it again. So, she talked to him again. In response, she explained to him that she was moving his frog to yellow and had him sit in a time-out on the carpet, "just for a second." She described Colin as being very upset, so she followed up with him and asked if he understood what had happened. She explained, "When Miss Daley asks you something, it's because I just want you to be safe. That is not something we do." She moved his frog back to green, demonstrating that students could move back up within this system. A few days later, she observed another little boy playing guns, and Colin went up to him and said, "We don't do guns at school." Molly felt that this illustrated how effective the system was. She believed that the students whose frogs she moved were very responsive. She explained, "The ones I've just moved, just for a few minutes and have it soak in, they really stop." She continued, "I'm sure that's fear of getting in trouble, but it's not like I yell at them. I just talk about what's safe." She recounted other examples of students positively changing course after having the consequence of moving to yellow.

When she passed out the colored notes that corresponded to their lily pad color at the end of the session, I observed students' responses ranging from smiles, to pouting, to crying. Some of Molly's students who were moved to lower lily pads were very concerned about the consequence that would come when their parents saw the note. I observed one little boy run back into the classroom and ask Molly, "Can you send the note to my mom now?" He was very concerned that he had received a yellow note and knew that if he was not honest with his mom about this, he would be in trouble. Molly seemed unconcerned by this and replied, "I promise, I'll send an email right now." At no point did Molly display concern for how this may be impacting later family interactions with her students. 
She admitted that although she saw the lily pads and frog system, as well as the note system for parent communication, working for some students, these pieces were not working for others. She explained that she had several students in her morning class whose behaviors did not change when she moved their frogs to a lower lily pad. She stated, "I can move some of these boys, and it's ineffective." Molly did not feel that this outcome was related to her classroom practice, but instead that it was related to her students' home lives and upbringing. She continued, "I feel like this is because when I move them and send home the note, I notify the parents, and I talk to them, but sometimes the parents don't follow up." When I asked her if she was doing anything differently to support these students, she responded that she had been "trying to do many different things." However, she did not describe these different things to me, nor did I observe them in action on the days I was there.

Molly still had not removed the classroom rules poster that she had expressed such unhappiness with at the beginning of the year. Even yet, she did not refer to it at any point in the year with her students or create a new working guidelines or rules poster with them. Thus, knowing what helped a student stay on the green lily pad, versus get moved to the yellow or red, was murky the entire year, and learning about what would move a student's frog instead came out in admonishments and threats. Molly recounted a funny story that revealed one of these hidden rules and that helped her find levity in the stresses of the middle of the year. She shared that one boy kept refusing to put his boots on to go outside, insisting that they were not his, even though Molly had seen him arrive in them. When she threatened moving his frog to the yellow lily pad if he was lying, Molly revealed that lying to a teacher was a behavior that would move a student's frog. He insisted that he was not, and when she finally asked him whose boots they were, he honestly answered that they were “Tommy's [his brother's]!" Molly was incredulous in 
describing this, "He was answering my questions 100\% honestly!" Laughing she told him, "I said, 'next time you wear anything of Tommy's, just make sure you wear them to and from school.'" While this story humorously revealed the sincerity and frankness of young children, it also indicated the lack of clarity in this classroom about the guidelines and the reward-violation system. I would later learn that stealing would also lead to a student receiving a red note to take home, but again this was not a part of a set of guidelines for students or their families to understand. It was not until the middle of the year that I learned that Molly viewed the red notes as the primary form of communication with parents regarding troubling behaviors.

In connecting Molly's classroom management within the larger framework of PBIS at the school, she explained that she did not see that the practices she and Susan were using in their preschool classroom as sharply contrasting with those used throughout Field. She stated, "The school uses similar things to us. They use Hopper Hearts instead of the frogs." Mid-year, Molly was still not using these school-wide rewards with her students, because as she stated, "We don't use them in my classroom. They did it before, but they never made me a board for it. I was like, 'I can make my own,' but that's one of the last things on my to-do list." Thus, the Respect Bingo board remained blank. Without guidance or direction for the use of these school-wide tools, Molly felt no pressure or desire to use them.

In sum, Molly's winter. While Molly was figuring out the logistics of finding parity with Susan in her classroom management and teaching her "high-fliers," she was facing multiple layers of adult concerns in the school mid-year. Where a team could have helped her think through these issues, she felt very alone. She admitted that Rachel and Allison had offered her the chance to “'come in and eat with us,' which is great, and I'll go sometimes, but I don't eat lunch," which to my surprise, I had noticed the day I observed her in January. When I raised 
concern for her not eating, she pushed my concern aside, saying that she used her lunchtime to plan and did not have time to eat. She explained, "I feel like it's been really negative, and so when I go home, I don't want to be negative because that's my personal space. So, I try to get as much done at school during this time." Additionally, when she did eat with the other preschool teachers, she often felt like an outsider because she did not know what they were talking about. She felt that having shared students and staff made Allison and Rachel "have bonds on that level so much more," and she did not feel a part of this.

I got the sense that Molly felt most betrayed by the adult community at Field, including her administrators. She explained, "I feel invisible and alone in that school. It's terrible." As a first-year teacher, she had expected to find support and mentorship, and instead from both school and district levels, she was met with what appeared to be neglect, false promises, and a lack of follow-through. Molly described feeling offended in the beginning of the year when Susan would repeatedly introduce her to others as the "sub," but she stated, "as time went on, I wanted to just disown a lot of things we are doing in our classroom." In the winter, Molly seemed defeated. She continued, "I feel more comfortable being the sub." She quickly recovered from this statement, though and exclaimed that she would not say that in future interviews. She reasoned that if the administrators were not backing her up, then she was, "just a sub for the year," and she accepted this with a defeated look in her eyes.

In an angry tone, Molly blamed her university teacher preparation program for not better preparing her for dealing with the school-wide issues she was facing. She felt especially underprepared for the politics of teaching that seemed so overwhelming to her at Field. She explained, 
That aspect of complications that I see now is something that you're never taught. Like they talked to you about poor teaching, but no class or professor talks about what if you are having issues with the administration or having issues with a co-worker.

With still no mentor in sight, Molly was reaching out to her mom more and more. She explained that before this year, "I never really talked to my mom all this much," but that now she was calling her all the time.

She also guiltily admitted that she was watching the videos of herself from student teaching that she had submitted as evidence for the edTPA, the final performance-based evaluation that her Illinois state certification required. She shared that while watching this, she had reflected on the fact that, "I had a lot of fun with those kids. Not that I don't with these kids, but they were older and really into the lesson." In contrast to the limited planning she could do at Field, during student teaching, Molly felt that she was teaching the kinds of lessons she wanted. She shared that she had enjoyed watching her old videos because she was confident in herself then. She explained, "I felt like, 'This is going to be my job, and I love this!'” Talking about this led to her admission that she was questioning her decision to become a teacher, but she clarified later in our conversation that more than anything, "I'm just really looking forward to trying again in a different classroom where it's mine, and I can plan all of the lessons."

Knowing that Molly had previously expressed a desire to remain at Field into the following year, I asked her if she was still interested in staying there. Fighting back tears, she responded that she did not think it would be much better anywhere else. Seeing that Field's district had only two schools, she stated, "so if they can't get their stuff together, who can?" This was heartbreaking to hear, as I could envision Molly's spunky personality finding great success at another school. I wondered aloud about whether some of the issues she was 
experiencing were related to the fact that Field was so extremely small. She admitted loving growing up in a small town like Field, but her experiences at this school led her to state:

But now I don't think I'm very much a small-town kind of person. It was nice everybody knowing each other, but then, there's also a kind of issue with knowing everything. It was great knowing everybody walking down the street, but now I'm thinking it wasn't. At this point in the year, the issues for Molly were escalating to a level that was extremely sad and difficult to observe. Molly was one of the brightest students I had known, both smart and spunky, when she was my student, and here she was looking diminished, shoulders slumped, and fighting back tears the entire time. She was visibly uncomfortable describing many of the aspects of her daily life at Field, and when she discussed feeling alone at the school, tears came to her eyes.

In discussing her status quo, she turned on her teacher preparation. She explained that she felt her field experiences had helped her gain knowledge for where was today as a teacher, “however, my classes at MSTC - I don't want to sound mean—but I don't think they really helped me." Taking a deep breath and a pause, she continued from a more reflective stance, stating, "In classroom management, I guess I learned things." When I pressed her to consider that maybe it was hard to pull out university influences since she felt that none of what she was doing at Field was really hers, she responded, "Wow, I think that's it. You really hit the nail on the head!" She paused and continued that certain courses in her preparation had helped her, but that there were others like the beginning courses in her program, where she did not feel their influence today.

What she felt strongest about was her learning about lesson planning, stating, "But, looking at standards, planning for them, lesson plans and stuff like that helped." Talking about 
this lit Molly's face up, and she was the most animated that I had seen her during this time. She explained that she felt torn, stating, "Like earlier, I wasn't sure I want to continue teaching, and now I'm talking about if I had my own classroom, I could do this and this!' She expanded on this, stating,

There's so much going on at the school, where I feel like this is not what I want to do. But then, when we talk about what's appropriate and what's not, I know these things, so I can do that! This is not really an environment where I can show them that.

I asked her if she thought that our talks helped her to process all of this, and she replied, "I could talk for days." Like in the fall, Molly worried that in our conversations, she sounded, "vent-y." She shared that she felt she was showing weakness in talking to me, and at this, I had to fight back my own tears, as I attempted to uplift her spirits. I responded that she was not showing weakness by describing her experiences.

At the end of our interview in January, Molly tearfully shared, "I feel even more lost, not better." At this, my eyes were brimming with tears as well, and in my heart, I wanted to grab her in my arms and just hug her until I could not hug her anymore. I shared with her how much I wanted to help, but felt constricted by my role as a doctoral researcher, and how this stopped me from knowing what to do to help her. I pled to her to reach out to me or other faculty, if she needed to talk. Her response to this was maybe the saddest of our interactions mid-year. She responded, “Honestly, I don't even know what to do to help me, so I can’t. Suggestions are great. However, it's executing suggestions and doing things that are the problem. I've wracked my brain a billion times thinking about this..." It is here that the metaphor of the ravine is apropos, as she had fallen into its depths. In many ways, the light of her firecracker personality was fizzling out. 


\section{Into Springtime: “I'm Moving Home."}

This is how we left the January interview after my mid-year observation. I worried about Molly, and how she was doing, as she had seemed so low in spirit when we last met, but in the interim, she did not reach out. When I emailed her to schedule the springtime visit, she quickly responded. I was hesitant to learn how she was doing, and what I found out surprised me. After the darkness of the middle of the year, in the springtime, she made a concrete decision that she would move back to her parent's home in the suburbs at the year's end. Implying that Mrs. Thompson had decided to not return to Field at the end of her leave, Mrs. Stinson told Molly that the preschool position in which she was subbing, was now open for applications. Molly admitted that internally she felt pressure to apply for the full-time position because, "I felt like it's right there in front of me, why am I not going for it?" However, through reflection with her family and friends, she realized that she did not want to return. At this point, Molly told the Field's administrators that she would be leaving at year's end.

She explained that sharing this news had felt so good, stating with a big sigh, "I felt like, 'phew!'” In talking about this, it was as though a weight had been lifted from her. She was more upbeat, more smiley, with pep in her step - more like the Molly I knew from before and had seen at the start of the school year. At this point in the year, she knew whom they had offered the position to "off the record," and it was Allison, the other preschool substitute, and Molly seemed honestly happy for her. 'I'm still very unsupported there, but knowing that I don't have to come back feels right. That sounds terrible," she explained with a smile.

Once decided, she reassessed her relationship with Susan and began to infuse more of her academic goals with Susan's “crafty” goals in her daily planning, stating, “This is kind of how I plan now. I add thinking about her in just to make it work." She felt very good about teaching 
lessons like this with her students, and expressed, "we were more on the same level." She provided an example of a lesson on love where she led a discussion with the students about who they loved and why, taught a related math activity, and then conducted a painting activity during work-time. About this, she stated, "It all seemed to flow." She explained that she was still less than certain of Susan's expectations, but overall, the month of February had gone well. She realized that if she applied for and received Mrs. Thompson's position that she would continue to work with Susan. She acknowledged, "now, it's tolerable because I know I'm not coming back." She felt that if she returned in her second year, "we would butt heads way too much for it to even be worth it." She admitted that this also contributed to her reasons to not apply.

Classroom management in the spring. In the springtime, Molly's morning class seemed to be going much more smoothly than when I had observed mid-year. When I asked her about this, she paused and responded that the morning that I had observed in January had been one of her toughest. Now, she explained, "I feel like it has gotten a lot better at the carpet. It just seems to flow better, but I don't know what happened." A possible reason was that she had moved one student's assigned spot on the rug. About this, she exclaimed, "It's been amazing! Craziest, greatest change!" Trying to figure out the best place for him to be engaged had frustrated her, and she finally landed on the perfect spot with a chair for him, which was working well for him and the entire class.

In thinking about the extreme cases of student issues she had experienced so far this year, she explained, "It's been a really weird year." In March, Molly wove together multiple stories of students from across the year, and especially in the last few months, that had been extraordinary. She described one little boy exhibiting self-harm behaviors at home. His parents were seeking support for a reactive-attachment disorder diagnosis. A few others displayed challenging, defiant 
behaviors. Molly explained, "Both of these boys are at-risk, and I know that one specifically has a really hard home life." How Molly knew this, she did not state. One of these boys displayed regression in many areas of development in the springtime, and another was chronically absent. About him, Molly stated, "He's been in and out of my room. I wouldn't even really know what months he was here and he wasn't, because that's how inconsistent he is. He wasn't here today; he never shows up at school." Another little boy was repeatedly stealing, and Crystal displayed possible neglect and developmental delays. Interestingly, the only student whom Molly identified as challenging to work with was Crystal. All the others were cases that naturally surfaced in our discussions, even though to a bystander, they seemed very challenging.

About these challenging behaviors, Molly felt stretched to her limits in knowing what to do, and at every turn, she felt that she encountered a roadblock. Despite a lack of guidance, throughout the year, she had been learning on the job and trying to figure this out. She explained, "Since I'm a first-year teacher, I don't really know this stuff! How do I get an IEP in place? How do I do this?" She shared that she had reflected on our past conversations when talking to her administration about attending Individualized Education Plan (IEP) meetings, because after asking her about her teacher preparation, she realized that she had not been prepared for how to get services for students or go about putting an IEP in place. However, she explained,

I've been trying. Now I all I can do is be on top of things, like all of the emails I've sent my administration, all the emails our RTI person has sent to my administration, all of my data, I just it put in my files and make sure that the Kindergarten teachers know that I have been trying. 
She reached out to Mrs. Stinson for help, but she explained that Mrs. Stinson was unsupportive of IEPs at the preschool level, and was instead pushing for students to just move into the blended classroom. About this, Molly sassily commented, "This is fine. But if you're not going to give the kids the help they need, I don't understand how that is going to work." After almost a year of figuring this out, Molly now felt much more confident about the processes within special education services in general, especially for IEPs. She explained, "I'm really not an expert," but she was so glad that she had been able to participate in as many meetings as she did.

Within her classroom practice, Molly was proud to announce in the springtime, "I haven't used stickers at all!" She defended her prior use of them, stating,

I mostly did it for when they were in line, and I don't know what happened, but for some reason in February, they were quiet. I was like, 'Okay, I don't understand why, but let's go ahead and stop them!'

Instead, she was now using verbal praise and the reward of telling the principal about their good deeds, which she felt was working just as well as the stickers had. She described realizing that her students were not expecting the sticker as much as what she said when she gave it to them. She now felt much prouder of her students when they passed other classes in the hallway.

She was still using the frog and lily pad regulation system, along with the related notes to parents. About this, she stated, "I'd say for the most part, everyone goes home with a green note, except for a few kids who are touching and hitting each other." She explained that she followed up with everyone who went home with yellow or red notes by emailing parents immediately after dismissal. In her emails, she would write, "This is what we talked about today. This is what is going on. So, when he/she comes home, if you could just take care of it, thanks..." She described parents responding differently to this system. Some displayed confusion, and others 
asked her for help, which consistently surprised her, as she exclaimed, "I can't discipline your child at home, that's you!" Some outright disagreed with her assessment of their child's behavior.

She provided an example that highlighted a disgruntled parent and touched on many of the other issues that she was also experiencing at Field throughout the year. One of her 3-yearold students, Brian, started "taking things home with him that were not his," i.e. stealing objects, at the beginning of the year. In the beginning, she tried to address her concern with this by talking to him, and she brought up the issue at Parent/Teacher conferences in October. She asked his parents to look for classroom objects at home, but nothing returned to school with him. Eventually, she began moving his frog to the yellow lily pad and sending home the corresponding note in response. She explained, "We've told him, 'We do not take things.' We tell him and tell him and tell him!" Into the spring, Brian was still stealing small items and was now taking things from the Field hallway displays outside other classrooms. In desperation, she finally moved his frog to the red lily pad and sent a red note home with him. Before she had a chance to write his parents, she and Susan received a very angry email from his father.

Impassioned, she recounted the email message:

He pretty much called me out for being a first-year teacher! Even though everything he mentioned was in all PreK classrooms! He goes, 'we know he steals things at home, but we make accommodations for that, and we expect it. If he sees something he likes, he's going to want it, and he's going to take it.'

Hurt by these accusations, Molly resorted to a childish response, and told me, "I was like, 'Okay, well, you're a sucky parent!'” Again, I felt confident that this was not actually how she had replied and was instead an exaggeration for me. 
Brian's father then emailed Mr. Anderson to tell him about this exchange, how "mad they [he and his wife] were about the red note," and with more complaints about Molly as a new teacher, including an allegation that she served Brian the same snack every day, even though the family-donated snacks in her room changed daily. He included a complaint that her classroom was always the last preschool class to head to the buses at the end of the day, about which she remarked, "We're always on time!" I concurred with this self-assessment, as every day that I observed, hers was the only class on time for pick-up and drop-off. He also complained that Molly was disciplining Brian by "calling him out in front of the whole class," which hurt Molly's feelings. She explained, "It's always something where we pull him over and talk to him privately." Her self-assessment was in line with how I observed Molly following up behavior and redirecting in her teaching.

Additionally, he alleged that Molly was talking about Brian in front of other parents at pick-up, but Molly refuted this for two reasons: by saying that Brian's father had never been at pick-up to get him, and even if he were, that she would never do this. She was incredulous that he tried to make light of what they had been experiencing with Brian at school by asking, "“what other PreK students wouldn't steal things?' I'm like, 'All 35 of my other PreK kids do not steal things!" Molly was indignant about the accusations that this father alleged, stating, "I was so angry!" She rationalized that sending the red note home was a logical reaction to repeated theft. In this, she revealed a clarification about what constituted a move to the red lily pad and note in her rebuttal to this father, as this was still unclear in the classroom. Her response outlined:

Well, that's strange, but your kid is not immune to our system. For the issue of stealing, we can solve it by the red notes. Red notes are formal parent communication. We do this 
so that they can get enforced at home. If this happens again, I can talk to him about it. I told him this is how we give out red notes.

Molly shared that Susan was also felt upset by the email message, and they talked it through. Susan wanted to meet with him, but Molly was adamantly against this. Once she had calmed down after reading it, she told Susan, 'I'm not meeting with him because I am not going to have a parent yell at me and say all of these things and blame it on my only having one year of experience."' She described this as ridiculous.

Because of the incendiary nature of the email and the fact that in it, he demanded to meet with Molly, she reached out to Mr. Anderson to discuss the matter. She shared with him that she did not want to meet with this father because of the fiery nature of the exchange. Molly was shocked that Mr. Anderson's response was that he was unfamiliar with this family and to ask Molly if she had previous issues with the family, which to her seemed beside the point. She described that he seemed disinterested in the whole affair. Despite her worries that a meeting would be confrontational, Mr. Anderson offered to meet with Brian's father if that was his wish. She insisted that she would prefer to craft an email response for him to review and edit before sending back to Brian's dad, and to this he changed course and agreed. Overall, in this exchange, Molly felt very let down.

As of my visit in March, she had not received a response from Brian's family, nor had he stolen anything since. She was regularly checking his pockets. She shared how she was responding to some of the concerns his father raised by considering how she phrased redirections and reminders to him, even though she did not believe that she should have to do this daily. She explained, 
Also, I'm not going to call him out. You're saying I call him out, but saying, 'Brian, make sure you don't steal things,' is calling him out, and I'm not going to do that. So, I'll just say certain things like, 'Brian, I hope you're cleaning. Let's make sure nothing gets in your pockets!' Things like that. It's not every day, all the time, because we've talked about it.

From this experience, Molly learned that moving Brian's frog to the red lily pad and sending home a red note did not create the outcomes for which she was hoping. She exclaimed, "It's pointless with them! It's going to anger his parents. They'll say, 'don't worry about it,' and then he'll steal again." However, this did not make her pause about using the red notes in general, nor did it make her question why a parent could be so upset with the behavior monitoring system and form of parent communication as Brian's father had been. As there was no parent handbook or other communication explaining the classroom system, it was understandable that parents may be upset or concerned, yet Molly did not seem to realize this in her first year of teaching.

In other aspects of Molly's classroom management in the spring, the Respect Bingo board was no longer hanging near her big rug. She explained that they still were not using the school-wide Hopper Hearts related to it, and she moved it because they needed the space for their new teeth chart documenting lost teeth. Instead, she felt that having one-on-one conversations to process what happened after a behavior problem, especially for those students moving on to kindergarten, was more beneficial than using the school-wide rewards. She believed that helping them think through what would lead to a consequence in kindergarten was helping to set them up well for their next year.

Although she wished that she could have new and different components in her classroom management practices, by March, very little had changed from previous months. The classroom 
rules poster that she had expressed disliking throughout the year was still hanging. About this, she stated, "It just bugs me every time I look at it. Now that I know she's not coming back I would really like to move things!" I asked her why she had not taken it down now knowing that Mrs. Thompson would not be returning, and she deflected the question by telling me that Allison, the presumptive new teacher in this position, would often come in the room with her to plan together what needed to change. I was left wondering why she deflected the question and wondered if in the "sub" mindset from winter, she was avoiding any ownership within the classroom.

To Molly, finding connections between her classroom management approach and skills and what she had learned from her teacher preparation was still unclear. When I asked her to think about the potential for connections here, she responded, "That's always the tricky one, and I know that this [the study] is what this whole thing is about." She believed that classroom management was multi-faceted, and she struggled with seeing where her preparatory program had influenced any aspect of it. She shared, "The only time I really talked about classroom management was in your class. That's about it." However, in our conversations, Molly revealed learning about classroom management that did come from her university experiences. She grew reflective, sharing,

I feel like if I could have started over right now, I know I could have made our room more of a community, being able to do what I wanted with them. It would have been more fun for me, and more fun for them. I could just make it seem like this is our classroom community and do certain community things that I want to do like 'how we treat each other.' 
She recognized that Mrs. Wilson led the students through some activities like this, but her visits were infrequent. Instead, Molly had hoped to cover the topic of prosocial skills deeply at the beginning of the year because she knew that some of her students had never before been around other children in a setting like school. She reflected that she would have liked to start the year differently, "and I think that it would have helped to make a community." Here, I paused because Molly was essentially saying that amongst her current students, she did not feel that there was a sense of community. However, this negated the strong relationships I observed in her classroom between Molly and her students. Her comments illustrated her perception that because they had not started the year off in one specific way, they had not achieved a sense of community by spring, which was so disappointing to hear.

In sum, Molly's spring. She explained that the primary reason for not applying for the open position was due to a lack of support from the Field administrators throughout the year. She explained, "The whole year has felt crazy." Molly added that they had not helped her to "gain control of the classroom like I needed." She described sending repeated emails, having inthe-moment discussions, and raising her concerns about specific students in meetings with her larger ECE team and administration, to no avail. In her words, she stated, "I brought them up to everybody!” After finally receiving permission for the Field's Response to Intervention (RTI) support teacher to observe them, and "even she was noticing that they're not on the same page," Molly shared that the administrative response was, "There's nothing we can really do." She wholeheartedly disagreed, as she had significant documentation of their behaviors and had observed repeated inconsistencies.

Additionally, Rachel was advocating on her behalf, but Rachel relayed a message from Mr. Anderson that “'Well she [i.e. Molly] didn't bring them up at data day.' But, I did bring 
them up! Those are the only two people I talked about at data day!” Describing this, her frustration and annoyance were palpable. She exclaimed, "It's been a very frustrating ride." She believed that if she applied for the full-time preschool position, the disorganization and lack of support of this year would be the same. About this, she explained, "I don't want to be a part of that." In her opinion, she needed "to start new." Despite these frustrations, in March, Molly seemed much more upbeat. This clarity was helpful all around.

The sense of peace that Molly found in making the firm decision to not apply for nor return to Field the following year correlated with overall better behavior in her classes, a smoother relationship with Susan, and stronger clarity in her own sense of self. Although she still felt disconnected, she seemed much more at peace with her classroom management practices, her students and her teaching, and knowing to not expect much from her administration. These feelings would take her through the remaining months of the year. It seemed that she was climbing out of the ravine.

\section{The End of the First Year: "I'm Just Glad I Did It."}

The peace Molly displayed in March was sadly flat-lined when I returned in the last few days of her first school year. Although tough to do on her already petite frame, she seemed to have lost weight, and she shared that she was regularly not eating breakfast or lunch regularly. It seemed that she had given up and was just done with teaching. In sharp contrast to the upbeat delivery I had observed her using with students throughout the year, at the end, her tone, body language, and overall energy level seemed flat. I observed an example of this when one of her students walked up to her during quiet reading time to show her that one of the pages in her book was ripped. "Wow, that's a bummer," Molly replied flatly to her, which was so out of character for her but common on that day. In one of the moments where I saw a glimpse of the spunky 
Molly I knew before, the first thing she told me when I walked into her room was that they only had 10 more days of school left, and that she and the kids were very ready for the end. Not seeing Susan around, I asked her if Mrs. Lewis was present today, and with twinkling eyes, she replied, "Don't know. Really don't care."

After hearing herself referred to as the "sub" all year and experiencing the highs, but also the many lows of this role, she explained that now, "I've completely taken on the role of a sub." Molly was not yet finished with her first year, but in her words, "I'm just ready to get out." Taking on someone else's classroom in the beginning had sounded like a good way to gain teaching experience right out of college, but to Molly at year's end, she explained, "that was the underlying issue behind all the issues that I faced..." I asked her if not having a drawer desk for the bulk of the year was an illustration of this, and she replied, "Yes. Oh, yes. 100\%." She shared that she had been so frustrated at the beginning of the year, but at this point in the year, "it is what it is." Continuing, she stated, "But it just - it makes me - I don't know. It doesn't help my confidence. It makes me annoyed and sad." Walking back to the room after a tough morning on my last day of observation, Molly just seemed deflated. She quietly turned to me, saying that she was "done. I am terrible at this, and so I am just done." Her questions about whether she should be a teacher from the middle of the year resurfaced, and she shared, "This whole year has made me really question what I'm doing with my life." As one of the people who helped Molly become a teacher and who believed deeply in her and her abilities, this was heart-breaking to hear. She was neither terrible at this, nor was she someone who needed to leave the field; yet from her perspective, these statements were her reality.

End-of-the-year classroom management. By the end of the year, the relationship with Susan that she had described as going so much better when I visited in March, was also slowly 
unraveling. Overall, the interactions I observed between them were much more strained. On this last day of observation, I rarely saw Susan in the room. This was clearly not okay with Molly, as she told me, "I'm by myself all the time!" The problematic nature of Molly teaching a full class of preschoolers by herself was highlighted on my last day of observation at the gym. At the gym when social and behavioral problems are highly likely, having two teachers present for preschoolers is critical. On this day, Molly was there on her own. Students repeatedly crashed into each other with the scooters. After one crash, a little boy began crying as his hand was smashed into the oncoming scooter. Molly walked him out into the hallway to get a drink, and as there were no other adults in the gym, she asked me to watch the rest of the group as they continued to play. I wondered what she would have done if I had not been there. On this day, the stress that Molly felt throughout the year when she was by teaching by herself was clearly illustrated.

Molly attributed the stress she felt about working with Susan, and the fact that they were never able to establish a good co-teacher relationship to the circumstances of her substitute role. Getting hired so close to the start of the school year, and everything being already so set in stone in regards to room arrangement, daily schedule, and instructional planning, had originally made Molly appreciate that her year was ready to go. However, she had thought that she would get to build on to this, but "then I really didn't." Additionally, hearing competing messages about what her role was supposed to be as the year went on led her to feel that she could not make any changes, which ultimately stifled her creativity and created tension between the two of them. "I got pigeonholed," she flatly stated about the conditions in which they became partners.

With her students, Molly went a bit rogue in her routines for circle time and quiet reading time at the end of the year, which pushed back against Mrs. Thompson's and Susan's structures. 
I observed her trying to infuse that which she had described to me at various points across the year about more rigorous and developmentally appropriate activities and more teaching of prosocial skills for her classroom management through literature. However, she attempted to do this within the constraints of the daily schedule, which limited how well this worked out. I observed her break the tradition of the "calendar time," and embed a related video of The Three Little Pigs along with a storyboard that the students then sequenced. Later, I observed her teaching a comprehension mini-lesson about what took place in the Eric Carle text, The Very Greedy Ladybug. While these activities sound typical for preschool, they were very out of the ordinary as compared to the many highly-routined and meaningless activities she had felt pressured to teach throughout the year. At the end of the year, in lessons like these, Molly felt confident in how she had been prepared and was working hard to make sure her kindergarten-bound students were practicing the concepts and skills that she knew, from having student-taught in kindergarten, would be needed the following year.

At the end of the year, Molly reflected that she felt she had gained some confidence in her classroom management skills, but she felt that many of her classroom management decisions might be Susan's. In many ways, she felt that she had become stricter because of Susan's model. She explained,

When I student taught...I wouldn't say that I was really strict, but I was more firm. Here, at first, I was like, 'Oh, they're so young!' My class is a little awkward, but now when I'm the only one at the carpet, trying to control it-- it's more like, "No, you need to stop that," and my voice is just more firm. 
She saw this resolve in her mindset and behavior towards the students as working. She observed that her studnets had learned her expectations for things like rug behaviors, stating, "I just go, 'Just do it,' and they do it now." This made her feel more accomplished.

After hearing Molly's descriptions of many different students facing a multitude of issues in my springtime visit, I asked her for an update about them in our last conversation. She paused for a moment and stated,

It just breaks my heart. I'm still not getting IEPs for my two boys that really need them or RtI at the beginning of the year, which makes me really upset. But I've mentioned it multiple, multiple times. Even after I talked to you, I mentioned it multiple, multiple times, and now it's time for the report cards to be due, and our data day is Friday. If nothing gets done, nothing is going to get done. It's so frustrating.

She made the connection for one of them that his excessive absences from school were at the root of many of his behavioral issues, sharing that he had missed more than 50 days of the school.

Despite these frustrations, she reported that she was seeing gains with some of the students we had previously discussed. She explained, "For some of my behavior boys, yes. For one, it just feels like he'll be fine, and another one who I have, well, he was a hot button. But now, he's calmed down, but I still don't know." With another student, Nate, she worked with Mrs. Wilson to create a formal, individualized, behavior plan that applied to his behavior in the classroom and on the bus. This was one of the students that she had walked down to visit Mr. Anderson earlier in the year, and after this visit had no bearing on his behavior, she reached out to Mrs. Wilson for support. She described Mrs. Wilson, as “amazing." Together they tried several strategies and landed on doing a modified Check In/ Check Out with him every day. 
Mrs. Wilson gave her the idea to split his morning schedule into increments, and at these points, he would check in with Mrs. Wilson. Molly had observed Allison using a similar strategy in the blended preschool classroom and thought it was a great idea. She noticed that he was responding very well to Mrs. Wilson, and described this success as "awesome." Her relationship with Mrs. Wilson was one of the only ones that she consistently viewed as positive at Field, and it was only with her that she described feeling inspired, supported, and somewhat motivated in her practice.

Sadly, when I asked about her classroom management practices, Molly did not pull out any of the stronger management skills that I observed her use on my last observation. By the end of the year, she was managing most of the day on her own. She adeptly redirected students who got antsy during the too-long circle time and morning activities. She rearranged seating, called on students who were off task to participate, gave feedback about behavior, and did all of this without skipping a beat.

However, because Molly was teaching by herself for so much of the day, I also observed her redirecting and passing out logical consequences and punishments more quickly and with less guidance and follow-up than she had displayed earlier in the year. On my last observation, I noticed this specifically at the gym, where Molly was again left alone with all the students. The students, playing with scooters, were having a great time running and rolling around, but Molly seemed very stressed trying to manage it all. She stepped in and out of addressing "misbehaviors" including students chasing each other without being somehow connected to the scooter (of which she did not approve), ramming into each other, and other issues. I observed her giving out warnings to a few, but then she began taking scooters away and having the students sit in a time-out along the wall of the gymnasium. At one point, there were five different students sitting out. As she passed by me, she frustratingly remarked, "We haven't 
been here in a while. It seems like they've forgotten what to do." If this was true, I was surprised that they were then in trouble. I had not observed her or Susan providing the students with new guidelines or reminding them with prior guidelines for how to behave in the gym.

Later in the day, I heard shortness in Molly's remarks and responses to students. One little girl, Britney, was loudly admonishing other students who were off task during quiet reading time that day. With anger in her voice, Molly reproached her, "Britney, you need to stop yelling at your friends and find a space to read—now!" Correlating with her quickness to admonish and punish, Molly was still using the frog and lily pad regulation system, along with the corresponding notes at the end of the session. At the end of the year, Molly was finally able to explain the system more clearly, and I learned about another behavior that led to frogs being moved. She explained, "That's the main reason we used the frogs, [that is] when they're being physical to somebody. To teach them that this is not okay. We don't touch people at school." Without clear guidelines, over the year, I was forced to synthesize what the reasons for frog movement were from her students' reactions and her descriptions, just as I suspected her students and their families had to.

Molly and Susan regularly talked over the students' heads about the current location of their frogs to encourage/ coerce more appropriate behavior. In some cases, this would guide them to follow up with or ignore student behaviors. Nate, specifically, was one that they spoke of often. Molly shared that with his behavior plan, they factored in using the frogs and lily pads and having this be connected to his Check In/ Check Out with Mrs. Wilson. About this, she stated, "It's been so great. It was not so great today, but he was upset about getting on a different color pad." Molly continued, "I mean...it's not a good thing that he was upset, but you know, it's really not a bad thing either because at least it's a reaction." When Molly had moved 
children's frogs down the lily pads, it had often been for reactions from either them or their parents throughout the year.

To Molly, the most challenging aspect of her classroom management that year had been that there were two different personalities in the room, hers and Susan's. She explained, "So there are really two different expectations. I try to match my expectations with Susan's because I know she's not budging." In addition to the issue of competing viewpoints related to classroom management, Molly recognized, "The number two problem is...the lack of adults in the room. She's in the room, but as you saw, she's not really in the room." I asked her if she had addressed this specific issue with Susan, and with a deflated voice, she responded,

No. I just didn't. I just dealt with it. At first I was like, 'Oh, Susan, maybe if you'd sit at the carpet with me and them?' You know, that would have been a big help. And then, she was like, 'Well, I'm doing this instead.'

Building off of her descriptions from the spring, at year's end, Molly felt that her classroom management of the first year would have been better if she had received autonomy in setting up the classroom and establishing her own classroom community, instead of having these important facets of the classroom so set in stone, and Susan's presence so dominating.

When discussing her management, she rushed to exclaim, "I just feel like honestly, this is my disclaimer...This—-what you see about my classroom management—is not how I would want to run things." She shared, "I'm uncomfortable with my classroom management, to be honest, but I don't think I would be as uncomfortable if it was my own class." She strongly believed that if she could have built her own classroom community and establish her own expectations for the students, her overall management would have been different. She would have used more of the attention-getters she liked, more explicit expectations for behavior, and 
routines that were more developmentally appropriate. She described how she would have had Susan help her during center time and how this would have helped her overall management, stating, "If I'm trying to get something done, she could have a group, or I could have a group, or she could be with the kids doing classroom management, so that I can have a small group." These hopes did not seem unrealistic.

Molly also realized by year's end, that working with preschool-aged students was maybe not the age range with whom she most wanted to work. She explained, "I love my kids, but PreK is rough sometimes because the classroom management is a little bit different. There's always going to be talking, but this is more...shouting out. It is them learning, but I find it frustrating." She believed that if she were at the end of the year with a kindergarten class, she would not have to give as many reminders and there would be "less touching." She recanted this and offered the idea that $1^{\text {st }}$ or $2^{\text {nd }}$ grade were the grade levels where she believed students would need fewer reminders because they internalized more and understood guidelines more easily.

Molly described her classroom management with more clarity at the end of the year, but she was still unable to pick out the specifics of the school-wide approach of PBIS at Field. The only fact she knew solidly was that Field did use PBIS, just not in the same was as her student teaching site. At this point, when I inquired as to whether her classroom practices lined up with the larger school's PBIS framework, she responded, "Oh, I don't think they really did at all." She explained that the only aspect that was similar was the fact that both approaches used a monitoring system. In her classroom, this was with the lily pads, frogs, and notes, but she was not certain that the whole school used a notes-based system for parent communication. Instead, she explained, "Some classes might do a color-it-in calendar, or something like that. Really, I don't know." At no point was she asked by the Field administration or her larger ECE team to 
share data regarding student behavior. Regardless, she saved all her behavior-related documentation in her files.

In sum, Molly's end of the year. A good word to describe Molly's outlook at the end of the year was 'disillusioned.' She had entered the school year with such zest and excitement for what was to come, and on the other end of it all, she appeared beaten down and bruised from the experience. Without a coach or mentor or strong team to guide her through the choppy waters of being a first-year teacher and a substitute at Field, she had experienced many struggles while figuring everything out alone. She expressed frustration and hurt about this, stating:

I've tried so hard to plan with her [Rachel] and Allison. I feel like I participate with what the group is going to do. And with the conversations about next year, I'll add things like, 'oh, I think that's a great idea, or I've seen at this place they've done this.' But I feel like my words are not valid because they don't seem to consider them.

She reasoned aloud that this was most likely because she was not returning to Field the following year, but she shared that she had never truly felt welcomed at the school.

At other grade levels, Molly believed that teachers did collaborate and work together, although she did not believe that they collaborated about a rigorous or meaningful curriculum, instead describing a dinosaur art project theme and play that another grade level put on for the school. She reflected, "I just feel like PreK doesn't have that team, but hopefully they will next year." She explained,

I guess where I student taught, my cooperating teacher was more of a loner, but at least we were on the same page as far as curriculum and as far as lessons. Those teachers didn't run their classrooms the same way, but at least they were able to talk it through and share ideas. It was very open in sharing like, 'Oh, this is what we do for this.' And even 
just knowing what they did in their classrooms...I have no idea what these teachers at Field do, and I have tried to ask different teachers, 'What are you doing?' I get nothing. In highlighting her self-perception within this larger team, she sadly described, "Well, I've always been the black sheep of the group... whatever. So, I don't really care. Good luck!” This self-assigned label was not one that I would ever have given Molly because she was always friendly and amongst friends in my prior experiences with her.

Molly recognized that she had played a role in isolating herself at Field, leading to her feelings of sadness and loneliness. She reflected, "Well, I feel like I could have tried harder to be a part of the community, the Field community." The staff at Field had recently participated in a hoedown party, and she shared that she should have gone, but had not because she did not feel a part of it. However, she immediately deflected this responsibility by explaining that none of the preschool staff were very involved in the larger elementary community events, including Susan. Because she had not felt a part of her grade level, she felt it would have been even more awkward interacting with people outside of it, stating, "If I was more comfortable with my grade level, I'd be more comfortable within the school." She explained, "I feel like the way Susan referred to me as the 'sub,' I kind of felt like that's the way Field Elementary referred to me." Molly came to feel that the smallness of Field made it hard to connect with others. This led her to again apply that label, "So, I just I feel like such a black sheep in that school."

Despite her reluctance to credit her teacher preparation program with anything positive, she did name a few aspects of her teaching that she was proud to say she had learned at the university. From her field experiences, she learned most of the education terminology she threw around now with ease like "IEPs" and "FBAs" and "differentiation," and most of personal her classroom management techniques, even though she struggled at times with remembering this. 
What she felt most comfortable and positive about were the CCSS, even though she was not in a grade level where they were required. She apologized for speaking so negatively about her preparatory program, stating, “Sorry. I feel like I’m like ‘ergh, MSTC!' I really loved MSTC, and I loved learning there." I replied that she did not need to apologize.

In discussing these connections, I asked her if she had again revisited her edTPA videos like she had described doing mid-year when she was at her darkest. She quickly responded, "No, because then I'd remember when I could have done anything I wanted to do if I had had my own classroom!" She paused and laughed uncomfortably and continued by telling me that what motivated her to watch the videos mid-year was that she was trying to clean out her computer, although this contradicted what I remembered her saying while fighting back tears in January. At the end of the year, she explained:

It's so funny because I felt like I had more say in what went on in the classroom when I student taught even though that was just as much of an already set-up routine as the things that I do in the setting right now.

Ultimately, Molly believed the whole year would have been completely different if she had been hired to be the actual teacher of this classroom, and Susan had had a less intense personality. Looking broadly at the whole year, she seemed now able to fully separate herself from it, explaining, "there was a possibility I could have come back. I mean I wouldn't have gotten it [the position], but yeah, now I can't wait to get out of here!" At the end of the year, Molly seemed able to see the year in full, reflecting on her overall feelings of discomfort and angst. However, what she described being most of proud of was the fact that she had survived her first year. She exclaimed, "I'm just glad I did it." Through all the ups and downs, in the end, she was still standing. She explained, "Professionally, I feel like I was able to juggle all the meetings I 
went to and the report cards and the assessments. I feel like for that piece, it was a lot of work, but I was able to do it." For her first year, she was excited to have had the experiences that she had lived through so she could talk about them.

\section{Beyond the First Year: "Hopefully, It Will Be Different."}

At Field, the following year, Allison was set to take Mrs. Thompson's/ Molly's position and Molly was moving back home. Motivating this decision was the fact that her boyfriend, Will, was also moving back to the Chicago suburbs to complete his own student teaching. She also planned to save money to pay off her school loans, and living at home would help this. She planned to help Allison move into this classroom over the summer, and "then I'm gonna be out of there!" Molly said this last sentence with glee.

In thinking about how much Molly had changed over this year, I shared with her some of her responses to my interview questions from the beginning of the year. When I read her the response she gave about whether she would accept a job at Field for the following year if they offered, she laughed heartily. She reasoned that at the time, "I think I was just keeping my options open." Because the Molly that I knew at the beginning had been sincere when she made those excited and impassioned comments, I silently disagreed as I nodded my head. She explained, 'I' $d$ rather be an aide somewhere, take an aide position, even if I don't become the

head teacher." She now knew that she never wanted to feel so uncomfortable in a position again.

Molly described the strangely supportive reactions her administrators displayed when she told them she was leaving. She explained that they were surprisingly positive even though she felt they had been so unsupportive throughout the year. Mrs. Stinson reassured her that she would be okay and offered to write her a reference letter. Molly was shocked at how candid Mrs. Stinson was with her at the end of the year. Recounting the experience, she explained that 
Mrs. Stinson had told her, “'Things are different in other places, Molly. You will not have all these struggles!'” With this statement, Molly realized that Mrs. Stinson truly had known how difficult it had been for her over the year, leading her to feel even more frustrated and hurt that the administration had not been more supportive. In the letter of recommendation, Mrs. Stinson wrote extensively about the fact that Molly was good at working with difficult people. About this, Molly explained, “It's awkward, but she's my administrator. I feel proud, but I shouldn't. That problem [issues between Susan and her] should have been alleviated in the beginning by administration — well, a combination of me and administration." She shared how weird it was to have her administrators apologize to her, and shook her head in disbelief.

At year's end, Molly explained that she had been applying "like crazy anywhere within an hour radius." Having attended Catholic schools growing up, Molly was open to taking a position at either a public or private school. She preferred a public-school position but was willing to take a Catholic school position for a grade level higher than preschool. One of Molly's biggest disappointments from her teacher preparation was how unprepared she felt for the various facets of preschool that she experienced teaching at Field. In many ways, she struggled with identifying influences from her teacher preparation throughout the year because she felt she did not have much to go on, explaining, "Now PreK is my life, and I just feel like I didn't get enough of that at MSTC." Molly believed that her preparatory program's lack of focus on preschool was because most of her early childhood classmates were focused on teaching in kindergarten $-3^{\text {rd }}$ grade. She now wished that she had received more preparation for the range of her degree taking place before kindergarten, as she felt that this may have helped her first year go more smoothly. She reasoned that she would want to continue teaching preschool, 
"Maybe if I had my own classroom, but I feel like I need a break..." Thus, she was actively looking for non-preschool positions.

This was Molly's first experience with filling out an extensive number of teaching position applications as she had not had to do this the year prior for either of her jobs. She described feeling overwhelmed by the application process because she was unfamiliar with the terminology they used, stating, “And so, just as I'm writing these things on job applications, and they ask, 'How do you feel about this, this, and this?' I don't know the terminology." She felt that in her preparation program, she had learned about interviewing, but after such a confidencecrushing year, she was missing the right terminology to use on job applications and in interviews.

With months passing, I had noticed Molly becoming shakier and less confident in my interviews with her. At certain points over the year, she described herself as anxious, and while I would never have thought this label applied to the firecracker I knew in my class years before, after observing her describe the deep stress she felt, especially mid-year, I could understand her self-assessment here. I truly believe that her first-year experience directly impacted her selfperception. Despite this, in May, she had already completed a prescreening interview in one suburban district, which excited her. She explained, "There are so many schools underneath one district in the suburbs. Even just talking to them-I was able to say the right words when I went to my prescreening interview, which is great." She was pleasantly surprised that the screening had felt so good.

Regardless of where she found a job, Molly insisted, "I'm hoping I'm somewhere where I don't need an aide." When I asked her what she would do if she found herself in a co-teaching setting again, she replied that she would be smarter about how to work with another adult. She 
jumped in, 'I think I would make a list of expectations and be like, 'this is...'-well, first I would feel it out." She explained that she would plan to communicate with him or her first and ask, “'On the off chance you can...can you help with transitions? Okay, well, I'm gonna have you at the carpet with her,' or something like that." These were ideas she had gathered over the course of the year feeling frustrated in her communication with Susan.

In the last interview, Molly described how her confidence had wavered over the last year. She explained, "I feel from not feeling confident leaving this school and to putting in my application out there to like a million places and not getting called back, has made me be like, 'What is wrong with me!?!' It sucks!' She rationalized what it might be like if she did not get a lead teaching position for the following year. She admitted that she would be sad if this were the case, but she would love to again substitute teach or be an aide, herself. Molly believed that becoming a substitute teacher that moved from classroom to classroom would help her regain her confidence in classroom management by exposing her to different classrooms, grade levels, and students. She explained that she loved watching other teachers teach and explore what strategies they use. About this, she stated, 'I'd love to sub because right now I'm so confused, and I don't know if I want to teach, but I feel like once I sub, I can gain more confidence and learn more about different schools." She continued, "I'll just pick up so many things if I'm trying to sub as much as I can...but I actually don't know if it'll help me out much.” Here Molly highlighted her confusion and uncertainty moving forward.

Molly was nervous about what the next year would bring, but she described also feeling excited that with a new job would come a fresh start. She hoped that with another year teaching in a new place, she would feel secure in her decision to become a teacher. About this, she explained, 'I'm trying really hard to not make my decision like, 'no teaching stuff for me.' I'm 
leaning towards it [not teaching], but I really hope that I change my mind because I loved student teaching." Knowing her as a teacher candidate and knowing the kind of teacher she was and could become, I also "really hoped" this. About her year of ups and downs at Field, she summed it up, stating, "I have a better resume now, and that's pretty much all I can say. Oh, and I'll have recommendations...I know what I don't want to do. So, there's that." Her flat-line delivery of this last line highlighted how far she had come from the bright-eyed, fiery, and excited new teacher she had been at the start of the year, and I could only hope that with time, this Molly would again resurface.

\section{Molly's Year, a Metaphor}

In reflecting on a year in her life, I see Molly's role at Field that year as one of a "quasinew teacher," not fully a teacher candidate, not fully a new teacher. The substitute position brought with it the chance for her to grow wings and explode into the field of early childhood like the little firecracker she was! Still, bigger forces of that year dimmed this light, shifted her self-perception, and left her feeling like the "black sheep" - at once present, but not a part of. If her first year of teaching was a main stage with all the players, conflicts, and plot twists of a comedy-drama, off to the side was her classroom community, in which the components of the PBIS framework that could have provided her with guidance and support were missing, and where traditional, behavioristic practices pushed back against humanistic tendencies. A focus on developing her classroom management took a backseat to the other dramas that played out in her first year of teaching.

If I were a gambler, I could not have bet that this was the way that her first year would go based on what I knew of her upon graduation. However, in retrospect, Molly's timeline of experiences leading up to her accepting the position resonated as harbingers of things to come. 
Her pleasing nature that deferred to authority, her cooperating teacher's "lone wolf" model during student teaching, the rushed and weird nature of getting hired at Field, the realization that someone else in her shoes had quit before starting, these all seem like red flags in hindsight. At the time, Molly did not reveal that she realized these oddities, nor did I. However, looking back, they become clear. Had I realized any one of these issues at the time, I should have stepped in, waved frantically, and pulled her out (of the position) or up (more in spirit). As such, her story of first year teaching has been a critical one to tell, as it whispers, shouts, and screams of conditions in which new teachers can find themselves and the roles that teacher preparers and administrators can play in affecting these. 


\section{CHAPTER VI: KRISTIN: SKINNER'S IDEAL}

With a laidback and confident attitude, Kristin Beiersdorf, the second case study participant, was self-assured in a way that was uncommon among the teacher candidates and new teachers with whom I typically worked. Kristin, a white woman of medium height with dark blonde, thick and wavy hair, was 22-years-old at the start of the study. She presented herself as someone who was not easily flustered, and her even-tempered spirit made her someone with whom it was easy to get along. Although Kristin was not a student of mine like Vanessa or Molly, I had the chance to get to know her through presentations I led for her and the fellow members of the student NAEYC organization and in various courses where as a guest lecturer, I presented workshops related to classroom management and community-building in the classroom. I knew her to be a responsible and dependable student, yet someone who exuded a surprising level of certainty, which did not always match her performance. Despite this, she did well in her courses and clinical experiences.

Although eligible to participate in the focus groups for this study, Kristin was unable to coordinate her summer job schedule to attend. I sought her participation after reconsidering her as a third participant for the case studies and based on the recommendation of one of my advisors. Growing up in the suburbs of Chicago, she explained, "I always knew I wanted to be a teacher." She had known that she wanted to teach since a young age. Because studying a foreign language was a high school requirement for Kristin, she decided to take three years of Spanish language instruction. Learning a new language led her to appreciate the ways that students learn languages and piqued her interest in teaching language learners in the future. 


\section{The Path to Become a Teacher}

She entered the university as a native student and knew from the start that she wanted to become an early childhood teacher. She continued her Spanish language learning by taking an additional semester of Spanish in her freshman year. So she could work with students who were learning a second language like she had done, she decided to pursue the English as a Second Language (ESL) endorsement with her teaching license. She was also professionally motivated to do this because she knew that earning this endorsement would aid her in quickly securing a job after graduation, as ESL teachers were in high need across the state of Illinois. Despite her coursework in Spanish through high school and college, at no point did Kristin describe her Spanish-speaking skills as proficient. Her ESL endorsement did not require knowledge of a second language, instead focusing on her ability to help learners learn English. Thus, a lack of proficiency was not a problem.

\section{Student Teaching}

Unlike the other two case study participants, Kristin chose to pursue the Professional Development School (PDS) model, full-year, immersive student teaching experience for the last year of her program. Because pursuing the ESL endorsement required more course hours and specific field experiences, Kristin spent more semesters at the university than Molly and Vanessa, and completed a PDS experience that was considered non-traditional. Typically, in this model, teacher candidates were placed in the same partner classroom for the fall and spring semesters of their senior year, so that they would be with the same classroom from the beginning of the year to the end. Due to the state ESL licensure requirements, Kristin needed a specific number of hours in the field with ESL students; in her words, "I think over 100 hours in ESL classrooms." She explained that securing a continuous placement within an ESL classroom 
locally was difficult as there were a limited number of second-language learners in the PDS partner schools at the time. Thus, instead of being placed in the same classroom for a year, she was placed in the same local public-school district for a year. For one semester, she was placed in a kindergarten classroom with English language learners (ELLs) at Auburn Elementary and for the other, she was placed in a $1^{\text {st }}$-grade classroom at Chestnut Elementary where there were no ELLs. About her unique PDS experience, she explained, “And so, even though they're...in the same district, they're both run differently. And so, I got to see different ways of doing different ideas." Because the PBIS framework was required at the district level, Kristin experienced its implementation at both schools.

Kristin felt very positively about her experiences in both placements. Although the experience of balancing her time in the field with concurrent coursework, and especially in a setting with students who were learning English, was challenging, she found the time very rewarding. She explained, "I feel like most people say the first year of teaching is the hardest year for them, but I feel like my hardest year was student teaching because I had that full-year. And so, I learned how to teach...” Kristin soaked up the practices she observed her cooperating teachers implementing, especially literacy practices like the workshop model and the use of clip charts to monitor behavior. She felt that she learned more about second language learners and how to teach them at Auburn Elementary than she had in any of her college courses. While she had heard from other teacher candidates about "drama" between teachers in their sites, in her placements, overall, she felt that the adult relationships displayed a strong sense of community. She described feeling respected while in these field placements, and she felt very comfortable to voice her opinions. 
A lasting piece of classroom management learning for Kristin related to the way that her cooperating teacher at Auburn had used a clip chart to monitor behaviors. Outside of this, she described very little about specific aspects of classroom management or PBIS within these settings. However, aspects of her easy transition into using the framework later indicated that the models she observed there were possibly helpful to her growth.

\section{On the Job Hunt}

Finding a teaching position was more important than its location to Kristin, which led her to cast her net far and wide within the state of Illinois. She applied to many different ESL and non-ESL listings and was invited to interview for four positions at various schools across the state over the summer following graduation. She described her most challenging interview after graduation as one that was for an ESL position where all the interview questions centered on her ESL skills, about which, she felt less than confident. This was in part due to her feelings that her ESL coursework at the university had been less helpful than her other early childhood coursework. She described taking the majority of her ESL courses in the English department, as opposed to within the education department, where she felt they were completely unrelated to teaching. She explained, "I learned how to teach ELLs from being with the ELLs in my placement at Auburn, but not so much in the English classes." What she had learned, she felt was limited.

When she was then invited to interview for a kindergarten, ESL position at Monroe Elementary, a public school in Fayette, a small town in rural, north-central Illinois, she felt "pretty confident" in her ability to predict and respond to related questions. With the invaluable feedback gained from her tough ESL interviews, she had honed her responses. The interview process at Monroe was a team affair. For the first round of interviews, the interviewers included 
the principal, Mrs. Buchner, the assistant principal, and three of the Kindergarten teachers. The position for which she was interviewing was a new position at Monroe, the teacher of a full-day kindergarten ESL classroom, for which the state's board of education required someone with an ESL endorsement to teach. The population of English language learners (ELLs) at Monroe was steadily increasing each year with increased numbers of migrant workers for the large farming community around Fayette, and there was a need for this classroom.

While she struggled to remember the interview questions she had been asked once the school year began, she remembered feeling comfortable with the fact that there were so many team members in on the interview. She described the team of interviewers at Monroe as being very "friendly." About her classroom management, she remembered, "they asked me pretty generally about classroom management — what I think worked well and how I would want my classroom to look." They also asked her about how she would build a classroom community. She felt comfortable responding to this line of questioning because she had observed and taught in many different clinical classrooms in her time at the university. She described, "So I had seen multiple, different ways to do classroom management. And so, I knew what really worked well for me." From seeing some systems that worked and others that did not, she felt very confident that she now knew how she wanted to approach her overall management. Lasting about an hour, she felt the interview went very well.

By the end of the week, she was invited for a second interview that was again with a team of Monroe educators. Her confidence was heightened because, "I knew they liked me. So, that helped." Her confidence paid off because from this, the Monroe administrators offered her the position, and she gladly accepted it. One of Kristin's references, her student teaching cooperating teacher from Chestnut Elementary, called to congratulate her and shared the Fayette 
director of curriculum and instruction had called her to discuss Kristin's qualities. He told her that Kristin was more proficient than many of the tenured teachers who had interviewed within the district before. This news made her feel very proud.

\section{The Context of Kristin's First Year}

It was the end of June, and the school year was set to start near the beginning of August. So, Kristin excitedly moved from her suburban Chicago hometown to the town of Fayette, where Monroe was located. She was happy that a MSTC classmate and friend had also been hired at Monroe for a maternity-leave position. They decided to share rent and moved into an apartment together not far from the school. She was nervous, yet excited to be starting this next chapter of her life with her friend in a new town.

\section{Kristin's School Context}

Monroe Elementary, a Kindergarten through $5^{\text {th }}$-grade elementary school, was situated in the small, rural community of Fayette, Illinois. Historically, Fayette had been a mining and farming community, and in recent years, the town's population had shifted to include an increased number of Spanish-speaking migrant workers. With a population of just under 10,000 people at the time of the study, it was considered a big town compared to other smaller communities near it. There was a wide variety of shopping and restaurant options in the area. Monroe Elementary was one of three schools in Fayette Elementary District \#89, along with a state-funded preschool and a junior high. A large, one-story, building, the school was situated in a neighborhood of one-story ranches and cottages. With dark wood paneling and sharply-angled sides, the architecture of the school hinted that the building had most likely been built in the 1970's. The main door to the building was on the opposite side of the building from the staff 
parking lot, but there was guest parking near the front door. A large playground was connected off the back of the school with large yards on each side.

Serving around 600 students, Monroe represented the diversity that was evident in Fayette. Although only $15 \%$ of the local community was considered Hispanic, with the racial make-up of the population, predominantly white, Monroe's student population was $30 \%$ Hispanic, $60 \%$ white, $5 \%$ black, and 5\% mixed races in the year of the study. See the specific demographics of the school in Table 1 of the third chapter. The Fayette Falcon mascot stood to represent all schools in the district. Monroe's school website was housed as a link on the larger district's site and included basic information about the school, a welcome letter from the principal, and links to teacher pages. Students feeding into the Kindergarten came from the district preschool program, a local Head Start, and a few local childcare centers.

\section{Community, classroom management, and PBIS at Monroe Elementary.}

Kindergarten at Monroe consisted of five different classrooms with Kristin's classroom being the fifth for the first time that year. She was the only new Kindergarten teacher that year, although there were a few other new teachers in other grade levels. Although there were very few schoolwide faculty meetings held at Monroe, grade-level team meetings were held weekly. Schoolwide communication was primarily through email, and throughout the year, there were early dismissals on Wednesdays when the teachers participated in professional development. During this time, teachers would meet as “a committee, or sometimes it's grade level, or K-2, or sometimes someone comes in to teach us something." Thus, Kristin explained, "some people I

know better than others." Despite this, she felt that there was a feeling of community at Monroe because everyone had a strong community within their grade-level teams. 
At Monroe, there was a commitment to both the families within the school and a feeling of a family while in the school. Because of the large population of ELLs at the school, the administrators created an ELL parent/ teacher advisory board, of which six of Kristin's students' parents were members. The board met regularly, and she explained, "They get to talk about what they want to see in our day, and I'm there so I can say, 'okay.'” Mid-year, the parents decided to start a Spanish Club at the school to encourage bi-literacy. This optional club would be a place where the parents could "teach the kids how to read and write in Spanish," as Kristin said, "because I can't teach it!" Unflustered by this, she thought it was a great idea.

Like for Molly at Field, a cross-grade book buddies program was established at Monroe. A $5^{\text {th }}$-grade class partnered with Kristin's. She described how much her students loved this partnership, and I observed it one day when she told them, "Boys and girls, if today is Wednesday, then we have P.E.! So tomorrow, we'll have book buddies!" Many of her students shouted out with glee and gave each other high-fives. The fifth-grade teacher used "helping Miss Beiersdorf's students" as a reward for good behavior, so there were often $5^{\text {th }}$-graders volunteering in her classroom in the afternoons. $4^{\text {th }}$ - and $5^{\text {th }}$-grade volunteers served many roles at the school, and each afternoon an older student would come to pick up the recycling bin.

The school welcomed volunteers of all ages and sizes. Community volunteers, estimated to be in their 60's and called the "Monroe Grandmas," volunteered in the building daily. They read to students, brought in art to discuss, and helped in various other roles within the building. The students adored them, and the women were always smiling. There was a feeling of care for these extended members of the Monroe family. In Kristin's classroom, the art teacher was one such "Grandma." The students called her Grandma Alice, and at the end of the year, I observed 
her bringing the students a surprise gift. The students ran to hug her, and Kristin shared that the teachers appreciated these "grandmas" and the help they offered all year.

Kristin's familiarity with PBIS from her field experiences at the university, made her aware of the fact that Monroe was a school also using the PBIS framework. Although Monroe offered no training regarding the framework for new hires, the information for how PBIS was implemented within the larger Fayette district was located on the district's website under a PBIS tab. This page included much more information than Molly's school and district provided about the framework. Here, one could find general information from the Illinois PBIS Network about the network itself, the framework, its outcomes, and its goals. This general information was made more specific by the addition of a link to a parent informational flyer. The flyer laid out the details of the framework at the Fayette schools including the district-wide expectations of "Respect Yourself, Respect Others, Respect Property, Ready and Here" in English and in Spanish with explanations for each in English and detailed specific components at Monroe. These components included "Doozie Dollar" rewards, which were tickets given for desired behavior, "Dooziest Dollar" rewards, which were more infrequent sponsor coupon tickets rewarded for consistent positive behavior, and the "Doozie Cart," which was the rewards cart where students could purchase items with their Doozie Dollars, more commonly known as "Doozies." Additionally, at Monroe, "Cool Tools," which are the oft-used PBIS term for behavior lesson plans, were communicated through morning announcements, and served as the school-wide teaching of prosocial behaviors.

Monroe also held regular school-wide celebrations to improve student motivation and celebrate growth. The district's website included calendar announcements about PBIS scooter races, PBIS fundraisers, and PBIS movie nights amongst other events. However, at no point 
across the year, when I asked Kristin about the school-wide aspects of PBIS at Monroe did she mention these celebrations, leading me to question whether she connected them with the school's larger framework. Near the entrance of the school, there were multiple awards highlighting that Monroe was a "PBIS-Recognized School," earning the gold rating from the Illinois PBIS Network in the 2013-2014 school year. Here, the framework took on the role of an organization in the way it was applied and labeled for various facets of school functioning. I often heard teachers referring to the framework in form of a noun, such as, "Hmm...I think we need a PBIS for how to stand in line!" or "Remember that PBIS has a fundraiser coming up." As such, the framework was deeply embedded within Monroe Elementary.

Kristin's co-workers. Like Molly, Kristin worked directly with a para-professional in her classroom daily. Maria Elizalde was a Hispanic woman in her mid-40's who worked with Kristin and her ELLs at various points throughout the day. As a fluent Spanish speaker, she often served as a translator for Kristin during parent-teacher conferences. When she was not in Molly's classroom, she was teaching in the other ELL classrooms at Monroe. She always entered the room with a smile, and she and Kristin seemed to get along great throughout the year. In a stark contrast to Molly’s experience with Susan, Kristin explained, "Maria's happy to do anything! She's great to work with!” Kristin was very appreciative of the support that Maria provided, especially at the beginning of the year and when working with parents. Throughout the year, their relationship blossomed, and by the end of the year, Kristin described to me how she was planning to utilize Maria more as a co-teacher, rather than an assistant teacher in the following year.

Another striking difference between Kristin and Molly related to the ways each felt about their grade-level teams. Whereas Molly did not always feel supported or valued by her team 
members, Kristin felt oppositely about her large grade-level team. Very early on, she felt that the team of more veteran Kindergarten teachers, Ms. Malloy, Mrs. Ryland, Mrs. Beam, and Miss Williams, took her under their wings. She explained, "My little team is wonderful!" They had all been teaching at the school for many years, and she turned to them for support throughout the year. Meeting weekly on Mondays when they had a shared prep period, as well as sitting together at lunch, Kristin quickly felt a part of this team. Eating lunch with her in the staff lounge, I observed the camaraderie that these teachers had with each other and their extended team members, like Maria. They were a gregarious bunch, loudly laughing, passing jokes, and jumping from topic to topic easily, and towards the end of the year, I saw Kristin join in easily. Contrasting with Molly's experience, this team provided Kristin with more peace and happiness than stress. These teachers developed a rotating chart for recess duty and helped each other to make worksheet copies. Especially in the beginning, Kristin appreciated this support. A highlight of Kristin's first year was the kindergarten conference that her team members selected her to attend, making her feel very special. While they had shared responsibilities, they did not rigidly co-plan instruction, which Kristin appreciated. Mid-year, she described using a new planning form for her writer's workshop, but shared that she probably would not bring it up at her grade level meeting because, "They know that I do things differently with ESL. They just like to do things their way." This was okay with her because she wanted to be able to adapt her teaching for her students.

Like Molly, Kristin was not assigned a mentor within her school or at the district level. However, her approach to address the lack of mentorship was very different from Molly's. To her, mentorship “was just something they didn’t provide, so I found it myself." In the beginning, her solution was to seek out her grade-level team members for support. She explained, 
“Anything I need....any questions I have, they're there." Because of how available they were to her, she said, "I feel like have four or five mentors rather than one!" While they were always encouraging and willing to help, Kristin felt, "It would have been more beneficial to have one person to meet with "weekly/ bi-weekly, so that I could run by what I'm struggling with." As time passed, she realized that she needed more of an individual coach or mentor.

She found more of the support she was looking for in another teacher, Danielle Hoffman, Monroe's ELL teacher, with whom she co-taught. Danielle supported all the ELL classrooms at the school, including Kristin's. With daily co-teaching and weekly planning sessions, they realized they had a lot in common and formed a fast friendship. Although Kristin joked that Danielle was old enough to be her mom, she appreciated that Danielle was so knowledgeable about the CCSS. Just as Molly did, Kristin felt very confident with using the CCSS and did not feel like others at Monroe did, even on her grade-level team. She explained, "her [Danielle's] brain thinks in Common Core, and I don't feel like anybody else's does!" She appreciated that Danielle knew her students well and offered her concrete tips for improvement. Additionally, she shared, "when she teaches my class, I can...take back things from her and...do it...I see her teach, and I'm like, 'That's how I want to teach.”’ Mid-year, they attended a bilingual conference together, which strengthened their relationship. Kristin felt both positively challenged and supported by working with Danielle. She explained, "We have a good relationship." As their relationship grew over the year, I observed a positive correlation with Kristin using more developmentally-appropriate instruction for her kindergarteners.

Kristin also described having several friends in the building with whom she had great relationships. First was Haley, her roommate, in a second-grade maternity-leave position. She also developed a close friendship with Beth, the teacher of her class' fifth-grade reading buddies. 
Also, new to Monroe, she and Kristin got along great. By mid-year, she explained, "we're good friends." I also observed very positive interactions between Kristin and Mr. Butler, the P.E. teacher. It was clear that she felt much more a part of the larger school community than Molly did.

While I did not often interact with them, Mrs. Buchner and Mrs. Brady, Monroe's principal and assistant principal, provided me with easy access to work with Kristin. Although Kristin rarely brought them up in our conversations, I learned that Mrs. Buchner evaluated her teaching several times over the first year. It was clear that Monroe's administrative team supported their teachers' professional development at the school, as the administration provided substitutes for the multiple conferences that Kristin attended, established the team culture with the Wednesday professional development meetings, and they required teachers to create an evidence binder. Late in the year, when Kristin was sharing with me photos of her students in a community performance that she coordinated, she exclaimed, "This whole thing was just so neat! It is also really good for my evidence binder!" This binder served as a place to document her accomplishments and growth and Kristin described it being used for her teacher evaluation.

Although she did not share administrative issues or complaints, she revealed feelings of confusion early on. She explained, "Everyday I'd find out something new that they should have told me, but once the school year got going, it didn't matter as much because I knew what was going on." Kristin knew that her administrators were aware of the mentor-mentee relationship between Danielle and her, and she shared that "if they gave me a different teacher as my mentor, that might not have meshed as well." However, while she loved this relationship, when I asked her at the end of the year if she wished the school would have assigned her one, she replied, 
"Yeah, I wish they did." Despite a few issues throughout the year, working amongst these adults created an atmosphere in which Kristin was happy to work for her first year.

\section{Kristin's Classroom Context}

Kristin's classroom was positioned in the Kindergarten and first grade hallway, down several hallways from the main entrance. On the way from the school office to her room, I passed many different PBIS and Monroe community-related posters and signs throughout the year. These included huge black and white photos of the "Monroe Students of the Month" near the front of the building. In these images, students of all ages posed smiling on the school's playground equipment with their arms slung over each other's shoulders. Being welcomed into the school by these happy and friendly faces was very inviting. Throughout the year, hanging in the hallways were also informational posters about the PBIS rules, competition posters for school fundraising related to PBIS, and limited student artwork.

The kindergarten hallway had low ceilings and dark floor tile and was flanked by wooden student cubbies on both sides. There were windows into the classrooms along the upper walls of the hallway, but most were blocked with storage boxes and other teacher materials from the inside of the classrooms, making them impossible to peer into. Kristin's room was difficult to identify until midway in the year when she finally received a nametag on her door like the other teachers in the hall. Tucked between hanging student cubbies and amidst lots of decorations midway down this hallway was Kristin's classroom. Unlike the low ceilings of the hallway, Kristin's classroom had a high ceiling and was brightly decorated. Directly upon entrance, there was a bathroom with a toilet and sink to the side. Low orange counters ran along the wall that was shared with the hallway and brightly colored curtains hung below this counter, blocking hidden classroom storage underneath. The wall opposite this was flanked by similarly-sized 
shelves that rested under rectangular windows. These were covered with materials, boxes, bins, and tubs that blocked much of the outside light.

Kristin described how setting up the classroom environment was the hardest part of the start of the year because, "it was a complete mess." She exclaimed that I would have to see photos to believe her because, the prior teacher had left "stuff that had been there for 100 years!" Kristin felt challenged by having to go through everything and deciding what to keep versus throw out. She explained that just when she had figured out a good configuration for the furniture and materials, she would realize that she was "covering the vent, and I have to start all over and redo it." She explained that it took her a month before the school year began to go through everything and to finally get her own materials organized. Upon my first observation, she was so proud to walk me around and highlight the various spaces that she had painstakingly set up.

There was a large, brightly colored rug near a SmartBoard in one corner of the room, along with a teacher easel and adult chair, making this the main teaching and gathering area. A variety of tables were positioned in the classroom with a circular table near the front, a beanshaped table at the back, five rectangular, student work tables configured in the middle of the room, and a long rectangular table holding four very dusty black personal computers in the back. Anchor posters and informational materials hung throughout the room. A number line and alphabet were hung high on the walls, wrapping around the room, and a small word wall that was slowly filled with new words as the year progressed was displayed above the front boards. Near the SmartBoard hung a large calendar and day-of-the-week display. Hanging next to this was a number chart with number flashcards in its pockets. A behavior clip chart was hung front and center and other posters relating to behavior hung around the space, which highlighted the 
important role her classroom management decisions would play all year. At the start of each day, all students' clothespins were clipped to the green rectangle that was labeled, "Ready to Learn." While this was easily seen when in the middle of the room, when students were seated at the largest rug, which was where they spent most time seated on the floor, it was nearly impossible to look directly to the right and see the chart, which created problems all year.

Several reading strategy posters hung at the back of the room, along with a display of students' birthdays. On the student tables, large nameplates filled with lots of academic supports were taped down to establish assigned seats, amidst other loose materials like pencil boxes. Typically, a worksheet would be laid out every morning at each of the spots, and the tables would be cleared and ready for students. Book bins lined the shelves near the windows. A line of construction tape was taped to the floor from the doorway into the middle of the room, designating a place for students to line up. The bean table at the back of the room served primarily as Kristin's desk, but was also supposed to be for leading a guided group. On this table, there were often stacks of materials, manipulatives, and worksheets, leaving very little space to do so. Although I did not see Kristin use this table to lead a guided group on any of my dates of observation, I did observe her assessing students one-on-one there on several occasions. There was a small, plastic store window display in the back corner used for dramatic play near a small colorful rug with a bean bag and plastic cube chairs on it. Another small rug was just through a set of shelves from this space and was primarily a space for students to use Legos and other small manipulatives. Figure 11 illustrates an aerial view of her room arrangement. 


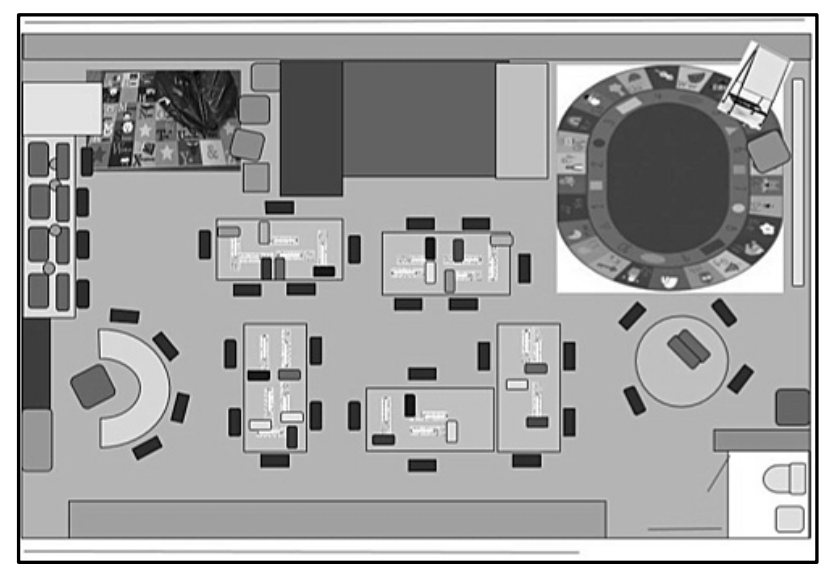

Figure 11. Kristin: classroom map (11/14-5/15).

Throughout the year, Kristin's room arrangement stayed consistent. Missing from the classroom were centers or displays that one might expect in a Kindergarten classroom, such as a science or social studies center or sensory tables. In addition, while there were bins of books on a few shelves near the teaching easel, I did not observe a large, labeled library that one might also expect. The more that I was in this Kindergarten and first-grade hallway, the more it seemed that Kristin's classroom environment was very much like all the rooms in this wingstocked full of brightly-colored materials on the floor, tables, and walls, with multiple stacks of materials on various surfaces. Very little student work hung on the walls of her room or the others', making the spaces seem somewhat impersonal. This would be her home for the year.

Kristin's students. Kristin was the only case study participant who worked with the same group of students for an entire day. Her classroom was comprised of 21 total students, 12 girls and nine boys. All Kristin's students were considered ELLs. Twenty were Spanishspeaking and one spoke Albanian. They varied in how much English they understood and spoke in the beginning of the year, from little to none for Nicolás and Mateo, to Veronica and Arlinda who were fully bilingual. Ten of her students had attended the Fayette preschool the year before, 
and a few had attended the local Head Start program. However, for the remaining students, her classroom was their first school experience. Those who had attended the Fayette preschool had experienced dual-language instruction where half of the day was spent in Spanish, and the other half in English. Although they received language supports in Kristin's class, the dominant language of instruction was English. While several terms can be used to describe school-age students who speak another language and who are learning English, the two that Kristin most often used when referring to her class and language support at Monroe were "ESL" and "ELL." Moving forward in this chapter, for consistency I will use the term "ELL" to refer to this language dimension of her students, and Kristin will use "ESL" to describe her endorsement title.

Addressing the language differences amongst her students was Kristin's biggest worry in the beginning. With three years of high school Spanish and one semester-long college course, she felt very limited in her ability to translate so that students would understand. She explained, "I know...very basic vocabulary. And so, I never speak in...full sentences with them, but I'll translate...the main words to get the concept across." She shared one anecdote, which she found funny:

I had student, one in particular-I would talk to him in English. He would talk to me in Spanish, and we could understand each other. We both knew enough...but we couldn't speak to each other in the other language...So, it was cool that it worked, but it was just like, 'oh, my goodness, how is this going to work with...teaching them content when they can't have a conversation with me?

Her worries quickly fell away because her students began understanding English quickly. Within a few months, she explained, "They're all speaking English, and a lot of their stories are better now in English than they are in Spanish!" She was proud of the fact that her Albanian- 
speaking student was becoming trilingual because she was also learning Spanish from the others. By the middle of the year, Kristin became a language advocate for her students, slightly changing her curriculum and improving her practice through collaboration with Danielle.

Like Molly, Kristin had genuine love and affection for her students, and she focused in the beginning of the year on developing relationships with each of them. In observation, I noticed her standing at the door in the morning greeting every student with a "hi," "how are you," and throughout the year, I observed her receiving many hugs and high-fives from them. She had a natural rapport with the students, and mid-year, she exclaimed to me, "I love them!" After the school breaks, she shared that the students upon return would say, "we missed school! I missed you!" This always brought a big smile to her face. By year's end, she shared how much she appreciated their different personalities, and what these brought to the classroom.

Possibly more than her love for them, Kristin's students loved her. Throughout the day, I heard her name called for her attention more than either of the other two participants. This was in part because they craved her attention, and also she did not consistently empower them to independently resolve conflicts. ““'Miss Beiersdorf, did you know I can run really fast now?” "Miss Beiersdorf, my pencil is not sharp." "Miss Beiersdorf, look at what I did!" "Miss Beiersdorf, did you see my new shoes?" As many of them spoke English with accents, the enunciation of her name's syllables was very sweetly pronounced, "Miss By-er-dorf!" About this, she laughed, "Yeah, they're crazy." This friendly group of students warmly welcomed me into the classroom and more than in either of the other two participants' classrooms, they would have questions and comments for me each time I visited. "Who are you?" "What are you doing here?" "What are you writing?" “Ooo, I like your earrings!" This was partially because Kristin 
did not formally introduce me to the group until later in the school year, and it was hard not to smile when amongst them.

Kristin's daily schedule. The Monroe school day began at 8:15 a.m. and ended at 3:00 p.m. on every day but the occasional Wednesday, when they let out for teacher professional development at 2:00 p.m. Kristin typically arrived by 7:45, her students around 8:00. While Kristin sent me a classroom schedule early into the school year, changes were made as the year progressed. It was difficult to follow along in person, because like in Molly's classroom, Kristin had no posted schedule for visitors like me, but more importantly, for the students. As such, this was not in line with what they had both learned in college, because I knew that the content of their required courses included learning about the need for posted schedules with young learners.

Kristin described her daily schedule as "pretty set from the beginning." She explained that this was in part because she had to accommodate one student, Nicolás, who began the year receiving inclusion minutes in another kindergarten class every morning. Additionally, because the teachers at Monroe tended to use several scripted curricula across the grade levels, including kindergarten, she explained that the structure of her day was "pretty much written into our curriculum." Another possible reason was the nature of scheduling lunches, recesses, and specials, such as P.E., music, and art, for the whole school, including common times for kindergarten. Kristin was the only participant whose students received these "specials." She explained that art and music class were pushed in to her room, stating, "It would be nice if they had a room, but we don't have rooms in our building." During this time, she either had her weekly meeting with Danielle, “or I can get copies done.” Throughout the year, during P.E., she would pull a few students out of class to assess, as she found that this was a good time to conduct one of the many assessments that dominated her instructional time. 
The morning hours consisted of "morning work," which was typically math worksheets laid out at table spots for completion as students put their things from home away, and Kristin reported attendance. Morning announcements came through during this time, but usually her students did not seem to pay them much attention other than to stand for the Pledge of Allegiance, which they mumbled through for a good part of the year. Kristin explained, "I don't think they know what it means, but they know what the vocabulary words are." Next came calendar time, which was not quite a circle time nor a morning meeting. Instead, she would review the day of the week and make a few announcements, and then they segued directly into math, as they counted how many days they had been at school and found numerals on the number chart. From math, they moved to vocabulary/ phonics time, and then literacy centers took place. Around 10:00 was the first time that the students were not in whole group instruction, as literacy centers were conducted in small groups. The block of time for their "specials" followed literacy centers, and then they went straight to lunch and a "mini-recess" from 11:00-11:35.

In the afternoon, Kristin's schedule had a few features that were distinct including a scheduled rest-time immediately following the mini-recess. She explained that because her students were a bundle of energy after lunch, this rest-time was a regularly-scheduled time of day. This feature is something that one does not always see in the fast-paced world of kindergarten today. Following this was another block of literacy instruction that included the Words Their Way program or reader's workshop, and writing workshop immediately after. It was not until an hour and a half later that the students were not in a teacher-directed activity, and they would often explode into their 30-minute recess block. Weather-permitting, this was outside, giving Kristin a prep period. However, in inclement weather, which was most of 
January-March, they had indoor recess. When Kristin had recess duty, this was an intense block of time for all involved, as she would have upwards of 39 students in her class playing in the various spaces around the room. This was a challenge to her classroom management skills and her sanity. From 2:00-2:20, her students received targeted ESL instruction with Danielle, Maria, and Kristin team-teaching when they were all present, or doing worksheets when Danielle and Maria were absent due to ACCESS testing taking place in the school, which was common.

The other distinct feature of Kristin's schedule was a 25-minute block of center-time that took place after ELL instruction. Kristin explained, "from 2:20 'til we go, they get to play.” As students completed their ELL work, they were free to play in the various centers around the room. Throughout my observations, none of the centers, nor the materials within them, changed from what I could observe. This was one of the only times of day where students were not teacher-directed, and they flourished despite the stagnancy of materials. While it was wonderful to see a "playtime" in today's Kindergarten, many students in Kristin's class were unable to play during this time. This was because they would either be still working on the ELL activity because it was too difficult for them to complete earlier, sitting out, as missing center-time was a punishment for being moved down the clip chart, or being pulled for assessment with Kristin or another teacher. Many of the students who missed out on center-time were students for whom self-directed play would have been most beneficial. However, Kristin did not seem to make this connection and instead explained, "especially at the end of the day, they're just playing or whatever. So, it's...the perfect time for them to get extra support." Clean up began around 2:45ish, and the bells for student dismissal rung at 2:50 for bus-riders, and 3:00 for everyone else. Often, if the room was picked up, and they were packed up quickly, she played a short literacy-focused movie for them to watch on the SmartBoard. 
While there were a few changes to the schedule over the year, it remained pretty consistent. She told me in the beginning that social studies and science would alternate with reader's workshop, but by year's end, I never observed her teaching these subjects. She admitted, "That was practically nonexistent." Additionally, it was not until the end of the school year that there was something akin to a morning message or true welcome to the day during "calendar" time. Literacy instruction in the morning was the only time of day where Kristin consistently taught through a small-group format. Outside of recess and center-time, the rest of the day was teacher-directed, large-group instruction. Because of this, Kristin layered in multiple "brain breaks" throughout the day that consisted of stretching and other exercises.

To an outsider, her schedule seemed very choppy and worked against her ability to establish a sense of community. In observing Kristin's students, they seemed to feel similarly, especially related to transitions and punishments taking away from critical times like recess and center-time. Throughout the year, without a visual timer or reminders related to how much time students had left for tasks, Kristin tended to abruptly end activities, saying, “Alright, alright! Time is up!" and continue to move on. Doing this, consistently led to groans from her students, and "hey! I'm not done" comments. Additionally, her timing slowed down transitions because inevitably, without warning many students ignored her next direction. Transitions within activities also seemed disconnected as Kristin often taught mini-lessons that were disconnected to the following activity, leading to confusion amongst her students. With her students leaving the room to receive specialized services, getting pulled by teachers to be assessed, and moving from room to room for indoor recess and inter-grade groupings mid-year, many more transition issues surfaced. At times, when students re-entered the space, they quickly rejoined the group, 
but often, they would stand confused for several minutes before rejoining the group, leading to missed learning opportunities and a feeling of disconnection, not community.

Another reason the schedule felt disjointed was because while Kristin tended to be prepared in the morning with the position of the clip chart clothespins and the day's worksheets, in other ways, she was unprepared with materials, leading to wasted instructional minutes. A consistent example of this related to the technology in the classroom. I encountered multiple times when students had to wait because she had not prepared the teacher's computer at the front of the room, which she used to report for attendance. Additionally, on every date of observation, the student computers, were asleep, had no specific activities set up when awoken, and needed updates when students went to use them during literacy centers and center-time. As a result, students often wasted time either sitting and waiting for Kristin to fix them or taking time to try and find her to solicit help. Ultimately, Kristin's schedule had a strong, and at times, negative, impact on her teaching and classroom management throughout the year.

Kristin's teaching. Of the three case study participants, Kristin's classroom management and ability to build a sense of community was the most impacted by her teaching methods, which underwent the most improvements as time passed. The teaching norms at Monroe Elementary that year highlighted a dependence on scripted curricula and traditional, didactic, teaching practices. For example, there was as a big school-wide emphasis on the use of direct instruction and worksheets, which played a big part in shaping Kristin's teaching across her first year. School-wide, consistency amongst teachers at grade levels was highly stressed, which in turn, meant that her grade-level team had a big influence on her teaching decisions. While Kristin did not speak about the CCSS as passionately as Molly did, over the year, I learned that she, like Molly, felt driven by these standards as this was how they had been 
prepared at the university. However, these standards did not seem closely connected to the scripted curricular choices used at Monroe.

Kindergarten-wide, the teachers used a scripted curriculum for math and phonemic awareness instruction and a grade-level-consistent format to literacy centers, as well as components of Lucy Calkins' Units of Study (Calkins, 2003) for writing workshop. Kristin explained that the math curriculum, Saxon, was "mandated by the school, but they [administrators] said we're allowed to supplement," because it was not yet aligned to the CCSS. I often observed Kristin teaching with a teacher's guidebook on her lap or in her hands, and I noticed one effect this had on her students when they would mimic the way she positioned the phonemic awareness instruction spiral notebook on her lap to review letter sounds while they played "school." Within the larger school, I observed others using teachers' guides and scripts as they were teaching. At one observation, Grandma Alice, their volunteer art teacher, read the entire art lesson from a scripted packet. For social studies and science, Kristin explained, "We don't have anything for kindergarten; we just use our own theme stuff." However, these two subject areas were rarely, if ever, taught, which she acknowledged at year's end.

The scripted nature of these curricula and grade-level curricular decisions seemed to also impact how Kristin planned for her instructional delivery. Early into the year, she indicated that "math is pretty much all whole group," as mandated by Saxon's curriculum, "reader's and writer's workshop is always a mini-lesson," which was also delivered in a large-group format, and because her grade-level team wanted small groups for literacy centers, this is what she did. Throughout the day, students' seating varied from sitting on the main rug, to sitting at their table spots, and while they may have had some differentiated materials, such as vocabulary sorting activities, the prominent format of delivery was to the whole group. I observed Kristin 
delivering instructions while the students sat at their tables poised to all begin the same task multiple times a day over the year.

At Monroe, there was a culture of teaching from worksheets, which I realized after Kristin mentioned getting copies made multiple times, and because every time I passed the large copier in the nearby hallway, I observed at least one teacher there making copies. In her classroom, there were often multiple stacks of copies on her bean table each morning when I would arrive, and I observed her using between five to eight different worksheets copied from either her teacher guide book or purchased from the website, TeachersPayTeachers.com. Of the worksheets that I observed students completing, very few targeted higher levels of thinking, were related to mini-lessons Kristin had just taught, or were explained in detail, and most were completed as a whole-group. Kristin did not describe, nor did I observe, much in the way of her teaching prosocial skills, especially skills of self-reliance, so coupled with these other conditions, many issues of a high dependence on Kristin, confusion, and off-task behavior surfaced, which led to frustration on Kristin's end and an increased use of her behavior management system over the year.

Literacy centers provided a brief respite from this by the nature of their small-group format, which incorporated two teacher-led stations, and two independent stations. Language and literacy instruction, in general, was a dominant feature of Kristin's day, which is not uncommon in kindergarten classrooms. Early on, she shared that "I was really excited to share...books that I loved and like to read aloud and to get them excited about reading." Having explained to me that reading was her favorite subject to teach, I was very excited to see her reading aloud. Yet on my days of observation, in total, I only observed her reading two short books aloud to the whole class, although there were countless opportunities for books to be read. 
The disjointed nature of literacy instruction with literacy centers in the morning and reading and writing workshops in the afternoon added to a feeling of choppiness in the day. Additionally, the format of the workshops was inconsistent. At times, Kristin delivered a mini-lesson and related activity, but often this was replaced with more vocabulary word sorts or sight word activities. Kristin also used the Words Their Way word study program, initially on her own in place of reading workshop at times, and then mid-year with the larger grade level. This program in her classroom involved her assessing students' vocabulary needs and planning specific word sorts for students to practice, based on these assessments. On my observations, students would engage with word sorts like this at multiple points in the day, and they always involved a significant amount of cutting and pasting. For some students, more energy was spent on these tasks rather than on sorting the words, leading to off-task behavior, confusion, and other behavioral issues. Kristin explained that much of her focus on language and literacy was because her students were ELLs. At Monroe, most Kindergarten bilingual students and dual-language learners were placed in Kristin's ELL-only classroom, with a few more fluent-speaking English students in other classrooms, but when they got to first grade, they were included in the general education classes and received pull-out support. Where Kristin deviated in instruction from her grade-level team members related to her students and their language needs. She explained, "At the beginning of the year, the other classes did literacy centers, but my classes were not ready for that. They needed vocabulary instruction." After attending multiple conferences and with support from Danielle, she altered the literacy centers to include a guided reading small group. She credited learning about this to one of her literacy professors at the university, and the exact format she used from a student teaching cooperating teacher. As her relationship with Danielle grew, she began to implement other visual supports within her lessons such as a planning form 
for students' writing, where before she had none. About breaking away from her grade-level team with these practices, she felt okay, stating, "But I feel like guided reading was important, and so I wanted to have that. I want to do what these kids need, and since they're ELLs, some of the things they need are different." She felt supported by Danielle in making this decision.

Like Molly, her biggest source of pride was when she saw positive effects of her teaching. Every time we connected, Kristin was excited to share what her students were then doing, such as in the fall, when she explained, "now, what I'm most excited about is writing because now they're learning their letters and sounds, and they're putting sounds together to make words, and it's so exciting," or at the end of the year, when she exclaimed, "They came in, they could count to 10 . They didn't know any letters. They didn't know any shapes, and now they're reading!" She observed growth in every aspect of their development across the year, and this made her so happy. Illustrating the ultimate teacher highlight of when a student transfers learning across contexts, in the spring, I overheard one little girl as she entered the classroom, excitedly announce to her, “Miss Beiersdorf, I helped a girl learn!” Kristin's response was genuine, and as she high-fived the little girl, she said, "Wow, that is so great!" Over the year, she developed so much pride in their growth and the people they were becoming.

Some of the strongest aspects of teaching that I observed from Kristin across the year, and where most of these gains were made, were when she broke from the scripts and the Monroe norms. She agreed, stating, "math doesn't teach 'em anything in Saxon," and "the reason that they don't have very many [words] is because I was just following the curriculum." When she broke away, students were more engaged, and there were fewer behavioral issues, which led to more positive feelings of community in her space. I observed her using engaging strategies like math partner games and tracing letters on students' backs and them on hers, teaching shared 
writing with great visuals, and creating a fantastic spelling game that her students loved. She shared information with me about a dynamic teaching project related to Cinco de Mayo that lit up her face in the springtime, and I observed her using developmental insights when differentiating for her students and planning for rest-time and center-time. However, for much of the year, dependence on whole group, worksheet-based, direct instruction correlated with classroom management concerns, and meant that with fewer chances to practice language, and little support for and teaching of self-reliance, her students possibly missed out on learning gains that could have been made.

\section{A Year in Her Life as a First-Year Teacher}

The next section of Kristin's chapter illustrates how these teaching practices and her classroom management decisions contributed to and worked against building a sense of community in her classroom, and how the omnipresence of PBIS at Monroe may have been the strongest influence on her first year.

\section{The Beginning of the Year: "In Every Classroom, There's a Clip Chart."}

Kristin described her first day as "amazing!" While many brand-new teachers after their first day may have been exhausted and overwhelmed, Kristin reflected that, "the kids were wonderful, and I had such a great day!" What made the start to her year feel so good was that she was finally able to try out what she had learned in her teacher preparation program and practiced in her field experiences. She exclaimed, "Everything I had learned, I got to do on my own...It just felt so good that everything just worked out." She was most excited to share with the students her love of reading and bring her favorite books into the classroom.

Her biggest concerns related to her students' language backgrounds. Knowing that her students spoke Spanish and Albanian, she was worried how she would communicate with them, 
especially at the start. At Monroe's Back to School Night, where she first got to meet her students and their families, this worry increased. She explained, "I was like, 'Oh I really hope somebody speaks English, because I don't know how I'm gonna teach these kids if none of them know English!" Only eight of her 21 students' families came to this event, but of the eight, all spoke English, which made her feel "so relieved, and like, 'Okay, I can do this!” She did not share whether it concerned her that the rest of her families did not attend the event, nor what she found their language proficiencies to be, but throughout the year, she mentioned using Maria as a translator when working with many of them. Very quickly, she began to form relationships with her students, and this felt good.

Beginning of the year classroom management. It was clear that Kristin felt a strong PBIS presence at Monroe, as the school-wide tools related to PBIS were the first aspects she described when asked about her classroom management. Having not received any formal preparation in PBIS, either at the university or at Monroe, her source of info about the framework was her grade-level team. She learned from them, "that 'in every classroom there's a clip chart." "Used across all grade levels, "even in $5^{\text {th }}$ grade—it's smaller, and they don't go up and down as many times," the clip chart was the primary tool at Monroe for monitoring student behavior. Teachers had choice in what rewards and consequences they used with the chart, but school-wide, they were required to post the chart. In the weeks before school started, her grade level team met to discuss this. Recounting this meeting, she shared, "last year, on their [the kindergarten-wide] clip chart, the kids could only move down." Only using the chart for punishment bothered Kristin greatly. She had observed her cooperating teacher at Auburn Elementary using a chart where students could also be rewarded from their starting position, and 
she much preferred this type of chart. So, she was very happy when another team member also expressed this idea, explaining,

...one teacher was like, "Well, I think we should do this clip chart so the kids could move up.” And I was...really strongly pushing that. I was like, 'yes, let's make it positive. Let's have them go up.' And so, everyone was on board! And so, our clip chart goes up and down.

This was Kristin's first encounter with working on her kindergarten team, and she was happy to be able to voice her opinions as she had done during student teaching and be a part of this decision. Describing it as a "team effort," she was very happy with the policy change.

Thus, in Kristin's room hung her clip chart, which would be her primary classroom management tool all year (Figure 12). Looking very similar to the one she had used in student teaching, she started the day students' clips at green, "Ready to Learn." By displaying appropriate behaviors, each student had the ability to be bumped up to blue, "Good Choices," purple, "Great Job," and pink, "Super Student." With inappropriate behavior, they could also be moved down to yellow, "Think about it," orange, "Teacher's Choice," or red, "Parent Contact." Kristin was the only person who could move their clips. Their clips moving up brought different rewards and moving down brought various punishments, such as missing out on recess. 


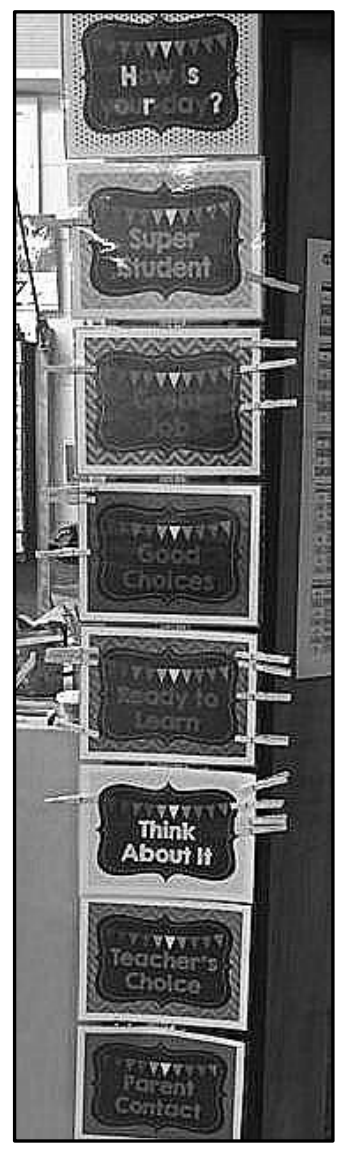

Figure 12. Kristin: Kindergarten-wide behavior monitoring clip chart (11/14-5/15).

Related to the clip chart, Kristin explained that the fact that her students knew how to behave was because their classroom rules. In the same way that she had learned about the clip chart, she discovered Whole Brain Teaching and the classroom rules within this approach (Whole Brain Teaching, n.d.). She explained, "One of the kindergarten teachers learned about it from a conference or something that she went to. So, she decided to bring it into the classroom. So, all of kindergarten does it." She believed that only the kindergarten classrooms were using these scripted rules, and in her classroom, she and the students practiced them every morning during calendar time. 
Each rule had a corresponding hand motion, and Kristin reviewed each in a very specific call-and-response format, which I learned was typical of the approach. She recited the rules, doing the hand motions for each and stating,

So, it's...rule number one, follow directions quickly (moving her hand in a fishswimming motion), and rule number two! Raise your hand for permission to speak (raising her hand and then bringing it back down in a talking motion). Rule number three, raise your hand for permission to leave your seat (raising her hand and then walking her fingers down her opposite arm). Rule number four, make smart choices (tapping the side of her head). And rule number five! Keep your dear teacher happy (smiling and using her hands to frame her face as she moved it side to side).

Throughout the year, whenever she described the last rule, she would blush and let out a little giggle, but otherwise, she seemed unbothered by the content of these rules. Remembering their wording and motions was what she found most challenging, describing it as, "definitely something I had to learn." Yet, she felt motivated by her team, stating, "Okay, that's what everyone is doing. I'm going to do it too." To remind her students, she hung posters of each of these rules/ behavioral expectations on the side wall of the class' bathroom (Figure 13). She described having to refer to it regularly because the rules were not yet "engrained" in her memory or the students'. 


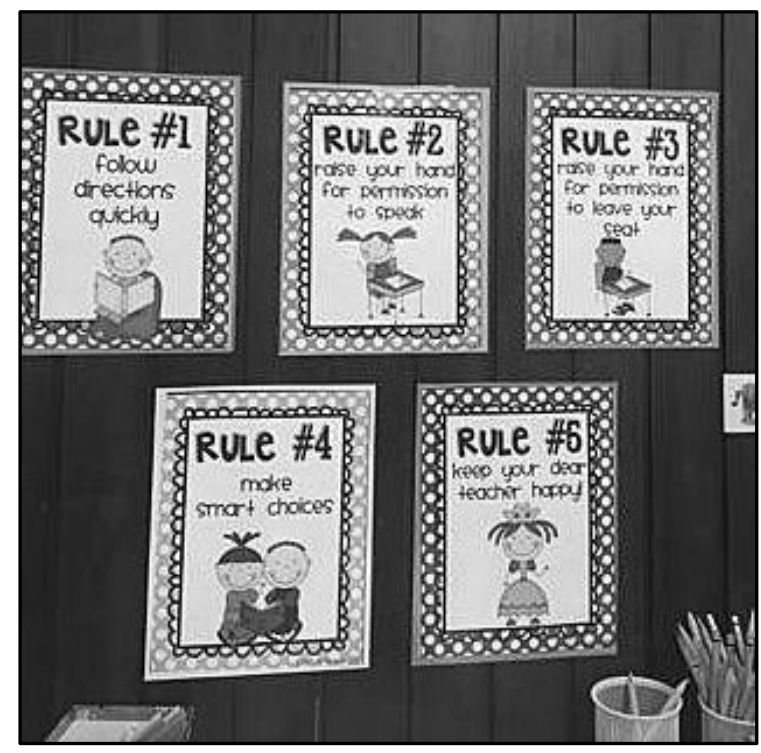

Figure 13. Kristin: classroom rules posters (11/14-5/15).

Another aspect of Kristin's classroom management at the beginning of the year was her use of the school-wide reward system, the "Doozie Dollars" (aka "Doozies"). Although the Fayette mascot was the Falcon, Kristin displayed uncertainty in explaining what these rewards were and whether they related to the mascot, stating, "I honestly don't even know. It's just...the PBIS logo on the little thing, and they call him Doozie Dollars." Describing it as "their spirit stuff," she had learned from her team that students received them when they did, "what they're supposed to be doing." A Doozie rewards cart came to her class every two weeks for the students to buy redeem their tickets for prizes, such as small trinkets.

One of the aspects of the chart, the rules, and the Doozies, that Kristin liked was that there was grade-level consistency. She explained, "Everybody in kindergarten has the same five rules with the motions." They also had similar rewards and consequences related to their clip charts, so that during recess or when they would be in others' classrooms throughout the year, the system was consistent for the students. Kristin was unsure whether the Monroe 
administration mandated that all these pieces be the same, but she explained, "it was just decided that we're gonna have the same." Ultimately, she felt that this consistency was due to the PBIS framework, embedded at Monroe.

Setting up the classroom routines was another big aspect of Kristin's beginning of the year classroom management. With no posted daily schedule or procedures for students, she spent significant time reviewing the daily practices with her students. Doing so highlighted where she needed to make changes in her practice right from the start. She explained, "Because I have a lot of vocal children, I have a lot of kids that can't be by each other, so I'll be like, 'Okay, these four kids can't be by each other at this table or this table..."' She assigned seats at each of the tables, the rug, and their spots for rest-time. As all her students received a hot lunch daily, she decided that they would stand alphabetically to make the hot lunch process more controlled. Otherwise, when standing in line, students could pick their spots. She described practicing line-walking with her students, using the phrase, "Okay, put a bubble in your mouth. Ready?" for them to be quiet in the hallways. As I would later observe this, Kristin's line of students was impressively quiet in the hallways.

Kristin also began using attention-getters to recapture students' attention, such as " $5,4,3$, 2,1 , the time to listen has begun!" However, what would become problematic for Kristin was that she rarely waited to ensure she had the students' attention, after calling this out, which led to consistent management issues as the year progressed. Towards the beginning of the year, she emailed me with images of her classroom management tools, and she included a photo of a poster hanging in her room that was a visual of an attention-getter promoted by the Whole Brain Teaching approach called "Hands and Eyes" (Figure 14). At no point in my visits did I observe her referencing this attention-getter or poster, despite that fact there were many times throughout 
the day where it, or another call-and-response, may have been beneficial. More often, I heard her raise her voice and say, "Okay boys and girls, shh_-," which had varying effects on capturing students' attention.

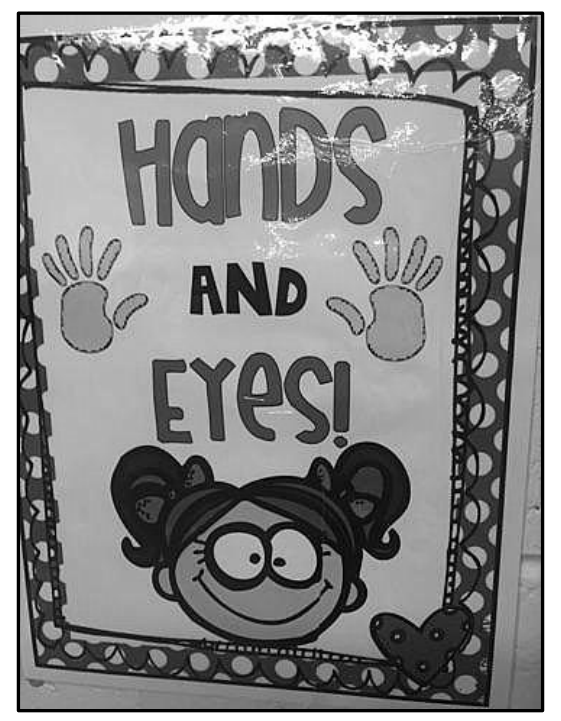

Figure 14. Kristin: classroom attention-getter poster (11/14-5/15).

In the first few weeks of school, Kristin described setting up the routines of the classroom, including rest-time, which her young students needed with the long school day, and center-time, which they loved. During rest-time, she pulled out plastic foam and yoga mats from a corner of the room, and each student took one to an assigned spot to rest. Also during this time, students who had unfinished work completed this at the tables, and she often pulled students to the back table to assess. If the computer was working that day, she played soft, instrumental music, and the expectation was that students were quietly reading or resting, even though very few of her students ever slept during this time. Instead, many students used this 
time to ask to use the restroom, ask other questions, chatter with friends, and play with materials on the shelves. So, less than relaxing, rest-time was filled with lots of ups and downs.

Related to center-time, Kristin quickly realized that this time of day would need more structure than she had originally imagined. With multiple open centers and no guidelines, she put in place some rules very quickly. She explained, "At the very beginning of the year, I would ask them where they wanted to play, so if they played at kitchen on Monday, they can't play at kitchen on Tuesday," which was the policy for the first few months of school. Keeping "it managed," she later changed her center-time policy to four students per center for the rest of the year, although she did not highly enforce this policy.

In getting to know her students, she quickly learned what their likes and dislikes were, as well as the ins and outs of their personalities. Like, Molly, she identified a few students who presented challenging behaviors and for whom her classroom mangement decisions did not seem to be working right from the start. In our first conversation, she described five students for whom she felt the clip chart was not working. Javier, who started one month late and did not speak English worried her. She explained that he "doesn't know how to play with others. He doesn't know anything academic... he's just never been in the school setting, and he's coming in late." With him, she described, "It's very hard with him to know what to do." Additionally, she described a set of twins, Carolina and Delfina, who displayed very challenging behaviors and left her feeling frustrated. She described them, "Delfina, has tantrums. So, any negative comments from anyone, ever, she'll just go into a tantrum mode. And then, the other one, Carolina, is very disrespectful to authority and very...naughty. She's very smart and very manipulative." From their behaviors, she was thinking more deeply than just what was on the surface, and she believed that they were seeking attention. She explained that Carolina concerned her the most 
because she had recently begun to mimic Kristin. About this, Kristin exclaimed, "It's was just...not okay. And it's hard to know, okay, what do I do in this situation? How do I even go about stopping this?" While this question was posed hypothetically, it represented her feelings about supporting Carolina's social-emotional and behavioral needs early on.

A fourth student, Melitza was also acting out in multiple ways. Again, Kristin believed that this student was seeking attention. She described calling Melitza's mother and grandmother regularly because of behavior issues. Additionally, a fifth student, "Nicolás (Nico) wouldn't talk at the beginning of the school year. It was a month before he said one word." She described her concerns with him as "more academic than behavior [sic]." Very quickly, her schedule was arranged so that he could receive special education services with Miss Williams each morning. At the beginning of the year, he was only in her room in the afternoons.

In sum, Kristin's beginning. Despite encountering these challenging behaviors, establishing rules and procedures, and putting in the hard work to clean out the classroom and set up her environment, Kristin was surprisingly self-assured at the beginning of the year. Feeling like student teaching had been more difficult, her beginning descriptions of the start to her year implied that she was not as overwhelmed as many new teachers can be in the first few months of their first year. With the strong presence of her grade-level team, a positive relationship with Maria, and a growing friendship with Danielle, it seemed that the support she felt contributed to these feelings. Arguing for rewards on the clip chart and the calm ways she described identifying these challenging behaviors highlighted Kristin's confidence and sense of teaching self-efficacy at the start of the year. However, the easy ways she accepted practices based on her team's wishes, such as the class rules, played out in different ways as the year progressed. 


\section{In the Fall: "...They Love Moving Up!"}

By fall, Kristin was loving working with her students. Steadily, she was seeing them make gains, and she excitedly pulled out a bin that had student writing in it to show me several pieces of her students' work. She was most excited to start a formal writing workshop with them “because they're learning their letters and sounds, and they're putting sounds together to make words." Parent-teacher conferences took place in November. While Kristin was nervous about the language barriers between the students' families and her, with Maria's help translating, she had very positive interactions with all. With pride, she shared that one student's mother had told her, "He wants to practice his letters and sounds every day. We wake up at 5:00 in the morning. 'Let's do letters and sounds.' And he doesn't want to do it once. He wants to go through like five times." She shared this anecdote with a big grin; she seemed to be enjoying herself.

Classroom management in the fall. With of my son's birth, my fall observation in Kristin's classroom had to be cancelled, making me unaware of the nuances of Kristin's day-today interactions with her students. Thus, I excitedly listened when our conversation shifted in November to her classroom management and classroom community, and she jumped in to discuss her class' clip chart. Knowing that she had worked hard to ensure that there were rewarding levels to the clip chart at the beginning of the year, I asked her what effect she felt this advocacy had on her daily use with the tool. With a surprising expression of emotion for Kristin, who was usually very reserved, she shared that she did not know what she would have done if her team members had disagreed, stating, "it would be terrible!" She explained, "It's...the whole classroom management system in my room - they...love moving up." To her, changing the chart to have rewarding levels and allowing student movement in both directions was the best decision she had made this year. 
Kristin explained that she was using the chart regularly and was seeing results. She continued, "They'll ask what they can do, so that they can move up." When she moved up a student's clip, she felt that this was a model for others, stating, "So, even children that I have behavior problems with, they're thinking about, 'okay, what do I need to do in order to have good behavior...what does that look like?"' She noticed students shifting in position, becoming more on task, stating, "I know they're constantly thinking about, 'Okay, I need to sit and do my work,' or 'I need to raise my hand before I talk,' etc." At the time, this gave me pause because I wondered whether students could pay attention well, if they were constantly thinking about the chart. With this, she highlighted an insight that I would observe in a few months.

In the fall, Kristin was also still dispersing the school-wide Doozie Dollars to reward appropriate student behavior, but she had made some changes to their distribution. She described that passing them out throughout the day was very disruptive and messy, exclaiming, "they had Doozies everywhere!" She learned that teachers could decide how Doozies would be dispersed and incorporated with their clip charts, such as one where students reaching the pink level received a glitter sticker on the clip that correlated with new clips and a Hall of Fame. Kristin explained that for her, "instead of just randomly handing them out when they're doing what they're supposed to be doing, I just correlate where they are on the chart with how many Doozies they get." At the end of the day, if students' clips were still on the green, "Ready to Learn" level, Kristin would award them one Doozie Dollar. If their clip was at the top of the chart, on the pink, "Super Student" level, she would award them four. Students kept their Doozies in their plastic mailbox bins on the wall next to the bathroom.

Kristin decided to use the Doozie dispersal time at the end of the day to hold a minibehavioral conference with each of her students. She explained, 
Along with the rewards, I tell them... what they did really great. I have a conference with each one...talking with them about how their day went. And if they're below green, we go over why they're below green, and then, what their goals are for the next day, so that they can be above green.

Having these conferences highlighted another reason to Kristin that the chart and its upward and downward motion was so great. She felt that conferencing helped her students set behavior goals for the next day. She recounted, "And so, at the end of the day, sometimes kids will be like, 'I want to be on pink tomorrow!' So, I'll be like, 'Okay, what are you going to do tomorrow so that you can be on pink?' She also found processing solutions for the next day to be a great way to wrap up the day.

Tying together these various pieces was her form of parent communication about students' behavior, which she began in the fall. At the beginning of the year, every student at Monroe had been given an assignment notebook/ planner spiral-bound notebook. While conferring with the students, Kristin used these to write down the color of the clip chart level that corresponded with the student's clip placement at the end of the day on that day's page in the notebook and initialed next to it. She did not take into consideration which other levels that child may have been at that day, simply the last level. Although this did not fully represent a child's full day of behavior, parents were required to review the final color level with their children overnight and initial that they had seen it. The next day, while students completed morning work, Kristin quickly reviewed these to see parents' initials. Throughout the year, I did not observe the students using these assignment notebooks for any other purpose.

Kristin was still using the classroom rules and explained that they related to her classroom management because she tied using them to her clip chart. With repeated use, her 
worries about remembering the phrasing of the rules had fallen by the wayside. In the fall, she saw many benefits to the rules, including that her students loved them. She explained that the students knew the language of the rules, so when she was teaching and said, "Oh, follow directions quickly," her students would "stop everything and go because they know what that means, and they know their clip is going to be moved down if they don't do what they're supposed to be doing." She believed that these rules were teaching her students about appropriate behavior. Illustrating this, she stated,

And sometimes they even ask me, they're like, 'Ms. Beiersdorf, are you happy? Were you happy with how we rested today?' And so, because... if they're being good resters, that means they have a correlation with 'good behavior makes the teacher happy.' And so... they want to have that good behavior.

This comment gave me pause because it seemed that Kristin believed that her students' role in behaving well was to please her, and not instead just learning how to behave properly, which was not in line with NAEYC's standards of developmentally-appropriate practice.

She also felt that the use of the rules was helping her students' language learning. Here she provided another anecdote about when she was explaining to the students that they would create a book cover during writing, and when they were done, they could get a piece of paper to start writing their first page. She explained, "And so, one of my students said, 'Without permission?"' While she did not say this in the recounting, the reason for this was that typically students had to ask permission before almost every step of the day, which is why asking was so engrained in the student's mind. In her description of the event, it did not seem that this was how Kristin interpreted the interaction. Instead, she explained how this student's question had shown her that because of the rules, this student understood the word "permission." Overall, she 
felt the rules were helping them. Because I was unable to observe her teaching in the fall, I did not know to press her for further analysis about this.

After describing these various facets, Kristin shared that "overall, it [her chart, the Doozies, the conferences, the notebooks, and the rules] works wonderfully for my class as a whole." She felt that it all worked together to help their community, but then she contradicted herself by describing how her classroom management was not working for all students. She explained, "I still have three students that have other behavior issues, that are...I'm just constantly trying to figure out what works with them, what I can do differently to help them." For each, she was digging deeper and learning more about them and their families and working towards solutions with the help of Monroe's social worker and her team. For Javier, her student with little English, she explained that his hitting was an expected behavior at this point, stating, "I don't think he understands the clip chart at all...he understands what he's supposed to be doing now, finally. But sometimes it doesn't transfer over into what he really does." After realizing that Javier also hit while playing at home, she believed that he just associated hitting with play. To help him remember to keep his hands to himself, she created picture cards that she wore on her key lanyard to remind him of proper behaviors (Figure 15). She explained, "So that when he was hitting somebody, I had a picture - so, I said, "No hitting!" She then showed him the correct image, and "he didn't understand the language, but when I showed him the pictures, he could understand the pictures." She believed that these cards helped him to begin to see that hitting was wrong. 


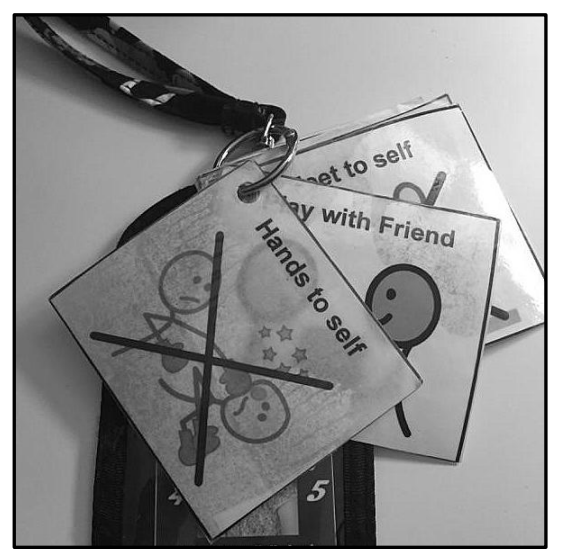

Figure 15. Kristin: individualized behavior expectation flashcards (11/14-5/15).

The twins, Carolina and Delfina, were still displaying challenging behavior, and she was sending their notebooks home each night, but their mother was not signing them. In the classroom, Kristin explained "I've had to add more to it [her classroom management] because that [the chart], in itself, wasn't enough for them." She then listed off numerous strategies that she tried to help these students including setting up a meeting with their mother, in which she learned many more details about the struggles within their household. She explained, "so, it gives me more empathy. Like this isn't just behavior that's purposeful, but there's more to it." From this, she worked on being more positive with both girls, "because they respond a lot better to positive. So, every time they're doing what they're supposed to be doing, they move up." She checked in throughout the day with Carolina, and she started an additional incentives system for them, where if they were well-behaved all day, they received a sticker on a chart she taped to their table spots (Figure 16). Highlighting how she was now also using food as an incentive, she explained, "and once they get five stickers, they get a ring pop." She observed a direct positive response from Carolina once she started using the new system, exemplified a few days earlier, when Carolina's clip was on the pink, "Super Student" level all day. 


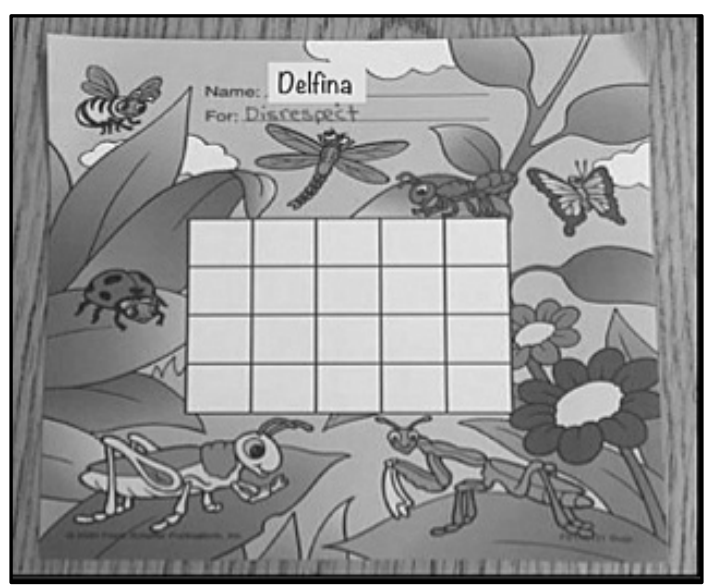

Figure 16. Kristin: individualized behavior incentive chart for two students (11/14-5/15).

Despite success with Carolina, she shared that Delfina was still having regular tantrums and had begun having wetting accidents while at school. With the support of Monroe's social worker, she created a small visual reminder to use the bathroom and taped this near Delfina's nametag (Figure 17). She also explained how she had talked to the social worker for advice on how to prevent the tantrums. 


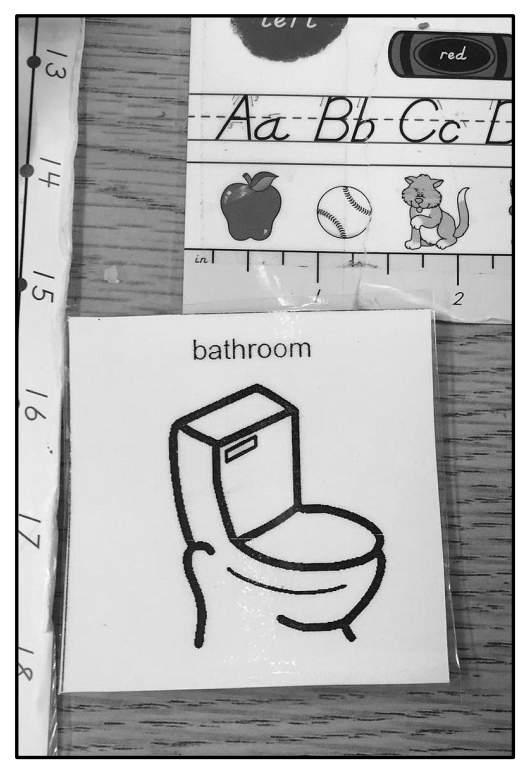

Figure 17. Kristin: individualized behavior expectation visual on table spot (11/14).

Monroe's social worker recommended that Kristin create a calm down area of the classroom for Delfina and other students to go when they needed to take a break, and Kristin was excited about this idea. I reflected upon the fact that she had also learned about this in a classroom management workshop I led for one of her classes at the university, but she did not express seeing the connection. She explained, "So...whenever she is having a tantrum, she has to go to the calm down area. And she sits there to calm down. And then, when she's ready, once she's calmed down, she can come back to the group." The calm-down area was a beanbag chair that sat in a back corner of her classroom (Figure 18). What Kristin discovered was that Delfina enjoyed the beanbag so much that she preferred to stay there instead of rejoining to the group. She shared that at times, she had to make her return to the class, but this did not seem to bother Kristin. 


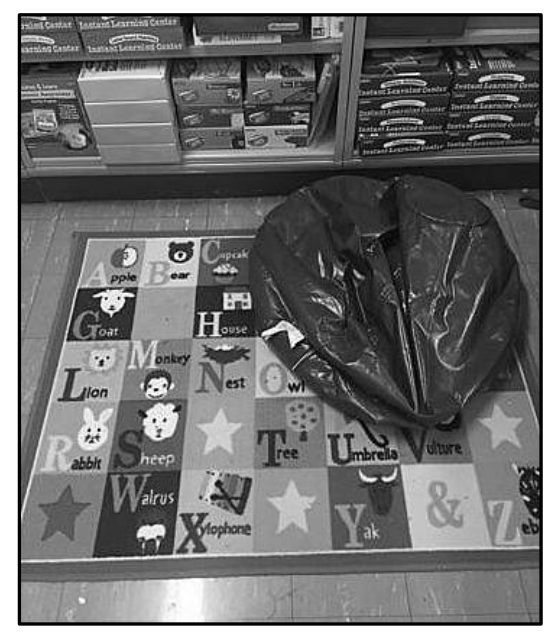

Figure 18. Kristin: calm-down corner (11/14-5/15).

Her concerns with Melitza persisted into the fall as well, and yet, like for the others, she was trying out solutions for this student. After gaining more context about Melitza's background, Melitza was moved into Tier 2 of the PBIS framework at Monroe, which meant Kristin would be using the Check In/Check Out tool for her, abbreviated as, "CICO" and pronounced "sicko" at Monroe. Throughout the day, Kristin and other teachers provided Melitza feedback about her behavior on a clipboard. Kristin saw this tool as appropriate for her because she felt that Melitza was looking for attention, and "so, it's mainly just to get that person that she can go to everyday that really cares about her... and just like helping her make good choices, and having that relationship." Although she felt overwhelmed by the amount of time it took to document Melitza's behaviors, she observed positive outcomes. She explained, "I mean...I was calling...grandma all the time for behaviors. And now... I don't consider her on my radar for being a problem at all.”

In sum, Kristin's fall. In describing how she managed the various parts of her classroom management, including the clip chart, Doozies, mini-conferences, notebooks, and then 
the multitude of supports being used with specific students, she laughingly admitted, "There's so many things!" Yet, she did not reveal whether this overwhelmed her, or whether she saw this as problematic. Unlike, Molly, whose fall was confusing and challenging, Kristin expressed a relaxed air of confidence that everything was going well. She reflected on how she would compare what she was experiencing with her student teaching experience, and she confidently stated, "now I feel like since I had that experience, I had all my trials and failures." Implying that all her worries were behind her, this was a bold statement for such a novice teacher to make. Clarifying, she explained how, "Now in my first year, I feel like I know more of what I'm doing, and I'm more confident in it than just not really knowing." From these descriptions, it seemed that she was getting a helpful amount of support from her various team members at Monroe. She was trying solutions out and seeing results. However, because I was unable to observe her practice, I was unable to triangulate this information or get a feel for how all of these various facets were impacting the sense of community within her space. On the surface, Kristin's descriptions made it all seem very positive.

At the end of the fall interview, Kristin asked specifically for my advice, as she would for each interview moving forward. More than either of the other two case study participants, Kristin saw my role as that of a coach. Here, she specifically asked for advice related to supporting Javier, Delfina, and Carolina. I was cautious when responding. Again, because I had not yet been able to observe in her classroom, I did not know whether there were bigger issues at play, such as problems within the schedule where students were seated too long, or whether she was putting tools in place that encouraged her students to be self-reliant. It would not be until the winter when I could see the impact of her teaching and management decisions. 


\section{The Middle of the Year: "Your Kids Are the Most Polite [sic]..."}

When I first observed Kristin's practice, it was a few weeks after winter break, and they had missed additional days of school due to heavy snow. My first day in her classroom since the start of the school year brought with it new insights into her daily practice, all with the understanding that after so many days away, student behaviors may be atypical. Kristin shared that she had been very impressed with how smoothly her students transitioned back to school after the break, stating, "They were so well-behaved. They were so happy to be back." Increasingly seeing growth from them, she noticed that they were now applying their learning, especially related to reading sight words. Before the winter break, she received parent feedback that the students were wanting to practice academics at home, and in class, they had started playing "school" during center-time, where they would pretend to be "Miss Beiersdorf." I had the chance to observe this, and it was so sweet to see them run to the front of the room, take the teacher's pointer and take on Kristin's persona, acting out the motions of the day. Related to the sense of community, what stood out to me was how quickly they intentionally misbehaved in order to be corrected by the child playing the "teacher," and the number of references they made to the clip chart, indicating that this tool continued to play a big role in the classroom.

Classroom management in the winter. In her words, there were no major changes to her classroom management from the fall, and she shared, "I think it's going well." As this would be my first opportunity to triangulate data for Kristin, I was eager to observe her teaching in action. I noticed students moving through the procedures of the day more easily than she had described earlier in the year. Thinking that she may have added a posted schedule by mid-year, I asked her about whether there was one that I was missing, and she confidently replied, "oh, they just know it." This reminded me of Molly's similar sentiment. Kristin explained, "Things are 
finally starting to click in and apply." She credited the routine with how students just knew the schedule, stating, "The routine helps them because they know what's coming," and in many ways, her students' behavior confirmed this statement. I noticed how when Kristin reviewed the class rules, the students happily repeated each phrase. Like little robots, their hands automatically moved into each position. Students announced when the next activity would take place, for example, when a little girl cried out, "Math's next!” Also, at a pause before the Pledge of Allegiance was to be recited in the morning announcements, the students, who had not been paying attention before, shot out of their seats. They knew it was coming. It was impressive that they had become so automatic in the morning procedures without the aid of a posted schedule. However, for 5- and 6-year-olds unable to tell time yet, I noticed the lack of a visual schedule bringing on stress later in the day.

Mid-year, observing her full day for the first time gave me context for her past descriptions and highlighted areas in the daily schedule and her instructional delivery that emphasized her novice status that year. Kristin's students were energetic, excited, and eager to be at school. With only a few breaks in the day, they predominantly spent time in a large-group format, whether this was sitting on the rug or at the tables. Especially in the morning hours in the first activities of the day, Kristin kept them engaged with a soft, natural flow to her delivery, and they were animated and ready to learn. However, as the hours of the morning passed, and with the scripted nature of back-to-back math and phonics instruction, I observed her students becoming very sluggish and off-task. With the extended time that they spent on the rug. I noticed Kristin resorting to reminding, cajoling, and threatening movement of the clips on the clip chart, and then actually moving the clips multiple times. At times, she recognized that the 
students needed to pause and take a stretching brain break, but when the time came, many students seemed unmotivated to do even this.

When at the tables, the large group format was especially problematic, because the work Kristin assigned tended to be worksheet-based activities. Because she was teaching alone for most of the day, managing the whole space stretched her very thin, as her students had endless questions and concerns. This was in part because Kristin inconsistently paused to capture students' attention before delivering instruction. Additionally, she rarely asked for confirmation of understanding before releasing students to work. All of this led to confusion and dependency on her from the start. The longer they spent at the tables, and the more confused they were, the more students fidgeted with materials on the tables, such as pencil boxes, and became distracted.

For these reasons, I observed Kristin using redirection for behaviors throughout the day. An example surfaced when I observed part of math instruction that day. Although having the students play a counting game with a partner throughout the room was a great break from sitting on the rug, Kristin sent them off to play without confirming that they understood what to do based on the one quick model she had displayed. Thus, I quickly noticed many students who were confused and off-task, and I overheard one little boy ask another, "What we supposed to do?" The need for Kristin to pause and check for understanding was especially strong because of her students' language needs.

The lack of clear directions and the choppiness of her schedule led to many languagebased challenges for Kristin's students. A consistent example of this related to the vocabulary word sorts that they completed throughout the day. Because Kristin did not clearly overview what the images were on the word sort worksheets, many of her students were confused when it came time to sort these on their own. On the days that I was present, several students asked me 
to identify images so they would know how to sort them. Tricky images such as a "blouse" and "sneakers," understandably confused these second-language learners because the simple cartoon image looked like a "shirt" and "shoes." However, those words did not correspond with that word sort of "bl-" or "sn-." Kristin knew that her students were confused by these tasks, and rather than previewing the images clearly or providing solutions for how to decipher the image independently, she chose to address this by asking that students bring every worksheet to her when complete so that she could review them.

For these reasons, students were constantly calling out her name, "Miss Beiersdorf!" “Miss Beiersdorf!” “Miss Beiersdorf, I need help!” “Look at my page, Miss Beiersdorf!” At one point, in January, I observed three of the students with raised hands calling her name and another five waving their worksheets in the air. A few students followed behind her with their worksheets. Over my observations, I did notice that she was often more responsive than not, slowly making her way across the room throughout the day. However, at times, I could see this wearing on her patience, as she often seemed frazzled and removed from what was happening all around her. Requiring that all the students check in with her, along with the number of redirections she gave, and the multiple explanations needed because of the lack of clear directions, used up a significant amount of her instructional time, and she, nor the students seemed happy with this.

As such, mid-year, she admitted that it felt "stressful" and disruptive to have the kids follow her around for help. However, she did not reveal that she recognized any of the countless reasons why they were so dependent on her, such as the format of her instructional delivery, nor the lack of clear directions or guidelines she provided, nor her insistence that they check in with her throughout the day. When in later conversation I asked her if there were any way that the 
students could self-check their work, so as not to check in with her so much, she paused, and responded, "I don't know. I usually just have to make sure they did it right.” At times, I observed her realizing in the moment that her students did not understand, and she would use an attention-getter to grab their attention and re-teach, yet this was rare.

Occasionally, I observed her teaching concepts clearly and with detail right from the start of a lesson, and these teaching behaviors significantly helped these concerns. A good example of this was when, while using the teacher's guide, she made sure to teach her students what the symbols on the playing cards were before she released them to play a card game of "war." I also noticed a student pull out a cutely-painted large clothespin, which was designed to look like an astronaut and ask, "Miss Beiersdorf, can I grab a spaceman?" Later, Kristin told me these were used as spacers to aid the students in spacing out their writing. These strategies focused on helping her students become independent learners and, in turn, led to fewer problematic behaviors from her students. However, they were used inconsistently, which negatively impacted the sense of community in her space.

Highlighting her responsiveness mid-year, Kristin was making changes to her curriculum after seeing that her students were competent and eager to learn more and realizing how limited her curricula were. She changed her literacy centers to include guided reading as one of the small group activities, and working with this small group was where I saw her teaching come alive. She was excited to read short texts with these students, and she kept them very engaged. On days where the schedule allowed, Maria also led a small group during this time, and having two adults with groups helped the students be more on-task, which in turn helped with overall behavior. However, Maria was often pulled out for assessment or to support others in the building, and Kristin tended to be on her own during this time. When students were at a student- 
led center, I observed them having many questions, being confused, and ultimately, becoming off-task. Alone, Kristin's management skills were stretched thin in order to address these issues. While so many of the problematic behaviors were related to her instructional delivery and the format of the day, it did not seem that Kristin considered these aspects of her teaching as part of her classroom management. When I asked her about her management in January, her first response was, "They love the behavior chart!" Thus, dismissing these other critical components of classroom management. She shared an aside with me that if her grade-level team had not agreed on the multi-directional clip chart, she now felt that she would have done it anyways. She explained that this decision was going to "make or break my whole year because if they could only move down, it's just too negative. They need something to reach for." In part, she felt this was because, she repeated, "They always want to move up! So, it really helps them if they're not on task. If you bring it up, they'll be on task." Although I could not say from observation that I noticed the students inherently wanting to move up the chart, I did notice them responding when she brought it up, which she did throughout the day.

On my first day in the classroom, I was taken aback at the amount of time that was spent with the clip chart. Because there were so many off-task behaviors, I noticed Kristin referencing the chart throughout the day to encourage/ coerce appropriate behaviors, as I had seen Molly and Susan do with their behavior monitoring system at times. On the rug in the morning when several children were not listening, I observed Kristin loudly stating, "I'm going to move Mateo up because he has been sitting crisscross with a bubble in his mouth." She walked over to the clip chart on the other side of the room, her students freezing in position, and demonstratively repositioned his clothespin one level higher, their eyes captivated by her movement. She asked, "Okay, are we ready to listen? Okay, let's remember what season we're in." At this point, hands 
shot up, even though half remained frozen, looking confused. This behavior would repeat itself throughout the day. Often, Kristin just hinted at moving up a clip for effect, such as "I need you to sit up and listen for the next thing. The quietest person might get moved up [emphasis added]." Kristin pointed towards the clip chart hanging by the door, and the students' eyes followed her there. I noticed her moving clips at various points throughout the day, even when students were not watching.

Mid-year, Kristin was also still regularly dispersing Doozies, Monroe's school-wide rewards system. I observed her enticing students with Doozies if they returned their homework, stating, "If you finish this and turn it in, remember that you'll get a Doozie!" Several students shouted out "woohoo," in response. Additionally, I noticed that she correlated movement on the clip chart with Doozies that students had received from other Monroe educators in places like the lunchroom, recess, and at specials. On more than one occasion, I was present to see the students rush in from P.E. with fistfuls of Doozies. This time of day was very hectic as it coincided with preparing for lunch in the Kindergarten and first-grade hallway, and there were always one or two students without any Doozies, standing to the side and pouting. While watching this, I first noticed Kristin inconsistently applying the reward. Because although everyone came in with Doozies, she only moved up the clips for one or two students.

The correlation between the last clip position on the chart and Doozies still took place during the mini-conferences at the end of the day. At times, she also passed out candy with this. I had the chance to observe these conferences mid-year, which she had described so positively in the fall. She loudly announced, "When I call your name, please come and get your Doozies!" Knowing their last placement on the chart, some students would run to the front of the room 
beaming, while others shuffled, looking downtrodden, and some ignored her at their seats and pouted.

In many ways, I observed this to be a very positive time of day for her students. While the location of a child's clip was always on public display, and thus inherently impacting the sense of community in her space, Kristin took care to speak softly to the students when discussing their behavior. She was always very encouraging of how each child could achieve the next day's goal. I overheard an example of this when she was talking to Eduardo, who had remained on the green: "Ready to Learn" level all day. She explained, "Eduardo, you got three Doozies today. The only thing to work on was moving very slowly when it was time to move on." He somberly nodded his head, and replied, "I think I can do this tomorrow!" "I know you can. You're very smart," she replied. While these conversations were encouraging, they highlighted an issue related to Kristin's inconsistent rewarding of students' behavior. An example of this was an interaction I observed with Veronica, who had ended the day on pink, "Super Student." When the time came for her conference, Kristin high-fived Veronica and simply said, "Wow! Good work today!" At first glance, this seemed very positive. Upon reflection, though, I remembered observing Veronica display multiple problematic behaviors throughout the day, such as interrupting Kristin, calling out answers and pushing other students while in line. At no point did Kristin acknowledge these behaviors as she did for others, and instead, she steadily moved Veronica's clip up the chart. This contrasted with Eduardo, whom I had observed quietly listening and following directions all day. However, he was the one who stayed on the green level and got critical feedback at the conference time. Her responses seemed very inconsistent and became routine to observe, as I would later notice this pattern at each visit. 
More than either of the other two participants' classrooms, I noticed certain students standing out in Kristin's classroom because of how many times she singled them out for verbal praise, assignment of special tasks, and upward movements of their clips on the chart. Because of the highly-competitive nature of the clip chart and rewards and consequences of her class, by the end of the year, I observed a pattern of the same students receiving rewards and consequences or punishments, and the students of the class noticed this as well. In many ways, Kristin developed observable favorites in her classroom that the clip chart exemplified.

Through asking her follow-up questions about specific students who were at the top of the chart, she admitted that she had certain students who were never below green, and this included Mateo and Veronica, whom I also noticed her favoring in my observations. Dismissing the idea of favoritism, she believed that the reason for their high placement on the chart was because they were always well-behaved. If the students stayed on green or above for the entire month, one of the Monroe "Grandmas" would bring them a prize at month's end. She proudly explained, "The first month, I had eight kids that got a prize." In discussing this, I asked if she felt that the students always at the top of the chart really needed this behavior monitoring system. She interpreted this question by asking me, "So, you mean, kids that are not bad, does it really help them?" When I nodded, she admitted that Mateo or Veronica, for example, would behave the same way without the chart, “...but I feel like the middle ones, though...” leaving her thought incomplete. At no point, did she indicate that she realized the subjective nature of the clip chart, nor question why Veronica was always at the top even though she needed so much redirection during the day.

When thinking about the "middle ones," Kristin believed that they needed the chart, and that it was working for everyone, "except Javier." However, in observation that day, because of 
the many off-task and disruptive behaviors I observed, I strongly disagreed. I noticed several students throughout the day who displayed either unresponsive or defiant behavior in response to her use of the chart. This included the twins, Delfina and Carolina, who rarely received Doozies throughout the day and were often below the green level on the chart. While seeing some gains from all her students with challenging behavior mid-year, these gains were partnered with continued behavior issues, indicating that there were issues that her classroom management decisions were not addressing.

As this was my first time meeting them, I had Kristin's descriptions of their behaviors in the back of my mind, and I easily noticed the challenges she had described. I also noticed her working to support each of these students throughout the day. She shared that Delfina cried on and off most days, and Carolina pushed back every chance she got, which made working with her the most frustrating to Kristin. However, she felt the differentiated instruction of the small group format for guided reading mid-year was helping to challenge and engage Carolina, and thus helped her stay better behaved. Kristin also focused on always starting the day positively with her. She explained, "Because if she walks in, and she's moved on the chart first thing, then she's gonna be bad the rest of the day." For Delfina, she was still using the sticker chart, but seeing little change. She explained, “We just ignore her [crying] because I mean, I don't know what else to do." Because she could not make her use the beanbag cool-off space, it sat unused, and she did not mention if she was troubleshooting how to make this space work for Delfina or the others.

Even though Javier was the only one for whom she felt the clip chart was not working, she noted that he was doing a "little bit better." She was still experiencing some issues with him, so she adapted rest-time to fit his needs. Instead of requiring him to lay on the mat and read, she 
allowed him to take a shorter rest time and then play with an iPad quietly at the tables, which I observed in January. I also noticed that she was doing Check In/ Check Out with him at this point in the year. Throughout the day, I observed her conferencing with him over a clip chart, and at the end of the day, she rewarded him with candy. Despite these gains, Kristin ultimately felt that the clip chart was not working for him, stating, "I would say Javier doesn't understand it [the clip chart]." Hinting that she was thinking more deeply about this, when asked to clarify, she replied, "Maybe he's just not motivated by it." This meaningful insight seemed to fall flat because it did not seem to push her to reconsider her use of the clip chart for him or anyone else.

By winter, Nico had an IEP in place at Monroe. She shared, "we decided that his academics were all high, and he needed the language support." Because of this, he was now in Kristin's classroom for the whole day and getting pulled out regularly for specialized supports. About this, I overheard one of her students ask Kristin, "how come Nico always goes?" Kristin did not respond, leading me to wonder if she had talked to the students about Nico joining their classroom community for the whole day, which may have been confusing to him and the other students. With him, she noticed lots of gains, especially related to his speaking skills. Applying what she and I had talked about in the fall, I observed her using an "if-then" tool to help him pace his day (Figure 19). With Velcro, she adhered a pencil image first and then a crayon image, and said, "Remember Nico to write and then color." At several points in the day, I observed him consulting it. 


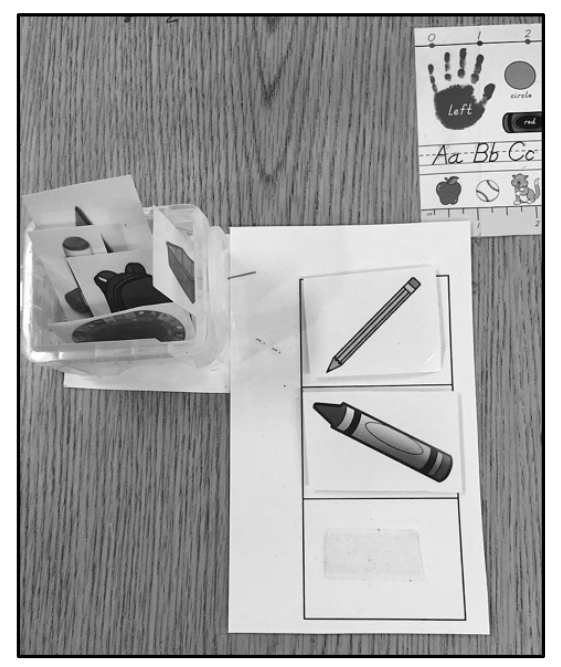

Figure 19. Kristin: individualized "if-then" chart on table spot (1/15).

Along with other students, I noticed the twins and Javier displaying disruptive behavior the longer they were in a whole-group format with no movement. Additionally, Nico and other students became easily distracted while working in the large group format at the tables or in student-led small groups when Kristin could not be in multiple places at once. As Kristin reflected with me about her challenges with specific students, she revealed that she was beginning to see how her daily schedule affected her classroom management. After a lengthy discussion about these behavioral challenges, she offered the idea of making some changes, stating, "Well, now that I have Nico all day, I could switch my schedule...I could do...math in the afternoon and writers' workshop in the morning because writer's and reader's workshop back to back is a bad idea." I was impressed to see her thinking through this because I had felt similarly watching behaviors devolve throughout the afternoon as they went from one large group activity to the next. I pressed her for why she felt that way, and she shared, "Because it [writing workshop] takes a lot of thinking power for them. And at the end of the day, they're done thinking. So, for writers' workshop, they're like 'Okay,' and then, readers' workshop, 
there's just...no attention span left." This highlighted a moment of introspection for Kristin, and I asked her if she felt she could make changes. She replied, "now, I guess I could switch it...I've been thinking about it." However, in subsequent observations, the schedule remained the same, with the same issues as mid-year.

Related to her classroom management, in the winter, I was first able to observe the Monroe Cool Tools behavioral lessons. Implemented as a universal support within Tier 1 of the PBIS framework at Monroe, these were often delivered through the morning announcements. On that morning's announcement, the woman speaking announced, "Good morning, Monroe School! In our Cool Tools, today we are working on transitioning. Yes, we have been having trouble at Monroe with transitioning..." She then explained what transitions were and what children should and should not be doing during them. She advised, "Keep this in mind today." I did not notice Kristin or her students paying attention as the announcement came through.

Later, when I asked Kristin about this, she responded that "yes," if the school was working on transitions, then her room was too, but she did not give any specifics. Despite this, I did not observe her addressing this topic with her students, even though in observation, it seemed that transitions once the day got going were very difficult, and a behavioral lesson addressing this may have been helpful. At no point in my observations did I see Kristin directly addressing the school-wide Cool Tools that I heard on each morning announcement. While she may have taught about these behaviors and attributes on other days, what I observed more was that Kristin expected the students to know these prosocial skills, but she provided them with few guidelines for doing so. Examples included when Delfina ran up to her, and said, "Miss Beiersdorf, they aren't sharing the markers!" Kristin responded, "That's a problem you can solve," but gave no reference for what Delfina should or could consult if she needed help in doing this. I observed 
the problem persisting when Delfina returned to the rug. At other times, I noticed Kristin giving up on listening to two students who were in a scuffle by saying, "girls you figure this out!" Because of their developmental and language needs, prompts and reminders may have been very helpful.

I noticed Kristin providing some behavioral guidelines and reminders at a few points in the day mid-year, such as when I observed her students using the American Sign Language sign for "bathroom," to request using the class restroom instead of calling her name out and asking. I also heard her tell the students, "Alright boys and girls, sit down in listening position." This indicated that she had taught them this position, but I noticed that many did not do so, which made me wonder. In the fall, Kristin had sent me an image of a poster hanging in the room that instructed students how to sit in a "listening position," but in observations, I never observed her referencing this visual, even when students did not follow her direction (Figure 20). This poster had been up since the beginning of the year, so possibly she expected that by mid-year, they knew this guideline, but in observing behaviors on the rug that day, it seemed that reviewing the visual may have helped. 


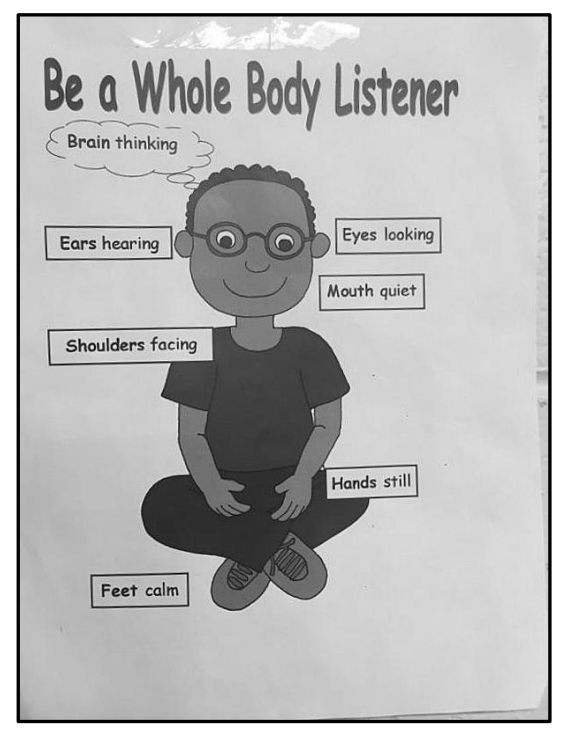

Figure 20. Kristin: rug behavior guidelines poster (11/14-5/15).

Additionally, Kristin had guidelines for problem-solving posted one above the other on her classroom door. These were also photos that she had sent me in the fall, and that I expected to see used in January, especially as conflicts between students arose throughout the day. At the end of the year, she explained that she had learned about the feelings chart and conflict prevention and resolution (C.P.R.) process in her student teaching classroom, and that it was for “...having kids communicate to each other, like why they're upset” (Figure 21). However, at no point on this day in January, nor on my other observations, did I observe her referencing these, although there were countless times where if prompted to consult these tools, students' interactions may have been positively impacted. I considered whether I was just not seeing these tools used on days that I was present, but not seeing the students' independently use them either indicated that they may not have been commonly used. 


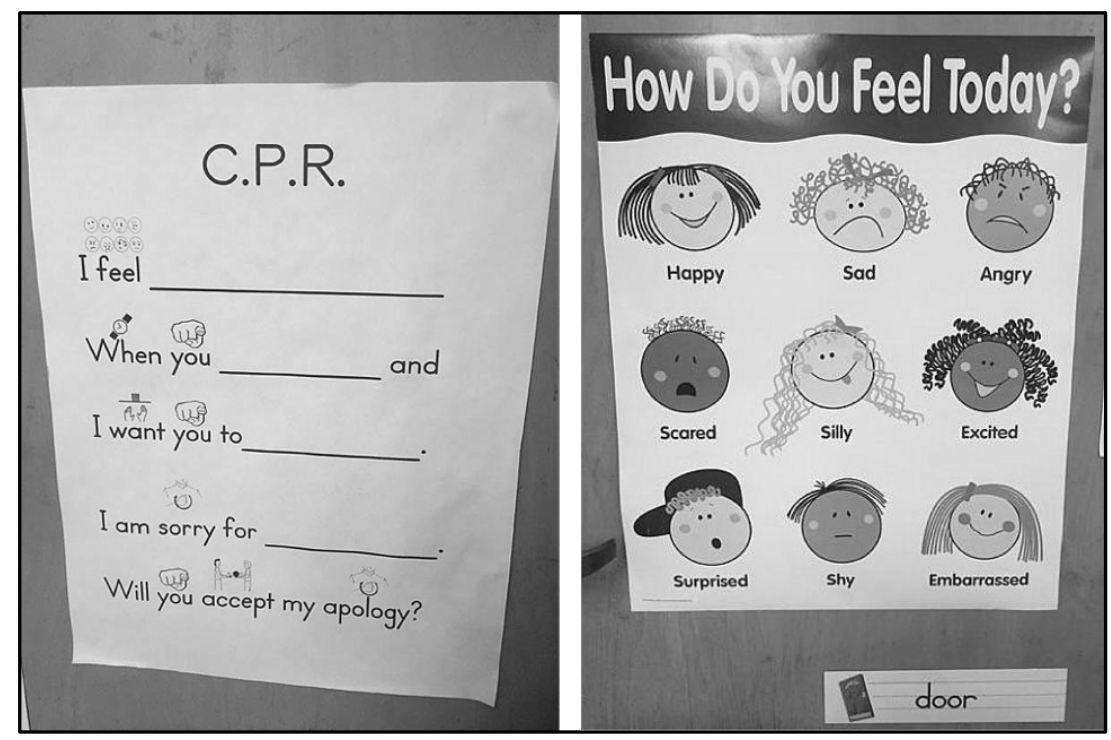

Figure 21. Kristin: unused behavior guidelines posters (11/14-5/15).

As such, without more guidelines or feedback for how to problem-solve, conflict resolution issues were a constant, especially during indoor recess and center-time, and also at other times of day. At the end of our conversation in January, she shared with me her worries about indoor recess, specifically, which highlighted many of these issues. When weather permitted, managing student behavior with the scheduled two kindergarten teachers felt feasible, but when they were indoors due to weather, and she was all alone with half of the school's kindergarteners, it did not. At times, she played a movie on the SmartBoard, but more often, the students engaged in unstructured play in her classroom centers. About this, she explained, "I couldn't do it every day. I'm better now than I was the first...day, where I was like, 'I could never do this, ever."' In discussing this in advance, she described how her classroom management was better now than on the first day, stating, "I think the kids know what they can do." However, in my observation, this did not seem to be the case, as students seemed very confused, and the overall feeling of the room was very intense. 
Once started, without warning, students would rush into her room, and within five minutes, there were 39 students in every corner of her small classroom. As her room typically held 21 students, this felt very overcrowded, and Kristin was on her own. Her typical centertime policy of no more than four students per center could not apply. Because the classes shared behavior systems, if the clips of children from other classrooms were on the yellow, orange, or red levels, then they sat out from recess in increasing increments during this time, regardless of location. Thus, Kristin typically had several students sitting out, including some of her own. The individualized plans that she and the other kindergarten teachers had for so many of their students were not considered or implemented. During this time, Kristin was constantly moving around the space addressing issues, such as students crying, arguing, and beseeching her help or sitting frozen because the computers were not ready. Just making sure that everyone was okay was a big task.

Kristin agreed that the overall feeling of the room was very intense, but she seemed unflustered about it once the day was over. She explained, "I think it's good when they get to go outside because they get to run around, and two teachers can manage everybody. But I think inside there's too many kids in one room." After spending the day with her, I agreed. At times, it seemed unsafe because she could not be in so many places at once. Illustrating Kristin's laidback acceptance of so many of her grade-level team's wishes, when asked if she would raise this concern with her team, she said, "I could, but I don't know if it'll change, because everyone wants their free time. If we just had recess within your own class, then you don't get the free time, and I like the extra planning time too." So, because she did not bring it up, nor did she indicate troubleshooting solutions for improvement, problems with this time of day persisted. 
In sum, Kristin's winter. After spending time in Kristin's classroom mid-year, I fully realized the necessity of triangulation in qualitative research. Seeing the nuances of her classroom management, where it worked and did not, put the interviews and artifacts she had sent me earlier in the year into context. Many of her practices displayed thought and meaning, yet so many were problematic. In observation, I agreed with Kristin that most of her students were responding to the clip chart, because I noticed the immediate change in their behavior as she hinted at and then made changes to their clip placement. However, as I got to know her students over time, their curiosity, excitement and love stood out to me. Throughout the year, I would argue that because Kristin's students were so excited to learn and because of their love for her, there would have been any number of ways other than the chart that she could have encouraged them to properly behave. Additionally, the impact of the clip chart's public nature and the favoritism inherent within her use of the chart did nothing to build a sense of good-will amongst the students, nor to build a strong sense of community.

In talking with her specifically about the behavior conferences at the end of the day in January, our discussion revealed a deep-set difference in how Kristin viewed the role of the chart and rewards that was distinct from my perspective. When I asked her about the mini conferences she held with her students, she explained,

...I feel like they like the encouragement of it...Yeah, they get Doozie Dollars at the end of the day with where they are on the chart. But I feel like what matters to them more is where they are on the chart. Like the Doozies don't even matter that much to them. They just want to know...how they're doing.

To dig deeper I asked her whether the chart was the important piece of this, or the feedback she provided them, and she responded, “...it's the feedback.” I asked her if the feedback that they 
appreciated was actually the opportunity to connect one-on-one with her, because I saw how much they valued their time with her. She sheepishly admitted, "yeah," smiling. I continued, "so, is it the chart?" Her response was, "no...They like the encouragement throughout the day." She gave examples of what her students might be thinking, "Like, 'Well, she saw that I was doing my work well,' or like, 'Wow, my teacher, she sees that I'm doing what I'm supposed to be doing,' and it builds their self-esteem." I would not argue that her students were motivated by and needed feedback from her, as all children do. However, had I been her coach, I would have encouraged her to think about using that kind of encouraging feedback without the chart, e.g. just giving a high-five, celebratory praise, or a simple acknowledgement of "I see you." Despite our discussion, Kristin seemed to feel that the feedback she provided be inexplicably tied into her chart and its related systems.

Mid-year, the consistency she saw across her grade-level, and the positive feedback she received from others in the building about her students' behavior, validated her teaching and classroom management decisions, despite the issues I had observed. She explained, "When I have subs, they're like, 'I've been in every single kindergarten class, and your kids are the most polite [sic] out of any of them." She felt that this was the case because, "I guess I just teach them. It's just in my nature that I do it, and I don't know I'm doing it." Highlighting her selfassurance, and disregarding the many problematic topics I had observed and we discussed, getting this feedback from others in Monroe helped solidify her classroom management practices. However, because of these practices, there were issues that continued to persist as the year went on, and that ultimately affected her classroom community. 


\section{Into Springtime: “It's Been Going Well."}

When I returned to Kristin's classroom in the spring, she was excited to tell me about her students' growth. I noticed more words on the word wall and large heart-shaped posters with sight words hanging on clotheslines across the windows. She explained that she had introduced these constant-verb-constant (CVC) high-frequency sight words, called "heart words" in her class in February to teach them sight word vocabulary, and she said, "it's been super motivating! They love learning more!" Because of this, she was seeing daily improvements in their reading and writing. She animatedly recounted when they would say to her, "Look! I can read!" She explained that throughout their literacy centers, "as well as if we have five minutes here or there, they're spelling words to see who can spell it the fastest." In response to this, she turned their spelling competiveness into a game that the students called, "Team 1-Team 2," and her students adored it. Any extra minute in the day, students would ask to play the game, and I observed this in action in the springtime. Sitting and waiting for their turn to spell a word in front of the teams was so exciting. Their energy level was palpable. What made Kristin so proud was that students chose to play this academic-based game instead of playing elsewhere in her room during indoor recess. She explained, "They like the competition of getting up there because it makes it exciting to spell words," and she reported that they were mostly good sports about it.

Like Molly, seeing her students' knowledge and skills take off excited her. She explained, "The kids have learned a lot since January. I just like that now that everything is getting more-you know, they're reading more, and they're doing a lot more, they're super excited to learn." Talking about this brought out more passion and emotion than Kristin's laidback personality usually displayed, and it was hard to not also be excited with her. 
Classroom management in the spring. Throughout my springtime observation, I

noticed small changes that Kristin had made since January that helped her students stay engaged, and which helped her day flow more smoothly. For the first time, I observed her reviewing a visual chart that detailed the grouping of students for literacy centers (Figure 22). This chart encouraged the students to manage centers more independently because they could take control of knowing where they were headed and what they would be doing, instead of having to repeatedly check in with her, as they had done most of the year. Because of this, the transition to literacy centers went much more smoothly, than I had previously observed.

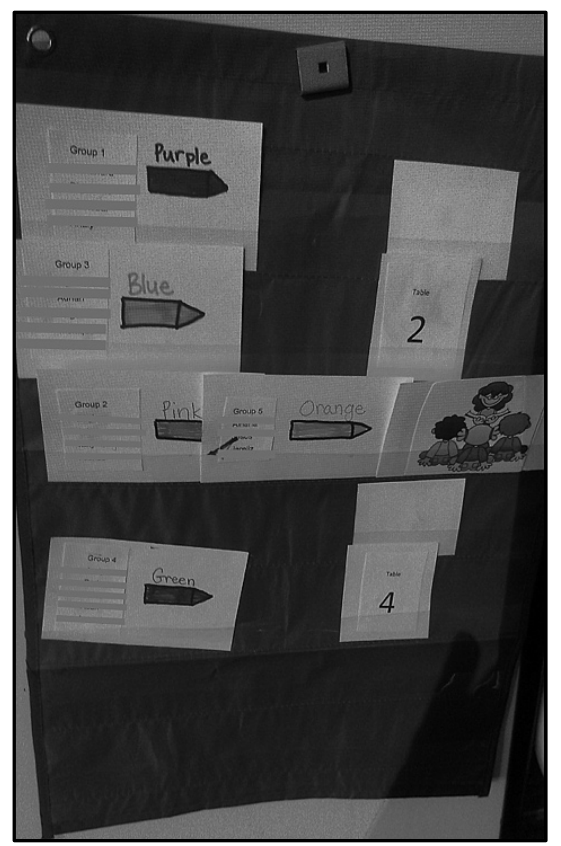

Figure 22. Kristin: literacy small groups organizational chart (3/15-5/15).

Kristin's relationship with Danielle, the ELL teacher, was going great, and Danielle arranged her schedule in the spring to also lead a small group during Kristin's literacy centers. When Maria was present, there were now three teachers leading these groups, and only one 
group was student-led, which also helped behaviors overall. For the one student-led group, Kristin explained that she was trying to engage her students in new and different ways so that they would stay on-task independently, which was also wonderful to see, as this highlighted Kristin's growth as a teacher. With activities like "writing the room," where they walked around wearing clear-frame glasses with clipboards and copying sight words she had taped on notecards around the room, students were now spread out across the space and excited about the task. She compared the way her centers had felt before, as "having them all...on top of each other," which I had observed, to now, where they "function better," with which I fully agreed. Not only was it fun and silly for students to wear the glasses to "write the room," but carrying their clipboards with pride, they were also they were delighted to do this task independently.

During literacy centers, I observed a great hum of noise as each group was on-task. I asked Kristin if her grade-level team members were also running their literacy centers like this, and I was surprised to learn that they were not. She did not share more, but I later learned that she had recently been evaluated by Mrs. Buchner, her principal. At the end of the year, Kristin shared with me that after observing her teach in February, Mrs. Buchner had given Kristin feedback where it seemed she was encouraging Kristin to build in more independence for her students during guided reading. While Kristin did not attribute the feedback to Mrs. Buchner, as she said, "After my evaluation in February, I made some changes..." It would seem that because of her principal's feedback on this evaluation, the positive changes relating to her literacy centers were made. Regardless, changes like this empowered both her and her students. After watching Molly struggle to get this kind of substantive feedback from her administrators, it was so nice to know that Kristin was getting it and putting it into action. This highlighted Kristin's continued 
responsiveness to feedback, and made me wonder what she could have done earlier with guidance like this.

When I asked Kristin in the spring how she felt her classroom management was going with the students, she paused for the first time in the interview, “...I just feel like it could be better, but I don't know." Having observed her overall management in January, I wondered if she was now noticing what I had seen. From what I could observe in the spring, in addition to the smoothness within literacy centers, her morning routines seemed much more automatic and independent than when I had visited in January. What had taken students over ten minutes to complete in arriving at school and getting to work on their worksheet then, now only took a few minutes. Yet, throughout the day, I observed Kristin's sentiment in action, as many of the same issues relating to her classroom schedule and instructional delivery persisted. She was now realizing this, as she explained,

The most frustrating thing is skills that I would expect them to know and be able to do, they just don't do. Like raising your hand to talk and working quietly and all of those little things that are just routine throughout the day.

After having spent most of the year in this classroom, it was reasonable for Kristin to expect that by the springtime, these kindergarteners would have a better handle on the procedures of the day.

In response to my question about why this might be, she replied, 'I don't know. It's probably part of, 'this is my first year."' While true in some ways, this response seemed to deflect responsibility for the many facets of her practice that she could control, regardless of being a first-year teacher. She continued, displaying more ownership, “or maybe if I'm not consistent in everything." After spending time in her classroom, this pinpointed what I had noticed. She explained that the most challenging aspect to her classroom management was, "my 
expectations for them at the carpet." While I agreed that her carpet expectations were somewhat problematic, I also noticed that her expectations for behavior were problematic at other points in the day. Outside of literacy centers, I observed her repeatedly calling for attention and providing countless redirections. I noticed this even more strongly when she was leading the whole class in completing worksheets at their tables. With Kristin's flow of large group all day long, the students were very easily distracted and with the lack of consistent empowerment and building of independence within them, they continued to be dependent on to her for everything.

In the spring, I observed the students still following Kristin throughout the day, with confusion and concerns. Although I observed her doing more modeling for activities than earlier in the year, it seemed she was still not truly setting students up with guidelines for an activity before dismissing them to begin. An example of this was again in math where they would be playing a dice game that day. Instead of first teaching the concept within the game and making sure they all understood, she first taught the concept of the game as she quickly modeled it with Veronica. Several students had questions that she cursorily answered. Without every really teaching or modeling the turn-taking aspect of the game, she dismissed them to play, leading to students running up to her with immediate questions. In another example, during writing workshop when Danielle was also present, the students were all working on their writing at the same time, and once Kristin announced, “Okay, start," hands immediately started flying up, "Miss Beiersdorf? Miss Beiersdorf? I need help!" Both Kristin and Danielle spent the entire time hopping from one confused student to the next. It seemed the need for the constant checkins were still connected to a lack of instructions and difficult tasks for her kindergarteners.

Specific times of day still frustrated her in the springtime. Because of the grade-level decision to change Words Their Way mid-year, Kristin now had multiple groups of students in 
her classroom working on word sorts, from across the five kindergarten classrooms. She was the only teacher who had two larger groups, focused on two different tasks for this activity. She explained, "I feel like there's no way I'm going to give them what they need, and then...it's just chaotic." However, because her grade-level team wanted this structure, she acquiesced. Considering other chaotic times of day for Kristin, indoor recess continued to be the norm, as the weather was persistently too dreary and cold to go outside for recess. Kristin was relieved to tell me that she was not on duty for recess on my observation day, as her entire class descended upon another Kindergarten room during this time. Alone in the classroom, she revealed how much she disliked indoor recess, and I understood why, remembering the chaos of this time of day in January. When I asked her if she had changed anything about the structure or policies of indoor recess, internally hoping that she had for her sake and that of the children, she responded, "nope." As such, the indoor recess problems remained. She felt that with time it was going more smoothly, but still not as well as during her center-time, when it was just her students and she had guidelines for the number of play participants in any given center.

However, during her center-time later that day, this time of day did not seem to go very smoothly either. Kristin spent the time pulling students to assess and then filling out the planners with the end-of-the-day clip position. I observed two students arguing, another one crying, and others frustrated by computers that were once again not working. Many opportunities for promoting conflict resolution and problem-solving surfaced, but I did not observe Kristin referencing the helpful guideline posters on her door, nor describing any sort of concrete way to help the children independently problem-solve. Instead, I noticed her becoming quiet and flat in her responses to students running to her with a problem and admonishing them to solve the problem on their own. 
Kristin shared that she felt like she was saying the same things every day, but students still struggled with what to do. When I asked her whether she felt her classroom rules helped, she responded, "The rules have just become something that they say, and they're not thinking." She felt they knew the rules, "but to apply them now, it's not as cohesive." She explained that she was not sure what to do. Because we had earlier discussed teaching mini-lessons related to behavior, I asked her if she would consider doing a mini-lesson to re-teach rug behaviors, especially. She hesitated and then responded, "Yes, but... when I say, 'You need to be following directions quickly,' that's their cue. But I don't know. I feel like I've been going over this all the time." At moments like these throughout the year, it was clear to me that the fact that she had not been assigned a mentor was hurting her, as she was searching for support.

In discussing these aspects of classroom practice with me, it felt at times like I provided Kristin with enough pauses to think through her concerns. After discussing her classroom management frustrations, she shared, "So, I think I need to take a new approach or something," which highlighted how she was beginning to think critically about her practices. Her ideas included, "Like for centers, if the kids are off-task, then I can do...a lesson on, 'okay_-' and model it. Like, "this is the right way. This is the wrong way." This sounded reasonable and helpful based on what I was observing, but she gave no indication that this is what she would do the next day. Again, she raised the idea of adjusting her daily schedule so that the writing and reading workshops were not back to back, but she still had not made this change since our discussion in January. As such, many of the same problems in the afternoon had persisted. Instead, she shared that this is what she planned to do the following year. Here, she acknowledged that her schedule was a part of her classroom management, but when I asked if she felt it would be helpful to post the schedule, she replied, "No, I think as long as it stays 
consistent, they get it. As long as it's not changing." Interestingly, this comment negated her earlier concerns about students not remembering the routines and procedures.

These issues across the day related to her classroom management, but Kristin did not connect these with her major management tools of the clip chart, Doozies, or conferences and question whether they were helping during these difficult times. Overall, she shared, "I think the chart is good, and the culture for learning and how they're always excited about everything." Her students were excited to learn. This was true. I observed it in their faces and voices. Also, Kristin felt that they knew how to respond to the chart, stating, "They're like, 'This is how I'm going to act because I know that this is what I'm supposed to do." However, for so much of my time there in the spring, they did not seem to know what to do, and she admitted as such.

Here, in the spring, I observed Kristin using the color chart more than at any other time. I tallied more clips moved on this date in March than in January or May. While she was still using the chart to encourage/ coerce behavior, such as "I like how I see Eduardo standing in line," and dramatically moving his clip for effect, here I also observed her using it more as a threat, e.g. telling students she was going to move them, but then not, or "Arlinda, raise your hand, or I'll move your clip down." Because of this modeling, I noticed the students using the clip chart as way to tattle on each other, as well, creating a toxic aspect within her classroom community. An example occurred when she was coaxing students to stand up for a brain break after a long period on the rug. I heard several students chime in with her, angrily saying, "Yeah, stand up, or you [Miss Beiersdorf] should move their names!” They pointed to the clip chart, and Kristin sighed and reluctantly said, "Yes, or their names will go down." Tattling had become much more rampant in the spring, as well. She was also still inconsistently using the chart, and students at this point called her out when she missed their name, such as, "Wait, Miss Beiersdorf, 
you forgot to move my name up!" At many points in the day, it disrupted student learning, such as when Arlinda, who was supposed to be writing, grabbed Kristin's arm, and asked, "Miss Beiersdorf, are you gonna move my name up since I did good now?” If Kristin noticed these aspects of her practice, she did not mention them to me, but I sensed the students' hurt, frustration, and anger towards her and others from her clip chart behavior.

In many ways, Kristin had become much swifter with her consequences and punishments in general, with or without the chart. Overall, I noticed her being less reflective with students as she had in the past. Instead, she was much quicker to correct and punish by moving their clip down the chart. In one extreme case, I observed her take out her frustration from the hectic Words Their Way inter-class activity after students returned to their homerooms and only her students remained. Kristin loudly reviewed whose clip was the lowest on the chart, implying who would be missing out on recess that day. When she realized that her name was called, one little girl cried out, "No!" With an uncharacteristically stern face, Kristin turned to her, "want more?" The little girl whimpered and stopped crying, but still seemed very upset.

Despite many issues throughout the day, Kristin felt strongly that the chart was teaching her students how to behave. However, I observed her using it absent-mindedly in the spring, and thus missing a teaching component altogether, when Arlinda asked her, "Miss Beiersdorf, I see my clip. Why am I there? Was it for before during lining up?" Kristin replied, "No, Arlinda, I don't think so. I must have moved you down for something else." Yet, Kristin did not share when that was, and Arlinda walked away looking frustrated and confused. Examples like these highlighted how the chart did not seem to be building a sense of community within her space. Instead, the chart created embarrassment, distractions, and opportunities to demean the students. 
In the spring, she shared that while she was seeing some gains for her students with challenging behavior, but that she still observed regular defiance with Carolina, and with Javier, who she said was "really a preschooler." Alternatively, Nico had made tremendous gains, as she described, "He's one of my brightest academically now." Despite this, she reported that he still got stuck starting tasks. She explained, "I had...graduated him from the picture chart because he was doing fine without it. Then there's...today where he doesn't get started." She did not mention whether she would bring the tool back out again. In the spring, she also brought up another student, Isidora, for whom she described, "academically, she can't do anything." After working with her for so long, Kristin had realized that the little girl was remembering very little of what they did during the day. She noticed that when Isidora worked with Maria, they saw small gains with her, but for the rest of the day, she seemed lost. She asked me for feedback, and I asked her if working more with her in a small group format would help, as so much of the day was still taught in a large-group format. Kristin seemed to disregard this idea and went back to describing their issues with this student. Because she let it go, I let it go as well.

All of this related to her individual classroom in the springtime, and Kristin felt that what she was doing in the classroom related closely to the other PBIS practices at Monroe. Contradicting this statement, I observed her not participating in a school-wide practice on my springtime observation. Because Kristin felt that her students had not been listening, she did not allow them to use their Doozies to buy prizes from the Doozies Cart when it stopped outside their room mid-day. Hinting at a bigger issue with the Doozies and the cart, she later shared that she was going to let them go out to the cart, but "I think I just decided that I didn't want to deal with it today because it takes so much instructional time." Kristin and I also discussed a Cool 
Tool that I had overheard on that morning's announcements. In the announcement, the woman had said,

Remember boys and girls, that we have been learning about appropriate language at school. That means no swear words, no dirty words, you know, no racial slurs, no sarcasm. Those are all things that people use to hurt other people's feelings. Here at Monroe, we use appropriate language instead.

However, this speaker did not outline what "appropriate language" included, and the announcement continued with birthdays. Kristin's students paid as little attention to 'Cool Tool' announcement as the one I had heard in January.

When Kristin and I discussed the messaging of this Cool Tool later, she shared, "I feel like it's appropriate for $2^{\text {nd }}$ grade and up, but I feel like with them, they don't even know." She was not sure if her students needed messaging about inappropriate words, stating, "I guess I could still talk about it in kindergarten with manners and using polite words and being nice and respectful..." However, on this day, I did not observe her having this conversation with them. This again led me to think that Kristin did not reinforce the Cool Tools much in her classroom, even though this prosocial aspect of PBIS could have helped her classroom management and her sense of community.

In sum, Kristin's spring. In describing the mentor-mentee relationship that she had forged with Danielle, as well as working on her grade level team, as well as her overall teaching, Kristin explained, "it's all going really well." However, despite observing moments of introspection and critical thinking from Kristin and seeing moments in the day where she was applying new ideas and making positive changes, many of her classroom management issues from earlier in the year persisted. While she was already thinking about positive changes to her 
daily schedule, curriculum, and overall teaching for the next year, she still had a few months to go with these students, and it did not seem that she felt the impetus to make any changes despite the frustrations she shared, and I observed. The sheer number of students who continued to struggle with aspects of her classroom, including the clip chart, seemed to not register on a deeper level with her, and seemed to give her little pause to reconsider her methods. Consequently, the feeling of community in her space was consistently challenged.

\section{The End of the First Year: "I Think the Color Chart Has Worked Wonders..."}

At the end of the first year, Kristin still had an optimistic outlook on her teaching. When asked how things were going, she responded, "I think it's gone surprisingly well for how I was just kind of thrown into everything!" I reflected upon this statement later, as she had been hired on June 20th for a late August start date. I wondered what she would have thought about Molly's last-minute hire date. Specifically, she shared, "They all love school, and I love that!" The students were constantly telling her, "You're the best teacher. I don't want to ever have a different teacher. I don't want someone to come. I want to come to school." I also noticed their excitement on my last visit. One turned to me in the morning and whispered, "Mrs. Hamann, we have only seven more days of school!" I smiled and responded, "wow!” Kristin was seeing growth across the board with their academic skills, and their language skills had exploded. At the end of the year, there were few changes to the classroom environment, including new assigned seats for a few students, new posters of rhyming words on display, and additional numbers on the number line circling the room, illustrating that the school year was almost over.

In taking stock of Kristin's teaching practices at the end of the year, I noticed many positive changes. It seemed that she was taking feedback from her principal, Danielle, and possibly even from our conversations and applying them to aspects of her day. Yet, for every 
positive change, issues remained because of both her schedule and dominant form of instructional delivery.

End-of-the-year classroom management. Although she did not connect this to her classroom management when I talked to her about her management practices, one of the highlights of my last visit was seeing that Kristin had built in more opportunities for her students to be self-reliant and independent throughout the day, helping her students be more engaged and on-task. I noticed that there was a tall colorful cart in the back corner of the classroom, and during literacy centers, students independently went to the cart and selected differentiated worksheets and writing templates. Kristin proudly told me that she had cheaply purchased the cart. After assessing their reading levels, she assigned them to one color of the cart, and with two drawers for each, students could pull their own worksheets based on that color. Here, she connected the reason for implementing the cart to her principal evaluation in February, but she again, she did not credit Mrs. Buchanan for this idea. When I asked if her evaluative feedback was that she purchase a cart, she got to the root of the feedback and shared, "No, it's just...for not losing instructional time with sending students to get to work. So, they can just grab it and get started." From this, it seemed that Kristin had received feedback mid-year related to how many instructional minutes were wasted when she insisted that she check all of her students' work, but it was only at the end of the year that she was fully implementing this feedback.

The colorful cart contributed to a time of day that seemed Kristin's strongest at the end of the year. On my last observation, her literacy centers ran more smoothly than ever before, as well as more smoothly than any other part of her day. She was still using the organizational chart from the spring, so that, coupled with these drawers, helped the students manage their behavior more than they were encouraged to at other times of the day. There was still quite a bit 
of up-and-down behavior for the students working independently on their word sort worksheets, because they would pull the sheets independently, but then were unable to read its directions, or they would race through the worksheet in order to excitedly retrieve another. Despite this, I saw this time of day as one that showed the most growth in Kristin's teaching, and one of the best for her classroom management.

However, Kristin felt differently. At the end of the year, Kristin honed in on the issues that I had seen for her literacy centers over the course of the year, and she described her biggest classroom management concern as "during literacy centers, running that smoothly." She described not knowing how to best help her kindergarteners be independent during this time because of their vocabulary questions. She explained, "I could tell them the picture, but they'll forget, and they don't know what it is. And then, I don't want to prevent them from succeeding on their work by saying, 'Oh, you can't come to me,' because then they're not gonna finish their work." Here, Kristin's comments highlighted how a coach or mentor could have helped her address her concerns. While the students' language needs that she now acknowledged were one reason that literacy centers and other times of the day had issues, they were not the only reason.

In the theme of student empowerment and Kristin's growing teacher skills, I noticed several other changes she had implemented at year's end. I observed her encouraging students to clean up after snack using a dustpan and broom where before they had left scraps and crumbs, and either the room stayed messy, or she would clean it all up. I also noticed more 'withitness' from Kristin throughout the day. Where before she tended to position herself with her back to most of the students, on my last observation, I noticed her turning and re-positioning herself more often, so that she could still see everyone when she bent down with a student or was working with a small group. Although not perfectly executed, as she missed several issues 
during rest-time because she turned away from a big group on their mats, overall, she seemed more cognizant of her positioning as an aspect of her classroom management.

In addition, Kristin described being responsive to the fact that her students were not resting during rest-time, and she made subsequent changes. She explained, "I gave them a book instead." Now, students took their reading bins with to lay on their mats. Kristin described this as a time now where the students "read to themselves," and this seemed supportive of their development, getting them ready for $1^{\text {st }}$ grade. She was also more focused on prosocial skills than I had observed her be in the past. In the last few weeks of school, she started an activity during their calendar time called "Special Person." Tying this into shared writing, one student a day was picked to be the special person, and as a group, they would make a poster about this child. Kristin was the scribe, and the students asked the special person two questions, and then this child picked three students who gave him/ her compliments, such as "she is a good friend, and "he is good at reading," which Kristin called "happy talk." At the end, the special person signed the poster and took it home. Kristin felt that this helped with their writing and spelling skills, and "it's great for the classroom community." She explained that this activity had boosted the confidence of some of her quiet students and helped them learn how to use positive language. In my observation of this activity, the atmosphere in the classroom did feel very positive and students were excited to share. It was disappointing that this meaningful activity had not been used sooner, because for so much of the year, prosocial skill teaching had not seemed a priority. Without focusing on this critical aspect of classroom management, Kristin's students inevitably encountered many conflicts throughout the year without an ability to solve them independently, and the sense of community had been negatively impacted. Yet, activities like this helped at the end. 
Despite these positive changes, many of Kristin's teaching and management practices at year's end were in line with how she had been teaching all year. Regardless of the positive change at rest-time, student behaviors were very similar to those in January and March. Students were still chattering across the shelves, popping up and down, and staring into space. Some students flipped through books, but very few students truly read anything while I was watching them. With no practiced or posted guidelines of rest-time expectations, consistent followthrough, nor alternatives for students who did not want to lay down, the off-task behaviors of rest-time had stayed the same. Additionally, doing the special-person activity did not mean that the whole day was conflict-free. For example, later that day, I observed Carolina stick her tongue out at Arlinda after Arlinda yelled that Carolina was reading aloud too slowly.

In addition, while the routines of the literacy centers had been improved, overall, Kristin described seeing "pretty, on and off" behaviors from her students, especially in remembering basic guidelines and procedures, and I noticed this on my last observation. She offered two reasons for this including the current rainy weather and the inability to play outside over the very long winter months, as well as the fact that it was nearing the end of the week. She explained, "the end of the week is always challenging because they're just kind of tired and done, and it's hard to get them all to listen..." She did not mention seeing a connection between her students inability to remember the routines, and the fact that there was still no posted schedule or guidelines for procedures.

Every morning, Kristin still lead the students in practicing the class rules, but she did not identify whether these related to her students' issues with remembering routines and procedures. At the end of the year, she reflected upon these rules, saying, "At the beginning of the year, it's like, 'Okay, I'll do this because everyone else is doing it,' but it wasn't the greatest thing." She 
explained that she felt that her students understood the language of the rules, and so when she said a rule to them, they knew to be on-task. However, as exemplified by the issues with her routines and procedures, as well as other behavior issues that still arose at the end of the year, it did not seem that the rules had worked as she had wanted.

One reason for this was because she was still inconsistently providing clear and meaningful directions for students before expecting them to work independently, and this, coupled with the large-group format of delivery and worksheet-based activities, continued to create a difficult combination to overcome. While she had shared how frustrating the students' up-and-down behavior and dependence on her was earlier in the year, because she had not changed these critical pieces of her practice, these behaviors were still present at the end of the year. On my last visit, Kristin seemed much more frustrated by this than in times past. After one lesson where I counted 15 different students who either asked a question or got up and walked to her, she exclaimed before the time was over, "Okay, everybody, put your papers in the bin!" She pointed to a bin on the bean table in the back of the room. Because the students were in the middle of their work, several shouted, "Wait!" "Miss Beiersdorf!" "I'm not done yet!" Kristin felt overwhelmed and told them that it was fine. They should just put their work in the bin. It did not seem that she had applied the feedback we had discussed about incorporating more small group instruction versus the large-group format where her students seemed to get lost and need to depend on her so much.

Like Molly, one consistent classroom management strategy that I observed Kristin yearround was verbal praise. In some cases, this was celebratory praise meant just for the students who received it, such as, "I really like how Javier and Rafael are waiting patiently for their turn!" At other times, it was intended for the larger audience and meant to encourage/ coerce 
appropriate behaviors, such as, when she sternly looked at those who were off-task and stated, "Well, I really like how Veronica is working on her own. I love how Mateo is staying in his seat." As it had for Molly, this tactic brought mixed results in the beginning of the year, and by the end of the year, very few results, as the praise some students received failed to motivate the rest.

Her praise connected with Kristin's use of the color clip chart, which was still a big feature of her practice at year's end. When I asked how she felt her classroom management was going, her first response was related to the chart, as it had been all year. Despite her continued frustrations with behavior in the classroom, she shared, "I think the color chart has worked wonders in the class." Per Kristin, the students loved it. In describing this love to me at the end of the year, she said, "If I didn't have it, part of their love of school, I feel, would go away." This was an unsettling comment, and I tried to suppress my look of surprise and dismay, as she said this. I had come to know Kristin's students as loving school because they loved her and they loved learning, regardless of the chart. She seemed unaffected by my reaction and continued, "But if I didn't have it at the beginning, maybe not...but I just feel like they love that encouragement throughout the day." This was Kristin's consistent reason for keeping the chart all year, but this belief dismissed the many issues that were related with her continued use of the chart, and its impact on the sense of community in her room.

At my last visit, there were again many references made to the chart throughout the day, both by her and her students. The same students were still missing out on recess because of downward clip being movement, and I observed several examples of how distracting the chart was for the children. This was exemplified by two little boys, already sitting in correct positions on the rug, who got up and left their spots to check on the placement their clips because Kristin, 
to encourage/ coerce the others into coming to sit on the rug, had mentioned moving up clips. I also noticed confusion as Kristin moved up the clip of a little boy who was just doing what he was supposed to be at the tables. He looked up at her with confused look on his face, and asked, "Me?" He seemed to have no idea why his clip had been moved. In addition, highlighting how pervasive the chart was across all contexts in her practice, I observed Kristin strangely using the chart to explain the word, "punish" to her students during a read aloud that afternoon. They encountered the word in the story, and her students were unsure of its meaning. To help explain it, Kristin used a reference to the clip chart, saying "Okay, like how red equals no recess and call Mom and Dad." Emphasizing its omnipresence in the classroom, her students readily accepted this definition, and in pure Kindergarten sweetness, one little boy interrupted her to ask how she had all their parents' phone numbers. In this explanation, Kristin identified that a move down the chart was a punishment, which was problematic for building a sense of community where one can learn from mistakes.

In reflecting on how her classroom practices had aligned with the bigger school-wide pieces of PBIS at Monroe across the year, Kristin confidently shared that they had. Using the clip chart and passing out the Doozies linked her class to the school-wide systems. Following up from my last visit, I asked if her students had gotten to use the Doozies Cart since then, and she responded that they had. She explained, 'I've been fine with it [the cart]. I think just because that one day, you were here, and I wouldn't let them have it." She reported that she did not have problems with students who had not earned enough Doozies shopping at the cart because "everyone has at least one where they can get something small." Yet, shopping at the cart took up one of her whole subject areas, which she did not like. She explained, "I feel like the color chart is enough without the cart for my class...but not for the whole school. I don't think my 
class needs it all, but it's a school-wide thing and I think other classes definitely do.” As such, she followed along with its use, even though she disagreed.

At the end of the year, Kristin felt her biggest challenges still related to her students with challenging behavior. She explained that the one area that she felt did not go well all year was, "Just like knowing the best way and how to manage the one person with hard behavior." By year's end, she had seen gains for these four or five students, and I noticed growth in each of them academically and behaviorally. Although she did not mention Nico, Melitza, or Isidora in our final conversation, she did share that for Javier, "It's very rare that he's physical with anybody," and for the twins, she shared that she noticed a big positive difference for them when mid-year, the content had become more challenging. She admitted, "I mean there's been gains, but it's not like any of it disappeared..." On that day, I noticed Delfina have a wetting accident, which Kristin said had not happened in quite some time. While Kristin described these students and their challenges as worrisome and problematic, and I would not disagree, what most impressed me was her problem-solving for each and tailoring her responses to each student. I noticed her taking the day in stride, both with Delfina's wetting accident and with Carolina's moments of sassiness throughout the day. Although Kristin's focus on learning more about them and her efforts to try new ideas to better reach each of their needs had seemed very inclusive, at year's end, it seemed her classroom management tools had not consistently helped these students who struggled in different ways, which in many ways, disconnected them from the rest of the classroom community.

Failing to acknowledge this, Kristin described the feeling of community in her classroom by stating, "the classroom community has been good." She justified this statement by explaining, "At the beginning of the year, with the hitting, that's gone. It doesn't happen 
anymore. I think he [Javier] learned that, 'you can't do that at school,' because I don't think he knew." It seemed that she was saying that because Javier was no longer hitting, now she and her students had a good classroom community. While I did not disagree that it was good that Javier had learned to stop hitting while in the classroom, this was not the reason that I believed she had developed a feeling of community within her classroom. Where I noticed aspects that contributed to the sense of community in her space happened earlier that day, when Kristin's whole demeanor had lit up as she shared details with me regarding two recent events with her students and their families. The first was a Kindergarten-wide Mother's Day event, and the second was a Cinco de Mayo celebration with just her students. With both events, she credited much of the work to her grade-level team and Danielle and Maria, yet with both, she felt tremendously proud because working with her students' families had been one of her biggest concerns all year. The Cinco de Mayo event was especially important, as her students performed a traditional Mexican dance in two presentations, one for the school and one at the local library. They had practiced every day for a month. As she proudly scrolled through the photos of these events on her phone, she showed me images of the students with their families, and their smiles said it all.

Contrasting with the overtly competitive, punitive, and at times, demeaning aspects of her classroom management tools, these positive events highlighted a sense of community that Kristin had built with her students, their families, and the local community. Even though she had not felt fully comfortable interacting with her students' families, especially because so much of the communication had been through Maria translating, she welcomed them into her classroom more than either of the other two case study participants. In the last week of school, Kristin planned to invite the families to her classroom one last time for an awards ceremony. Kristin explained, 
"So, every child earned an award for something they excelled in this year, like 'subject areas,' 'fantastic friend,' 'handy helper,' 'brightest smile,' 'lovely listener,' etc.” She described asking the specials teachers to nominate students and planned for them to walk down a "red carpet" made of butcher block paper to accept the award in front of their friends. Despite the ups and downs of her first year, Kristin had worked hard to form relationships with her students, and this is what shone through at the end.

In sum, Kristin's end of the year. Throughout the year, Kristin struggled to make connections between what she was doing at Monroe and how she had been prepared at the university. When the topic of her teacher preparation would come up in our conversations, Kristin commonly responded vaguely. Over the course of the year, I learned that she felt, "I learned the most from my student teaching placement." Only from that experience, did she feel any connection to her classroom management practices of the clip chart, Doozies, and behavioral conferences. She attributed her knowledge of literacy instruction to her clinical experiences and to one literacy course taken in her senior year. She took a critical stance reflecting on her ESL preparation at the university, and felt that it had been lacking. Again, she felt she learned the most about how to teach ELLs while in the field.

At the end of the year, Kristin was more reflective than at any other time in the year. When learning about theorists in her preparatory program, she remembered thinking, "“this is stupid, why do I have to learn this?' But now I'm like, 'no, I'm really glad I learned that!'” Not only did she feel that learning about theorists like Vygotsky and concepts like Bloom's Taxonomy helped her complete her edTPA, student teaching assessment, but also, it was, "like everything you do. So, if you weren't taught how to scaffold, then you're not being taught how to teach." She credited the MSTC "brand" with getting hired at Monroe, because she felt her 
administrators looked favorably on the institution, and she believed that the literacy instructional skills that she learned there gave her an edge in the interviewing process.

Kristin described working at Monroe Elementary for her first year as "great!" She had been worried about teacher competiveness and drama, but she did not believe that teachers there behaved in this way. She explained, "Yeah, everyone supports each other." She felt that she truly fit in at Monroe, and she had a relationship with every teacher, especially Danielle. In discussing this relationship, she shared, "I couldn't have had a better mentor." Unlike the other case study participants, Kristin had also formed community relationships outside of the school. As compared to Molly's experience, some of Kristin's biggest highlights over her first year were done in collaboration, making her various teams including her grade-level team and her classroom team of Danielle and Maria, such important players in her first-year experience. While her teaching and classroom management practices inconsistently displayed traditional early childhood messages of autonomy, democracy, self-regulation, and care for others, challenging her ability to build a sense of community. However, it was clear that Kristin cared about her students and felt welcomed within the larger school community of Monroe, whose presence was in many ways, one of the strongest influences on her first-year teaching experience.

\section{Beyond the First Year: "What Can We Do Better, and What Do These Kids Need?"}

Kristin intended to return to her same position at Monroe the following year. Smiling, she shared that her grade-level team told her, "You won't be the new person next year! You won't be the newbie!" There was to be another new Kindergarten teacher next year, and working on the team again excited her.

From the Fayette district preschool, she knew that there were 17 ELL students who were set to start kindergarten in her room the following year, and she believed that most would be 
Spanish-only speakers at the start of the year. Because of this, she planned to use what she had learned this year in order to hit the ground running to best support them. Kristin would again be working closely with Danielle, because "she's gonna be mentoring all of the ELL teachers because everybody is new to ELL." The following year, Monroe would have ELL classrooms at kindergarten, $1^{\text {st }}$ and $3^{\text {rd }}$ grades, and at $2^{\text {nd }}$ grade in as a special education class. Of these classrooms, two teachers would be new and from MSTC, as well.

Regarding her classroom management plans, she planned to keep "the color chart and Doozies" the same, and she planned to use the Whole Brain Teaching classroom rules again despite her initial reluctance and the mixed results from her first year. More importantly to her, when I asked about her classroom management plans, was that "a lot of the curriculum will be different." This comment illustrated that she was seeing her teaching and classroom management as more intertwined and co-dependent by year's end. In discussing her future teaching plans, she took on the most critical and reflective stance I had seen her use all year. She spoke with confidence that the curricula that she had used this year had not been what was best for her ELLs, and so "Next year, we're doing a lot of things differently based on what they're missing." She described wanting to do what these students needed, as their needs were different from the rest of kindergarten.

In collaboration with Danielle and Maria, and based on feedback she had heard about ELL students struggling in other grades, she planned to overhaul her reading instruction to focus more on comprehension strategies, saying, "I mean comprehension is where ELLs struggle." In addition, she planned to introduce sight words and guided reading instruction earlier in the schoolyear, because she had seen how her students this year had flourished, and she felt an earlier introduction would be beneficial. Additionally, she intended to adjust her daily schedule 
so that students would not be seated at the carpet for as long, and this on its own would have significant benefits. After attending a math workshop at the kindergarten conference about number sense, she was also excited to take the math curriculum home over the summer, "and every lesson that's not Common Core, supplement Common Core..." Her classroom team also decided to utilize Maria's Spanish skills in the following year to provide more Spanish-language support for the kindergarteners, especially in math and reading. Here, she showed strong understanding of what ELL students need, stating,

Because the kids that are strong in Spanish need it, and they're not going to be learning the skill if they're trying to catch up with all the English. So, if you can teach it to them where it's easier to learn the skill, then they can learn the English. If they've already heard the book in their language, they can understand more when it's in English.

She shared that at this point, she and her colleagues were asking, "What can we do better, and what do these kids need?" Kristin was animated and excited describing these changes for her second year, and she felt confident that they would improve her overall instruction. Because of this, it seemed her overall classroom management would most likely be positively impacted as the curricular choices of her first year had had such a major bearing on her overall management, as well as the sense of community in her classroom.

\section{Kristin's Year, a Metaphor}

My experience working with Kristin across her first year was a rewarding one as a researcher and a teacher educator. Kristin was the only participant for whom triangulation of sources provided such strikingly different realities; one, the reality that Kristin described, and the other, the reality that I observed in her classroom practices. Kristin was unlike any of my other participants in that many of her interview responses were one-word phrases, such as "right," 
"yeah." "uh-huh." The times that I saw her become most alive and descriptive were when she discussed her teaching, especially when she was describing her own ideas, and when this correlated with her students' growth. Kristin's self-assurance led her to be surprisingly laidback in her first year of teaching. This allowed her to move through the year with what appeared to be less stress than one might assume for a first-year teacher, and yet at times, it seemed that these personality traits prevented her from thinking more deeply about some of her teaching practices. This especially related to her classroom management practices, including the clip chart and rewards. The amount of time each day that was spent on these aspects of her practice was reason alone to think critically about their use in her classroom, in addition to all of the other negative outcomes of using them. For most of the year, it did not seem that Kristin realized this. However, her small pushback of rejecting the Doozies cart because of time constraints in the spring hinted that she may have been realizing this aspect of using these tools.

Kristin was welcomed into the Monroe family with open arms, and in some ways, the support she felt there was what she needed in her first year. The strong school-wide presence of PBIS at Monroe that mandated many aspects of her classroom management, her strong gradelevel team that constantly encouraged her, and her strong teaching team that supported and stretched her thinking were each a component of the first-year experience that teacher preparers would want all teacher graduates to have. Kristin's sense of teaching self-efficacy in her first year was enhanced by being a member of these various teams, as many of her successes across the year were because of them and with them.

However, in other ways, these same components are what challenged her classroom management and ability to build a strong classroom community in her first year. The teaching norms of Monroe related to didactic, worksheet-based, one-size-fits-all instruction, and this 
sharply contrasted with Kristin's teacher preparation, as well as with NAEYC standards for early childhood education. Additionally, the strong presence of PBIS and the school-wide aspects that Monroe closely adhered to presented her with a model of the clip chart and rewards-punishments that she did not challenge. Once she observed most of her students responding to these tools, and the community around her validated this observation, she believed that these tools were what her students needed. Her comments throughout the year indicated that she inexplicably felt that her classroom management was these tools, and these tools were her management. With the very green eyes of a new teacher in the field, under the heavy presence of these various components at Monroe, and without a constant coach or mentor, in her first-year, Kristin did not appear to recognize that her teaching practices were directly and expressly connected to her classroom management decisions until the end of the school year. These tools alone worked against her ability to build a sense of community. The clip chart and rewards-punishment system at Monroe illustrated top-down management versus a more democratic approach, student dependence on the teacher for regulation versus self-regulation, and exclusion from the classroom community versus inclusion within one, all aspects working against a sense of community within classrooms. Additionally, because independently, Kristin did not consistently empower her students through her strategies and practices, her students lacked overall autonomy and many conflicts surfaced. Ultimately, the Monroe norms led Kristin to use classroom practices that in many ways created classroom management problems for her and negatively impacted the sense of community within her classroom.

It is for these reasons, that I have applied the metaphor of 'Skinner's Ideal' for Kristin in her first year of teaching. For PBIS to be effective school-wide, various components need to be present. Monroe provided the school-related components, and Kristin's easy-going nature 
provided the individual teacher-related component of smooth buy-in. Kristin in her first year, easily coalesced to Monroe's norms at the school-wide level, as well as at the grade level. Although she aligned with another teacher in the beginning of the year who was pushing back against the status quo of a purely punitive behavior monitoring system, this was the only example where Kristin questioned what she was being asked to do by the larger school in the name of classroom management. Even when she was not quite comfortable, such as with the Whole Brain Teaching classroom rules, or indoor recess, or the scripted curricula, she agreed to do what she was told because the group was doing it. Not only did she follow along, but in doing so, possibly behavioristic aspects of teaching that she had seen before in her own upbringing and field experiences became even more engrained in her practice. Seeing the teacher as the all-knowing persona, the rule of "keep your dear teacher happy," the emphasis on direct instruction for so much of the day, making students check in with her throughout the day, the competitive nature of the clip chart and other competitions in the classroom, and the rewards and punishments of the clip chart were all trademarks of a behavioristic model, and she seemed to wholly buy into this instructional theory.

I reflected on whether what my analysis was related to the fact that Kristin was a firstyear teacher. Possibly, she followed along easily because she did not want to "rock the boat," as Molly had described. However, upon reflection, I do not think that this was the case. At no point did Kristin indicate that she felt this sentiment, and in describing her conditions at Monroe and the practices of her classroom, she rarely displayed angst or discomfort in implementation or description. This sharply contrasted with Molly's experience.

Despite her easy acceptance of PBIS and classroom practices at Monroe, Kristin began to push back within her teaching in small ways by mid-year. I observed strong motivation from her 
to begin to do better by her students, who it seemed in some ways, she felt were disadvantaged by school because of their language needs. Kristin's sense of agency was high throughout the year, and she was responsive to support and feedback, trying new ideas even up to the end of the year. She implemented many solutions based on feedback from others, and at each turn, her practice began to improve. However, without an official mentor or coach, or a designated responsibility to Danielle to provide mentorship for her outside of her co-teaching duties, many of Kristin's questions and concerns were left unanswered, and her practice was left untouched. While Danielle's and her grade-level team's support were helpful and at times, pushed her thinking as a teacher, a more frequent and impartial observer could have significantly aided her at multiple points across the year. I will make the case for her, as I did for Molly, that for these reasons, she was primed for coaching. Throughout the year, she seemed to be seeking someone in a coaching position to observe her practice and to push her in her thinking. No matter how much I wanted to help her in this way, this was not my intended researcher role for this study, and I felt powerless to do more.

Despite this, on her own, Kristin was possibly breaking the Skinnerian mold as she considered her future as a teacher. By year's end, I observed her thinking much more critically about her curriculum and teaching, as well as beginning to understand that her teaching and classroom management were interconnected. Kristin's focus on the relationships she was forming with her students throughout the year, and their families towards the end of the year, especially in thinking about these students as individuals, resounded of humanistic, communityfocused tendencies within her, even while she was using a very behavioristic form of classroom management through Monroe's norms. Her focus on building up her community at the end of 
the year with practices in and out of her classroom did not correlate with the competitive components of behaviorism at Monroe that she had used all year.

As such, there was a possibility that she would break the mold of Skinner's ideal and potentially push back against some of Monroe's norms in the year to come. In her second year, what would be most interesting would be to see if the Monroe model would still be as strong for her, especially as it related to her specific classroom management practices. If she were to consistently use more meaningful curricula across the day, combined with a smoother daily schedule, the clip chart and rewards-punishments would be some of the only pieces working against her ability to build a strong, inclusive classroom community, and possibly she may not see the need to use them quite as much as she had this first year, if at all.

The remaining question regarding Kristin's story is whether "Skinner's Ideal" is the norm for new graduates. As teacher educators, do we prepare teachers to walk into settings like Monroe, and soak up the practices there without questioning? Or is Kristin's experience the norm for the first year - trying to figure out one's own practice and slide under the radar? Kristin never let on that this was the case for her first year, but I recognize that she may not have felt comfortable divulging her discomfort. Like Molly, it is important that Kristin's story has been told, and that we read her story for insights into where supports and challenges are at for every stage of preparing teachers for, and then supporting them in the field. Additionally, meaningful questions of community arise out of Kristin's story. I do not deny that there was a sense of community within her space related to the relationships she built. However, so many of her daily practices challenged her ability to build a feeling of community, and more than once across the year, this feeling seemed missing. Can there be a sense of community within a classroom if the classroom practices do not support all students? Can there be a sense of 
community when students are on display or ostracized? Can there be a sense of community when students are excluded? I believe that after telling and reading Kristin's story, these are important questions to continue asking. 


\section{CHAPTER VII: VANESSA: THE SHOOTING STAR}

The third participant in the case studies, Vanessa Jansen, a tall and slender white woman with straight brunette hair and olive skin was 22-years-old at the start of the school year. Family was a big part of her life, as she lived near her extended family in the western suburbs of Chicago with her long-time boyfriend. When I met Vanessa in her junior year of teacher preparation, her strong and passionate personality was what impressed me most. As a teacher candidate, she was dedicated, well-liked by her classmates and faculty, considered a "good schoolie," laid-back, yet a high-performer. I was her clinical supervisor for two semesters of field experience leading up to student teaching, and I was also her course instructor for her social studies methods course in her senior year. Like many teachers, Vanessa grew up very near where she ended up teaching.

She described knowing that she wanted to become a teacher after starting to work with young students while in junior high. She explained, "It was always something that was fun to me, and it seemed more of a privilege, rather than a job." Becoming a teacher was the only career path she could see herself following and continuing to feel fulfilled in because every year was different. Because of this, she felt that teaching was "impactful in your own life!" The fact that she could help people is what ultimately led her to pursue this career.

\section{The Path to Become a Teacher}

Vanessa felt that Midwest State Teacher's College was a great place to begin this journey. She began her teaching career as an early childhood major at the university directly after high school, and by choice, she ended her program with a traditional 16-week student teaching placement. 


\section{Student Teaching}

Her student teaching experience took place in a $1^{\text {st }}-2^{\text {nd }}$ grade split classroom at a suburban elementary school, Washington Elementary, west of Chicago. This was in the same district, District 27, in which she would later be hired, and was not far from her childhood home. Like Molly, choosing to complete a traditional student teaching placement, versus being a part of the PDS program like Kristin, was an intentional choice on Vanessa's end. She selected this option because she knew that this was the district in which she wanted to find a job after graduation. Washington Elementary implemented the PBIS framework, and Vanessa described her overall experience there in a very positive light, stating, "I loved my placement! It went really well. My class was awesome!" Because before this, she had never experienced a multi-grade classroom model, she felt that teaching there was a helpful experience.

However, Vanessa also reported stress from this experience, stating, "There were a lot of background politics that I was exposed to though in that position...There were big changes happening in my school, and we, as student teachers got kind of caught in the middle of it." Despite these issues, this experience provided her with valuable insights into one of the most sought-after districts in the state and gave her experience with the politics of educational settings. She described District 27 as, "...really unique in the way that the day is designed and set up," and she felt "lucky" to have been placed there. Despite the differences in student populations across the schools in the district, she believed that there was strong consistency in regards to curriculum and technology, which she felt would be helpful when on the job hunt.

Vanessa described feeling comfortable with the successes and stresses of her student teaching experience because of her teacher preparation. She stated, "By the time I got to student teaching, I realized this is a different world of my comfortability and how prepared I felt." She 
described this as a good thing. Like Kristin, she felt very prepared before beginning student teaching, as she stated,

Someone else in student teaching told me they were in over their head for student teaching, like 'I have no idea what I'm doing!' But in student teaching, I thought that we were set up very well because MSTC had so many clinical experiences.

Even though these had been helpful, she viewed student teaching as a "drastic switch from clinicals," making her shift her mindset "because it was my last step." Very little in her student teaching experience surprised her, which she believed helped the experience go more smoothly. "I think I had a lot to carry over from MSTC that made me more prepped for it. Everything I was seeing...were things that I had encountered before..." District 27 had recently adopted the CCSS along with new math and literacy curricula to support these standards. Like the other two case study participants, Vanessa shared that she felt that her teacher prep program had provided her with a strong background in both literacy and math, so even though the district did not implement a "perfect match, it was just finding a way to navigate that within our curriculums here." Vanessa described, "All of the teachers were kind of fretting over that a little bit, but none of that was new to me," which was similar Molly's and Kristin's sentiments about CCSS implementation at their schools. Additionally, she easily described the way that her cooperating teacher had balanced her own classroom management style with the PBIS framework, leaving Vanessa with the idea that "I mean I'm in a PBIS school, so I know I have to do that to stay connected, but we've all talked about how just because you're in a PBIS school doesn't mean it's PBIS gung-ho all the way. It's not gonna totally take over how my classroom is." Her cooperating teacher's strong model and encouragement to Vanessa to try some of her own ideas had a lasting impact. 
She described that teaching in general matched what she thought it was going to be, stating, "I think what was the biggest eye opener for me was just how different the actual district push is, and how mandates from districts affect teaching." She described experiencing less freedom to teach how she wanted, along with many more district-level requirements within District 27 than she would have predicted. Vanessa saw this push as both a positive and a negative aspect of working in the district and knew that experiencing this would be helpful for her future.

\section{On the Job Hunt}

I knew Vanessa to be a go-getter from my time with her in class, and during student teaching, she exemplified this attribute. While still student teaching, she began applying for teaching positions within District 27 and others nearby. In April, while still student teaching, Vanessa interviewed for and was offered a position to start the following fall at an elementary school in a nearby district. Because she had been so intent on working in District 27, she explained, “I wasn't really as thrilled about this as I should've been, or would have been if I really wanted it." She shared that while she was happy to get this position, she was not sure that it would be a perfect fit for her, and she continued her search.

Upon graduation, Vanessa was asked to be a substitute for her student teaching cooperating teacher at Washington, as this woman retired two weeks before end of the school year. Her decision to student teach and then substitute at Washington paid off when in July of that year, much to her surprise and happiness, she had back-to-back interviews at this school and another in District 27, Smith Elementary. At Washington, the position was for her cooperating teacher's position, and at Smith for a full teaching position as a half-day kindergarten teacher and half-day resource teacher. The Smith position was dependent on kindergarten enrollment. 
During the week of these interviews, she disappointingly learned that the position at Washington was being offered to someone else. Yet, the next day, she was offered the position at Smith. Later, through the school district grapevine, Vanessa learned that Washington had been unable to offer her the position because Smith had already informed the district administrators that they intended to offer it to her.

Vanessa believed that she received the initial call from Smith because of personal connections between the two schools. About this, she smiled and stated, "My cooperating teacher's daughter is a best friend of Smith's interim assistant principal. I think that there was a little bit of pull." Once offered and accepted, she realized that she had to quit the position in the other district that she had accepted back in April. She was worried that she was "ruining her reputation" in that district, but felt that it was the right decision because working in a District 27 school had been her first choice. Like Molly, after she quit her first job after graduation, Vanessa felt badly about doing so. She explained, "It was hard for me. I probably stalled about two days, figuring out how I was going to word it, and whom I was going to talk to and reach out to first." Yet, the district administrators displayed understanding, and she felt relieved.

Her interview at Smith, lasting "14 minutes" in her opinion, "yeah, they were on a time crunch," was with Smith's principal, Mrs. Neuberger, who was in her second year at Smith, the interim assistant principal, Sarah Jones, who went on to become Vanessa's literacy coach, and one other teacher. One interpretation of the short interview could be that the school administrators felt strongly enough about her from information they gleaned from Washington Elementary administrators who were also vying for her, as well as her high internal recommendations, that they did not need to conduct a lengthy interview. Unlike Molly and Kristin, who were asked little about topics relating to this study's scope, in Vanessa's interview, 
she remembered being asked about her beliefs about "a 'culture for learning.' That's our motto at our school this year. It's just how I build a classroom based on respect." She remembered, "quite a few questions just about how I would handle classroom management in general, like what I would do if they didn't respond to my verbal reminders." She also remembered that there were many questions dealing with her knowledge and experience with the Response to Intervention (RtI) framework because they were considering making her a support staff-resource teacher for the other half of her position. Because she had worked with "Tier 2 students before" in clinicals and student teaching, she felt that she could speak to the interview questions regarding RtI, although she felt caught off-guard by a few questions. In the end, she was offered the position after this short interview, and she happily accepted.

\section{The Context of Vanessa's First Year}

Vanessa entered her first year as a very strong teacher candidate, so much so that she was sought after for a position immediately upon her graduation and offered not just one, but two public school teaching positions within a few months of graduating. Amidst multiple possibilities, she ultimately landed a position in her most desired district. The intentionallyplanned decision to complete traditional student teaching in her hometown, and most-desired district highlighted Vanessa's focus on her professional future. Not only did she learn the innerworkings of the district this way, but also she formed relationships with the people most critical for securing her dream job. The inter-connected ways in which she found and secured this position illustrated her ability to collaborate and benefit from these relationships, which would carry her through her first year. The image of the shooting star beginning her ascent comes to mind here, as all of this primed her to start her year off well. 


\section{Vanessa's School Context}

Smith Elementary, a large stately, light tan brick building was situated on a wide corner in the middle of a residential large, suburban neighborhood. Smith was a kindergarten through $5^{\text {th }}$ grade school within District 27 that enrolled nearly 600 elementary-aged students from the local community and represented much of the diversity within this community. The neighborhood surrounding the school was filled with good-sized ranches, split-levels, and twostory homes with tidy yards and large, full-grown leafy trees. See the specific demographics of the school in Table 1 of the third chapter. With three to four classrooms of students at each grade level, there were also eight support staff members, 12 instructional aides, two instructional coaches, service team members, and music, art, and P.E. teachers on staff. Unlike Kristin's model of kindergarten at Monroe, kindergarten in District 27 was a half-day model.

The year of the study, there were enough kindergarteners enrolled for three sessions, which could be served by one full-time teacher and one part-time teacher. Yet, the reason that the position had been posted was because all of the prior year's kindergarten teachers had been reassigned to other schools within the district. This was due to issues that Vanessa quietly alluded to over the course of the year in very diplomatic, but suggestive ways, such as, “They're all working in the district in another school, in other grade levels, and we know why..." In asides, Vanessa revealed that these teachers had used what the Smith administrators felt were very poor instructional and managerial strategies, leading to low student growth by the time they entered $1^{\text {st }}$ grade. While many new teachers may have felt intimidated upon learning this, Vanessa felt invigorated by the chance to display her skills.

The second-year principal of Smith, Mrs. Neuberger, realized that there was flexibility in the way that the kindergarten sessions were delivered, and that she knew the school needed more 
resource teachers to support the early childhood classrooms. Thus, instead of just replacing the reassigned teachers, she would hire three new kindergarten teachers who would teach the three kindergarten sessions in the morning, and become support staff resource teachers with RtI in the afternoons. Vanessa learned that like her, the other two kindergarten teachers would also be new to Smith this year. In sharp contrast to Molly's perceptions and experiences, about this, Vanessa stated,

My principal says that she really doesn't like having lone rangers, that is, any teachers who feel like they're alone in their position at the school. So, she was able to and thought it would be more beneficial for us all to just be the same team.

This focus on support and relationships was one that would become the norm for Vanessa.

Community, classroom management, and PBIS at Smith Elementary. Vanessa described Smith Elementary as having, "a really good and strong school community with the teachers," and after observing in all three sites, I would concur. Vanessa was one of nine new teachers at Smith since Mrs. Neuberger had been hired the year before, and most of the teaching staff was under the age of 45. Unlike Molly, Vanessa saw her stamp of newness as something that connected her to these others, stating, "It's really helpful because we're all in the same boat." Additionally, several of the teachers at Smith were also MSTC graduates, including Kate, one of the other new kindergarten teachers. Vanessa quickly got to know the faculty and staff in her building, and at each observation, I observed her engaged in warm, and comfortable exchanges with every adult with whom she worked and passed by in the hallways.

Rituals at Smith were the norm. Every Friday, there was a sign-up for shared food in the teacher's lounge. On one day of observation in the teacher's lounge, I observed a folding table set up with sodas, baked potatoes, and cookies on it. These were leftovers from the prior day's 
'baked potato day.' Vanessa shared, "The social committee at Smith loves doing things like this! We do a lot of things like that." There were clear catchphrases at Smith, as well. Teacher lingo like "culture for learning" and "PLCs" were the norm. This shared vocabulary served as another unifier of this large teaching staff.

Additionally, there was a culture of collaboration within the district and the school, which I had not observed in the other two settings. On Wednesdays, the whole school participated in staff development in the library, and the meetings always started with a team-building activity. These meetings gave her the opportunity to interact with teachers at upper grade levels on different floors of the building. At the end of the year, she shared that at one of these meetings, the staff had focused on the school's new adopted book, Having Hard Conversations. After reading the book and attending related staff meetings Vanessa shared, "I think it just gave everyone that boost that we are really able to have conversations safely if there's an issue." She felt that this blocked time for collaboration and professional development was helpful.

Vanessa realized that she had first learned about the role of teams and personal learning communities (PLCs) in her teacher preparation. By the middle of the year, she shared, "I'm fully functioning in PLCs now here. That is, they eat, breathe, and sleep PLC here.” The district had recently constructed a collaboration building, entitled "The PLC Building," and she explained, "It's where we all go meet and collaborate." Professional development was a big focus at the district and school level, and she mentioned attending several trainings throughout the year that contributed to her classroom management and overall development. This collaborative focus helped Vanessa feel connected to the larger community at Smith throughout the year. However, at year's end, she stated, “There's still a little separation, not worlds, just this hallway and upstairs. So, I don't feel like I know everyone, but I do feel very welcomed." At times, she 
sensed amongst the teachers, “... a cliquey-ness. I mean, grade levels, of course, have their bonds between their own PLCs who they spend all of their time with. But it's not intimidating, and I can talk with anyone."

Vanessa consistently described the adults with whom she worked as "we" regardless of whether they were new or veteran, lead or assistant teachers. She stated, "There are just a really great group of veteran teachers here who are willing to be flexible with the kinds of changes taking place in education over the past few years." The Smith staff were in their second year of the new CCSS reading program, and in Vanessa's first year they were also navigating new district curricula for math. About this, she described, "So while they're veteran teachers, we're all at square one phase." This helped her feel like she was on an equal playing field with all of Smith's teachers, which was possibly more than most new teachers feel in their first years of teaching.

Vanessa's experiences with PBIS at Washington Elementary served to prepare her for Smith's PBIS components, being that they were within the same district and utilized the PBIS framework similarly. Instead of the cheetah mascot and his 'lightning' rewards like at Washington, Smith's mascot was the tiger, "Titus." The oft-used school-wide expectations of “Be Safe, Be Responsible, and Be Respectful” were packaged under “Titus' Truths.” Smith's website gave detailed descriptions of what PBIS looked like at the school. The site explained that Titus' Truths were taught through demonstrations, role-plays, and community meetings, and Vanessa experienced these throughout her first year. Rewards for "appropriate behaviors" from students included "Paw Pride" tickets, entries into school-wide drawings for prizes, and schoolwide celebrations. The website explained, "behavioral errors are corrected proactively by individual and school-wide problem-solving and teaching." Indicating the use of data at PBIS 
Tier 1, behavioral referral forms were used to document behaviors and communicate with families. The label of "minors" was attributed to misbehavior that could be handled in the classroom, and these were to be communicated to administration through weekly referral forms. Misbehaviors that necessitated administrative intervention were labeled, "majors," and these were documented on an office referral form and sent home. The website explained that the data from these forms was then used to "design lessons that re-teach expectations." On the site, it was clear that teachers, students, and families were always expected to follow Titus' Truths.

I noticed tremendous consistency in implementation of these various tools across the school. Like at Kristin's school, Monroe, flanking the hallway walls was a lot of PBIS signage. Flyers, posters, and student creations related to school-wide goals covered hallway spaces as the year went on. Titus the Tiger and his Tiger Truths were posted on a flashy poster outside of Vanessa's classroom, and every day in the student-delivered morning announcements, Titus' Truths were broadcast. In addition, I noticed similar PBIS posters and other visuals in various classrooms I spent time in with Vanessa, and I observed teachers and support staff members using similar verbiage in responding to student behavior. Across the year, there were multiple school-wide initiatives related to behavioral and curricular goals. One such curriculum goal was related to literacy in the winter. Vanessa explained, "we created a school-wide goal to be working on vocabulary with all Smith students." Each grade level problem-solved how to do this, and the kindergarten team chose to use flash cards and Dolch assessments. At follow-up meetings, they shared this info across classrooms and grade levels.

Resources at the school seemed endless. From multiple support staff members floating between classrooms, to technology hubs and bathrooms within each of the kindergarten classrooms, and to multiple before- and after-school "clubs" for students who benefitted from 
extra support, the resources at Smith were visible. To a more poorly-funded school, this would seem like a dream school. One such wonderful resource for Vanessa was Smith's book room. This room, tucked away at the end of a hallway, was designated as a space for teachers to pull literacy materials for guided reading instruction, and Vanessa regularly used this space, consulting her lesson plans, grabbing materials from the bins, and marking off which sets she had taken on clipboards hanging from the shelves' ends.

Vanessa's co-workers. Teaching in Vanessa's school was always a collaborative affair, as she was rarely alone when teaching. Vanessa, Kate, and Michelle made up the "Kindergarten Team," and all three shared students during guided reading and math rotations. One of these other new teachers, Kate, was in her second year of teaching overall, having taught 2 nd grade within another school in the district the year before. The other, Michelle, previously taught in a Head Start classroom within the district for nine years before coming to Smith. In reflecting on the fact that all three were new teachers to Smith, Vanessa shared, "If I had been the only one that was new, it probably would have been a lot different." Their newness was the initial binding factor, and Vanessa shared, "We felt like we were able to find a good flow...I think everyone has been comfortable working together, and we have a very strong mutual respect for each other's opinions." Throughout the year, all three were in sync. Despite their closeness, they were very welcoming to others, and they seemed to be the ones that others wanted to be around.

To Vanessa, the three of them together just clicked. She believed that they exemplified a solid team by constantly focusing on students during their times together, stating, "We don't wait until our PLC times on Monday and Wednesday, our one hour, to talk about kids. Every single lunch, we're working through every single lunch and talking." She felt that doing this allowed them to be responsive in the moment. After observing these meetings on days that I spent at 
Smith, I was wholly impressed. They were efficient, professional, and impressive in their teaching and problem solving. Meetings consisted of a few minutes of chit-chat, and then professional conversations related to planning ideas, division of tasks, reflection on past lessons, and questions about best practices. Each came prepared with her district-issued laptop, and a feeling of comfortable productivity permeated their interactions.

Vanessa also worked closely with many of the instructional aides and support staff members at Smith, both as a kindergarten teacher in the morning and as one of them in the afternoons. These paraprofessionals worked in all the lower elementary grades. Like the kindergarten teachers who moved into each other's spaces to teach, they also carried bins of their teaching materials with them, taking their teaching wherever they went. I often observed teachers traveling within the kindergarten hallway to work in each other's rooms. Vanessa's closest relationship with an instructional aide was with Mrs. Bowman, an older white woman, who was assigned to support Vanessa's class during guided reading and math times. As Vanessa sought help for one student with challenging behaviors specifically, the Smith administration altered Mrs. Bowman's schedule so she could be there to individually support him more. By the end of the year, Vanessa spent most of her kindergarten session with Mrs. Bowman at her side. When I was at Smith to observe, Mrs. Bowman only had positive things to say about Vanessa, making it a point to compliment Vanessa to me across the year. An initial comment included, Oh, she's [Vanessa] just awesome! When I started working with her, I asked her how many years she had been teaching, and she said that this was her first year! I was just thinking last night, 'she really knows how to manage behaviors so well!' Especially because she's in her first year! 
While I was initially surprised at comments like this, and for a moment, I wondered if Mrs. Bowman had been prompted to tell me these things, this feeling passed as I gauged her intentions over time. She explained that prior to this year, she had worked with teachers and students at another school, but now that she was here, she loved working with Vanessa. To comments like these, Vanessa would blush and deflect the compliment back to Mrs. Bowman. It was clear that they had respect for each other. Vanessa stated, "I've been really fortunate to have some of those IAs [instructional aides] who are just phenomenal and really helpful." She explained that many of her team members wore many different hats within the school, and she always showed appreciation for Mrs. Bowman and the others with whom she had worked.

In the afternoons of the fall semester, along with Kate, Michelle, and other support staff members, Vanessa worked as a resource teacher. Supporting all of the $1^{\text {st }}$-grade teachers in a rotating capacity, she pulled small groups of $1^{\text {st }}$-grade students from across classes based on student needs in reading and math. The scenario of three new kindergarten teachers being asked to play the role of support staff for three very veteran first grade teachers was rife for reward and conflict. About this, Vanessa stated, “Even our principal was always very aware of...and curious, and asking ways to help that. But there's just always been kind of a...we don't want to step on their toes." Bringing this to a head was the decision by the administrative team to overhaul the $1^{\text {st }}$-grade literacy program mid-year based on low growth on students' MAP assessments. They rescheduled the $1^{\text {st }}$-grade day so that guided reading moved to the afternoons instead of the mornings because they wanted the kindergarten teachers, whose skills with literacy instruction impressed them greatly, to play a stronger role in this time of day. Additionally, Vanessa learned that each of the kindergarten teachers, along with one other support staff member, would be reassigned to support one specific classroom of students instead of assisting 
all, as they had done in the fall. Vanessa was paired with Ms. Allie Yardley, a young white teacher, who had been teaching at the school for about seven years.

Due to the dynamic and disruptive nature in which this partnership was forged, Vanessa's relationship with Allie was one that was very different than she had with others with whom she worked. While they could have approached this from a co-teaching model, as they were both certified teachers, it did not seem that Vanessa had a choice in this format. What I observed was that Allie often took on the role of lead teacher, and Vanessa, assistant, although she turned to her for planning ideas throughout the spring. I always observed Vanessa's behavior as more than polite and respectful with Allie, yet at times, I sensed tension and stress between them. Throughout the year, Allie never seemed to grow comfortable with me following Vanessa into her classroom. From our first meeting amidst a last-minute change in the afternoon plans, which Vanessa described as common, she always seemed wary of me in her space. It seemed that she was uncomfortable with Vanessa's expertise and confidence with the students, and at times, I got the feeling that she felt undermined to have been matched with this new teacher.

Vanessa's team included even more personnel with whom she worked each week. This included Mrs. Gonzalez, the English Language Learner (ELL) support teacher who worked with Vanessa's students during their literacy block of instruction and who conducted assessments with her ELLs, as well as the school's behavioral specialist, Ms. Brown, who she at times referred to as a "behavior interventionist." Vanessa worked very closely with Ms. Brown over the course of the school year because of concerns she had specifically about one student, Tyler. Vanessa formed a quick relationship with her, "she's a wonderful, wonderful teacher so I figured, 'Well, that's going to be my go-to. I'm going to go problem-solve and troubleshoot with her."' While 
Vanessa did not believe that it was Ms. Brown's job to identify students who might need services, she did much to support Vanessa's students as the year progressed.

Part of the school's administrative team, the school's literacy coach, Mrs. Sarah Jones, was also someone with whom Vanessa worked closely. In addition to her role as the literacy coach, she was charged with mentoring all new teachers at Smith including Vanessa, Kate, and Michelle. Sarah had a very strong personality, and Vanessa appreciated her strong mentorship, and her willingness to co-teach and guide her, especially around early literacy instruction. Sarah often participated in the daily kindergarten team planning meetings, daily pulled small groups for reading workshop, co-taught math with Vanessa twice a week, and regularly modeled minilessons for her. While their relationship shifted throughout the year, Vanessa consistently shared that she felt supported by her.

In addition, District 27 had a comprehensive new teacher mentorship program in place Vanessa's first year, and Becky was the district mentor assigned to Vanessa. Highlighting how interconnected Vanessa's student teaching experience was with her first job, Becky, was the daughter of her cooperating teacher at Washington who was best friends with Sarah at Smith, and whose pull was one of the reasons that Vanessa got her job. Becky was assigned to mentor new teachers in three schools within the district, some of whom were new kindergarten teachers like Vanessa, and others at different grade levels. Over the course of her first year, Becky was scheduled to observe Vanessa teaching every other week with a visit on the opposite week for debriefing, meaning that Vanessa saw her weekly. However by mid-year, Becky realized that Vanessa was a very strong new teacher with quite a bit of internal support at Smith, and she pulled back to twice-monthly visits. About the continuous stream of feedback from Becky, Vanessa reported, "It's been so nice to have her because she's not here to do evaluation. I just 
get to talk with her and get feedback!” While for some new teachers, having someone regularly observe them and record their performance may seem nerve-wracking, Vanessa was comfortable with her visits. She explained, "That might have terrified me at the beginning of the year just thinking, 'Gosh, she's going to see this!' But now I really welcome her feedback. She's come in many times and just observed." I had the chance to observe one of these debriefing sessions, and when I met her, Becky shared equal admiration about Vanessa and shared with me how lucky she felt that the district was having hired her as a teacher.

Not only did Vanessa receive support from her grade-level team, the literacy coach, the behavioral specialist, and her district mentor, but she also admitted that she felt supported by Smith's principal, Mrs. Neuberger. In contrast to the other two case study participants' relationships with their respective principals, about her relationship with Mrs. Neuberger, Vanessa explained, "What's really nice is she's just very involved in the classroom, and I feel like it's more of a mentorship role than she's my boss or someone that I should be afraid of." She felt relaxed "and not tense" when Mrs. Neuberger visited her space. In many ways, Vanessa viewed her as, "a huge mentor, especially because she was so involved in kindergarten." Vanessa explained that she would "just pop in whenever" for informal observations, but when she scheduled formal observations, "she'll come in structured with her laptop, taking notes." Over the course of the year, Mrs. Neuberger completed three formal observations and two informal observations of Vanessa's teaching, and in the spring, she provided Vanessa with her annual, summative observation and evaluation. This administrative support stood in sharp contrast to the complete lack of support that Molly experienced and the sparse interactions with administrators that Kristin encountered. 
Vanessa was used to teaming as it was implemented at Smith, as well as the grouping of students in many ways, as she experienced these teaching approaches in her student teaching experience at Washington Elementary. There she had been in a multi-grade classroom, so she had "three different math classes, and three different literacy classes." Students rotated between teachers based on their various abilities in literacy and math, and she did not stay with same group all day, because of these "reading and math accelerations" times of day. She explained, "Because there was so much mingling, there was a huge community at the grade levels where kids knew someone from every single classroom. They knew all of the teachers. It was very much a team effort in that respect." This experience set Vanessa up to see the adults at Smith as her allies and co-teachers. About these relationships, she expressed, "Really, I have about 100 mentors!" She admitted, "I know that's something that isn't true in all schools." Although it was not always easy working with so many different personalities, belief systems, and perspectives, Vanessa recognized the work that everyone put in, and this support freed her up to focus on her own teaching and classroom management.

\section{Vanessa's Classroom Context}

Despite her part-time status as a general education teacher at Smith, Vanessa was given a not-too-big, not-too-small, rectangular classroom as her teaching space. Her room was in a hallway of the school, which like Kristin, housed the kindergarten and $1^{\text {st }}$ grade classrooms. The room had tall ceilings and low-pile, light gray carpeting. There were two tall, unadorned windows flanking a bulletin board on one wall with a row of upper and lower cabinets and a counter and sink on the opposite wall. Additionally, there was a small bathroom in the corner of this side of the room. Technology in the room was impressive, illustrating a school and district with either good funding or good use of grants. Tech consisted of an interactive white board and 
projector facing the middle of the room, along with a document camera and computer to the side of the Smart Board. These tools were incorporated daily in her practice. There was a built-in speaker system with speakers in the ceiling and a control panel near this computer, which Vanessa used to play soft jazz and classical music throughout various times of the day. Figure 23 illustrates an aerial view of her room arrangement.

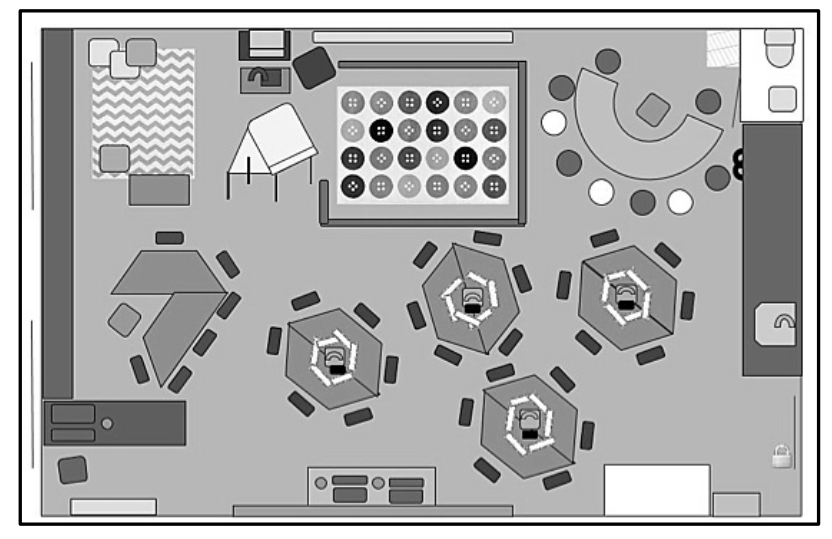

Figure 23. Vanessa: classroom map (11/14-6/15).

Singular to Vanessa's setting in this study and illustrating current safety and security concerns in America's schools, Vanessa's classroom door was always locked with a small window in its center and to the side of it. Vanessa shared, "All of the doors are locked all of the time. This was new a few months into the school year." Faculty and staff wore keys clipped onto their nametags to enter and exit all rooms in the building. There were visible emergency materials including a red, landline telephone hanging near the door, a large buzzer near this to call the main office, along with a backpack of First Aid materials and safety informational posters, all hanging near the door. 
Seeing these safety materials may have initially alarmed those who entered her space. However, Vanessa's room always felt open, airy, and inviting. She set up her classroom to feel warm and welcoming using neutral colors and a less-is-more mentality to classroom design. Her room was tidily kept, and the walls and bulletin boards were simply decorated with consistent bulletin board borders. While many of Vanessa's materials appeared to be store-bought, and some specifically from the website TeachersPayTeachers.com like Kristin's, her anchor charts were handmade and prolific. About them, she explained, "A lot of them were in the moment, what my kids needed. We just wrote it down and threw it up." I noticed bulletin boards and student work on display changed with the passing months, and always related to student learning. There was a designated bulletin board for mathematics and another for literacy, which highlighted the literacy focus of each week. One wall was designated the "word wall," and her kindergarten students' names and high-frequency "heart" words were organized on tags on this board. In the corner of the room near the literacy bulletin board, there was a classroom library set up with a soft rug, bean bags, and shelves of children's books organized into baskets. On the shelves near this, there was a magazine box for each child with reading materials in it.

There were two small bulletin boards underneath hanging cabinets on one wall that were labeled as the social studies and science boards, but the content on these rarely changed over the year. A daily schedule was posted on one wall, along with a clip chart that looked remarkably similar to Kristin's. While the daily schedule was on display, there was no calendar or reporting of the date or month anywhere in the room. Although calendars tend to be staples in early childhood classrooms, helping students document their lives in time, focused on for social studies, math, and literacy goals, at Smith, there were no calendars in any of the kindergarten or first grade classrooms. Vanessa shared that she had expected to have a calendar in her classroom 
because she saw this tool as foundational in the early childhood years, and she knew that it would prepare students for content that would be assessed on MAP assessments. Yet, Sarah, the literacy coach—internal mentor "hated "calendar time." The fact that her students had no visual for highlighting their place in time frustrated Vanessa, but, "we as a team felt that it was kind of red tape, so we didn't do it." There was a laminated paper ladder going up one cabinet door with clothespins clipped onto it, and Vanessa reported that this marked her students' growth in reading and contributed to a feeling of community within her space (Figure 24).

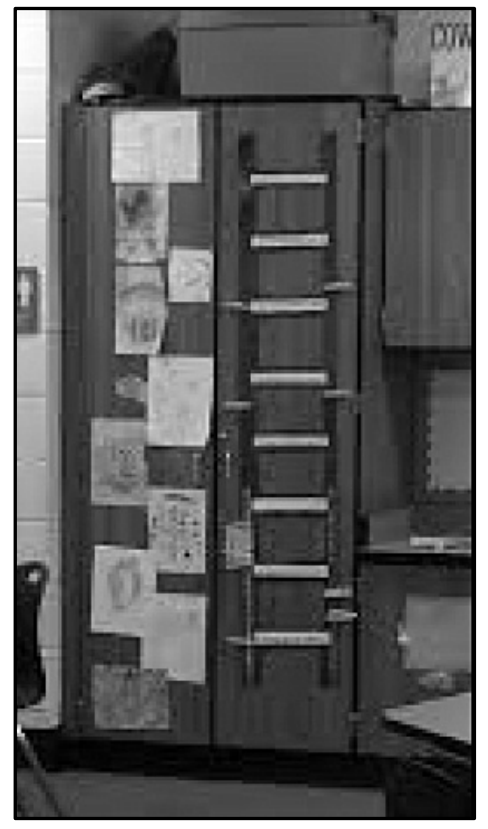

Figure 24. Vanessa: sight word success ladder-community-builder (11/14-6/15).

Trapezoid-shaped tables were combined to create hexagons throughout the room, and this is where students had assigned spots for various activities throughout the day. Numbered pennants hung above each hexagon indicating that table's team of students. The table tops were carefully arranged with communal-use shower caddies in the center filled with markers, 
whiteboard markers with pompoms glued to the end with which to erase, pencils, and small tubs filled with crayons. Nametags displaying students' names were taped to each spot at the tables, and under the center of each hexagon was a milk crate filled with picture dictionaries and small white boards. Drawers attached under each table spot held students' individual materials.

While she complained about the small size of her classroom to me at various points in the year, I did not notice it ever feeling cramped. Her classroom always seemed cozy and comfortable versus other early childhood classrooms I was in at other schools, including as sites for this study, as well as other rooms at Smith, such as Allie's. Where Vanessa's room was very tidy and simply laid out, presenting an air of calm as you entered, Allie's classroom, which became Vanessa's second classroom context beginning in January, was crowded, messy, and even a little smelly at times. While smartly decorated in stylish borders, the bulletin boards were packed with teacher-made and student materials, and the shelves along the window wall were overflowing with paper and other materials. Allie's room had a kidney-shaped table that was covered in stacks of worksheets and other teaching materials, leaving very little space to lead a guided group and reminding me of Kristin's bean table at the back of the room. Her $1^{\text {st }}$-grade students sat at individual rectangular desks that were pushed into random configurations, and materials overflowed from the open front drawer under their desks, adding to the room's air of chaos. As in Vanessa's room, Allie's had two large windows, but both were semi-blocked by stacks of boxed teaching materials, making the room seem darker than it should have. While the size of the classroom was similar to Vanessa's, it felt much more crowded, with no clear library or gathering space.

In contrast, Vanessa's classroom had enough space for student tables, two collaborative, guided spaces, as well as a teacher desk and a library, and it felt open and spacious. This space, 
and the way she used it, offered her flexibility in grouping throughout the day, which she maximized. She not only taught her morning half-day kindergarten class there, but she also taught her small groups of $1^{\text {st }}$ graders there in the afternoon throughout the year. A big aspect contributing to the feeling of openness in her room was the fact that it was always impeccably organized and clean. It seemed that there was a home for all materials, as there were no loose sheets of paper or other materials anywhere. The level of preparation that seemed to go into making sure that this environment was primed for children's use and learning was evident. In describing her room after a year of living in it, she shared, "I think that this is cozy. It's comfortable." By the end of her first year of teaching, Vanessa had only slightly changed the layout of her classroom, including her horseshoe table shifting to face a different direction in the room, as she landed on a layout that worked well from the start (Figure 25).

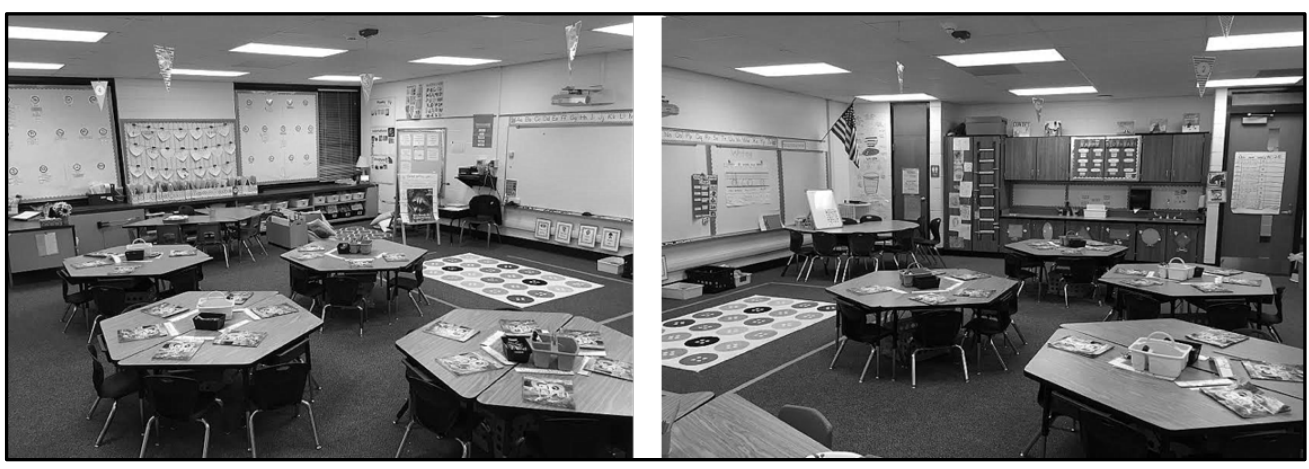

Figure 25. Vanessa: classroom photos (11/14-6/15).

Vanessa's students. In her first year of teaching, Vanessa worked with two main groups of students. In the morning hours, she was teacher to 21 Kindergarten students, aged 5- and 6years-old. Eleven were girls, and 10 were boys, and two more boys joined her classroom by May of that year. Her school district ranked 13th in the state in size with around 14,400 students 
at the time of the study and had a very diverse population of students by race/ethnicity, economic level, and home language. Vanessa's class was no different. Half of her class was comprised of students considered ELLs, speaking a variety of different home languages including Gujarati/ Urdu, Slovak, and Spanish. Racially and ethnically, her class make-up was similarly diverse. By the end of the year, she had six students who had immigrated to the area from India, one whose family was Romanian, another who was Slovakian-American, and one whose family had emigrated from Albania. Nine of her students identified as Hispanic, six as Asian-American, five as Caucasian, and three as African-American. Most of her students were eligible for freeand reduced-lunches per federal guidelines. She explained, "The demographics of the school are very different from any place that I taught during clinicals or student teaching. Really, it's kind of a melting pot." This was new for her, and she was excited because of it.

Very few of Vanessa's kindergarten students had attended preschool the year before. Before knowing this, she expressed surprise that they lacked skills that she had predicted they would have. She explained, "only two of my students could read at the start of the year," some were working on letter sounds and basic counting, and “one kiddo didn't even know his name." Here she meant that he did not recognize his written name. This was not uncommon for many students of this age, but at Smith, the highly rigorous expectations for kindergarten behaviors made her surprised by this. Some of her reaction was also because of the age difference in the students with whom she had worked during her student teaching semester and the ones in her new classroom. She remarked, "I mean, there's such a difference...I was student teaching in a $1^{\text {st }}-2^{\text {nd }}$ classroom in the second semester of the school, and I came to kindergarten where it was first exposure to school ever, and it was just of like, 'Wow!” For much of the school year, 
Vanessa did not have any students with IEPs or Section 504 plans, although she noticed a few who displayed challenging behavior.

In the afternoons, the students with whom she worked in $1^{\text {st }}$ grade for push-in and pull-out support were similarly racially-, ethnically-, and linguistically-diverse. Her small groups consisted of between four and 14 students from one or more $1^{\text {st }}$-grade classrooms in the fall, and solely from Allie's classroom in the spring. These groups were supposed to change throughout the year, yet, they ended up only changing slightly. These $1^{\text {st }}$ graders had been kindergarteners the year before with the prior kindergarten teachers who had been re-assigned within the district. Vanessa described how she felt that because of issues the prior year, these $1^{\text {st }}$ graders seemed to enter $1^{\text {st }}$ grade, as though they had gained little in their kindergarten experience.

Like Kristin and Molly, Vanessa loved her students and demonstrated that love for them all year. I regularly observed her standing at the classroom door throughout the day welcoming students into the room and interacting with those in the hallway. These exchanges were always warm and excited, "Hello Adhira, how are you today?" and "Hi, Miss J.!" and "Miss J., let me tell you about this!" Throughout the year, everything for Vanessa came back to her "kiddos," as she called them. Her upbeat and easy-going nature, as well as her genuine interest in forming relationships, helped her start the year off well with all her students. She explained, Getting to know my students went really well. At a really early point in the year, I knew them. I knew what they were interested in, and I knew what I could talk to them about. If they were frustrated, or if I could see they were coming in grumpy, I could say, 'Hey, did you watch Batman last night?' and we could be off to a good relationship-based conversation. This kind of drove the whole year. 
The first graders also always lit up around Vanessa, and I often heard them excitedly relaying information about their personal lives with her. She displayed genuine warmth and care with each of her students, and I regularly observed them giving her hugs.

Additionally, like the other two cases study participants, Vanessa was excited by her students' success and growth within the first few months of school and then throughout the year. She exclaimed, "I can see the moment when something clicks. I love seeing that they are proud of their work!" Her favorite part of the day was "seeing them have that connection to "this is why I'm in school. This why we're here."' In January, she participated in a data meeting with her kindergarten grade-level team and the Smith administration, and "Kindergarten was by far the most progressed of all the grade levels!" She was proud to report that this information had been shared on a spreadsheet with all of the Smith staff. Vanessa shared that this was a big validation for the Kindergarten team "because it made us feel like we are working really hard, and it's going somewhere and the kids are moving!" At the beginning of the year, she had 11 students not reading Level A texts independently, but by the middle of the year, that number had dropped to two. By year's end, Vanessa was astonished at the gains her kindergarten students had made over the course of what was for many of them, their first year in school. She explained, "Their commitment to themselves and their commitment to learning and to our classroom has been my favorite part!" She continued, "I've seen my Kindergarteners do things that I didn't think Kindergarteners could do, and being proved wrong time and time again by them has been not only the best part, but also the most rewarding." Vanessa beamed as she described this. 
Vanessa's daily schedule. In the mornings, Vanessa served as one of the three kindergarten teachers, and unlike Molly and Kristin, she had a posted daily schedule for her kindergartners that stayed consistent the entire year (Figure 26).

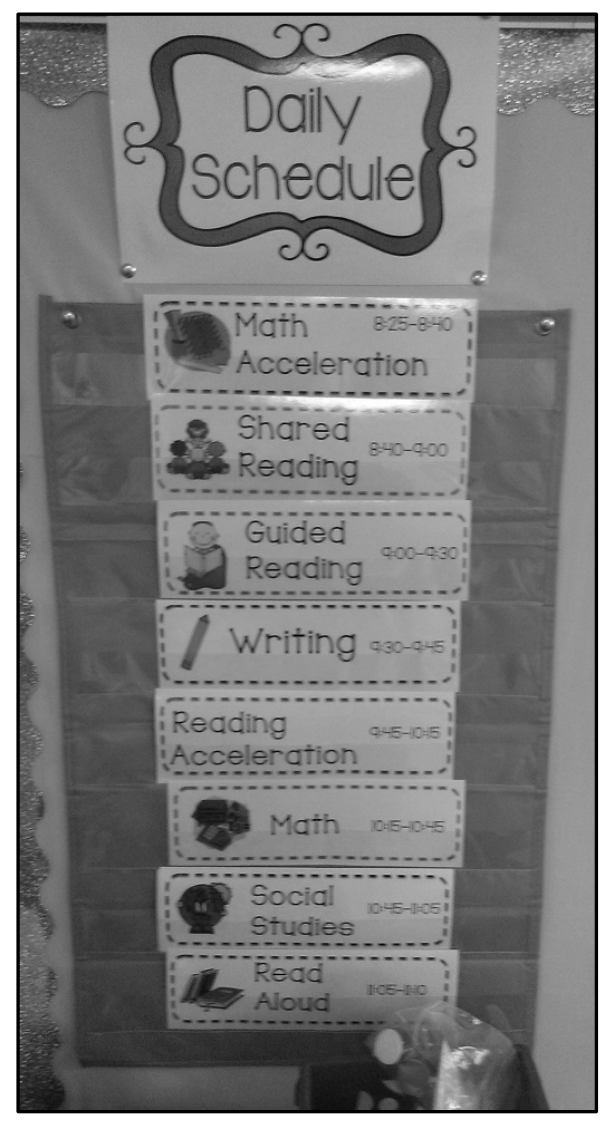

Figure 26. Vanessa: posted daily schedule (11/14-6/15).

Her day typically began around 7:45 when she arrived at school. She started the day by collecting materials she needed for that day's lesson, often stopping by Smith's book room, and then preparing her morning task for the students to be displayed on the interactive board. The Smith school day actually began at 8:40, but the administration and teachers "intentionally told the parents $8: 25$, so the kids will come now for extra support. That's why we get the trickle. I 
think some parents think the school starts at 8:25, so some students are here." Vanessa used this time by connecting more with the students that were there and focusing on make-up work or subjects that they did not have as much time to cover later in the morning, yet this practice seemed somewhat deceptive for families. The kindergarteners' morning schedule was fastpaced, and it often seemed like they had just started an activity when it was time to transition to the next. About this, Mrs. Bowman shared with me, "Can't you imagine when Kindergarten is full-day next year! It won't be so rushed!”

Shared reading served as both an actual shared read-aloud and a mini-lesson, as well as a mini-morning meeting at the start of each day. Unlike in Kristin's class where they did not discuss a welcome to the day until they had been in school for quite some time, and Molly, whose students sat on the carpet for a very long time for the circle time, Vanessa's mini-morning meeting with shared reading felt like just the right amount of time, and being welcomed right at the start of the day helped to establish a feeling of community for the students. During morning activities, like in Kristin's school, school announcements would break in over the loudspeaker, and Vanessa and her students would stand for the Pledge of Allegiance. Announcements at Smith were typically reported by two of the older students in the building, and an administrator would often come on at the end to add updates for teachers and staff in the building, as well as to pose the riddle of the day, which always led Vanessa's students to discuss it in excited whispers. The announcements consistently ended with, "Today's message was brought to you by...Have a great day, and let's make today a learning day!” As they gave this last line, Vanessa and her students would chime in.

Guided reading and writing instruction typically followed the shared reading activity, and thus her literacy block of instruction utilized more of a workshop model than Kristin's literacy 
instruction did. During guided reading, the students were strategically grouped into four small groups that rotated throughout the week. Three of these were teacher-led activities including one by Vanessa, one by Mrs. Gonzalez, one by Mrs. Bowman, and one was student-led where they engaged in independent reading, when they could also eat snack. These groups varied based on need, and from the beginning, Vanessa displayed a visual of the small groups and the rotation on the interactive board so that students could self-manage this time. Following this came a districtwide time of day called "reading acceleration," which at Smith, looked similar to Kristin's Words Their Way groups mid-year, in that across the kindergarten classrooms, students were grouped based on need and received small-group instruction. This time of day amazingly ran like clockwork because of tremendous planning on the front end between the three kindergarten teachers. Math and social studies/ science followed, and while she delivered math instruction in a modified workshop model, social studies and science were not as meaningfully addressed, despite her belief, "that's my kids' favorite time of day!" If other morning activities ran late, social studies and science were the first two subject areas to be cut. When the subject of social studies was covered, it tended to include superficial, broad topics, and those related to schoolwide behavior expectations that had been passed down from administration, which did not illustrate the breadth and depth of learning Vanessa had gained in her methods courses in college. This time in the schedule was shared by social studies and science, and science time was often treated similarly.

While the schedule included strong content area times of the day, missing from it were things that one might expect on a traditional Kindergarten schedule, such as circle time/ morning meeting/ class meeting, music, gym, center-time, play-time, or recess/ gross motor time. In part, this may have been due to the fact that it was a half-day program, but also because District 27 
focused on having a very structured and rigorous day for Kindergarteners. Vanessa worked hard to make her instruction developmentally-appropriate, but the schedule on its own, especially at the beginning of the year, was a challenge for her students, and they were often tired once math time began. Her mornings flew by, but a hallmark of the fast-paced session was always the goodbye song and process they went through to pack up and say goodbye at the end of each morning. The session ended by 11:10.

Vanessa would then have a half-hour break, when she would meet with team members. From this, she transformed into a support staff-resource teacher, and she often did not know if she would be pushing in support in a $1^{\text {st }}$-grade classroom or pulling students out for assessment or small groups during this time. About this, she described, "Well, you got to see some 'flex' in there!" The kinds of literacy activities she did with her heterogeneous group of $1^{\text {st }}$ graders were similar to the kinds of activities she did during this time for kindergarten. A 45-minute lunch break following this provided a great time for her grade-level team to meet, and in the spring, she collaborated with Allie every few weeks during this time. From 1:00-2:55, she pulled small groups of $1^{\text {st }}$ graders for guided reading and math instruction and assisted $1^{\text {st }}$-grade teachers in their classrooms.

Although no timer was set at any point in the day, Vanessa quickly internalized how long her segments of the day should take, and she would often glance up at the classroom clock to make note of how much time was left in an activity. While she knew about which activity came next, in the afternoons, without a timer her $1^{\text {st }}$ graders often seemed unprepared for time to run out, and thus, the transitions tended to feel abrupt. This reminded me of Kristin's day. Despite this, afternoon routines were well-rehearsed. This was in part because unlike Molly and Kristin, Vanessa consistently reminded students of Titus' Truths (i.e. the school-wide behavioral 
expectations), reviewed the groupings, such as for reading acceleration, and then released the students from activity to activity.

Her school day with students ended at 2:55 every afternoon. At this point, she would pick up her classroom, although it rarely needed much tidying. On some days, she met with her kindergarten grade-level team, on other days, her district mentor, Becky debriefed an observation with her, and on others, she attended district professional development. Most days, she did not leave until at least 3:45.

Vanessa's teaching. To plan her day, Vanessa used a district-level curricular resource binder that mapped her daily schedule out in detail, down to the number of minutes she had for certain blocks of the day. She easily accepted this tool, stating, "At first, it was overwhelming, and then it was really comforting. I said, 'Well, I don't know what I'm doing. It's my first-year teaching, and so I have this." While this sentiment was similar to both Molly's and Kristin's, more than either, Vanessa felt that she could "flex a little. It's not stick to this or you're getting fired!" In observation, I noted her doing just this, as she put her own twist on much of her teaching.

The choices Vanessa made regarding curriculum and instruction always centered on what was best for her students' learning. Vanessa's lessons were filled with engaging tasks, creative materials, and variations in grouping. As compared to Kristin's entry worksheet activity that was similar every time I observed, an example of Vanessa's teaching was illustrated in her entry activities, which typically incorporated something different on the interactive board each day. One day I observed, the directions for the task asked the students to create a picture using shapes, and on another day, the task instructed students to write about the image on the screen, which happened to be a photo of a rabbit talking on a phone. These activities were inviting, 
independent, and often brought on giggles from her young students. Vanessa's materials were innovative as well. I noticed red "catch-up" folders at each spot that had an image of a bottle of ketchup glued to the front. Although only with her Kindergarteners for a half-day, on each observation, I observed Vanessa reading more texts with her students, and her students engaged in more independent reading than either Molly's or Kristin's. She often infused technology into her teaching, such as displaying texts using the document camera, playing a game on the interactive board, and having students write on the board.

Overall, from the start and growing stronger across the year, Vanessa displayed adept pedagogical and strong managerial skills through her lesson planning and delivery. She was skilled at capturing students' attention and drawing them in to nuanced details within their reading, and she used a variety of strategies to select students for participation including drawing names from a cup. Layered into her reading, writing, and math mini-lessons, there was both direct instruction and active application where she would have the students do turn-and-talks to apply what they had just learned in her mini-lesson, and then a share time at the end. This variation kept the students engaged and applying their knowledge in new ways. Like a more veteran teacher, she often gave guidelines for what to do next before releasing her students with consistent reminders to follow Titus' Truths, and appropriate student behavior was an outcome of this. Additionally, she tended to wrap up her mini-lessons with a proud reflection on what her students were now able to accomplish based on what they had just learned. The students would often respond, "yeah," or "we're smarter now!" Her intuition and 'withitness' developed across the year, and her teaching behaviors were impressive for a novice teacher. I was continuously captivated by the ways that she so adeptly managed the room during the many transitions from whole group, to working with partners, and back to group work, and how she grabbed their 
attention, held it, and then released it back to them. She also was skilled at physically managing her space, as she easily wove in and out of classroom spaces as needed.

Often, I observed her varying her delivery based on students' needs, such as brain breaks when they had been sitting too long, a partner activity when she had been talking too long, an attention-getter when the room got too loud, or a softer voice when she wanted to draw them in. I noticed her consistently using redirection when needed, such as when one $1^{\text {st }}$ grader accidentally started to write the vocabulary words on Vanessa's copy of math flashcards, instead of on his own. Vanessa calmly redirected him, stating, "Marco, that's the set for teachers, not for kids. That is why we have notecards here for you. But I love how you're writing it." Handing him a new set of notecards, she continued, "Let's switch to these notecards instead." I also often heard her redirecting students during group activities such as math games, stating, "let's find a space in the room that you can concentrate and play."

Overall her instructional decisions focused on teaching students how to be self-reliant and how to problem-solve their way through difficult spots in every aspect of their lives, including academics. This sharply contrasted with the behaviors I observed Molly and Kristin using that forced their students to rely on them to problem-solve issues. Infusing guidelines, both visual and verbal, crafting developmentally-appropriate lessons, setting up independently-used materials, and teaching catchphrases and mantras helped instill strong growth mindsets in her kindergarteners. Phrases such as "be in the moment," "give your brain a kiss," "ready, mathematicians?" "let's click on our brains," and flashing a heart sign with their hands when they encountered "heart" words in their reading all served as reminders to students that they were smart and talented. She also intentionally modeled and taught problem-solving skills throughout the year, and spent time dissecting appropriate behaviors as a group. I observed her admitting 
her own mistakes to students. For example, when she wrote an inaccurate number on the board during math, acknowledged it, and modeled that it was okay to make mistakes.

These strategies worked together to make her teaching very strong in her first year. With these strategies, Vanessa saw a direct connection between her teaching decisions and growth in her students and could identify and explain this. An example of this took place in March, when she described seeing huge progress with her students' reading and writing skills. She explained that this progress was due to a kindergarten-wide switch in how they conducted guided reading. She shared, "I can't say it's like a light switch turning on because really they've been growing all year. It wasn't like it was one day they weren't doing it, and the next day they were." From my time spent in her classroom, I would agree.

There was an overall joy to learning in Vanessa's classroom. Some of this could be attributed to Smith's “culture of learning," which Vanessa bought into quickly, but some of it was just her personality. In my field notes, I noted how her demeanor was consistently upbeat, positive, energetic, and enthusiastic for every learning opportunity and task throughout the day at each observation. Throughout it all, Vanessa had a keen ability to hold the children's attention in the palm of her hand. She adeptly used redirection and attention-getters to capture students' attention, and then through clear explanations and empowering mantras and catchphrases, she kept it. In the last few days of the school year, I observed her saying, "Boys and girls, remember that we only have four days left until the end of the school year. Let's keep growing our brains then! Remember to take control of your own body and learning." As she said this, I observed students readjusting their bodies and positions on the rug and could tell that this was a practiced message in this class by their responses. Additionally, she embedded celebratory pieces into her daily practice with students, such as using special claps, chants, high-fives, golden paw print 
parties, growth sheets for reading, and verbal acknowledgement of their growth, like "Boys and girls, I am so impressed by how you worked together on this task to make the flashcards. People were working quietly, they were focused, and wow, how productive!" I often observed her using special claps like the pancake clap or the fireworks clap to celebrate learning in her room. When I brought this up to her, she remarked, “I don't always think, 'oh, I learned it in this course at MSTC,' but it's there." These behaviors contributed to unifying her classroom community and brought fun to her students' days.

\section{A Year in Her Life as a First-Year Teacher}

The above section did much to highlight how Vanessa's teaching choices affected her overall classroom management across her year. In the next section, dissecting her year into quarters will reveal the specifics for how these behaviors came to life for her.

\section{The Beginning of the Year: "My Head Is Above Water..."}

Vanessa described the start of her first year as "a little overwhelming," but reported that she had expected this feeling from what she knew of first-year experiences. She was most excited to "have my own classroom," which would allow her "to put my own twist on teaching and to really be able to take ownership of that. And give a lot of the ownership to the kiddos." She was most worried about how to cover everything she was supposed to in a half-day kindergarten model. Additionally, like Kristin, she worried about how to best work with students whose home language was different than English. She explained that the year started out "crazy, but not in a bad way." She went on to explain,

I was so excited that the last four years of college were over, and I couldn't wait to set up my room, and then the day I sat down, there was an empty desk. I looked around, and 
said, 'I can't do it. I can't do it!' I spent the next month painstakingly laminating things, and two weeks later, I said that it was crazy spending that much time, but I needed it. She quickly set to starting the year off great. From the start, she attributed the successes she experienced in her classroom and teaching to her many co-teachers and team members, "It's the team. Yeah. It's definitely the team." She also felt very supported by Sarah, the literacy coach/ internal mentor at Smith, stating, "She's usually my go-to if I'm ever confused about something — my initial thought is I'll just ask Sarah." She realized how nice this was to have someone so accessible in her building, and she acknowledged that this was something that felt very comfortable, stating, "I think that's something that she stressed to me at the beginning. Just, 'you can be vulnerable, and I will not judge you. No question is wrong."' This, along with the camaraderie she felt amongst her grade level team members, boosted her confidence.

From the beginning of the year, Vanessa shared how positively she felt about her role and responsibilities in the afternoon as a resource teacher working with first graders, stating, "I really like that part of the day." Typically, she conducted her small group instruction with the first graders in her own kindergarten classroom, "and we just kind of ran with it." Her confidence with this stemmed from the fact that she had taught similar content and in a similar format with $1^{\text {st }}$ graders during student teaching.

Beginning of the year classroom management. Vanessa started the year by stating, "I was definitely worried about classroom management. Not worried, or thinking I couldn't do it, but just knowing I was going to be tested." More than anything, she wanted, "to start and hit the ground running with letting the kiddos know how much I respect them and how much they respect me, and build that rapport." Thus, she started setting the foundation for her classroom community right from the beginning of the year with "classroom expectations and what the 
culture of the room is going to look like" over "four days' worth of getting-to-know-youactivities," which her principal fully supported. Vanessa shared that the kindergarten team had received guidance from her to "not worry about jumping right into curriculum." Because of this, she and her team spent time doing these activities and "to really just go slow with them." Vanessa felt that this laid the groundwork for her classroom community.

Vanessa placed much thought and consideration on her room design from the beginning of the year on. Everything had a home, and every time I observed, the room was tidily arranged at the start of the day. There was a layer of intentionality in the placement of each basket, pillow, and chair. Her arrangement of students throughout the day was no different. Vanessa used nameplates at the table spots to designate assigned seats, and her table pods were assigned rows on the button rug. She described this, "There are times when if I know we really need to focus, or if it's been a really antsy day, I'll have them sit just at their tables. At the rug, their table sits in the row." Highlighting a meaningful insight related to strong classroom management, Vanessa saw this intentionality as contributing to her overall management, stating, "Having more structure, and having them know where they're supposed to be, especially on wiggly days, helps. I think that they are a lot more focused.” In the beginning of the year, she rearranged the assigned seats regularly.

Drawing from her past experiences and with the support of her team, she began implementing strong teacher behaviors, such as using attention-getters. Like Molly and Kristin, she credited the university for learning about how attention-getters helped with teachers' classroom management. Chants she used included repeating "loud and proud," "eyes on me in 5, 4, 3, 2, 1, 0," "holy moly—student response: guacamole," "macaroni and cheese—student response: everybody freeze," "if you can hear my voice, clap 5 times...," and "hands on top- 
student response: everybody stop," among others. At the beginning of the year, she taught her students these attention-getting calls and responses, and they practiced them repeatedly.

Additionally, from the start, Vanessa was responsive to the needs of the class and the individuals within it. Like Kristin, when she noticed that students were getting antsy, she would smartly layer in "brain breaks" that were as simple as stretching and exercise activities that they counted to, for example, "We need to get our wiggles out. Let's stretch!" She observed that by breaking up the fast-pace of the morning, she would elicit better behavior from the students, and she also used quick stretches to motivate the first graders in the afternoon.

Very quickly, Vanessa established guidelines for behavior that were visual reminders to both the students and her. After noticing repeated behavior issues during independent reading time at the beginning of the year, she realized that they needed guidelines for how to sit at their seats and independently read. So, she created a poster for these expectations (Figure 27). She also realized that she needed to outline how she expected them to sit on the rug for any of the large group activities there. She created posters to represent these guidelines, and I often heard her referencing these when redirecting or drawing attention to behaviors (Figure 28). 


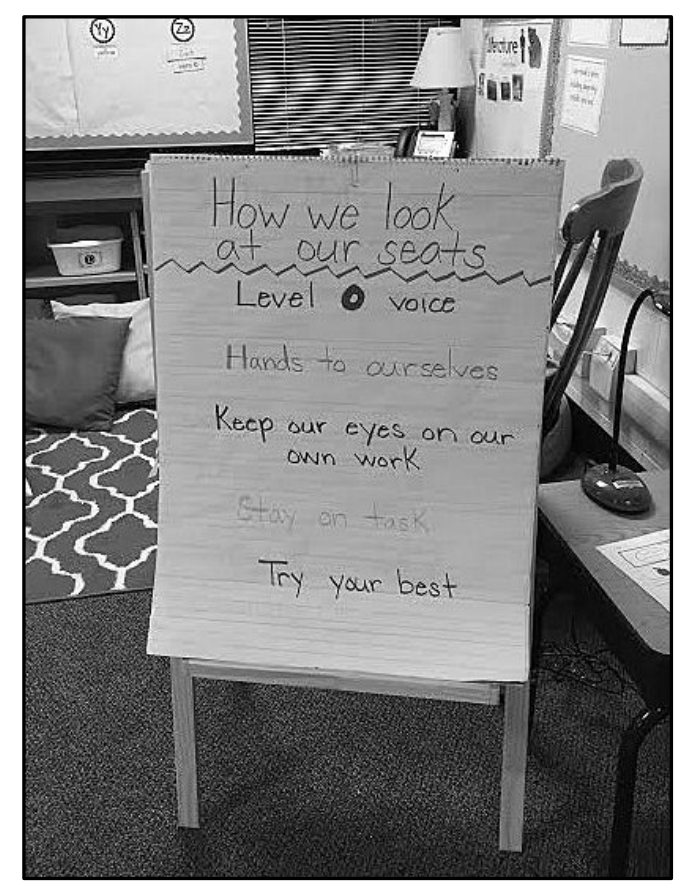

Figure 27. Vanessa: behavior guidelines for seatwork chart (11/14-6/15).

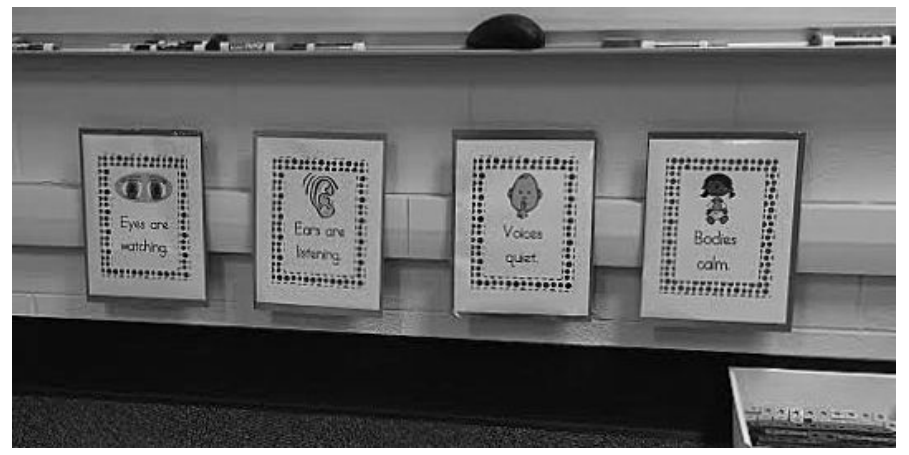

Figure 28. Vanessa: rug behavior guidelines posters (11/14-6/15).

Often in redirecting misguided behaviors, she phrased her guidance in the form of a tip; for example, "I see we're really crowded over here. I have a tip for you: if you don't have enough space and you need it, find another space where you can have it in the room." On multiple occasions when I observed a student not knowing an answer in response to one of her 
questions, I noticed Vanessa encouraging them to ask a friend for help. Students typically followed along with her helpful tips.

When she did not have a visual guideline to refer to, she instead gave students oral reminders and guidelines. Because transitioning during kindergarten reading acceleration time meant traveling across the hallway to various classrooms, she knew she needed to provide her students with guidelines for how to behave. So, at the beginning of the week, she reviewed with them which small group they would be going to that week, in which Kindergarten room it would be, and with which teacher, support staff member, or administrator they would be working. Later in the week, she stood at the door and announced group names. On one day of observation, the group names were based on characters in Bill Martin Jr.'s book, Brown Bear, Brown Bear, What Do You See? Groups included the 'Yellow Ducks,' 'Brown Bears,' 'Purple Dogs,' etc. This transition was one that was very well-rehearsed, and after practicing this slowly and repeatedly for the first few months, it flowed smoothly as the year progressed.

Unlike Molly and Kristin, Vanessa learned about the PBIS framework at Smith from a n actual training. She attended a half-day Institute Day training with the whole Smith staff before the school year began, and this became another aspect of her classroom management. She described this as a "crash course" where she "learned about how PBIS works in the school, and how that ties with our culture for learning." Even though this was the second year of PBIS implementation at Smith, she believed that this training was offered since there were many changes in how it would be implemented this year. A big take-away from this experience was that she learned "what the school expects us to do," including the nuances of the PBIS framework at Smith and her role within them. These details included passing out blue paw pride tickets to students obeying Titus' Truths (Figure 29). Vanessa explained that everything tied 
back to these three rules of "Be Safe, Be Responsible, and Be Respectful." Students could then spend their tickets twice a week on rewards like pencils and erasers that arrived during lunch on the "Paw Pride" cart.

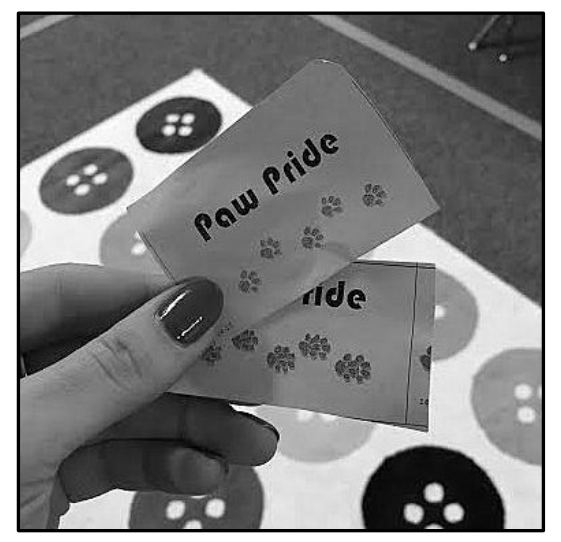

Figure 29. Vanessa: PBIS student incentive tickets (11/14-6/15).

To teach the students about these expectations and policies, the PBIS committee at Smith, called the "Student Leadership Team," coordinated presentations, which she described as, "little PBIS skits that came into the classroom.” These took place in the first few days of the school year. Additionally, from this team, every teacher also received a Picture Exchange System (PECS)-created chart of Titus' Truths to display in his/ her classroom, and it stayed posted in Vanessa's room all year (Figure 30). Highlighting consistency, I also observed it in other teachers' classrooms. 


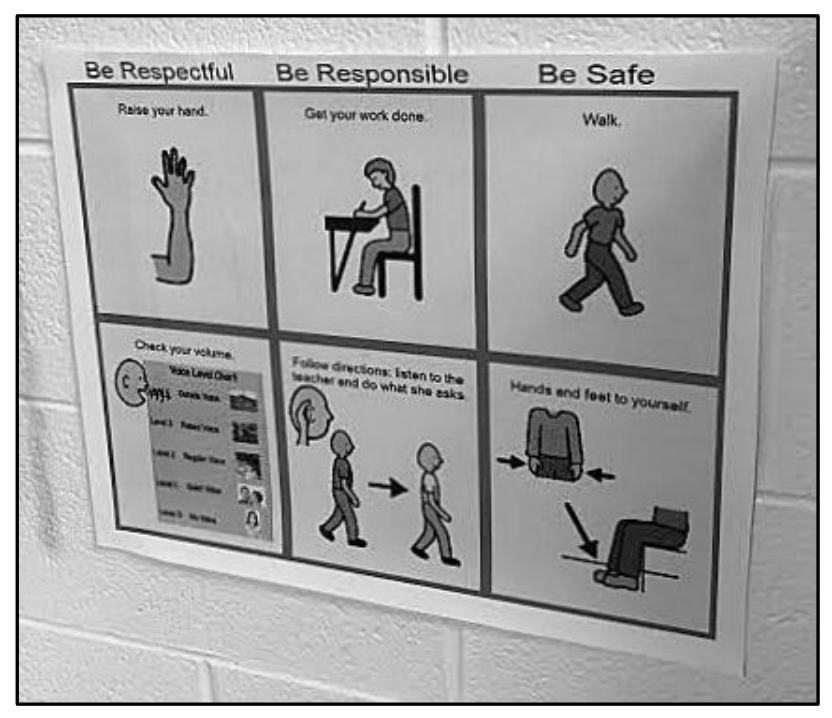

Figure 30. Vanessa: PBIS expectations anchor chart (11/14-6/15).

To follow up on these presentations in her classroom, Vanessa led the kindergarteners in breaking down the meaning of each of Titus' Truths for kindergarten. She created multiple anchor charts from these discussions that then hung in her classroom for the remainder of the year, and to which I often observed her referring. I noticed this when I heard her state, "Boys and girls, I am seeing that it has taken us five minutes to clean up from guided reading and get started on our writing. Yikes! Is that what we do in our room?" Several students shouted out, "No!" To this, she replied, "Let's remember what we do at Smith Elementary and what are Titus' Truths," and she pointed to this set of anchor charts as a visual reminder (Figure 31). 


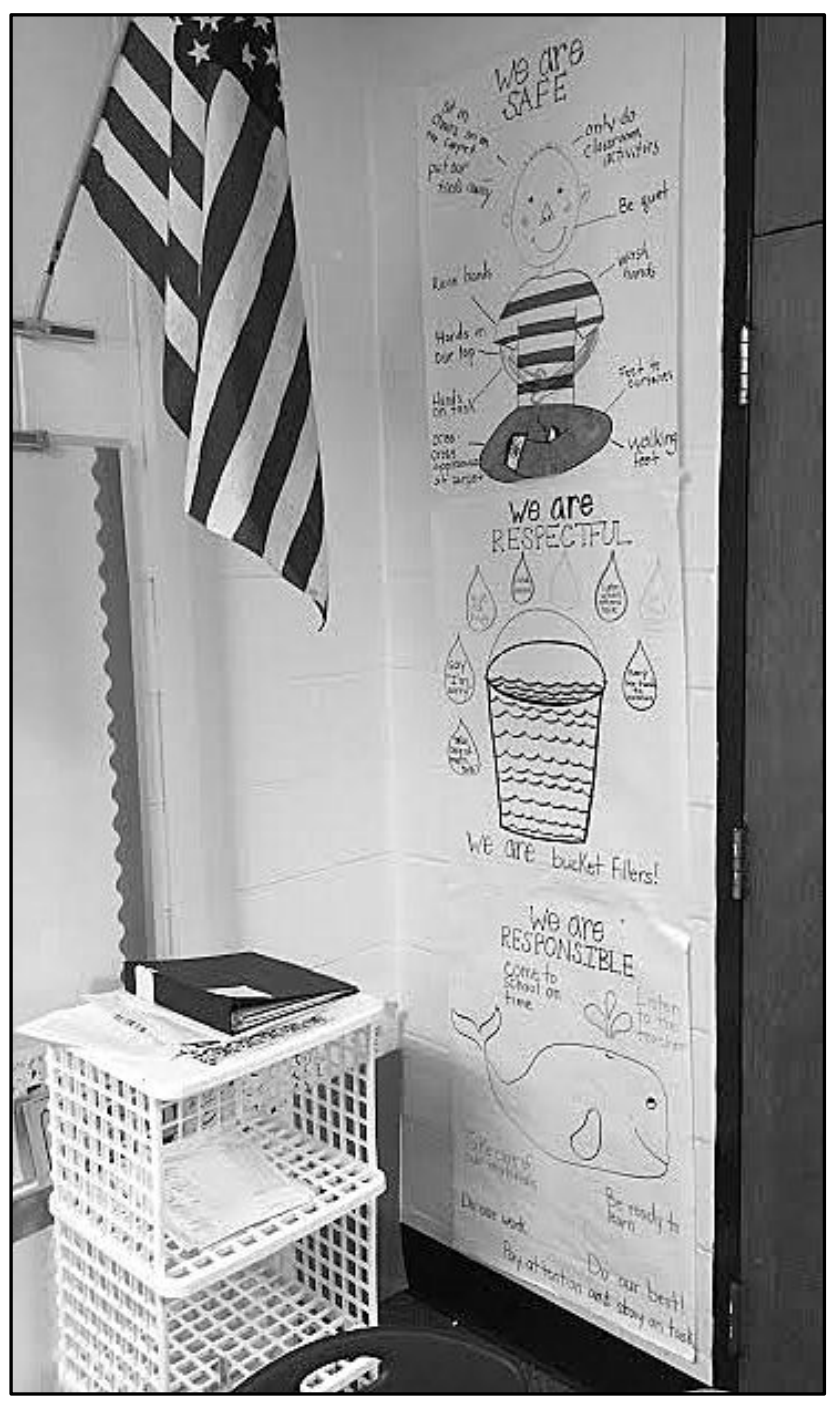

Figure 31. Vanessa: PBIS rules class-created anchor charts (11/14-6/15).

In discussing the rewards tickets and cart, Vanessa explained that they were not as big of a deal in her classroom as she had seen in others during her teacher preparation, and that she was seeing in other grade levels at Smith, like $1^{\text {st }}$ grade. She explained, "Kinder flies in our own path. We haven't had the cart in probably two weeks, but it's because we have such short days, and we don't have lunch." Despite not passing these reward tickets out often, she knew that she did not want the collection and storage of them to be a distraction for her students, so she created 
an envelope system by affixing small envelopes on the back side of her teacher desk, and this is where she asked the students to keep their blue paw pride tickets (Figure 32).

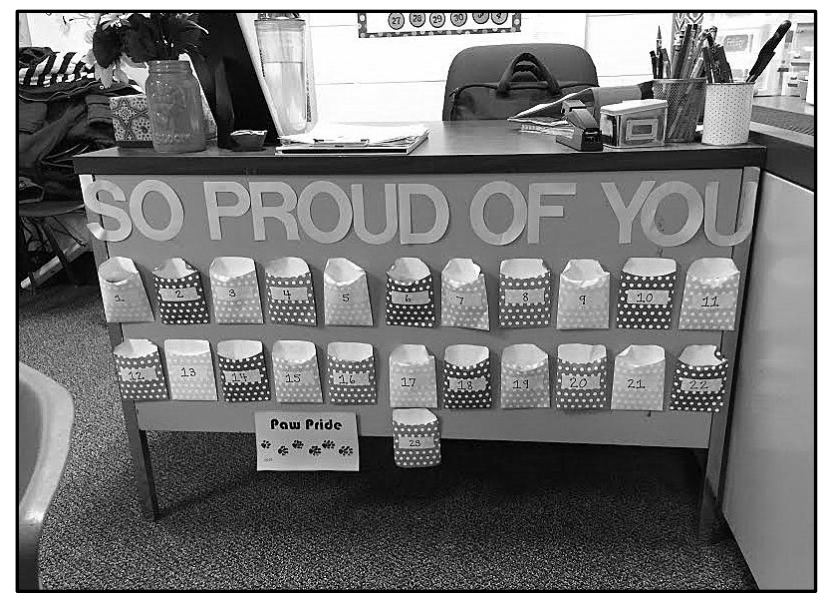

Figure 32. Vanessa: PBIS student incentive ticket storage system (11/14-6/15).

At the day of training, Vanessa also learned that Smith had several other school-wide policies related to PBIS. One of these included that all teachers use a consistent voice level chart that was to be posted and referenced in each classroom. Throughout the year, I noticed Vanessa often referring to this chart when she would ask students for quieter voices, or to give them guidelines as to how loud their voices should be for various activities of the day (Figure 33). I also noticed these charts being used in other classrooms on days I observed. 


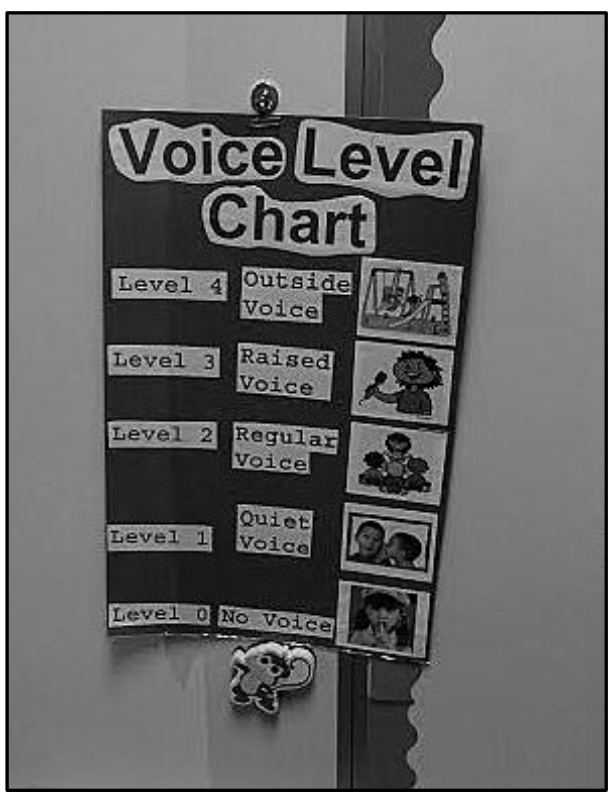

Figure 33. Vanessa: school-wide voice level chart (11/14).

Smith had another universal PBIS support focused on the collection of data to drive decisions related to behavior. Vanessa described that Smith's data collection forms were called "green sheets," and she quickly explained, "they're really just referrals." She described learning that if a student needed more than three reminders from a teacher, that this "warrants them to be put on the green sheet." Teachers were charged with writing these down and turning them in weekly to the administration to track behaviors for referral for additional support. She believed that they went into a school-wide data collection system that was then reviewed monthly, stating, "We look at all of the results each month." However, Vanessa explained that kindergarten was not yet using the green sheet documentation forms because “...we've kind of been on a little island, doing things at a different pace, and really getting that going." She was unsure of if or when they would begin to use them. 
Related to this, Vanessa explained that Smith, in its second year of using PBIS, was rolling out the use of Tier 2 supports in the form of Check In/ Check Out (CICO), which she had observed students using during student teaching. This was the same strategy that Kristin used, but a striking difference between the two sites was how they abbreviated the name of this strategy. Vanessa explained that at Smith, “...we don’t call it CICO [sicko] for short. That's not a nice name! We call it 'Titus' Club for Kids' after our school mascot, the Smith Tiger, Titus.” She and her grade-level team members were only considering "rolling this out in Kindergarten," and at the beginning of the year, they did not have any students in need of this Tier 2 support. Although not mandated to use one, as Kristin was, Vanessa chose to use a clip chart behavior monitoring tool about a month into the school year (Figure 34). This chart hung next to her daily schedule on the back wall, all year. It was one that she purchased from the TeachersPayTeachers.com website and was very similar to Kristin's, with the same verbiage. In a simple Google search for "clip chart," this specific chart pops up. 


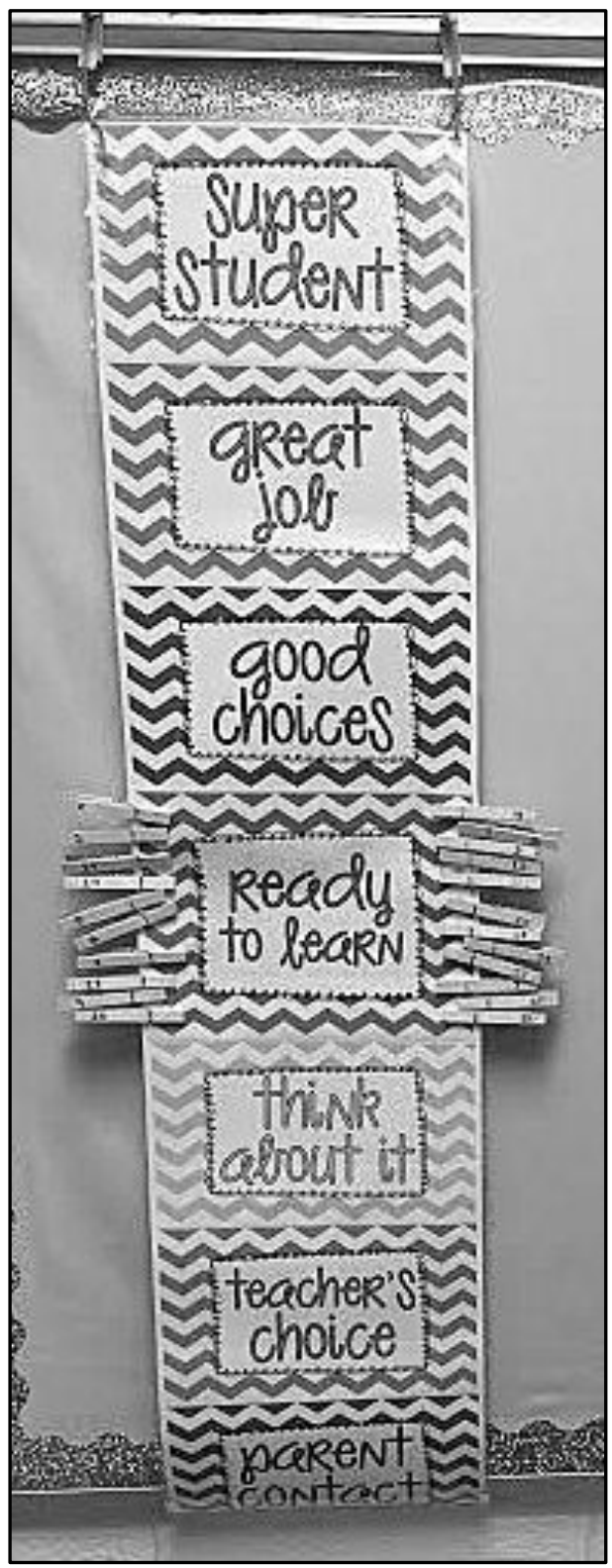

Figure 34. Vanessa: behavior monitoring clip chart (11/14-6/15).

Like Kristin, she described how she and her team members discussed the use of the clip chart regularly in their grade-level team meetings to find consensus, and like Molly, she and her teammates noticed that there were many clip charts at Smith Elementary. So, while she was not required to use it, "the school uses a lot of practices that are similar to it. So, thinking about 
using it just kind of seemed to fall into place." However, unlike Kristin and her team, the kindergarten team at Smith wavered over whether to use them at all. Vanessa shared, "We're trying not to use them because we had many discussions about the pros and cons." Yet, a month into the school year, they changed their minds because, "we felt like we were running out of steam with constant reminders of level zero voices.” Each child was assigned a numbered clothespin clip that was moved denoting their behavioral choices throughout the day. Vanessa was proud that these clothespins did not state the students' names, explaining, "They have a number; it doesn't have their name on it." This helped her feel better about using it, and yet, the chart still put each child's behavioral rating on display. She described that her use of the clip chart was limited, and that she always looked first for students to first self-correct their behavior. She explained, "After three or four of the same reminders, I might move their clip down, and if that happens, then once I get a moment, I sit down and talk to them one-on-one.” Unlike Kristin and Molly, Vanessa's students never ended the day below the starting level, green. She felt passionate that students should never leave without having moved their clip back up, and stated that she never let this happen.

Because of Vanessa's dual roles within Smith, she had to establish her own classroom management and work to build a classroom community for both her kindergarteners in the morning, as well as with her $1^{\text {st }}$ graders in the afternoon. Like she had with her kindergartners, Vanessa very quickly established an easy rapport with each of her $1^{\text {st }}$-grade students. I got the sense that she viewed all these children as her students, as well. Nevertheless, while Vanessa could control the ways in which she worked with these students when leading small groups back in her classroom, when she assisted the $1^{\text {st }}$-grade teachers, she had to follow along with their 
classroom management approach. Because of the consistencies in Smith's school-wide approach, Vanessa did not describe difficulty doing this at the beginning of the year.

The biggest challenge Vanessa faced at the beginning of the year with her management related to students' challenging behaviors. Like Molly and Kristin, Vanessa also felt stumped by a few students that presented challenging behaviors to her novice eyes. From her perspective, there were two kindergarten students for whom she expressed, "I am trying to figure out what's going on, and what do I need to do to fix these issues?" She further explained, "I'm just really worried about these two kiddos because the rest of the class is getting it, and they're running with it, but I really feel like those two are being held back in so many ways.” She explained that their behavior was negatively affecting their academic performance. She explained, "I've tried everything I can think of, and I've tried to change my way of thinking, and I've talked to teachers about it, and I just don't know how to best help them." Discussing their behaviors was one of the first times Vanessa expressed frustration in my first interview with her.

One of these kindergarteners was Akshay, whom she described as "just really defiant, but not in an outwardly, outspoken way." In describing his behaviors from the beginning of the year, Vanessa shared, "It was probably two months before I heard him speak a word to me, and I think a part of it was the language barrier there." She also described noticing that he had difficulty with communicating his emotions and feelings, especially when something was bothering him, and she explained that she hoped to get an IEP in place for him. At the same time, she had a kindergartener, Tyler, whom she described as "constantly off track" and "who needs many reminders." She found that she and Mrs. Bowman needed to spend more time with him than with many of her other students, redirecting, grabbing his attention, and diverting potential problems with other students. Like Molly, she reflected that she had not felt very 
prepared from her teacher preparation experiences for figuring out whom to contact regarding her concerns about Tyler, stating, "I think that with the whole "who do I contact in my building, we might not have touched on [at MSTC]." However, unlike Molly, she felt confident in identifying that his behaviors warranted more attention and in brainstorming ideas for how she could help him. She shared,

Even before another teacher or individual is in the room helping me take him on breaks, I was doing things that I learned in some of my SPED [special education] classes. Things like pressure and weighted balls and things like that. Just little tidbits here and there that I just had in my memory bank...

Despite feeling frustrated, Vanessa used the strong team in place at Smith to begin finding resources, which contrasted sharply with Molly's experience of isolation in supporting students with similar behaviors.

In sum, Vanessa's beginning. Even with Smith's school-wide policies, Vanessa felt confident that she could individualize her classroom management, stating, "I learned that there are places for me to put in my own touches and my own classroom management style, but that we are expected to also follow the school-wide plan.” To sum up her beginning as a teacher, Vanessa reported,

I feel really good about this year. I'd hear war stories about first-year teaching, that it would be impossible. And I keep on telling myself, 'When is it going to get that bad?' Because I feel like it's going good. My head is above water. I'm feeling okay. Vanessa and her team members focused on teaching the students self-reliance, and her classroom practices helped to achieve this. The support she felt from others the first day of the year helped to jumpstart her first year on the right foot. From this, she was poised for a great first year. 


\section{In the Fall: "I Really Got to Step Away from Using These Kinds of Supports."}

A big aspect of her job at Smith, Vanessa shared that she was growing more comfortable with the team-teaching mentality at Smith. While she felt that her preparatory program had prepared her well for not feeling as nervous teaching in front of others, due to all of the clinical experiences and observations from supervisors, she admitted that she had felt somewhat nervous at the beginning of her first year because,

I mean, when there's eight different people throughout the day who are watching you teach, it was just in the back of my mind, constantly, 'what are they thinking? Are they judging? Are they taking tips? Is there something I could be doing better?'

She explained that although it was somewhat intimidating, she knew it improved her teaching because it forced her to reflect on her own teaching and work to put "the best foot forward." Vanessa was honest in sharing that everything was not as rosy as it had first appeared, because she explained that working with so many adults proved challenging. Amongst all of these competing voices in meetings and during her teaching, she stated, "I think, at the beginning of the year, I was just kind of trying to find my voice and trying to find my place in that." She described how at their daily planning sessions, there were often eight team members present, making it hard for the three kindergarten teachers to feel that they collectively or individually had a voice. Yet, they found a way to make this work, and decided to use their lunch periods as a planning period just for them. Vanessa explained, "Now it's been really good!" because they were coming to the larger team meetings feeling more prepared.

While team-teaching in kindergarten was going well, tensions were growing amongst the three kindergarten teachers and their $1^{\text {st }}$-grade counterparts when they served as support staff members in the afternoon. A poignant example of this related to teacher mindsets, where there 
were sharp contrasts in the asset-based, growth mindset Vanessa, Kate, and Michelle displayed versus the more deficit-oriented, fixed mindsets of the $1^{\text {st }}$-grade teachers towards the $1^{\text {st }}$ graders. When the kindergarten team created small groups with their students, they consulted data and the groupings of students changed every few weeks, leading the students to work with many different students and teachers and contributing to a larger feel of community at the grade level. Yet in first grade, Vanessa's small groups that were created by the $1^{\text {st }}$-grade teachers remained consistent throughout the year. For guided reading, Vanessa was charged with working with the first graders in Allie's class who were at the lowest levels on their reading assessments. In a moment of honest frustration, she shared,

You know, they're closest to kindergarten, so it makes logical sense, but I feel like there could be more switching between teachers because if these kids are still stuck at a level 'E' or 'F' with me, maybe it's time to switch it up. Let's see if they have more success with another teacher.

Vanessa explained that this was highlighted in a cross-grade level meeting she had recently attended. At this meeting, teaching self-reliance was a big topic, and the kindergarten teachers, including her, were blunt in their descriptions of letting students struggle in order to facilitate the teaching of problem-solving. Instead of swooping into provide strategies, such as for reading, she described teaching strategies and then encouraging students to use them. An example she provided while smiling was, “'you can do it 15 times in one book, Marco, but I'm still not going to tell you what strategy you have to use.' It's just persistence and making sure they're still encouraged." This empowerment was in sharp contrast to the dependence that both Kristin's and Smith's first grade teachers' classroom practices created for their students, and it perfectly captured Vanessa's developing overall approach to classroom management. 
Classroom management in the fall. In the fall, Vanessa grew more adept with all of her teaching strategies, including her classroom management skills. If a team member was late to guided reading or absent altogether, she often had to troubleshoot her management in the moment and redirect that group of students to another task. She was also being reflective about the way she was structuring learning in the classroom for her students, explaining, "There are times, though, that I don't want it to always be so structured." Vanessa's responsive nature made her consider both sides of having the structure of assigned spots at the tables and rug.

As the students of Smith were getting used to the individual blue paw pride ticket reward system, the administration revealed a class-wide reward component to be used across the school. Vanessa explained that each class worked together to earn golden paw pride tickets, and they were stored for all to see on a poster on the classroom door (Figure 35). The poster's title, "We are working towards..." highlighted an arbitrary number of tickets they needed to reach before earning a class reward such as a dance party. The class could earn these from their teacher or anyone else in the building, such as, "in the hallway from the janitor if he sees them walking in a quiet line." Across the year, her class slowly, but steadily, filled up their charts. This was because unlike in other classrooms where the classroom teacher also awarded these, Vanessa very rarely did. Thus, her students mostly earned them from other adults in the building. Despite this, the charts did fill up, and at almost every one of my observations, a new chart hung on her door. 


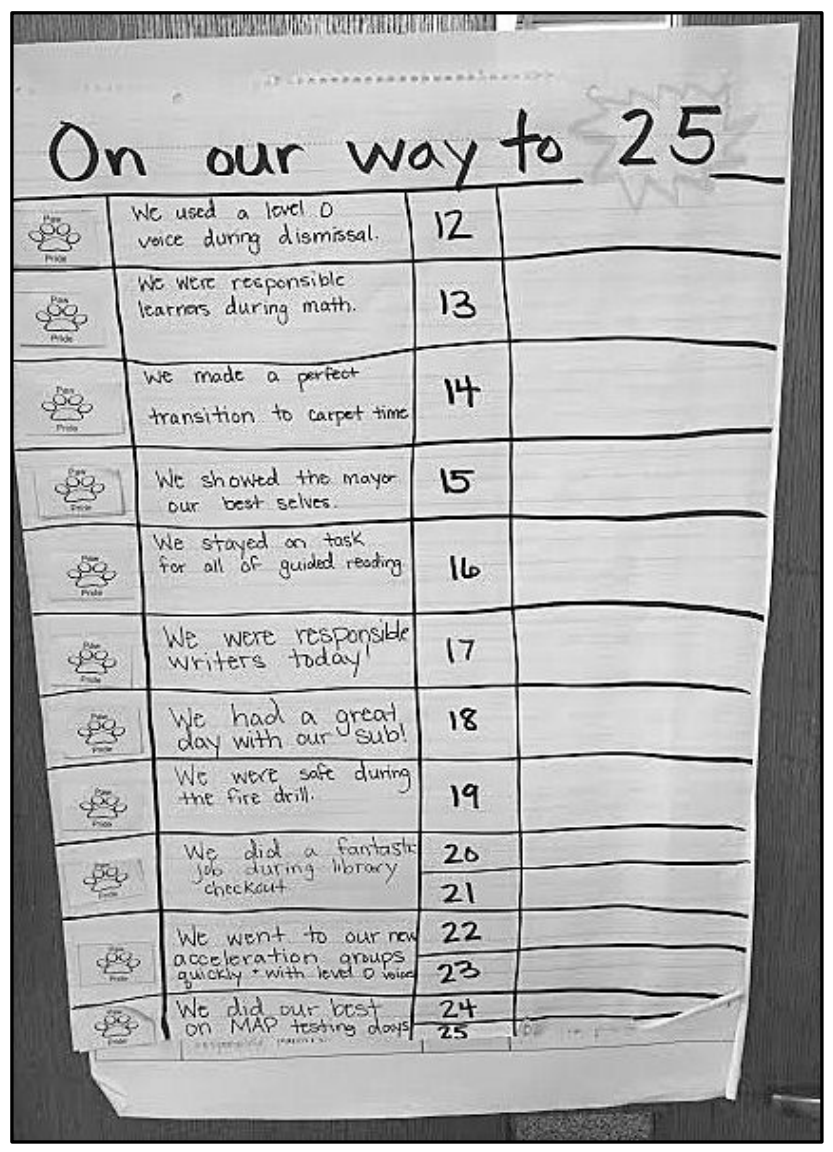

Figure 35. Vanessa: PBIS whole-class rewards charts (11/14).

By November, Vanessa was questioning several aspects of her classroom management. Because of this, she began to add in her own management tools, "towards maybe our fifth week of school when I just didn't think that the blue paw pride tickets were really working. They were still working, but they may have lost a little bit of their excitement." She found that one of her biggest management challenges was taking place during guided reading when she needed for her kindergarteners to stay on task and be independent. What she observed was off-task behavior and consistent interruptions that took away her ability to meet with her small group, making her feel like she was "pulling my hair out!" She reflected upon this, and "on a whim one day, I had a little jar that I wasn't using for anything, and I just stopped the class in its tracks and said, 'Okay, 
class, I want to show you something. Come to the carpet." She had found the idea of a "quiet pompom jar" while searching online, but did not know that this is what it would be used for in that moment. On the fly, she explained that she would fill the jar with a pompom every time she realized that they were being quiet during guided reading and at other times of the day (Figure 36). She continued, "So, they asked me what happens if we fill it all the way up, and I said, 'it's a surprise! Wait and see if you can earn it!' to give myself time to figure it out!" When she and I chatted in the fall, she still did not know what the final prize would be.

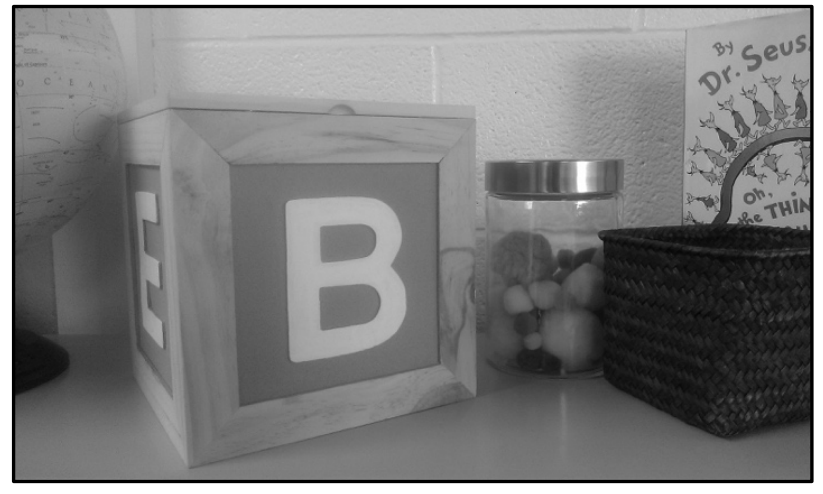

Figure 36. Vanessa: prize box \& class-wide incentive pompom jar (11/14-6/15).

Her equivocations over whether to use the Smith rewards tickets or the pompom jar did not stop her from seeing that her choices were right for her students, stating, "What I like is that I really got to step away from using these kinds of supports. I don't like having to use reward systems, and I don't necessarily agree with all the components of PBIS and the rewards." She explained that by the end of November, she was using the rewards jar and clip chart less frequently, “because I just don't really feel like they need them right now. There are days when my class might be off, but for the most part, they're really just starting to get into it, and they're 
respecting each other." She described seeing more self-reliance and independence from her students, which made her realize she did not need to depend on these tools as much. She summed up her overall belief about her students and their behaviors by stating,

Every now and then, I'll just have a day where it seems like all the kiddos in my class are off, and that we're back in that first week of school. And so, some of those days, I just need to remind myself that they're 5-years-old. It's gonna happen.

In this, she displayed an understanding of a basic aspect of building classroom community, insight into children's development.

Specifically, in the fall, Vanessa was learning more about her students whom she identified as having challenging behaviors. She participated in the IEP process with Akshay, whom she described in the beginning of the year as "just shutting down." More recently, she had observed him being "very sneaky behind my back. When I try to conference with him, his face goes flat, and he won't talk for 20 minutes!" Despite this, she was hopeful for an IEP process for him because she felt the support from one would help. For Tyler, she was using everything she could think of to help his mornings go more smoothly. Once she learned to whom she could reach out, she did. Ideas she had for helping him included starting the Check In/ Check Out process or asking her behavioral specialist, Ms. Brown to help, because "a social group with the interventionists would be really great."

The classroom management successes that Vanessa felt in the morning were not always repeated in the afternoon. In the fall, she put a positive spin on the difficult behaviors of the $1^{\text {st }}$ graders and explained, "I've had a really awesome, and challenging, and rewarding experience in my support staff role." She described observing one student in Allie's classroom that displayed disruptive behaviors like crawling under desks, throwing chairs, and yelling in the classroom. 
Mrs. Neuberger, Smith's principal, asked for a "problem-solving meeting, and it was me, his $1^{\text {st }}$ grade teacher, the school psychologist, the social worker, and the behavior interventionist. It was a big team meeting." He was fast-tracked to Tier 3 supports, and thus, the team conducted a Functional Behavior Assessment (FBA) and behavior plan. Vanessa was excited to be a part of this experience.

To prepare for his FBA and for working with him, Vanessa reflected on her clinical and student teaching experiences, where she had worked with two cooperating teachers who served on FBA teams, as well as what she had learned about FBAs from her coursework at the university. She explained that personally, she had been doing well with him during her math small groups, stating, "We kind of developed a relationship. Because it was only one kiddo, I was able to use a lot more of the learning and the practices that I picked up at MSTC. I was positive with him as much as I could be.” At the meeting, she applied her knowledge and shared that, "isolating him is not working. I've seen students like this. I feel he needs just a little more patience and positivity and to clean up the negatives with him. Vanessa's team saw how well she was doing with him, so they created an action plan based on her ideas with rewards for small behaviors. Immediately following the meeting, the team saw a drop in his office discipline referrals. Vanessa excitedly shared that he was now in the $1^{\text {st }}$-grade classroom all day, instead of getting pulled out. About this, she stated, "It's been really awesome working with the whole team, problem solving and finding these things, and really getting to understand him and his needs and likes and what is at the root of his misbehaviors." Vanessa demurely acknowledged, "It was the first time that my principal singled me out and pulled me aside and told really good, positive feedback." This anecdote highlights stark differences between Molly's experiences with challenging behavior and administrative support versus Vanessa's. 
In sum, Vanessa's fall. In reflecting on her overall classroom management after a few months of teaching, Vanessa still felt good about fusing her own ideas with PBIS at Smith because she was so connected to her grade-level team. She explained, "As long as everything stays hunky dory, and I just stay on track, I think it will be okay." After the first few months of trying things out, she realized, "I think that's been the biggest eye opener for me is that I really don't need to be turning to all of these little tricks and reward systems and charts." She shared that she planned to keep her clip chart in place as, "a reminder until I don't have to use it anymore." She explained,

I will totally love to be able to take down my clip chart and tell them how proud I am of how far they've come since the beginning of Kindergarten and link that into a teachable moment of being more mature learners.

However, she did not forecast if or when that day would come, and so it stayed in place.

\section{The Middle of the Year: "I Don't Mean to Toot My Own Horn..."}

By the middle of the year, Vanessa was flying high with her teaching. Despite a few hiccups, she was finding success with her students, with her team, and within the larger school and district. She summed this up by stating, "I haven't felt like there was anything that I've been missing." Co-teaching had become "like second nature" for her, and she realized that being both a lead teacher and a support staff teacher helped her to gain deeper insights, stating, "It really helped me being that support staff in the afternoon, because then I was able to see, 'What am I missing? What can I do better as a teacher to support mine?"' These relationships took work, which Vanessa viewed as normal. She admitted that at times, she felt frustrated within her kindergarten team, but, "I'm very fortunate though that we, as the three kindergarten teachers, we feel like we're safe to talk, and not gossip, but you know, share if we are noticing the same 
frustrations. What can we do about it?" With Kate and Michelle, their grade-level team grew closer, becoming more efficient in their planning by delegating specific tasks to each other. Vanessa had been to a specific writing training in the district, and thus, she was now the lead planner for all kindergarten writing activities. Michelle often took the lead for math planning, Kate was the note-taker, and they all collaborated for literacy planning.

Highlighting a theme across cases was the fact that Vanessa was excited mid-year to share the many successes she was seeing with her young learners. In January, she shared, "I don't mean to toot my own horn, but the kindergarteners are doing phenomenal [sic]!" Vanessa attributed their growth to the 'culture of learning' that she was establishing in her classroom, stating, "They know my expectations for them are high, and they want to reach it, and so it's neat to see them hold themselves accountable and then reach their goals." Their successes were present despite the half-day nature of her day, leaving her with less time for reaching these goals. About the half-day nature, she explained, "It definitely tests me. I feel like my heels lock in when I walk in the door, and two minutes later I look up, and it's time to pack up." Deflecting some ownership of this growth in her students, she seemed relieved to "see how fortunate we are in kindergarten to have them already reach that understanding," hinting that this was the not the same for her $1^{\text {st }}$ grade students. For her kindergartners, she shared, "I don't really see anything as a challenge."

However, stark differences between the successes she saw in her mornings and the "stagnancy" she was seeing in her afternoons related to mounting issues with her role as a support staff member in first grade. In January, she reported, "Everything has been really changing drastically." She was referring to the fact that her afternoon responsibilities had been restructured, and she was now assigned to support Allie's students instead of all of the $1^{\text {st }}$ 
graders. Understandably, these changes created tensions within these teams and amongst the larger school community. Seeming embarrassed, Vanessa shared that support staff and others in the building compared the first graders to the kindergarteners. She explained, It's a very touchy subject because our kindergarteners, kind of flew, and whatever we were doing as a team with the all of the support we had, it worked. And there was a lot of focus on kinder this year because they weren't really seen last year.

These compliments and comparisons made her very uncomfortable, and I observed this discomfort in her body language as we discussed this in January. She continued, "We had a lot of success because of that, and I don't want, and the other K teachers don't want, first grade to think that we were kind of coming in to save the day." She was very concerned about this perception and did not want it to be lasting.

Additionally, by the middle of the year, Vanessa, like Kristin, began to feel frustrated by a lack of growth displayed by some of her students, stating, "This carries over between kindergarten and $1^{\text {st }}$ grade, what's not going well are those stagnant moments." She shared that these "stagnant moments" were across the board for some of her students, explaining, "We've been talking about this as a team, 'What can we do with those kids who are just stuck?' Because we don't want to leave them behind." When pressed to think about what may be the cause, Vanessa credited their lack of growth with possibly being due to instructional inconsistencies because of the multiple times of the day that students were learning in varied groupings with different classmates and teachers. However, later in the year, she felt differently about this.

Classroom management in the winter. Also, like the other two case study participants, in the middle of the year, Vanessa described several of her students who were experiencing and displaying issues. This included one of her little girls who was missing eight teeth because of 
"dental hygiene issues in her family," and another little girl with little tiny marks all over her body. Another little boy was displaying "weird behaviors" that were new as well. She described learning from the parents of another student that this little boy had shown their daughter his private parts. When she asked him about this directly, he honestly admitted to it. Part of her concern with these issues related to the perception Vanessa was developing that her students' families were not supportive of what she was doing in the classroom, although she provided no specific examples for why she felt this way. Describing this myriad of issues mid-year, she seemed weary, but took a big breath and smiled, "onward we go!"

Vanessa's overall classroom management skills showed improvements mid-year, and I observed her regularly using attention getters and focusing on teaching self-reliance. Because of this, her kindergarteners were becoming very self-sufficient, which excited her. A great example of this was during the transition to and from reading acceleration, where they moved to other classrooms with astonishing ease for their age. Vanessa explained,

They just know it. It's taken a lot of work establishing those groups throughout the year. Actually, we had data meetings on Thursday, and that was something that came up because our principal was wondering the same thing. I think because it's very in sync. Laughing, Vanessa reflected, “They have gotten very good at traveling!” Vanessa casually reflected that this may be because they used student data regularly to change groups, so students had to get to know the routine of shifting rooms, and it highlighted the natural ways she addressed her planning and instruction.

This success highlighted a philosophical and practical aspect of Vanessa's classroom management mindset in her first year. This was illustrated by observing her working with Allie, as spending time with them together made it clear that Vanessa and Allie had very different 
teaching styles. Where Vanessa's teaching demeanor was both calm and collected, Allie always seemed frazzled and frustrated by her students. Vanessa gave very clear directions and guidelines and always seemed to have students' developmental understanding in mind, such as the writing guidelines she created for her first graders (Figure 37). In contrast, Allie often charged her students with tasks that were developmentally-inappropriate and taught them in confusing ways, leading to puzzlement and frustration in her classroom.

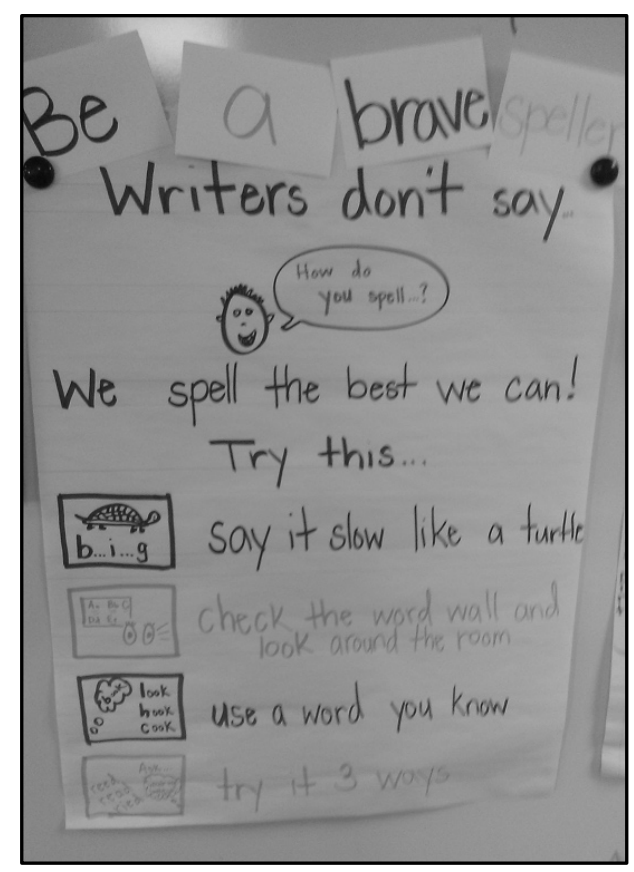

Figure 37. Vanessa: writing guidelines for kindergarten $\& 1^{\text {st }}$ graders $(1 / 15-6 / 15)$.

Their two classrooms presented as opposites, and their interactions with students were just as different. I never once heard Vanessa be short or cross with a child, but on more than one occasion, I observed Allie being so with students. While Vanessa's good behavior might have been for show when I was present, my same presence did not seem to positively affect Allie's behaviors. Additionally, on more than one occasion, others at Vanessa's school reinforced the 
observations I had of Vanessa, helping me feel confident that what I observed was her true character.

The differences between Vanessa and Allie influenced students' behavior. Vanessa explained, "This [academic growth spurt] is just something that we haven't seen really in the $1^{\text {st }}$ grade as much." She relayed an anecdote that Ms. Brown had shared with her about the $1^{\text {st }}$ graders, stating, "The teacher asked the girl, 'What did you learn while reading that book?' She said, 'Nothing, you didn't tell me to learn something." Vanessa viewed this attitude as problematic and so different from her that of her kindergartners. A specific issue she described in working with $1^{\text {st }}$ graders was that they interrupted her teaching. Vanessa worked with one $1^{\text {st }}$ grade student, Gabby, who continuously interrupted her throughout the year. She explained, "She cannot read and keep her thoughts in her head for the life of her...She'll say, 'I'm gonna be in the moment,' or 'I'm gonna stop everything now,' but then she talks through that!' Instead of feeling frustrated by this, Vanessa seemed reflective, "It's a little frustrating, but then I know they're in $1^{\text {st }}$ grade, and we push them so hard, and they need those outlets." She seemed invigorated by figuring out how to work with the $1^{\text {st }}$ graders, and she intentionally looked for ways to highlight their abilities to problem-solve and take pride in their work.

PBIS at Smith continued to be a big part of Vanessa's classroom management, especially related to school-wide initiatives. In the middle of her first year, the PBIS team decided that classrooms would work towards using their golden paw pride tickets to create a class snowman (Figure 38). Vanessa explained, "We had a little meeting where all of the kids discussed what it means to be a responsible student, and they found out that for every time they got a golden paw pride for being responsible, they got a piece to their snowman." Each class' snowman could 
have a different theme. She decided that theirs would be an astronaut snowman, and she created his parts. She happily exclaimed, "When I brought out the jetpack, they lost their minds!"

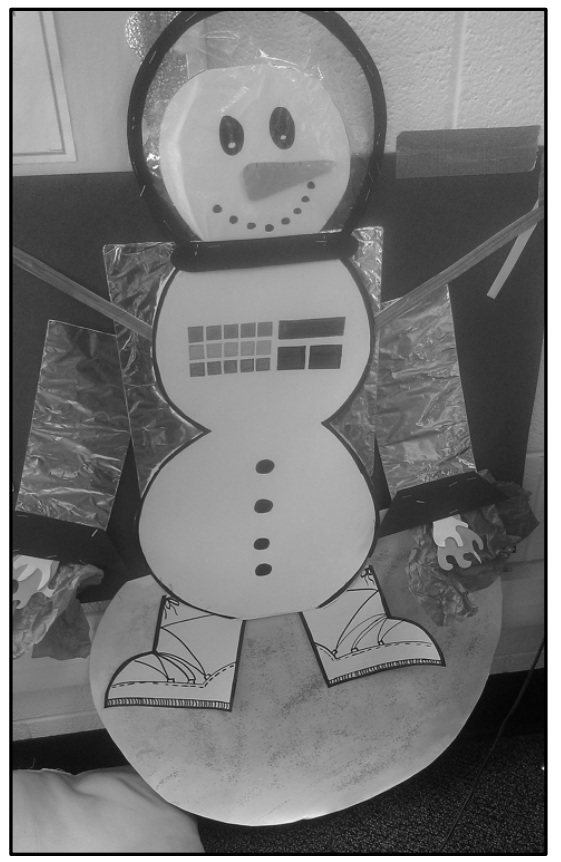

Figure 38. Vanessa: PBIS incentive chart-community-builder (1/15).

Vanessa believed that she could put her own spin on this school-wide initiative. She explained, "But what we started doing is, I didn't really stick very heavily to giving the paw prides. I just did if I noticed they were responsible and gave them another piece. And we built it, and they loved it." At the end of the month, there was a whole-school assembly and a parade of the snowmen. The students of Smith got to vote for their favorite snowman. Vanessa saw this PBIS initiative fitting so nicely into the fabric of her classroom community. She explained that having conversations about behavior like this was what she preferred to do, versus moving students' clothespins down the clip chart. Later in the year, I overheard two of her students standing near the snowman, who remained in her classroom for the rest of the year as a testament 
to what they had accomplished, reminiscing about this creation, and saying, "Remember when we got the rocket launchers!" The other responded, "Yeah, that was a good day!" Vanessa felt that her students had truly enjoyed building the snowman, by stating, "What I liked about it is that since it was school-wide, and we all got to participate together. They were all focused on something. I think it really showed a strong culture for the school environment." Because the school-wide response to the snowmen was so positive, at a staff development meeting, the Smith staff discussed starting a new version of this school-wide initiative for the spring, and Vanessa was excited about this idea.

By the middle of the year, she explained that fitting her classroom management in with the school-wide components of PBIS was "going good. It's not too different than where we were. I don't feel a lot of frustration or a big pull." She described feeling the presence of her teacher preparation at work here, as she explained that she had learned alternative strategies instead of just using the paw pride tickets, PBIS, and clip charts. She continued, "MSTC has made me question that and find other ways of listening to kids and letting them talk and explain, and really just having those conversations and being more student-focused." She felt that she could use the aspects of Smith's PBIS framework that worked for her students and not others. While she did not use rewards as frequently as I noticed Kristin and Molly using them, I did observe her using them mid-year, which negated her earlier statements about them. After students were talking over her directions to sit back down once a brain break had ended, she loudly called out, "Wow, Table 4, great job! You quietly sat down." With large movements, she demonstratively passed out blue tickets to these students. Some of the others saw this and quickly sat down, but others did not seem to notice and continued talking loudly. She knew she needed to capture their attention, so, she used an attention-getter, and this worked better. The 
other few times I noticed her or Mrs. Bowman passing them out it was also done in demonstrative ways, i.e. to draw others' attention to the receipt of the reward. Still, like for Kristin, this praise to encourage/ coerce behavior resulted in mixed success, yet neither acknowledged this. Vanessa clarified her stance, stating, "I will hand out paw prides if we're having a really tough day where everyone is getting really wiggly, just to kind of reinforce." She explained that she was seeing that passing out the tickets at these times was positively affecting her students' behavior, and "the kids really like that." She commented that Mrs. Bowman passed out many more than she did.

The Smith PBIS-rewards cart came for the first time in a few weeks around this time of the year, and she was so happy that all her students had tickets to spend on the prizes. Vanessa's students had been saving them up, and the fact that everyone had tickets to spend made her reflectively comment, "which kind of says something there. Because at that point, there were probably some kiddos who had not been behaving the best within the last two weeks, but they had paw prides saved up for two months." In discussing this experience with me after school, Vanessa paused and continued, "so you know...I don't know if that's very consistent with the message, and I didn't think about that that day. They were just, 'Okay, let's count our paw prides!" Her realization hung in the air, and she continued describing the system at Smith, but this hinted at some disconnections she was realizing.

She explained that the paw pride tickets were now being tabulated at the school-wide level as data about behavior. Here, she again took a critical, reflective stance, stating, "I think it would be interesting if you were to be using that data to decide if the program is really true to what it's trying to do." She went on to explain that she realized that teachers inconsistently rewarded behaviors with the tickets, and that ultimately deciding what deserved the reward was 
"kind of up to the teacher's discretion." Because of the variance in what behaviors earned the reward with everything from "saying something nice to their friend," or "finishing all their work,” she added, “...so, I don't know if that data would be very informative.” Whereas, Molly did not acknowledge that certain students received rewards more than others, and Kristin overtly rewarded specific students and believed that it was because of their good behavior, Vanessa admitted that not all her students received rewards for equal behavior because she was intentionally making this decision. For example, Tyler received tickets every day for reaching his individual goals, while the rest of the students would not be rewarded for the same behavior, and I observed this to be true. She described sometimes passing out the tickets "on our more wiggly days, but not nearly as much as the rest of the school does." Ultimately, she felt that the use of the paw prints was not "very strictly monitored," by administration, so if she did not use them very much, it was okay.

As for the class-wide golden paw print tickets on the door chart, she explained that she preferred dispersing these rewards, and that her students earned most of them from Smith's head custodian, Mr. Brian, especially for keeping the room tidy. I observed Mr. Brian knock on the classroom door one day and announce, "Boys and girls, I have three golden paw prints for your class because you have been keeping the room so clean for me!" She explained, "They really like when Mr. Brian brings them these, and I do too because there are just some days where they really work hard, and they do get really excited about them, more so than the individual ones." While this was a reward for her students, it was a more of a testament to Vanessa and the work she did to model, teach, and encourage good organization and tidiness.

Like at Monroe, Kristin's school, Smith's Tier 1 support of Cool Tools was the school's way of addressing the PBIS component of teaching pro-social behaviors. Throughout the year, 
these Cool Tools were conveyed through morning messages and activities. However, unlike at Monroe, at Smith, the teachers were expected to do these activities with their students, such as the Microsoft PowerPoint presentation of guidelines for playground behavior throughout the seasons that I observed Vanessa teaching in January. Many of Smith's Cool Tools were based on aspects of Whole Brain Teaching (WBT), which was a hallmark in Kristin's classroom. One of these tools was a WBT class-wide management tool called "Beat the Teacher" that I observed Vanessa using in January. With this competitive classroom management strategy, if the students remembered rules and followed them without being told by the teacher, they would earn points. If they forgot rules or misbehaved, and the teacher identified these transgressions, then the teacher got a point. The goal was to have the students earn more points than the teacher. In January, I observed a small scoreboard in the upper left hand side of the front interactive board that stated, "Miss J.: 1, Students: _." As Vanessa wrapped up a read-aloud and noticed that all of her students were behaving appropriately, she excitedly clapped her hands together and asked, “One for all?" They quickly shouted back, "Yes!" She added a tally mark in their column of the scoreboard. This tool seemed an odd addition to her repertoire because of its competitive and tattling nature, which contrasted with the more supportive and encouraging practices I also observed her using.

Although she had mentioned possibly removing it when I spoke with her in the fall, Vanessa's clip chart was still hanging in her classroom mid-year. However, I only saw her use it once the day I observed. This stood out to me as I had recently been in Kristin's classroom where it had been used multiple times throughout the day. Vanessa's sole use took place when I observed her praising and rewarding two students whose behavior was on-task during independent reading. Bending down next to them, she announced, "Wow, look at you two on 
task! Please move your clips up one!" This contrasted with Kristin's demonstrative rewarding and punishing with the clip chart, and here Vanessa's students moved the clips, not Vanessa. What distinguished Vanessa's use from the others, was that she rarely used the clip chart to "move students down," or punish them. She later clarified, "I mean I have moved clips down before, but it's been after me saying, 'this is your third one, this is your fourth one,' where I know other teachers would use the clips as a warning." She described that she often observed behaviors that she knew might cause another teacher to move a clip down as a punishment, but that this was rare for her.

Despite her rare use of the chart, the distracting effect it had on students was no different for Vanessa's kindergartners than for Kristin's. During guided reading time, two boys were supposed to be independently reading. Neither of their clothespins had been moved off the green level of the chart, but for a full rotation of this activity, they stood and gleefully discussed their clips' placement on the chart. Because of this, they did not read at all. Vanessa approached them when the rotation was over. Demonstrating what she earlier described, instead of moving their clips down as another teacher may have for their off-task behavior, she talked with them about being more focused tomorrow, patted them on their backs, and moved along, but as in Kristin's classroom, the chart was eating up her instructional minutes.

Vanessa's infrequent use of the clip chart mid-year led me to ask her whether she felt her students needed it. She quickly responded, “I don't think so." Prompting this quick reaction were her memories of the dependence that Allie's students had displayed earlier that day. In Allie's $1^{\text {st }}$-grade classroom, the clip chart was used often and intentionally to punish behaviors, and Vanessa saw a connection between the use of the chart in this way and the dependence that they had on Allie and her to regulate their behaviors. This realization highlighted a stark 
difference between her classroom management approach and Allie's. At my mid-year observation, I observed Vanessa serving as an aide within Allie's classroom and overheard her telling Vanessa that there had been an issue of cheating in the classroom that day. Oddly, later in the day, Allie interrupted the kindergarten grade-level team during their lunch break to posture for a solution for the cheating problem and to inquire as to what they felt the child's punishment should be. However, she rejected every solution Kate, Michelle, and Vanessa offered. Reflecting on this interaction, Vanessa shared,

Even when Allie came in at lunchtime and was saying, 'I don't know what her punishment should be,' that's not the mentality that I have. I get the sense that, that's it [referring to the punishment example Allie presents]. That's why we have the paw pride rewards and the celebrations and things like that. It's more of the district approach and its mentality.

Vanessa explained that the disconnect between the PBIS "district approach and mentality" and her beliefs and practices was something she faced daily, stating, "That's where I'm just trying to navigate, how can I comply with district norms." Yet, she saw the collaboration and somewhat isolated nature of the choices made at the kindergarten level as helping her bridge the disconnect, stating, "it's [PBIS] one less pressure on my management decisions."

Ultimately, she described her discomfort with removing the chart, stating, "But then part of me has a comfortability there, just knowing that in a desperate time, it's something that the kids know. Yet, I know that's not why I want it there because it's comfortable and good...” Like Kristin, she deflected in her following statement, "But it's just my first year in, so I'm getting the feel of it." Both Vanessa and Kristin attributed/ blamed their use of the chart with all of its related issues on their status as first-year teachers. However, Vanessa was the only study 
participant who was consistently self-critical and reflective about using a behavior monitoring system like this, as well as consistently questioning her related management decisions.

In the middle of the year, she explained that she wanted to find a balance between using the clip chart versus just removing it. She was quick to describe her students as, "great! It's not a terrible class. I don't pull my hair out because they're misbehaving or anything," and "I don't always want to be relying so heavily on those [extrinsic rewards], because it's [sic] not necessarily making my classroom any more phenomenal than the next." She additionally noticed that she had slowly stopped using the "quiet pompom jar." She described, "We have not done them, and it wasn't that there was a day when I said, 'Okay, we're gonna take this down. We don't need it,' but I could have." She found that she felt motivated to remove the jar after a student asked her if they would receive a pompom reward in response to showing good behavior during reading time. Caught off-guard, Vanessa realized that they had not used this class-wide reward in weeks, and she explained to this student that they did not need the rewards anymore. About this, she reflected, "That would have been a good teachable moment." Having rewards like this slowly fade away was what she ultimately wanted for the clip chart.

While Vanessa did not make this connection, it appeared that she was focusing less and less on the extrinsic tools of the clip chart and pompom jar because as she described, "I'm seeing my kiddos respect each other." In Vanessa's classroom, very rarely did students have conflict with each other. She shared that she believed that this was because of their beginning-of-theyear work. From observations, I noticed that this could also be due to the fact that the day moved very quickly without a dull moment to get off track, how they were grouped varied and encouraged positive interactions, and Vanessa's positivity was contagious. She recognized that all her work in the fall months was paying off, stating, "We laid a really good framework that 
just - this is our class, and we're all one community, and we're here to work together and respect each other." She explained that she consistently embedded this point into conversations with students "when something comes up."

Some of the behavior issues she identified mid-year were students chatting and talking out turn. These behaviors were mild as compared to the challenges she faced working with Tyler. Mid-year, she described now knowing where to find support for him, as his off-task and defiant behavior had persisted, but "it's just really hard for someone else to come in and fully grasp the severity of the situation." Thus, she described feeling frustrated, and "at my wit's end, and that was a challenge for me." Yet, Vanessa's reflective and problem-solving nature prevailed. She explained, 'Until one weekend it just hit me, and I said, 'It's not his fault.' I need to know that. He's doing the best he can. I need to service him better instead of getting frustrated." She turned to Ms. Brown, the behavior specialist, whom she described as "awesome," and her bilingual teacher, Mrs. Gonzalez, who had been "an absolute asset to me in figuring this out," to assist her in documenting his behaviors and trouble-shooting several issues. One such issue was when she realized that Tyler was repeatedly pressing the call button to the main office. With the support of Ms. Brown, Vanessa worked individually to teach him that this was inappropriate. She created a behavior contract with him, which he signed, and she believed that this was at least helping to address this specific behavior (Figure 39). 


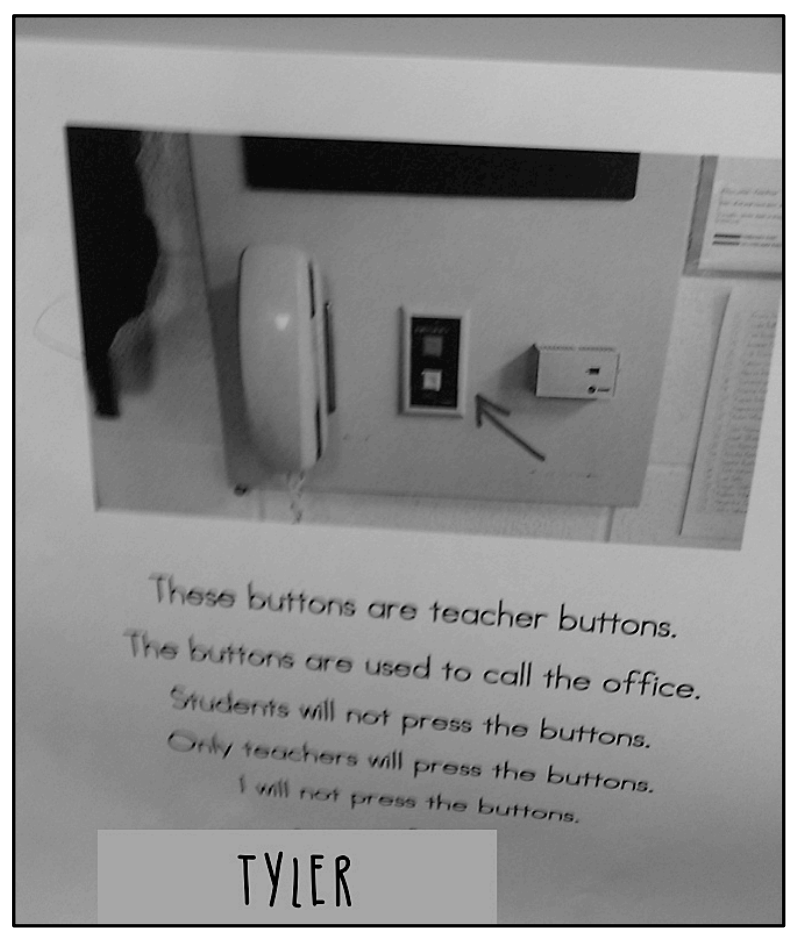

Figure 39. Vanessa: individualized behavior contract (1/15).

She explained, 'I'll never take a challenge as something negative, it's just another area for me to grow." For further steps with Tyler, she described that "really nothing else can be done besides the support," because her team was in the process of creating him an IEP through the district's new documentation process. She met with Kate and Michelle, and as a team, they decided to start using Smith's "green sheet" documentation forms for PBIS Tier 2 because then they would have data backing them up when they reached out for support in situations like this from the interventionists, such as Ms. Brown.

With her $1^{\text {st }}$ graders, mid-year and for the rest of the year, Vanessa had several students who were in and out of PBIS-Tier 2 supports at Smith because of behavioral concerns. While at the Tier 2 level, they participated in Titus Club for Kids, and Vanessa was responsible for evaluating their behavior at the end of small group activities she led. At times, I observed her 
students being worried about this process. In one example, Gabby, who had been very jittery and distracted during a small group rotation, remained in Vanessa's room when all the other students had returned to their classroom. Vanessa asked, "Gabby, what are you still doing here?" In a whiny voice, she replied, "I need you to check me out, but I don't want you to write down what I was doing at the start." Vanessa gave her a hug, "Gabby, it's okay. You got back on track, but it's important that I share with others that it took you awhile to get there. Come on, girl. Let's go down to your room." She patted her on the back, and Gabby seemed satisfied enough to leave the room.

In sum, Vanessa's winter. By the middle of the year, she reported, "It's been a slow, gradual kind of work back up into the stamina of getting through the full day after break, but it's been a good year." Despite the stresses of working with various adults in the building, it seemed that Vanessa was realizing the benefits of having such a large team, stating, "It's good. I feel like I could say it again and again—it's just a lot of support from a lot of people that I can talk to." At no point did Vanessa indicate that she was unsure of where to go to find help with issues she was having in the classroom, and she saw the relationships she was developing with these individuals as the reason for this.

At this point in the year, Vanessa indicated that she was beginning to have a real handle on her own teaching, stating, "It's been a lot more focused on the kids and not so much the, 'what are we doing, and how are we handling this transition and schedule changing?' Those things." Yet, she recognized that she was still learning. She explained,

I have my days where I feel like routines and just day-to-days in my classroom are still a struggle, and I know that they're in kindergarten, and so they're 5-years-old. So, they're not always going to be $100 \%$. That's not an excuse. It's a reality. 
It was clear that like Kristin and Molly, she was recognizing the rigor of today's early childhood classrooms was different from their own kindergarten experiences. An example of this disconnect came close to home for her, as she explained that her boyfriend had recently asked her, “'Well, you can teach this when you're teaching colors.' I'm like, 'that's not what we do. We don't just sing the alphabet and teach colors here." Always focused on growing professionally, in the winter, Vanessa asked me for advice related to starting in a Master's program, stating, "maybe I want to do something that could expand me!" As the conversation wrapped up, she reflected upon the fact that she knew it was early in her career to be considering this, and she shared, "Maybe I should think about moving out first, and then, a Master's!" Her shooting star was flying high.

\section{Into Springtime: “...Doing So Much More than Surviving.”}

By springtime, positive things seemed to be happening for Vanessa both in school and out. She and her boyfriend had just purchased their first home together, and she seemed to have hit her stride in the classroom. She shared with me, "I've heard so many people saying that my first year of teaching is gonna be the worst. 'You're gonna just survive.' I feel like I've been doing so much more than just surviving." By March, she was seeing even more gains with her kindergarteners, especially with their reading and writing. She described their progress as "exploding." Vanessa also viewed her afternoons as going much better than earlier in the year, stating, "It's going very well. I think we've been in a groove, and things have just been really good." She admitted that when the administration switched things up in January, things had been rocky, but that in the springtime months, "it's really kind of smoothed out." Despite this, her biggest concerns continued to be related to working in her $1^{\text {st }}$-grade role. 
Classroom management in the spring. Into the spring months, Vanessa found herself using the clip chart even less frequently than mid-year. She clarified, "Well, I have used it recently for moving clips up because of squirminess, and the kids get really excited about moving up.” She qualified her statement, "I know that I should take it down because we don't necessarily need it." On the day, I observed in March, I did not see her use it once. She laughed when I mentioned this to her, "Yeah, I didn't talk about it once, and you know, the day was fine. We got through the day, so in that regard, I feel we don't need it." Here, like earlier in the year, she wavered,

We could take it down... but then, there are those days where I'm thinking if we're going to re-teach, and we want to be really modeling those good behaviors. Moving the clips up, the kids get so excited, and they really work together to see that...I don't know... She went on to explain that she felt badly when she moved clips up because she knew she was missing other students, whose clips could also be moved up.

"I don't know," she continued, "maybe it's just a safety net for me." She stated that possibly if she were having a difficult day with them, praising and rewarding one child for good behavior may have a "ripple effect" on the others. Yet, she reflected, "but maybe that's not a good reason to implement something..." Here, her face scrunched into a silly, "who knows?" look, and she shrugged her shoulders. In discussing this, Vanessa shared her real fear of being a 'mean' teacher, stating, "I don't want to be a punitive teacher." In this discussion, I expressed a growing worry of my own - that she was vacillating in her opinions about the chart because she felt pressured by me. She defiantly responded,

No, but it's [talking about the chart] making me confront my inner beliefs, Kira. I mean it. Even before I started teaching, and we talked about this at MSTC, I knew what kind 
of teacher I wanted to be, and I really do strongly believe that rewards and incentives are not necessary. Yet, I think that it's a harder path to go down without them because it's just kind of the easy thing to do, to buy into paw prides, or something like that. And it takes a little bit more time and a little more dedication and buy-in on the kids' part to really understand a management system without something like that.

She continued, "It's easier to explain something when there's that there. It's been harder to try and instill those same messages without it, but I know it can be done." She paused, and I perceived that she may be asking me to weigh in. I waited, and she continued,

I mean, maybe just —I don't know. Like how do I... because now I'm going to be thinking for the next three months about, if I have this divide with the behavior management system at Smith that is PBIS, I guess...how do I just get rid of all of them? The tickets, the chart, everything...

At this point, she was directly asking me to weigh in for the first time all year.

Always conscious of my researcher role, I cautiously shared that in my own experience I had seen that someone could teach without a clip chart because I had done this, and I had observed others teaching without them, as well. She reacted with surprise and reflection, stating, "Figuring it out is where I'm at." She felt that for her first year of teaching, "it's almost like, 'Well, everyone is following paw prides. Everyone has a clip chart.' So, it's kind of falling into the middle of the pack because if they're seeing success with it, then it works." Yet, in Vanessa's reflective way, she continued, "But then, I'm also internally thinking, 'I don't want my kids to leave the class today feeling like they are less of a student because they aren't up on 'good choices,' and someone next to them is."' These honest comments highlighted the stress Vanessa felt as she navigated the two worlds of democratic, teacher preparation messages and 
behavioristic, school and district messages related to PBIS. Discussing her questions and concerns inevitably led her to state, "Probably by the next time you get here, I'll take it [the clip chart] down just because when we think about things like that, I don't want to be punishing kids. Right? The world won't end!" Yet, she had suggested removing the chart before and had not followed though, so I was hesitant in believing that it would be down by year's end.

Again, in the spring, Vanessa described her community as one built on respect, but she did not make the strong connection that this was a major reason why she rarely saw the need to use the clip chart. She explained, "One thing that I'm really competent in, and that I feel really good about is that I do think there's a lot of respect between the kids and me." She proudly described, "They will engage with me. They'll listen, and they will be honest if I talk to them about, 'What do you think you could do better next time?' They have really genuine answers.” I would not disagree with Vanessa's self-assessment of "When I talk to them, I feel it's warm and heartfelt, and they come back and they're excited to see me, and they're excited to be there," because this was exactly what I observed each day I was at Smith.

Another aspect of mutual respect was the encouragement she showed her students. Throughout the year, Vanessa took time to reflect with her students about the growth they were making every day. A reading-related example surfaced in March when she shared, "especially with the hard words, we've been saying, 'look where you are now!'” Vanessa was always just as delighted as her students to see that they had acquired new words in reading and writing. In my March interview with her, she exclaimed, "It's been really awesome to see! They are just realizing, 'Wow, I can do this. I can write.' I'm getting a lot less of 'Ms. J., Ms. J., Ms. J.' and 'I can't write. I can't do that." This was so different than the dependence I noticed in Kristin's classroom. 
Vanessa attributed the growth and independence she observed in her kindergartners to several aspects of her teaching and community-building, stating, "I think it's kind of a perfect storm. I mean I've really tried to let go a lot in the last few weeks. 'How can you problem-solve if there's something going on?"” By this point in the year, I heard several of Vanessa's students referring to themselves as "problem-solvers," and I wondered if she had held class discussions about being a problem-solver. About this, she shared, "That's the funny thing because I have not said that! Like we never had a sit-down. We just said, 'Let's be problem-solvers."' Although she may not have noticed the times when she was instilling this mindset in her students, as an observer, I did. Vanessa consistently empowered her students to be responsible for their own learning, especially outlining guidelines and using anchor charts to do this. An example was the poster guidelines that she created for math problem-solving and team functioning. She noticed that the posters helped her students when working with partners during math time (Figure 40). While seemingly unable to self-identify these empowering aspects, they were obvious to an observer. 


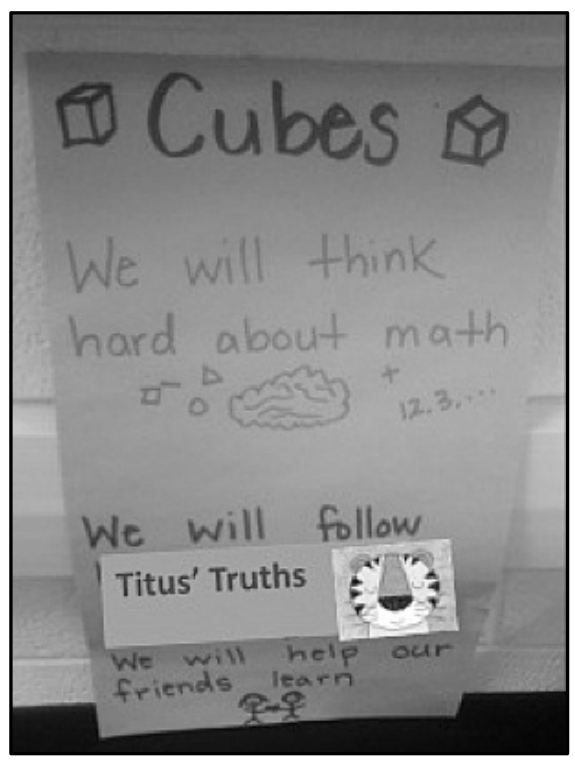

Figure 40. Vanessa: math guidelines chart (3/15-6/15).

The gains Vanessa observed amongst her kindergarteners also applied to those students who displayed challenging behaviors. In the spring, she reported that Tyler was now receiving pull-out support from Ms. Brown and was in and out of the classroom all day. Also, with guidance from Ms. Brown, they were using new progress monitoring tools with him. She explained, "We're really developing his case." Vanessa was proud of the growth he was showing and was excited to show me his monitoring sheets (Figure 41). At various down times in the morning, she checked in on him with this tool. Meeting about this form with him was always done very discreetly, and I did not notice other students paying it much attention. She shared that Tyler, who was gaining independence like all of her students, would also occasionally leave the classroom without notice, which was very problematic. Again, with the help of Ms. Brown, she created a contract with him that outlined the guidelines for leaving the classroom, and like the other contracts they had created for Tyler, she felt that this was helpful (Figure 42). 


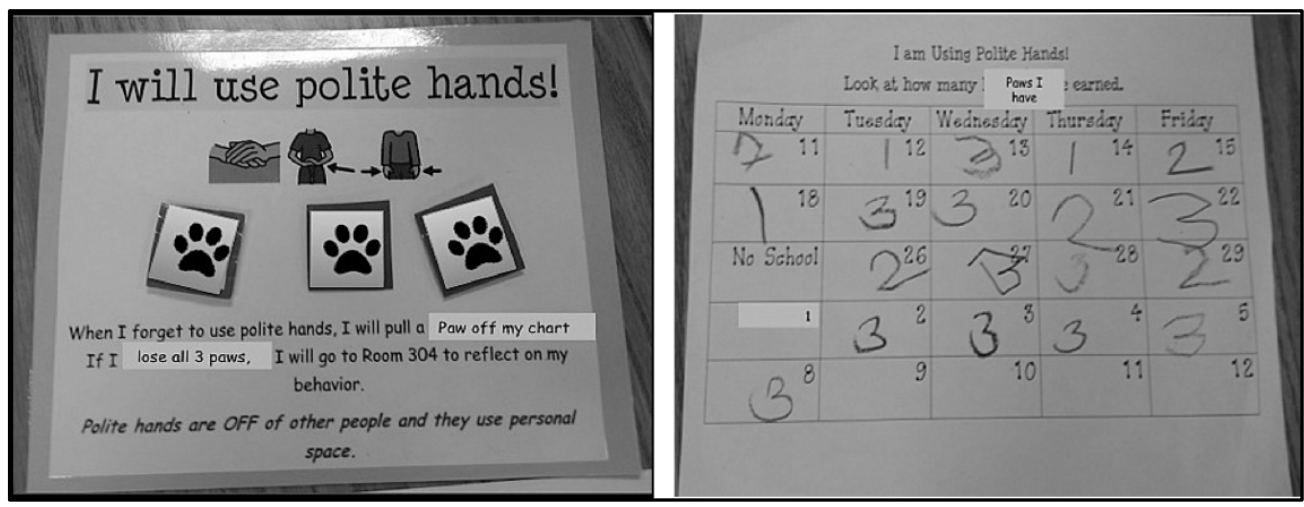

Figure 41. Vanessa: individualized behavior monitoring charts (3/15-6/15).

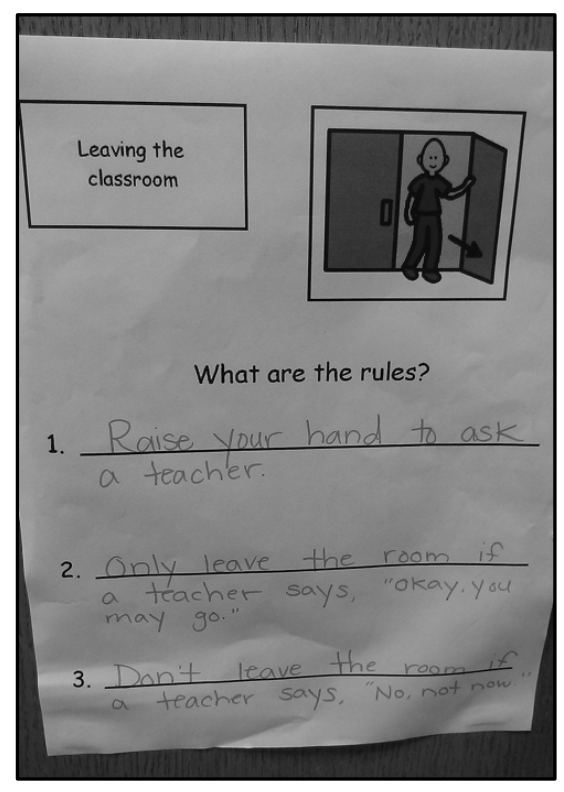

Figure 42. Vanessa: individualized behavior guidelines (3/15).

While she worked to instill a sense of problem-solving in her $1^{\text {st }}$ graders as she did with her kindergartners, the deficit mindset commonly seen in her $1^{\text {st }}$ graders persisted into the spring months. Upon observation, I still overheard first graders saying phrases like, "I can’t do this," and "This is too hard," and they routinely gave up on tasks. With Kate and Michelle, she reflected about this concern as it was consistent across their experiences. Unlike the $1^{\text {st }}$ graders, 
they described their kindergarteners as having a, "deep-rooted, problem-solving air about them." She noticed that she had fewer interruptions with them, versus the $1^{\text {st }}$ graders who were "not so problem-solving-oriented." She explained, "We use the metaphor of the YouTube video where there's an escalator, and it's broken, and there's just someone standing in the middle of it screaming, 'Help! Help! Help!'” At one of her first staff meetings of the year, the Smith administration had played this video for the school staff. To Vanessa, its message had been, “Don't let our kids get stuck on the escalator! Teach them if the escalator is broken to keep walking. You don't just stand there!" She connected this back to what she was seeing in first grade, stating, "We felt like the first graders at the beginning of the year were stuck on the escalator." Vanessa relayed a recent example that she felt exemplified this issue and illustrated that the problem was still present. She was holding the classroom door open for the first graders to enter, when she noticed that someone's winter hat had fallen in the middle of the doorway. She explained,

I had an entire line of students just walk and stop to look at the hat. They would look at me, and then they'd walk around it. Normally, I would say, 'well, pick it up!' But I just watched this, and it wasn't until the very last girl in line, she picked it up. And I was like, 'Thank you, escalator!'

Vanessa shared that working to instill a growth mindset in the students was what the $1^{\text {st }}$-grade teachers were doing in the second half of the year. She recognized that they were making strides, but this was very different from her norm in Kindergarten.

Vanessa had gotten into a routine of meeting with her district mentor, Becky, and she described how helpful it was to learn what she was doing well from her, stating, "As my mentor pointed out, I think I have some good strategies. Like if I notice all the kids are distracted, I'll 
suggest something we could do, 'Put all your pencils down,' but sometimes just saying it is not enough.” Becky pointed out that Vanessa needed to consistently follow-through with her directions and expect that the students would too. In reflecting upon this, she shared, "If I get serious, they do hold themselves accountable." One way that Vanessa believed she was making her students hold themselves accountable was with another Smith PBIS Cool Tool, based on WBT, called "The Guff Counter." Vanessa excitedly described, "Guff means disrespectful talk." A blue, laminated sheet with this title hung in the place of the "Beat the Teacher" scorecard that I had observed in January (Figure 43). The game worked like this: if Vanessa heard students using disrespectful language, then she put a tally on the scoreboard. The goal was to have fewer than five tallies each day. If her students self-identified disrespectful language amongst their peers, then she would erase a tally. Because her students, in their excitement to self-identify "guff" would often shout out, she taught them to "whisper-shout" their reporting.

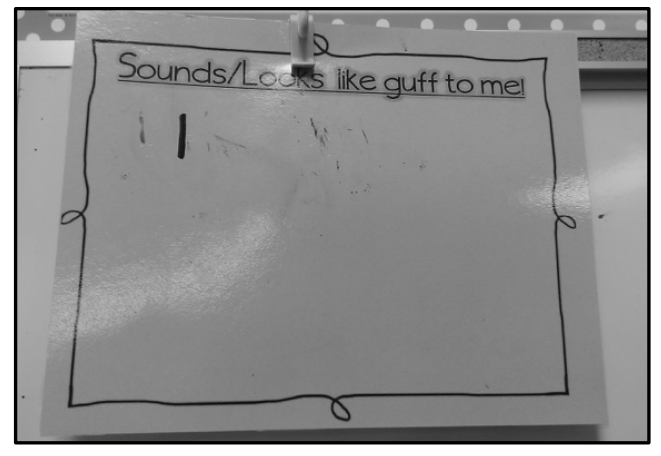

Figure 43. Vanessa: PBIS Cool Tool WBT behavior scorecard (3/15).

I observed this in action when several students shouted over each other in their excitement to report that they had heard "guff" while they were seated on the rug. Although seated near them, I did not hear anything that had seemed disrespectful. One student called out 
over the rest, "Miss Jansen, I heard 'guff,' and I told him, 'please stop!'” Without pausing to find out the content of the "guff" statement, nor the veracity of the report, Vanessa replied, "Wow, nice work, we don't like 'guff."' She demonstratively shook her head and erased a tally. The students looked up and smiled in response. They continued without pause, and I was left puzzled by the strangeness of the tattling, competitive, and disruptive nature of this management strategy. This, like the "Beat the Teacher" game, seemed run counter to Vanessa's daily practices that were more collaborative than competitive, and I wondered if she used them because they were a school-wide tool.

Not all of Smith's Cool Tools focused on competition, as I also noticed colorful heart worksheets hanging on display in her classroom. When I asked Vanessa about these, she exclaimed, "I love those worksheets! They were a part of the school-wide Cool Tool about how to be respectful. We did it a few weeks ago. The kids drew names, and they wrote a heart message for that student" (Figure 44). Unlike at Monroe, where the 'Cool Tool' was addressed only through the morning announcements, at Smith, teachers embedded this character education into their daily practice. Vanessa regularly applied them within her teaching.

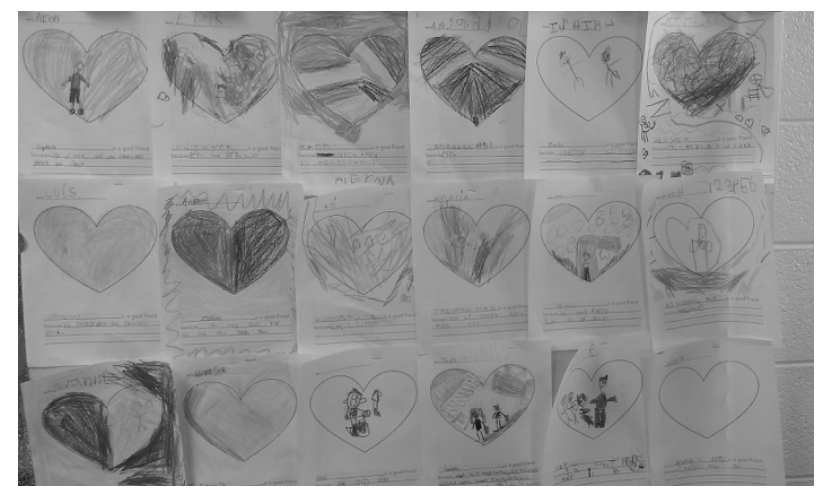

Figure 44. Vanessa: PBIS Cool Tools friends writing activity (3/15). 
Classroom management challenges she felt she faced in the spring were very similar to ones she had shared in the fall, and she realized this. She asked, "Would it be selfish of me to say, 'inconsistency with behavior,' sometimes is still most challenging?" She described seeing "overall chattiness during independent time. Even some of my leaders I'm seeing are getting a little bit sillier. I don't want to get frustrated because I know that that's not going to help." Here, Vanessa inserted something she had learned about neurological responses to behavior from a seminar I had led when she was at MSTC, stating, "It's just like you've said, 'if I flip my lid, they're going to flip their lid right back."' Most of Vanessa's teaching concerns in the spring centered around the topic of, in her words, "how can I make their behavior more consistent?" She explained that she felt that she was addressing this, but in a debriefing session with Becky, this issue resurfaced, indicating that it was still problematic. She explained, "We have conversations about it all the time, so I feel like I can address it, but I just don't know if it's resonating with them, or if they remember that the next time." To address this, Becky recommended that Vanessa re-teach some of her routines and procedures to help the students consistently remember what to do. This is what Vanessa wanted to do, versus, "just a conversation or a lecture because that's boring. It's boring for me to sit there and talk to them about it." Vanessa was also consistently using attention-getters throughout her day, but I observed her quickly jumping ahead, even if she had not fully captured all their attention, which reminded me of Kristin's behavior. However, Vanessa had a mentor who helped her recognize the behavior and change it. I observed Becky raise this issue in their debriefing session. In response, Vanessa shared, "And so, I think that might be one big thing for me. I think that pausing to make my point more clear would be a big goal of mine for behavior management." 
This all came back to her goal of the year of, "If I'm going to manage that behavior, making sure I'm doing it meaningfully."

Even though she did not fully agree with the rewards-punishment systems in place at Smith, by spring's end, Vanessa realized that what she was doing was not contrary to Smith's PBIS goals, stating,

I think at the end of the day, our overall goal as a school is to establish a culture for learning, and for all kids to know why they're here and to be responsible, ready to learn. I really do think that the Titus' Truths kind of fall under that. I think we are pretty on par with the end goal.

Vanessa's kindergarten team members were on board with her views about limited use of the clip charts and rewards, and in the spring months, their first-grade counterparts were also considering limiting their use after seeing the positive outcomes that the kindergarteners displayed as a result of these pedagogical decisions.

In sum, Vanessa's spring. Within her professional roles at the school, in March, Vanessa had already received her annual, summative observation and evaluation from Mrs. Neuberger, her principal. Regarding this, Vanessa shared, "It went very well. I think kindergarten had theirs a little earlier because of all of the shifts in kindergarten for next year. We all got asked to come back based on that!" Over the winter months, Vanessa learned that there was enough funding at the district level, as well as enough interested students and families, to offer full-day kindergarten for the first time at every elementary school within the district the following year. As a testament to their effectiveness, Mrs. Neuberger asked that she, Kate, and Michelle return to be the teachers of these new full-day classrooms. Vanessa was beyond "excited." Through district meetings, she learned more about the change. She explained, "I 
think that it's just gonna be really good. I mean it's a busy day. How can you make a busy day even busier with extra time? They did it." Within the updated daily schedule, she hoped that this move would allow for more time for writing, specials like art and music, social studies, and science. Time would tell if it would and how much this would change her teaching.

\section{The End of the First Year: "It's Been a Good Year."}

At year's end, Vanessa shared, "Friday is our last day! I am so nostalgic because what a journey this year has been. Some of my students have been so sad about it. You know, this is their constant." She continued to see amazing growth in her students. She described this as, “just things that I know you can probably notice," and I did notice her students moving seamlessly through the day's routines. They were all excited to be at school, and they were on task. She shared, "They can do so much. Kids that came in barely speaking English are now reading level G texts!" She so proud of their growth, and at year's end, she continued to see so much potential in them.

While she was seeing similar gains for some of her first graders, they had made little to no growth over the last few months of the year. For her, the "stagnancy" their behavior demonstrated was the most challenging aspect of her work across the year. She explained, "I notice that there is a small pocket of kiddos who have not moved, be it in math, or writing, or reading. I feel like I can try so hard and try to change up things or get other teachers' input, and still..." Vanessa's voice dropped in disappointment as she shared that she was still unsure of how to change this. She shared that she had experienced a "huge a-ha moment" when she realized that all four of her lowest guided-reading groups had over 30 combined absences. Vanessa felt relieved by this realization and repeatedly stated that seeing this highlighted a pattern, but that it was not an excuse for a lack of growth. About this, she explained, 'I don't 
want to make an excuse. You know, I really firmly believe that every student can learn no matter where they're coming from, so I don't want to make it an excuse, but it is a connection." Additionally, she reflected that even though she provided Allie with feedback about students' gains, which would have been cause for a grouping change in kindergarten, in $1^{\text {st }}$ grade, the assignment of students to her small groups changed only slightly in the second semester, and she was often with more students within her groups and in her classroom than Allie had in hers.

At times over the year, I observed Vanessa having up to $161^{\text {st }}$ graders in her classroom for small groups, along with at least one other adult. This was $2 / 3$ of Allie's $1^{\text {st }}$ graders. However, in kindergarten for guided reading, Vanessa, Kate, and Michelle did not group their students so that any one teacher had a majority like this. Also, they rotated equally between each other's rooms, meaning that no one classroom had more than any other during guided reading or math. Vanessa attributed this to differences in classroom furniture. Even though Allie's class room was much larger than Vanessa's, she had only one table fit for leading a guided group, and it was often covered with materials.

About her first graders, she stated, "They have made some growth. Yet seeing some new teachers and being exposed to different styles instead of doing the same thing with me could have helped." Based on my observations of Vanessa's teaching and interactions with them during her time with them, I disagreed with her self-assessment. Possibly, their lack of growth was due to this as Vanessa stated, but it also was possibly because they experienced more deficit mindsets from their primary teacher, Allie. Instead, Vanessa's reflection highlighted her selfdeprecating nature and her true belief in collaboration and shared teaching responsibilities.

Where Vanessa did not see gains in her students' performance, she took ownership and continued to be critical of her own teaching practices. The area she was most reflective about 
was her teaching of guided reading because while it seemed like her kindergarteners had made so many gains in their reading, their test scores did not all correlate. She sounded very disappointed as she shared this news. She explained, "I think I might have had 10 kids below the 40th percentile in fall, and I left the year with eight kids below. So, while all of them were moving up, and I only had a couple of kids that were stuck, I'm thinking, 'man, we could've done better!'” About this, she connected these outcomes with the classroom management she displayed during this time of the day. She continued, "I feel like I just never really found a good groove of what can my kids be doing independently that's going to engage them. I feel a lot of that time was more behavior management, and it was taking away from the instruction." At least on the days that I observed, I did not see what she was describing here. However, because she felt this way about guided reading time, she planned to focus more on it moving forward.

End-of-year classroom management. Specific behavioral concerns persisted into the end of the year for Vanessa. She was still puzzled by some of Akshay's behaviors, as she had noticed regression in his behavior that was reminiscent of the defiance he had displayed in the beginning. She observed him being increasingly off-task and rattled by events in the classroom, and that these behaviors "kind of trickle through the whole day." Academically, she felt that he was very strong, but that there were days in which he needed a lot of positive reinforcement. She and her team members would respond, "almost like petting to keep him going...," which frustrated her. In contrast, by year's end, Vanessa had worked through the steps to get Tyler support with guidance and encouragement from her team. After almost a whole year of identifying his needs, documenting his behaviors, and beginning conversations with his family, by the end of the year, they organized a formal meeting with his parents. Vanessa worked with 
Mrs. Brown to prepare for this meeting, and saw this is as such a good way to end the school year with him.

Several end-of-year rituals illustrated Smith's school-wide focus on establishing a community as well as Vanessa's personal focus on classroom community. Although I observed in each of the participant's classrooms in the last two weeks of school, Vanessa's was the only in which I could see rituals like this, and they were exciting to experience. On my last observation, I overheard her Kindergarteners talking about "what letter of the alphabet?" that day was. Vanessa excitedly shared that Smith was doing an alphabet countdown as a school-wide event that helped the whole school count down to the last day in June. Each letter of the alphabet corresponded with an activity that everyone in the school engaged in, including teachers and staff. Every day, the students' excitement grew exponentially. Some activities were academicbased, and others were what Vanessa described as "fun-based." For some of the activities, teachers had choice, but for most, the Student Leadership Team at Smith prepared school-wide activities. She shared some specifics of the past few days in the countdown, stating, "'N' was awesome! It was 'pick a new name day.' We had everything from George to Scott to Kelly Clarkson to Kim Kardashian! It was hilarious!' 'P' was partner day where the students spent the day with a partner, and Vanessa explained that, “' $z$ ' is the last day — I don't know what zany things we'll do that day!" Vanessa marked these by drawing an arrow next to the letter of that day on the class alphabet. My last classroom observation fell on 'w' day, and the whole school was engaged in writing letters (Figure 45). 


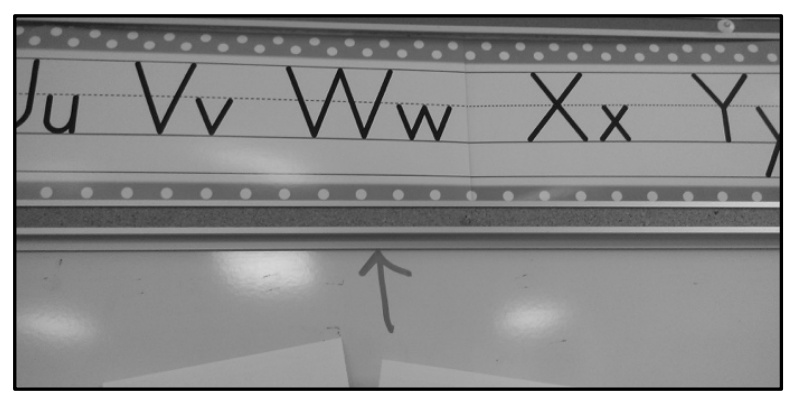

Figure 45. Vanessa: school-wide end-of-year countdown challenge (6/15).

On that morning's announcements, the student announcers explained that that day's whole school task was to write a letter to either the future students of your current classroom or to your teacher for the next year. Vanessa explained this to the students, "Boys and girls, you are really kindergarten experts! So, this could be really easy for you to tell them what it's like in kindergarten at Smith!” The next day would be the ' $X$ ' day where the students exchanged signatures. This made every day feel exciting when typically, students and staff are anxious at the year's end.

With Vanessa's classroom community, she easily wove in these school-wide activities, along with several other rituals that she personally wanted to create for the last few days of school. I noticed the students writing their names on raffle tickets and collecting them in a communal basket on the rug. Throughout the day, Vanessa added to a stack of class-created anchor charts that had been used in their room throughout that year, and I could see the students getting more and more excited with each additional poster she took down from the walls and added to the pile. Then, at the end of the day, Vanessa gathered the students on the rug, explaining, "Boys and girls, it is our last week of school! One way that you can remember kindergarten this year is to take a piece of it home with you!" Each student got to pick one class anchor chart from that year to take home. 
The excitement in the room was palpable. Shouts of "hooray" and "yes!" rung out across the rug. Every time a new poster was passed out, Vanessa reminisced with the students about when they had learned about that concept or used that poster over the course of the year. The students excitedly offered memories of its use, and what it meant to them to see it in the classroom. As each name was drawn, the students clapped and cheered for the lucky child who got to pick their favorite. Most of the time, students were happy with their choices, but a few remarked, "I wanted that one!" It was very sweet to observe them reminiscing about how much they liked these teacher- and class-created posters. Vanessa had modeled to them beforehand how to roll up the poster after they picked it out, but as the activity went on, students became antsy with this. Highlighting her reflective nature in action, Vanessa turned to me, "wow, I needed to think through the logistics of 23 giant posters with their little bodies!” Regardless of whether they loved the poster they received, they were all very excited to now own a piece of the classroom. It was clear that they felt a connection as a community to these materials.

Additionally, Vanessa built in other activities that she felt contributed to her overall classroom community, including literacy lessons that highlighted student learning from across the year. On my last observation, I listened to her read "a great book for the last week of school!" It was a big-book version of, The Important Book, by Margaret Wise Brown, which was published in 1949 (Figure 46). This book, that some might think was outdated, was a vessel in which Vanessa could carry her students back in time to when they had been learning about the central message in stories, and the students participated in this interactive read-aloud in awe. 


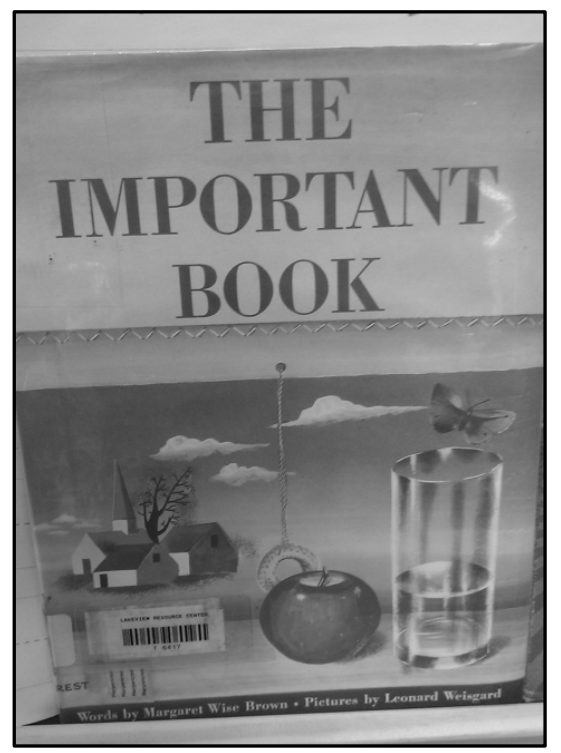

Figure 46. Vanessa: mini-lesson read-aloud-community-builder (6/15).

At the end of the year, I noticed many small rectangular laminated cards of students' writing hung throughout the room. Vanessa shared, "Those are examples of student writing about following Titus' Truths. They are posters to remind students of what to do. We did that for social studies a few weeks ago." She had integrated this school-wide task with her kindergarten writing goals related to using word choice and finding ways to use the right words. She explained, "So we were focusing on how we could use the word 'please' to construct a command. They were all given a card, and they were able to write 'please,' and we wanted them to take ownership of the room." The students wrote a tip for the classroom or a rule to remember, decorated them, and then Vanessa and Mrs. Bowman hung them around the space (Figure 47). Additionally, her students continued to earn golden paw print tickets from various teachers and staff members in the school. The class was on its last class-wide sheet of the year. 


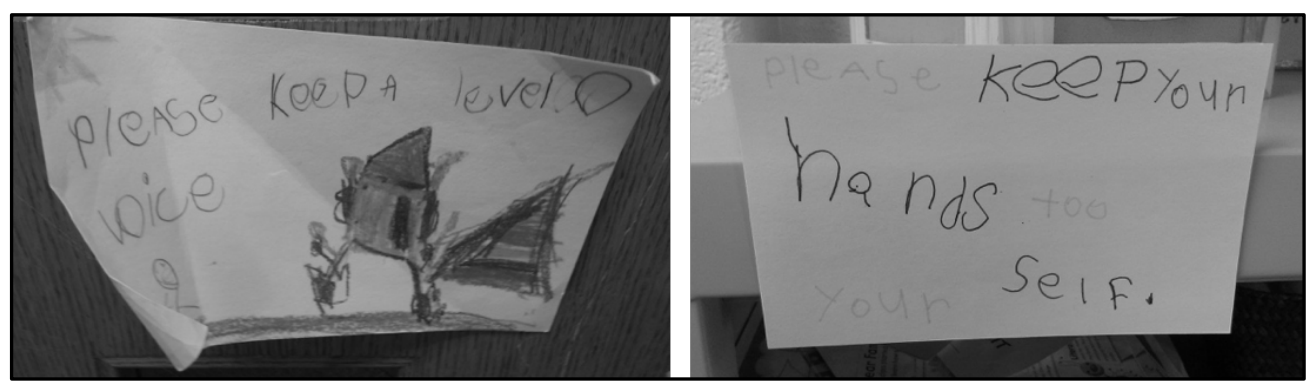

Figure 47. Vanessa: PBIS Cool Tools student drawings (6/15).

At the end of the year, Vanessa's views about how her management and community fit within Smith's PBIS framework were much more concrete than earlier in the year. She explained, "I have stopped relying on so many concrete rewards and incentives and things that I see a lot of other teachers using more often." Understanding what she meant, I reflected on how I had observed several paraprofessionals passing out the blue paw pride rewards tickets. About this, Vanessa reflected, "I think that that might just be a way that they follow the school, not being the classroom teacher." Yet, as a lead teacher, she saw her role differently. She elaborated,

I think I've learned a lot about the way I want to manage behavior in my classroom, and I'm still working on it, because I still feel like there are days I'm like, 'my class is the craziest class in the whole school!' But then I look at them, and they are rocking and rolling.

She admitted that she still had questions. Although this was not the researcher role that I had intended for myself, she stated, “....and I think that I can owe a lot of that to having you here and kind of playing devil's advocate." While I never intended to be contrary with her, she clarified that my questions had made her think deeply about her practice over the year. 
When at the end, I reminded her of her intention to take down the clip chart after my last observation, she laughed and replied, “I know. I know! It's still up! I didn't take it down, but we haven't touched it." She explained that she had been planning to take it down two weeks before my visit, but then on the end-of-the-year teacher's bulletin, Mrs. Neuberger had instructed the teachers to not take down classroom materials until the last two days of school. She laughed and said, "I was like, 'I don't want that to be seen as I'm wrapping up the year!"” So, she left it in place. She explained that she would have loved to tell her students that these charts were not used when they would be in first grade, but, "ultimately, they are in the first-grade classrooms."

Instead, she discussed with them how they no longer needed the chart. She believed that conversations like this were "really empowering." She shared how much she wrestled with what to do with her chart in advance of my visit, stating,

Then I just struggled with that for a few days, and I came up to this week. I was like, 'Kira is coming next week, and now I don't want to take it down just because Kira is going to be here.' So, I decided to just leave it there. We ignore it. We haven't really touched it.

Upon hearing this, I felt terrible, like I had unduly influenced her to reconsider the chart. However, she took ownership of this decision, explaining that she did not mean that she would just take the chart down so that I would not see it. She described this in more detail, stating, "I feel like the chart is something that if I hadn't been having these conversations, I probably would have just been continuing to just do it because that's the way it goes." At the time, this comment pacified my concerns, yet, it highlighted how as a qualitative researcher doing field work, it is truly impossible to be the "fly on the wall" (Emerson et al., 2011, p. 4). It also illustrated the critical need for conversations like ours to happen for all new teachers. 
In sum, Vanessa's end of the year. Like Kristin, Vanessa asked me for overall feedback after each of my observations throughout the year. At our last interview, Vanessa once again asked for this, stating, "I think I've asked this each time that you've been here, just if there was anything, any feedback, anything you've noticed that stood out to you." As I had every other time, I deflected this question back to her, and this allowed her to jump into successes she felt about her practice. Vanessa's attributed much of her first-year success to her kindergarten grade-level team. Overall, these three women presented themselves as a force with which to be reckoned. She shared that as a team they had noted when there were support staff not following through on team plans, and she recognized that they each had different classroom management styles, but that they worked to find consistency, expressing, "That's a constant working piece to try and find a way to be constant for our kids," and communication is what facilitated this. She explained that, "without it [email for communication], it would be impossible." She summed it up her feelings, stating, "Coming into a brand-new school with three brand-new teachers on one team, brand-new to the grade and really building up that team...that relationship is a big success.” She believed that this was a hallmark of her first year, and I would not disagree.

Vanessa was not as upbeat in reflecting on her roles in $1^{\text {st }}$ grade from across the year. At the end of the year, she divulged more than she had any point in the year about her relationship with Allie and the whole experience of being a para-professional. I am not sure if this was because she felt more comfortable with me at that point, or if it was because the year was coming to an end. She reflected on this relationship that had consumed her year, stating,

We [she and Allie] were never fully in tune, so I could walk into that class and know exactly what was going on without asking. It did get a lot better, and I have to give them a lot of credit because they worked hard for that... 
However, in the last week of school, the first-grade classrooms were packed up early despite the school bulletin's message regarding this, and Allie and the other first grade teachers provided no guidance or collaboration for planning the instruction for the afternoons, which created undue stress for the three kindergarten teachers.

To work through these challenges, Vanessa recognized that, "I always had someone that I could go to talk to, even if it was something that I could just handle in the building really quickly." She realized that the benefits of having this many mentors within her school, as well as a district-level mentor to provide an outside perspective, were endless, and she knew that this kind of support was atypical. She explained, "So that's something that I know I'm very fortunate to have, because I haven't seen that everywhere." Ultimately, she captured her feelings in a oneline sentiment, "It's been very uplifting having someone there." This was such a telling statement for her first-year experience as compared to Molly's, especially.

Vanessa described the impact that her teaching preparatory program had on her first-year experience globally, stating, "One thing that MSTC definitely instilled in me in almost every single class, every single course I took, was just that constant reflection piece. I think that that played a huge factor in any success that I found this year." I would agree with this sentiment, as Vanessa had demonstrated a responsive, reflective nature at every turn. She continued,

I was always thinking about, "is this the teacher I want to be? Is this the type of class I want to have? Is this the type of behavior management I want to be using? Is this the guided reading structure that's going to work for these kids?'

She felt that everything she was questioning in her practice connected back to learning she experienced in a course at the university. 
Ultimately, using the clip chart was consistently the aspect of her practice with which she grappled most. About this, she stated, “I know that that's been one of my battles. I don't look at it in the way that I have to change. I look at it just as a constant conversation and just a reflection." She reflected on what she had learned from this "battle" with herself about using the clip chart, stating,

I think one thing that has stuck with me, and that totally—not scared me away from it, but just made me almost mad at myself was I don't ever want a student to leave my classroom feeling bad because they're on red. I don't ever want to put someone down. How eye-opening is that to realize you're telling a child to go move their clip down on a chart! Like when you think about it that way—it might be easy for me in a moment—in a tizzy, just being like, 'You know, you're being disruptive. Go move your clip down!' That's easy for me to move past, but that might ruin their day.

Ultimately, this is sentiment is what drove almost all of Vanessa's management decisions of her first year. She explained that she never wanted a child to feel badly because of the chart or her reaction to the behavior, and she knew that there were other ways to address the behavior. Her top substitution was to "have a conversation," and if need to be, to do this every day.

She attributed much of her knowledge and skills in the first year back to her teacher preparation. She described feeling appreciative for the well-rounded background she thought that her preparatory program had provided her. She explained, "I will toot MSTC's horn. I feel like I got a really good preparation for what I got into." Vanessa realized that she was positioned in a strong district with tremendous support, yet, she acknowledged, "but I just really feel like I had good stuff coming in." She summed up what she had been told prior to starting her first year, stating, "I'll say again that I was warned so many times in college, 'your first year is gonna 
suck.' Flat out. 'It's going to suck, and you just drink a lot of wine, and you'll get through it.' These are literal things that I was told." She admitted that there had been times when she had cried on her way home, but she felt grateful for never becoming too overwhelmed. She explained, "There were definitely times where I was frustrated, or I was questioning like, 'holy cow, am I failing these kids?' or little crisis moments, but I just don't feel like I was surviving." Ultimately, she shared, "It's been a good year." For this new teacher's shooting star, I agreed.

\section{Beyond the First Year: "I'm So Excited!"}

At year's end, the kindergarten grade-level team was fast at work preparing for the following year. Smith's administrative team did much to include them in the process of planning for this transition. Earlier in the spring, Mrs. Neuberger asked Kate, Michelle, and Vanessa to create a staffing plan for the upcoming year by selecting, "who we think we work well with and who will support the kindergarteners best." Vanessa saw the benefit in this, stating,

That's very helpful for us. It's not that one or two mistakes is gonna make us never want to work with a teacher again, but we put a lot of time into making sure that we do try to communicate with everyone because we want to make sure that working with the kids is working.

By year's end, they had completed lists of students for each room. At one of the last planning sessions I observed with the three of them, Vanessa's teammate, Kate, remarked, 'It's going to be so great having them the whole day!" Vanessa and Michelle nodded their heads in agreement. Vanessa was giddy with excitement about the changes for the upcoming school year. She exclaimed, 'I'm so excited! I cannot wait for whole-day kinder. I really can't. I can't wait to have just the same kids all day long." She explained that she loved being a support staff 
member that year, and she knew that it made her a stronger teacher, but planning for one group, versus many, sounded wonderful.

Vanessa, Kate, and Michelle were asked to participate in a planning meeting to set up the new $1^{\text {st }}$-grade schedule that would address the choppiness in the $1^{\text {st }}$-grade day, since they would no longer be supporting the $1^{\text {st }}$-grade teachers. The administrative team was concerned about this as Vanessa relayed, "our principal is still kind of puzzled." Not only would the $1^{\text {st }}$-grade teachers not have the three kindergarten teachers as support staff, but they also would not have use of their classrooms for small group instruction. Additionally, the support staff would be stretched across both grade levels for the full day. Vanessa projected that there would be staff reductions for the entire early childhood team in the following year, but with the longer day, she felt confident in teaching alone.

Vanessa's reflective nature meant that throughout my interactions with her, she was always talking about ways to improve her practice. In her second year, she planned to improve some of her basic procedures within the day, such as rethinking the arrival activities so that all students could start the day together. Also, her grade-level team planned to incorporate calendar time into the morning routines, despite knowing that Sarah, her literacy coach-internal mentor, still had strong negative feelings about calendar time. Vanessa explained, "That's been a conversation now that we've [she and her team members] found our voice, and now that we have a year under our belts. And I think the three of us have a lot more freedom in our rooms next year." She felt that a daily calendar activity would contribute to the building of their classroom community, which was something she had learned in my social studies methods course at the university, explaining that the full day would, “...be a great time to incorporate calendar and the community piece. I want my students to know what a month is. How cool would that be if in 
the calendar time, we could do something like your timelines!" Here she was referring to another idea that she had learned in my course about creating birthday timelines, as well as creating a timeline of the class' collective learning across the whole year.

In thinking about other plans for establishing a sense of community in her space, she had lots of ideas. Regarding the Smith PBIS tools, she planned to be consistent with the rest of the school and continue to pass out the golden and blue paw pride tickets, albeit sparingly. She explained, "I don't feel totally comfortable nixing them, just because that is what the school uses. Plus, even if we don't do it, they're gonna see it in first grade, and I don't want to use that as an excuse, but..." Yet, she was still not wholly confident about what to do with her clip chart. She explained, "I probably...I definitely will not put up the chart just because that just made me think so much this year. They don't need it!" She recounted a day from a few weeks earlier where her students had been having a "tougher" day, and she realized that she should have taken down the chart. Instead of what she had planned to cover for social studies at that time, she called the students over to the rug for an impromptu meeting. She continued,

We reiterated why we're at school, why it's so important to be focused... I had the kids come up with three rules. Not rules, three promises. That's how we word them, promises, to make the rest of the year go really smooth, kind of like a classroom constitution that we sort of did in the beginning of the year. I wrote it in their kid language, like 'listen so good...'

She had the students line up, and one by one, they signed their names. The promise hung in the classroom for a while after this, which she thought was "awesome" because it was a silent guideline to which she could refer the children. In thinking about the next year, she stated, "I think I would much rather make a really fancy-pants awesome classroom constitution, where 
they all signed it and put that up in place of the clip chart. That's more like a little reminder than a slap on the wrist." The idea was a big part of her future classroom management plans, and, "next year, it's giving me a chance to do that!"

Despite her continued wavering at the end of the year, others in her school community had noticed her expertise in building classroom communities across her first year. At year's end, Vanessa was asked to join the PBIS Tier 2 team the following year. She explained, "I was actually kind of excited. That's pretty neat!" She admitted that she would probably join, but "I just want to make sure that I'm not biting off more than I can chew." Additionally, she had been asked to sponsor one of Smith's tutoring clubs, but she felt that joining the PBIS team could be a smart move professionally. She continued, "I think that will be just really neat to get my foot in the door, especially since that's got teachers from every grade level, and to just be able to build more relationships." Her questioning of the PBIS practices at Smith did not stop her from seeing an opportunity to learn more and forge additional friendships.

Because she would be in the same classroom, she was additionally thinking about how to maximize the space. Although she had complained about the classroom's size throughout the year, by year's end, she shared, 'It's my home now. I think I've kind of settled with the fact that I had the most students in kindergarten this year, and I had the tiniest room, but that's okay. We made it work." An idea for improvement that she shared was related to replacing the content in the students' math bins under their table spots, based on realizing what she had learned about their needs. She felt this would better help her students be organized.

Always focused on her own professional growth, Vanessa had numerous plans for summer professional development workshops she would be attending, along with "I'm already looking at what I want to read, read, read this summer!" With her district mentor's support, she 
had already reached out to the district's literacy director to learn how she could observe guided reading instruction from other strong teachers in the fall. At the beginning of the following year, she had plans in place for her district mentor to cover her class, so she could do this. She looked forward to working again with Becky, as they would again be partnered for two scheduled observation-debriefings over the course of her second year. This was significantly less contact than she had experienced with Becky this year, “...but anything I need, I can still reach out to her." By year's end, Vanessa reflected that she could now see herself becoming a mentor to a new teacher the following year. She explained, "I really hope that someone would be comfortable enough to come to me, because being a second-year teacher and having had that first-year experience, but still being new, maybe it wouldn't so intimidating for them." I could easily see her taking on this role within her practice the following year.

\section{Vanessa's Year, a Metaphor}

Vanessa was one of the most reflective first-year teachers with whom I have ever worked. Throughout the year, I observed her in the act of reflecting upon her practice, describing revelations and reflections and wrestling with her own beliefs and practices. Ranging from her struggle with balancing her own classroom management beliefs and the PBIS practices at Smith, her literacy instruction, her work within the $1^{\text {st }}$-grade classrooms, her supervision and co-teaching with paraprofessionals at Smith, her empowerment of her students, her strategies for best supporting students with challenging behavior, her future professional plans, and questions about her daily schedule, almost everything we discussed, she connected back to her teacher preparation. Upon every aspect of her teaching, Vanessa employed a critical eye.

For Vanessa, more than any of the other participants, the supports she received within her school were utopic. Her descriptions of connecting with others, seeking and finding help, 
contributing ideas, and collaborating and brainstorming, bled through every aspect of her practice. Many of these supports served to empower Vanessa to take initiative, try new ideas, and wrestle with the status quo. For example, did she need the behavioristic rewards and punishment of the PBIS rewards system used at Smith or her clip chart? From an outside perspective, no. From Vanessa's perspective, she struggled all year with this answer, and I believe that deep down, she also knew that she did not need them. Despite this, she was adept at managing the politics of education, and going along with school-wide practices was easier in the long run for her.

Throughout the year, Vanessa showed extreme agency and ownership of her practice, her roles, and her responsibilities; a locus of control was firmly planted inside of her. From the beginning of the year, I noted that she displayed a strong sense of self-efficacy and agency, that was consistently made stronger by the social supports she felt. She focused on classroom management and community foundations, making her proud of her practice, based the guidance and support of Mrs. Neuberger, Smith's principal. She felt more certain about her implementation of a specific type of clip chart after deep conversations and reflection with her grade-level team. She also felt good about the decision to not use the green referral sheets with the support of her grade-level team. Overtime, Vanessa displayed more initiative in her practices, including the decision to use the "quiet pompom jar," the ideas for helping the $1^{\text {st }}$ grader with challenging behavior, and her confidence in moving away from passing out a lot of rewards tickets connected to PBIS. At the end of the year, I reflected that Vanessa's agency was enhanced through being a team member, but also that she had developed a strong sense of her own efficacy. This sense of teacher self-efficacy seemed to drive every decision she made. 
Although she was a novice teacher and not perfect in her practice, she exhibited more teaching strategies that truly demonstrated consistent learning from her university preparation than either of the other participants. This could be attributed to the multiple levels of support she received at Smith, or it could be attributed to Vanessa's drive and determination alone. Vanessa's first year was an over-arching success. At every level of her practice, and within her teams and individually, I observed and she described aspects that were successful. Vanessa, as a new graduate, shimmered with the possibilities of things to come, as many teacher graduates do. Then, within the contexts of her first year, her star-like qualities continued to be fueled. Her future was limitless. Vanessa's story reveals what a very determined and passionate teacher can accomplish when the stars align by way of administrative, collaborative, and contextual support. From her story, an understanding of a what a utopic first-year experience has emerged offering hope and context for preparing and supporting new teachers of the future. 


\section{CHAPTER VIII: SUMMARY, REFLECTIONS, AND NEXT STEPS}

Ideas are judged by their explanatory power or their capacity to inspire the work of others.

Wolcott, 1994, p. 38

It is with Wolcott's words that I attempt to synthesize the magnitude of what was uncovered by engaging in this research study and fashion it into a lasting message for the readers of this work. A review of the relevant literature on the topics of classroom management, teacher preparation for management, the PBIS framework, and how the two intersect in building classroom communities within early childhood classrooms revealed a gap in the literature related to the perspectives of teacher candidates and new teachers. Thus, the purpose of this study was to explore early childhood teacher candidates' perceptions and actions in working within PBIS frameworks and university messages of building classroom communities, and how these changed or remained the same into their first year of teaching.

\section{Summary}

To achieve this goal, and using an interpretivist paradigm, I conducted a collective case study using ethnomethodological techniques. First exploring the perceptions of early childhood teacher candidates immediately upon their graduation about their related student teaching experiences, and then staying close with three graduates as they became first-year teachers, I documented and investigated their classroom practices as they related to classroom management, PBIS, and classroom community. Each case within the study presented a similar, yet different perspective on the reality of being a new teacher, working within a dominant classroom management framework of PBIS. In this last chapter, I return to the questions that guided the study to synthesize and summarize these new teachers' perceptions, practices, and beliefs: How 
do teacher candidates, through their last year of coursework and first year as teachers, experience, understand, and explain their beliefs and practices regarding classroom management? How do the contexts of PBIS and participants' teacher preparation shape and influence the teacher candidates' beliefs and practices about classroom management? Based upon the first two research questions, what are the implications for policy and practice both in PreK-12 settings and teacher preparation programs? I offer reflection upon my role within the study as it relates to these first two questions. Finally, I offer implications that this study has on further research.

\section{In Sum, the First Research Question}

How do teacher candidates, through their last year of coursework and first year as teachers, experience, understand, and explain their beliefs and practices regarding classroom management?

This research question was answered in different ways across both phases of the study. The specific perspectives of this study's teacher candidate participants were explored in the study's first phase through the focus group interviews. Big findings from these interviews were revealed in Chapter IV of the dissertation and included that through their last year of coursework, these participants had experienced little to no preparation for classroom management, PBIS, or community-building. Then in student teaching, they were hit full force with all three of these components. One of the most predominant ways that teacher candidates explained their classroom management beliefs were through the lens of PBIS. However, because of their lack of preparation and the differences in PBIS implementation within their schools revealed by their descriptions, their understandings of the framework were limited. Within their schools, participants experienced a myriad of strategies and approaches being used to manage behavior. 
As the work of others has revealed with the components of PBIS (Adams, 2011; Chitiyo et al., 2012; Critchfield, 2015; Johnston et al., 2006), those classroom management practices that these participants described observing and using during student teaching tended to fit under the larger umbrella of behaviorism. With very little training for classroom management or PBIS, they revealed a limited understanding of the PBIS framework, as well as alternatives for it. Their conversations within the focus groups hinted at knowing that curriculum and lesson planning related to classroom management, but they saw aspects of practice related to building classroom communities as distinct. Overall, similar to teacher candidate and new teacher perspectives that other studies have revealed (Cakmak, 2008; Clement, 2010 Fall; Hoy \& Woolfolk, 1990; Kaufman \& Moss, 2010), the recent graduates of this study displayed feelings of being overwhelmed and underprepared when it came to their own classroom management, and very few had comprehensive or concrete plans for their future teaching. This relates to findings by O’Neill and Stephenson (2012) who found that with less training and support in classroom management, new teacher graduates felt less prepared for their future classrooms.

As some of these participants transitioned into first-year teachers, the opportunity presented itself to see how their beliefs and practices changed with the passage of time. As such, this study does much to reveal the first-year experiences of early childhood educators, each in a distinct role. Findings from the yearlong phase of the study shed light on every aspect of a firstyear experience, and specifically the successes and failures of first-year classroom management.

First-year experiences with classroom management. This study's participants described their first year of teaching in highs and lows, frustrations and successes, feelings of anger and love. They experienced classroom management "in the trenches" every day with their students. The anecdotes they revealed across the study's two phases highlighted intimacies of 
classroom practice that are rarely shared with outsiders, such as parents, past teacher educators, administrators, or even colleagues. From describing interactions of cooperating teachers shaming students to the point of tears, to sharing a sweet hug with a child, to hilarious anecdotes of student behavior, to Vanessa hearing her words of "we are problem-solvers" amongst her students, to Kristin observing her students intentionally misbehave to only mimic her in disciplining each other, or to Molly crying as she described watching her old videos, discussing classroom management in this study brought out raw emotion. Classroom management, as the fabric of classroom practice, was a very personal and emotional aspect of these participants' lives as graduates and new teachers.

First-year understandings of classroom management. As first-year teachers, each of the case study participants, Molly, Kristin, and Vanessa, grew in their understanding of classroom management. In descriptions and explanations of their beliefs and practices, their classroom management development was revealed. For all three, over time, I observed, and they described moving away from only thinking about classroom management as the PBIS-specific strategies, programs, or approaches of their schools and classrooms, to understanding that classroom management was a comprehensive aspect of their practice. Revealing the multiple definitions of classroom management (Evertson et al., 1996; Kaufman \& Moss, 2010; Martin et al., 1998; Martin et al., $2006 \&$ 2007-2008; Marzano et al., 2003; Tal, 2010), over time, each of the participants, displayed an increasingly deep understanding of how various aspects of their daily practice, such as their schedule, classroom environments, curricular decisions, and instructional delivery choices, had just as much of an impact on their classroom management as specific management strategies, including the clip chart behavior monitoring system, stickers, and school-wide rewards. Kristin, realizing by year's end that her daily schedule forced the 
students to be seated for too long, Vanessa, identifying that she first needed to review and display guidelines in order to conduct partner work in her classroom, and Molly, describing how her students were more engaged when she taught meaningful lessons-each revealed that these first-year teachers recognized the all-encompassing nature of a teacher's classroom management. Specifically, by year's end, all had noticed the impact that the daily schedule played on students' behavior within their settings.

With time, all three new teachers revealed that their teaching practices were expressly connected to their classroom management decisions. Vanessa consistently, Kristin occasionally, and Molly when she had the freedom to, demonstrated teaching practices that encouraged positive student behavior and highlighted the documented teacher preparation mindset that stronger teaching practices result in fewer behavioral issues (Farkas \& Duffett, 2010). At various points in the year, all three seemed to see the connection that good teaching was a part of their classroom management (Martin et al., 1998; Martin et al., 2006 \& 2007-2008.), and with it the need to layer in other tools, such as the clip chart, were negated. The stronger their overall teaching was, including their lesson planning and delivery, the more they observed positive outcomes for behavior and cognitive learning with their students, and the less they seemed dependent on the behavior monitoring systems in place. Vanessa was the only participant whose teaching was consistently tied to her classroom management decisions. Because her teaching was engaging and creative, her students tended to be more on-task, and thus, she found that she had little need for her clip chart, behavior monitoring system. Related to this, I posit that if Molly had been able to implement more of her ideas related to content and community, she may have felt more ownership and have been less dependent on the existing management strategies, such as the frog and lily pad behavior monitoring system. Out of the three case study 
participants, Kristin's teaching practices seemed to work against her ability to guide and manage students' behavior, yet, by year's end, even she was seeing that the more variety she built into her planning and delivery instead of worksheet-based, direct instruction, the more engaged her students were.

A big component that linked together teaching and classroom management was how much these new teachers empowered their young students to be independent learners. With the help of her school's social worker, Molly used visual reminders for how to behave on the rug, and Kristin created step-by-step guidelines for specific students who needed them. However, Vanessa was the only participant who consistently taught problem-solving and conflict resolution skills, highlighting her understanding that the more students felt efficacious, the better her overall management and teaching would be become (Alderman \& MacDonald, 2015). While the other two participants described issues of conflict between students, and I observed these issues in action, only Vanessa consistently addressed them with supportive teaching tools. Through mini-lessons, anchor charts, mantras, and repetition, she consistently encouraged her students to be "problem-solvers," displaying that she fully realized the role of prosocial teaching as an aspect of classroom management (Alderman \& MacDonald, 2015).

First-year explanations of classroom management. For each participant in the study, their descriptions of classroom management practices were explained through specific tools and practices with their students and other adults. The tools that facilitated their classroom management strategies and skills, and their interactions with others across the year revealed meaningful insights related to their classroom management.

Tools of classroom management. Across the yearlong phase of the study, I curated a collection of images revealing how each of the case study participants understood and practiced 
classroom management in her first year. These artifacts helped to uncover aspects of their teaching that descriptions and observations failed to capture (Glesne, 2011; Miles et al., 2014). What each of the participants chose to share as an artifact highlighted a nuance that she felt connected to the study, and what I chose to select provided a different perspective. Examples of this included Molly's word wall of names (Figure 4), which I would not have originally selected, but that she felt helped contribute to her students' sense of community, and Vanessa's sight-word ladder (Figure 24), which I similarly dismissed, and she added in. Another example of this was Kristin's guidelines for problem-solving (Figure 21), which she sent to me, and I would have collected on my own, but that she seldom used. Each of our decisions in the curation of these artifacts helped to reveal their first-year experiences and tell their stories.

Their tools explain the role that behaviorism had in each of their settings through their behavior monitoring systems and multiple tools related to rewards. They also highlight forms of parent communication, school-wide initiatives, and individual tools that these new teachers used. Additionally, seeing the collection of their artifacts altogether helps to feature the role or presence that classroom management had in each of their classrooms, with Molly having very few tools, and none changing across the year (Figure 48), to Kristin having more, especially related to individualized supports for students (Figure 49), to Vanessa having the most artifacts that grew as months passed (Figure 50), especially related to prosocial teaching strategies such as her guidelines and anchor charts. Their artifacts revealed pressure from administration, gradelevel teams, or teachers not present in the case of Molly, but they also displayed initiative related to classroom management ideas in the cases of Kristin and Vanessa. 


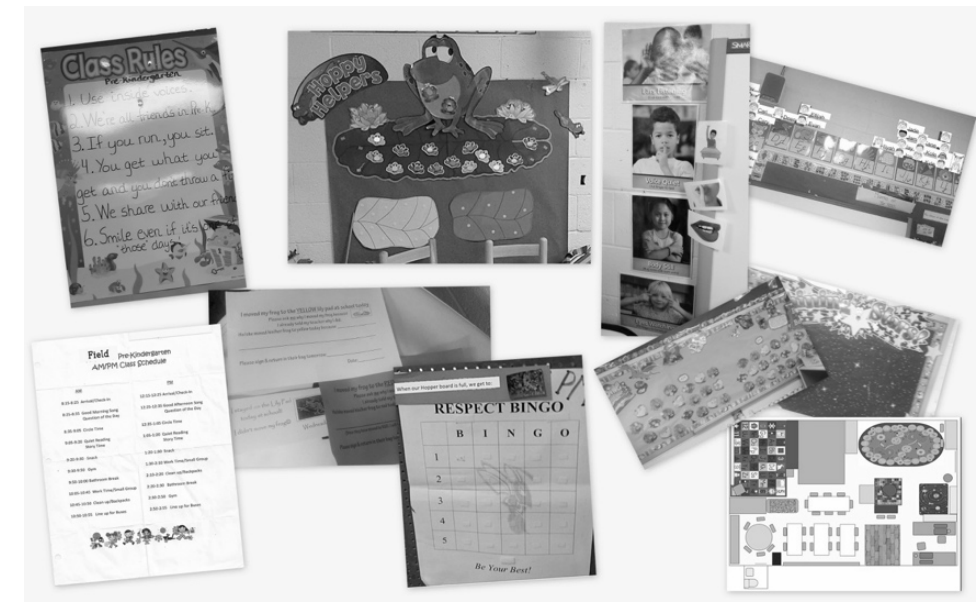

Figure 48. Molly: collection of classroom management artifacts.

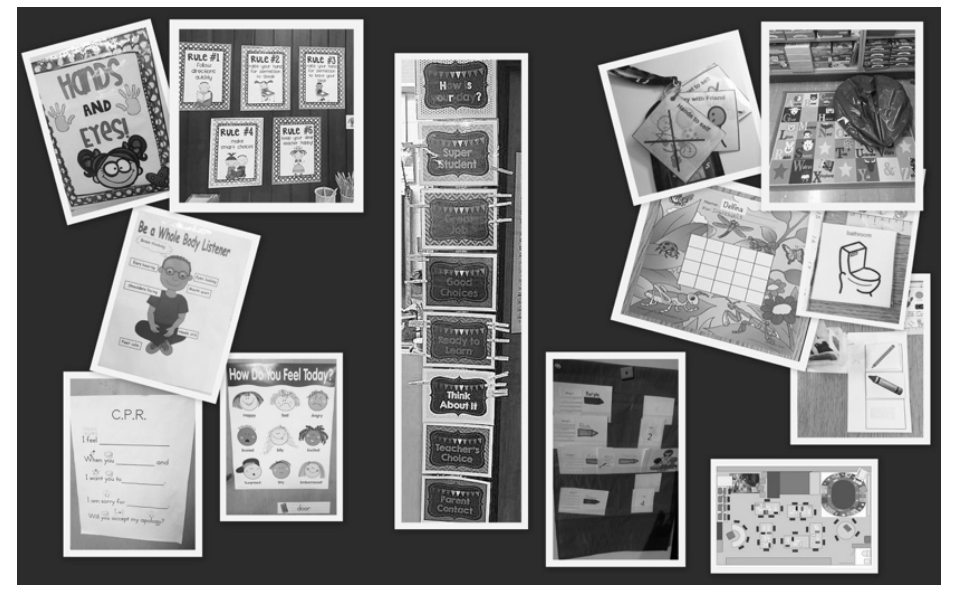

Figure 49. Kristin: collection of classroom management artifacts. 


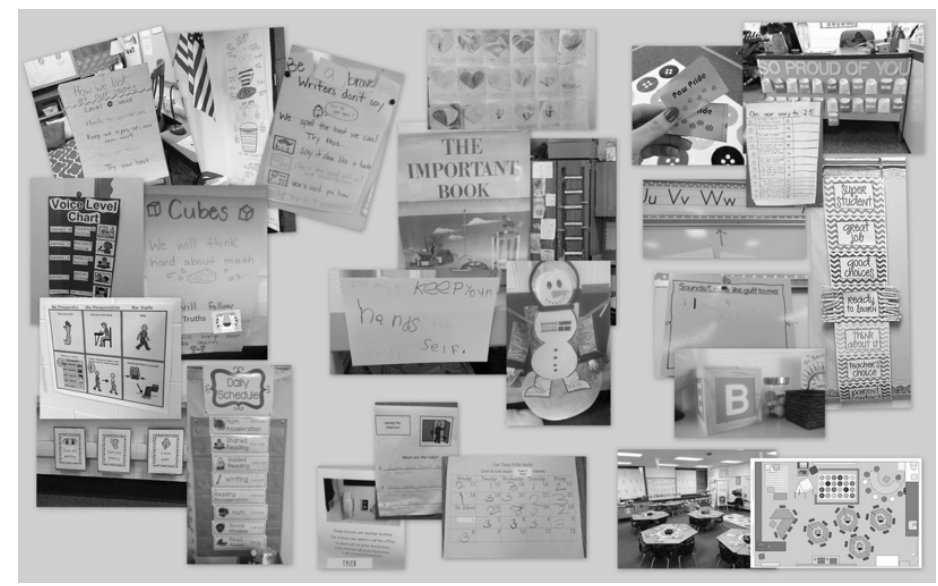

Figure 50. Vanessa: collection of classroom management artifacts.

Interactions with students. In addition to the tools of their practice, these participants explained their classroom management beliefs and practices through interactions with students. While they displayed happiness and pride when discussing the many successes of their students throughout the year, no emotions were as intense as the frustrations participants felt when encountering a student that they could not seem to reach. Each of the case study participants described intense frustration and disappointment when students were not showing growth or when a student's behavior seemed challenging. Most of the focus group participants, and each of the case study participants described their classroom management practices through identifying the students for whom the management decisions of their cooperating teacher during student teaching, or their own management decisions of the first year, did not seem to be working. As, the early years tend to be where challenging behaviors are first identified in students (Powell et. al, 2007) and preparation for working with challenging behaviors is consistently lacking in teacher education (Hemmeter, Santos, \& Ostrosky, 2006; Tillery et. al, 2010), it was not surprising that so many of them were faced with student behavior that they identified as challenging. 
Across the focus group participants, most worked with at least one student whom they identified as having challenging behavior, and within the case studies, this was no different. On and off all year, Vanessa identified three students, Kristin identified six students, and Molly identified four, about whom they felt confused, challenged, and overwhelmed. Of these students, very few had IEPs in place. Experiencing more minor behaviors such as talking out of turn and being distracted, to more major behaviors of students crying, being defiant and aggressive, wetting or hurting themselves, and throwing furniture were emotionally and at times, physically draining for them, as others have found for early childhood educators confronted with these types of behavior (Gebbie, Ceglowski, Taylor, \& Miels, 2010). Even though Vanessa was the only one who described feeling prepared to work with these students based on her coursework and field experiences, all of the case study participants independently tried solutions to address their students' challenging behaviors, and thus individualized their classroom management. Interestingly, having presented information on the assessment of behavior in their undergraduate assessment course, outside of Vanessa, I did not observe Kristin nor Molly drawing on the tools presented in this workshop. Each of the first-year teachers had varying success with receiving support for these students, from Molly who received very little support, to Kristin who received more, to Vanessa who had a tremendous amount. With less support, participants continued to feel challenged by these students, and similar to other early childhood educators when confronted with challenging behavior (Gebbie et. al, 2010), their overall teacher self-efficacy was negatively impacted.

Interactions with adults. In descriptions and explanations of their management across the year, the adults in their professional lives inevitably surfaced. For the teacher candidates, this was with their cooperating teacher. For the case study participants, this was with co-teachers, 
colleagues, parents, and administrators. Whether it was Susan for Molly, Maria and Danielle for Kristin, or Mrs. Bowman, Allie, or any one of the eight other team members for Vanessa, each of the case study participants worked in a co-teaching setting. In early childhood classrooms, working with another adult in some capacity is a reality of the field (Whitebook, 2014), and with this comes reward and challenge (Cook \& Friend, 1995; Sileo, 2011). Each of these adult relationships brought sources of success for the participants, but were also fraught with issues that impacted their overall teaching and classroom management. Concerns of instructional beliefs, parity signals, noise, and pet peeves, amongst others impacted the classroom management decisions of Molly, Kristin, and Vanessa, and thus in discussing their management, the topic of these adults often arose.

First-year changes and stagnancy over time. As time passed from student teaching across the months of their first year, I observed, and they described changes in their classroom management beliefs and practices. Throughout the year, each varied in how behavioristic or humanistic her practice was. In reflecting on the types of management practices they described and I observed them using, Molly demonstrated humanistic tendencies, such as redirecting and problem-solving with students in the beginning of the year, despite living within the confine of the behavior monitoring system of the prior teacher. However, as her year passed, she moved to more behavioristic classroom management strategies including sticker-rewards, and an increased use of the monitoring system and related consequences/ punishments of the note system. Kristin displayed strong behavioristic approaches to classroom management from the start with her clip chart and school-wide rewards and consequence/ punishments, and yet, at various points in the year, she displayed humanistic strategies including the cool-off space, always searching for deeper meaning in behaviors, and by the end of the year, much more empowerment of her 
students. Vanessa balanced behavioristic and humanistic practices all year, but swung more in the direction of person-centered classroom management. As the year went on, she dropped her use of various competitive and rewards-based strategies, including the use of the clip chart behavior monitoring system altogether.

One of the salient pieces that showed little change across the year, and that seemed to be disconnected, if not missing, in these participants' explanations of their classroom management, was a consistent connection between their classroom management practices, whether PBIS or not, and practices that contributed to building a classroom community. Within the focus groups, most participants described their classroom management practices as distinct from communitybuilding practices, and regardless of very negative and exclusionary practices with children, insisted that "there's a really good feeling of community." For the most part, how many of the teacher candidates from their student teaching experiences, and then Molly and Kristin within their first years, described classroom communities revealed what Wisneski (2005, p. 229) describes as the "ideal community," that is, that classrooms will only feel a sense of community if everyone is being nice and everyone is getting along. Students who were different, or displayed challenging behaviors, or did not fit the norms of the classroom, negatively impacted what many of the participants described as the feeling of community within their space. Participants, including Molly, felt badly about this. Yet, few described changing their classroom management to address this.

Kristin presented an interesting case, as for most of the year, she described her classroom management decisions as a separate dimension of her teaching than community-building, even as some of her teaching and management practices worked against a feeling of togetherness all year. Vanessa's description of classroom management provided still another perspective, more 
in the line with researchers who support conflict resolution as a strong classroom community practice (Blank \& Schneider, 2011; Oakes et al., 2013; Souto-Manning, 2014; Wisneski, 2005). She regularly described how her classroom management practices impacted her classroom community by building a "culture of learning." Instead of removing the possibility of conflict, this culture of togetherness and problem-solving supported her students in their problem-solving and conflict resolution. Consistently, her descriptions of classroom management practices related to fostering a sense of community in her space, including friendship drawings, reading of specific texts, the use of catchphrases and mantras, and specific conversations she and her students had, amongst others.

The participants' attitudes towards the connection between the sense of community in their space and their classroom management decisions, whether PBIS-driven or their own, remained consistent throughout the year, hinting that bigger contexts were impacting these perceptions. This was because ultimately, each of the participants understood and explained their classroom management within context, as the contexts of their backgrounds, preparation, and current setting, amongst others, impacted their beliefs and practices. Other researchers have revealed that the influence of context on classroom management is paramount (Emmer \& Stough, 2001). As such, the findings of the second research question illustrate this influence.

\section{In Sum, the Second Research Question}

How do the contexts of PBIS and participants' teacher preparation shape and influence the teacher candidates' beliefs and practices about classroom management?

The initial contexts I set out to investigate included the contexts of teacher preparation and PBIS settings, in which they were all situated. As the study progressed, additional contexts seemed to have more of an impact on the participants' classroom management beliefs and 
practices. Related to their teacher preparation, several findings emerged, relating to positive and negative influences on these participants' classroom management beliefs and practices. What I discovered is that each layer built on the last in the impact it had on the teacher candidates' and new teachers' overall experience, as well as their classroom management beliefs and practices. Figure 48 outlines these concentric influences, centering around the teacher candidate- new teacher, including the impact of teacher preparation, PBIS, the interplay between these two domains, and outside contexts.

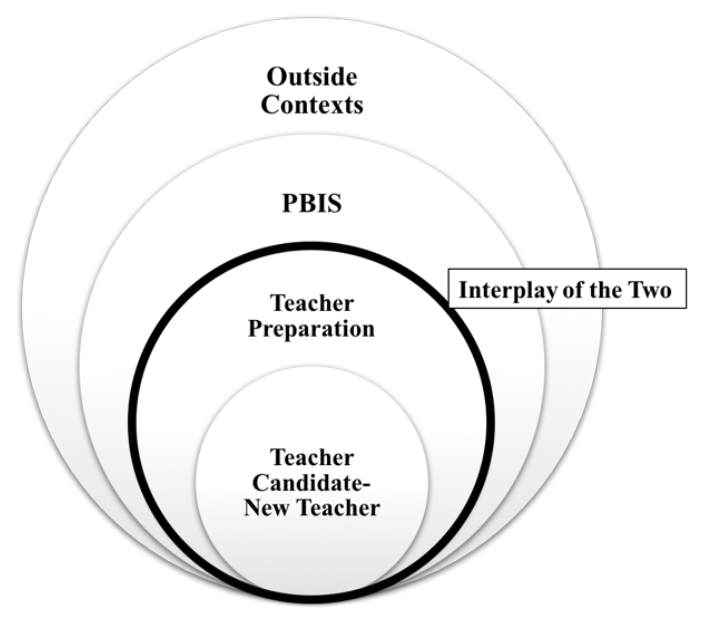

Figure 51. Contextual influences on classroom management of teacher candidates \& new teachers.

Teacher preparation. All participants had gone through the same teacher preparation program. In the focus groups, several participants repeated what some researchers explain as the hallmark of university perspectives about teaching classroom management, that is, that fewer discipline issues result from stronger teaching (Farkas \& Duffett, 2010), which it seemed they had heard before. They all talked extensively about using standards, especially the CCSS, to 
drive their instruction, and felt confident in teaching with rigor and meaning. This was one area of their preparation in which they felt solidly prepared. Each case study participant highlighted how the focus on quality planning and instruction in her teacher preparation had impacted her classroom management within her first year of teaching.

Molly felt that her classroom management suffered because she was unable to teach with the CCSS, or at least teach in a more meaningful, rigorous way. When she finally went a bit rogue in her teaching in the spring and taught with ideas from the CCSS, her students were much more engaged, and she felt her classroom management was stronger. In small ways for her, even earlier than this, her dynamic teaching skills were evident when she led small groups. Kristin felt that her classroom management and community would be stronger the following year because she would be able to better supplement her math curriculum with the CCSS and bolster her other curricula, and from what I observed, the more she worked to differentiate her instruction, focus on small groups, and plan more engaging lessons, the more on-task and involved her students would be, aiding her classroom management. Vanessa's knowledge of CCSS helped her have one less first-year worry with the newly aligned district curriculum. This freed her up to focus more on her classroom management and overall sense of community. Her teaching strategies, which were meaningful and rigorous, led to fewer behavior issues and better overall management. All three of the case study participants described feeling more proud of their practice when using the CCSS and teaching methods that connected with what they had learned at the university. They felt advantaged by knowing these standards, when each of their districts across the state of Illinois were just beginning to enforce the implementation of these standards sets. This finding indicated that for these participants, the university was at the forefront in preparing them for this curricular change and for related meaningful instruction. 
For each participant in the study, her teaching was enhanced when she felt that her teaching methods were working and students were learning, in line with other research studies that have found positive correlations between these components (Knoblauch \& Hoy, 2008; Hoy \& Woolfolk, 1990; Tschannen-Moran et. al, 1998). All participants remarked about student growth over time, and not only did they find happiness in seeing how their teaching led to this growth, they derived a sense of success and confidence from this, which strengthened their teacher self-efficacy. From their descriptions and my observations, there was a direct correlation between the use of more dynamic teaching practices and stronger teacher self-efficacy, in which these teachers tended to show stronger classroom management and achieve more positive outcomes with their students. A positive cycle ensued, as each would then describe next steps that were more in line with strong classroom management, thus fueling stronger teaching practices and outcomes with students. These findings mirror those of other researchers exploring the concept of teaching self-efficacy (Bandura, 1997; Knoblauch \& Hoy, 2008; TschannenMoran et. al, 1998). Where their classroom management and sense of teaching self-efficacy were most negatively affected was with students who did not demonstrate growth despite what each was doing to support this child or who displayed challenging behavior despite their efforts (Gebbie et. al, 2010).

Despite feeling confident about using standards to drive meaningful instruction, across both phases of the study, participants reflected on their lack of preparation from the university for classroom management, in general, and about the PBIS framework, specifically. Like many teacher candidates across the country, these participants had no classroom management-specific course in their preparatory sequence (Blum, 1994; Christofferson \& Sullivan, 2015; Hammerness, 2011). A few remembered classroom management pieces layered into their 
courses, as is common with classroom management preparation (Brophy, 2006; Hammerness, 2011; Landau, 2001; Oliver \& Reschly, 2010; Stough, 2006), but the most they remembered were a few specifics from the one or two workshops I had presented in their other courses, or that they had learned from me in a few seminars of the clinical course I supervised. All three of the case study participants remembered learning about the use of attention-getters to grab students' attention before teaching, and used these to different outcomes, and I observed Vanessa and Molly using celebratory claps that they acknowledged learning from my course. In addition, throughout the year, Vanessa revealed small connections she was making back to the classroom management content she had learned with me such as "flipped lids" when talking about mirror neurons and mimicking behavior, or the reference to learning about assessing behavior.

However, these references were minimal, because their learning about classroom management had been sporadic and surface-level. I remembered teaching all of the participants much more specific classroom management content both in my social studies methods course and in the guest presentations I led, including the basics of classroom management style, the connection between classroom management style and theory, the power of a posted daily schedule, multiple strategies for teaching self-regulation, behavioristic and humanistic strategies for assessing behavior, amongst other specific ideas. However, these ideas, learned sporadically within the preparation sequence, did not seem to resurface in their first years of teaching, either in what I observed or what they described. Interestingly, when describing their plans for their second year, both Vanessa and Molly highlighted ideas that revealed memories of this learning at the university, but within the context of their first-year, they had not remembered or used. These findings speak to the work of others who have revealed the deleterious effects of sporadic classroom management learning on future teaching, and the need for a more comprehensive 
preparation (Christofferson \& Sullivan, 2015; Clement, 2002; Landau, 2001; Putman, 2009; Stoughton, 2007).

What these new teachers did remember from their teacher preparation that related to their classroom management was foundational. Each participant described and demonstrated love and commitment for learning about, caring for, and being with their students. Although no one identified one single course where they had learned about this, it seemed that each had taken away from the fullness of their teacher preparation that relationships with students were at the heart of all classroom communities and all classroom management decisions (Kirylo, 2012; NAEYC, 2009; Stone, 2001). For all three of the case study participants, I observed a wonderful rapport with students, and I saw evidence of genuine care and love for their young learners. From hugs, to "I love you, Miss__," to pictures they had drawn, to excitement to show her their work, it was clear that these students also cared for each of my participants. Molly's love for her students is what seemed to pull her through her toughest times in her first year; Kristin's love led her to become an advocate for her students; and Vanessa's love empowered her students to be some of the most independent and happy kindergarteners I have ever observed. Learning that relationships are at the heart of an early childhood classroom was in line with messages from their teacher preparation and helped each participant have better classroom management overall (Croake, 2011; Kirylo, 2012; Marzano et al., 2003; NAEYC, 2009; Stone, 2001).

While forming strong relationships with students and teaching dynamic lessons can help, as other researchers have found (Emmer \& Stough, 2001; Farkas \& Duffett, 2010), for these participants, many issues arose within each of their classrooms due to a lack of more formal classroom management preparation. From feelings of confusion about classroom management and PBIS within their student teaching semester, which carried over into their first-year 
experience in varying degrees, not having a solid understanding of classroom management made it difficult for each of the participants to make sense of her own management decisions within the other stresses of the first year. This also meant that more of what they remembered and then drew from came from what they had learned about classroom management in field placements, including student teaching, which is consistent with where teacher candidates nationwide feel they learn the most about classroom management (Clement, 2002; Christofferson \& Sullivan, 2015; Putman, 2009; Stough, et. al, 2015). In the focus groups, the teacher candidates consistently cited classroom management learning from their student teaching experience that they would most likely use, and often, these were very behavioristic practices, and every time I asked her for connections between her practice and her preparation, Kristin reminded me that she had learned about the up-and-down clip chart from her student teaching cooperating teacher. Like the student teachers in Hoy and Woolfolk's seminal study of student teachers in 1990, several participants mentioned being uncomfortable with their cooperating teachers' practices, but by the end of the semester, with no better options, many planned to use these same practices in the future; Molly and Vanessa exemplified this in their first years with the use of their behavior monitoring systems that they had both complained about in the focus groups.

At the same time, these two participants also described observing different forms of character education at their student teaching sites that they liked and had seen students succeed in using, and this learning from the field carried over into their first years. While Molly was frustrated that she did not feel able to layer in this kind of teaching, Vanessa was able to, and she regularly addressed character education within her teaching that was similar to what she had experienced during student teaching. Vanessa described how her cooperating teacher's model of balancing the use of PBIS with her own classroom management style helped her feel confident 
that she could behave similarly. These examples illustrate the "much-needed foundation" for classroom management that Clement (2002, p. 59) discusses; yet, that so few teacher candidates, including most participants in this study, received. Kristin also described her cooperating teachers as providing strong models, but theirs was a model of behavioristic, top-down management, that as Kristin used in her first year, ultimately challenged her classroom community. Regardless of whether their classroom management models of the field resonated with the messages of building classroom communities from their coursework, these field experience models truly did have a very strong impact on the successes of each of the participants' first-year experience.

Related to their teacher preparation, overall, all three case study participants described areas where they had wished for stronger preparation. In addition to more training for classroom management, Vanessa felt frustrated by a lack of writing methods, Kristin felt discouraged by a lack of practical learning in her ESL courses from the English department, and Molly felt wholly let down by her preparation, especially at the darkest parts of her first year. Although each felt frustrated with some parts of their teacher preparation, their preparatory program was not wholly responsible for the aspects of these new teachers' first years that created the most strife for them, as the university had no control of the settings in which Molly, Kristin, and Vanessa were hired. However, one would hope that their teacher preparation had set up a sequence of events that would prepare each for the same chance of success regardless of job conditions they would encounter in their first year. While each of the case study participants was a strong graduate at the end of their program, each of their student teaching experiences would have a lasting impact on their first-year experience, both positive and negative, and still, other contexts would have even more of an influence. 
PBIS. In many ways, the context of PBIS within these teachers' field experiences and first year of teaching had a stronger impact on their classroom management decisions, because working within this framework was the setting of the impactful field experience of teacher preparation, as well as the setting of their first years in the field. Each of the case studies presented variations for how closely their classroom management practices were connected to the various components of PBIS at their sites. This ranged from little to no connection at all for Molly, to Kristin whose practices were an exact match to the school-wide aspects of PBIS at Monroe. Vanessa's practice was somewhere between these two. Although, she used the PBIS components that she felt benefitted her classroom community, she often adapted pieces that she did not find as helpful or appropriate. However, because of the impact of the framework at her school, she also used behavioristic practices, such as the Whole Brain Teaching scoreboard and "guff" game, which worked oppositely from so many of her other teaching practices. Without the presence of these components within the framework, she may not have used them.

The behavioristic influence of rewards-punishments and behavior monitoring seemed to be present for all of the participants with or without the presence of the PBIS framework, and this could be attributed to the long-standing role of behaviorism in schools (Bruning et al., 2011; Freiberg, 1999). Kristin was the only participant mandated to use a clip chart behavior monitoring system, as a part of the PBIS framework at her school, yet both Molly and Vanessa had similar systems that they used varyingly, even though they both expressed discomfort with using them. While none of the participants cited learning about a behavior monitoring system during their preparatory coursework, each had seen and used one during her field experiences within PBIS settings, highlighting the impact that this experience had on them. Other 
behavioristic components of PBIS at each school showed up in numerous ways in their classrooms.

The influence of this PBIS context on each of these teachers' classroom management beliefs and practices was very dependent on the fidelity with which PBIS was implemented at their schools. Again, while the purpose of this study was not to investigate the fidelity of PBIS implementation, related to how the teacher candidates and new teachers made sense of the framework, findings indicated inconsistencies with PBIS implementation. Participants' lack of formal preparation or training for the framework, with the exception of Vanessa, may have impacted their interpretations, but spending times in the classrooms and schools provided another layer of understanding to the study. From Molly's perspective and my observations, Field was not a strong PBIS school, as several critical components as laid out in the PBIS-SET tool (Sugai et al., 2001) seemed to be missing, including school-wide implementation. Her preschool classroom was allowed to be exempt from following the majority of PBIS components at Field, amongst other missing pieces. For Kristin, on the surface, Monroe presented as a very strong PBIS school having won various state-level PBIS designations. However, mandates to use a behavior monitoring system with little connection to actual data collection, a lack of formal training or support for new teachers, and a lack of focus on teaching prosocial skills, meant it was not truly faithful to the framework either. In contrast, of the three sites, Smith Elementary seemed to be the most faithful to the components of the PBIS framework as laid out in the SET (Sugai et. al, 2001). Vanessa was the only participant who received formal training about how to use the framework, which may have helped to explain why she felt so much more connected to the school-wide aspects of PBIS than Molly or Kristin. Additionally, this was the only site where I consistently observed the teaching of school-wide pro-social skills and the use of data to 
consistently and comprehensively inform classroom management and other teaching decisions. From the lens of teacher candidates and new teachers, the positive outcomes associated with use of the framework, such as the unification of academic and behavioral approaches for students (Coffey \& Sugai 2012) and improving school climate (Sugai \& Simonsen, 2012), seemed to be directly correlated with greater fidelity of implementation. This finding is consistent with other studies focused on PBIS implementation (Molloy et al., 2013), but highlights an important lens, as it comes from the perspective of teacher candidates and new teachers, which have before not been considered.

How strong a presence PBIS was at their school seemed profoundly related to the participants' feelings of teacher self-efficacy and their own personal sense of community. While school climate and teacher burnout were not original foci of the study, another important study finding connected the fidelity of PBIS implementation with the participants' overall first-year experience. At Field, where a school-wide effort was lacking, Molly felt disconnected and disengaged, and she questioned staying in the field. At both Monroe and Smith, where there were more faithful implementations of the framework, both Kristin and Vanessa seemed to be more invested in their school communities, as well as more committed to using PBIS components. For Kristin and Vanessa, their descriptions and my observations revealed a more positive school climate in their settings that fostered collaboration, care, and support of all people within the building, including the adults. This finding relates to the work of others, who have found that with stronger use of the PBIS framework, outcomes include more positive school climates (Wasilewski, Gifford, and Bonneau, 2008) and decreased levels of teacher burnout (Ross, Romer, \& Horner, 2012). These feelings of a positive school climate and less teacher 
burnout directly impacted every aspect of these participants' classroom management of their first year.

However, findings from this study did not indicate that correlation between the presence of the framework and these positive outcomes was solely attributable to the PBIS framework, or instead due to other possibilities. For these three participants, that which was impactful for their first-year experience was whether classroom management and teaching norms were provided and then supported at a school-wide level. These findings point to the impact of the school-wide presence of an approach, as this is what seemed to bind together Kristin and Vanessa's classroom management experiences in their first year, in a way that was very different than Molly's. Because Kristin was mandated by her administration, and then strongly supported by her gradelevel team, to use many of her classroom management strategies, she used them and felt confident in doing so. Because of administrative oversight and school-wide support of her classroom management practices, Vanessa used her management strategies and felt similarly. However, without any administrative presence or consistent grade-level support, Molly felt less than confident in using her classroom management strategies.

As such, although the addition of the PBIS framework may have changed the status quo related to classroom management in American schools because it promoted a school-wide approach to addressing classroom management (Sugai \& Horner, 2002), it did little within the classrooms of this study to change the status quo of traditional behavioristic classroom management practices, to which the work of Johnston et al. (2006) alludes. Instead, behavioristic practices were just subsumed within the framework's components. What seemed to be the most powerful aspect of PBIS for these three new teachers was the school-wide effort, 
as the context of school-wide norms seemed to be a stronger influence on these new teachers' classroom management beliefs and practices than any one aspect of PBIS.

The interplay of these two contexts. Where the two investigated contexts of teacher preparation and PBIS interacted became a context in and of itself, and had a stronger impact on the participants' experiences than either context alone. In many ways, the interplay of these two contexts led to the predictable "two-worlds pitfall" once again, as messages from teacher preparation about classroom management for these participants seemed to sharply contrast with messages of the field (Anagnostopolous, Smith, \& Basmidjan, 2007; Feiman-Nemser \& Buchmann, 1983; Smith, 2007; Smith \& Avetisian, 2011; Zeichner, 2010). Adding to the literature, in this study, this pitfall related to PBIS settings, and it was not just present for the student teaching semester, but also within the first-year experience. For the focus group participants, being firmly rooted in the "two-worlds pitfall" was a strong finding from their experiences, and having lived within this pitfall with little support to analyze and confront their discomforts, many of the participants displayed uncertainty with their future plans.

Within the yearlong phase of the study, Molly and Vanessa continued to feel the pitfall's, as anxieties and pressure resulting from conflicting messages persisted. For Molly, living within the pitfall brought tremendous stress, leading her to question her decision to become a teacher. In contrast, Vanessa's experience in the pitfall was what Feiman-Nemser and Buchmann (1983/ 1985) would have hoped for, as she had layers of support to help her analyze and confront her discomfort. Alternatively, Kristin was the only participant who seemed unaffected by the conflict of competing messages about classroom management, even though she was also firmly positioned within this "two-worlds pitfall." I knew that she had heard contrary messages in her teacher preparation to the purely behavioristic messages of her field experiences, similar to 
Molly and Vanessa, because I had been a faculty member presenting these ideas to her. Yet, the impact of her field experiences seemed to have a much stronger influence on her first year of teaching. However, the label of having "premature closure" applied to Kristin because the novice judgments and understandings she developed about classroom management during student teaching, that were purely top-down behavioristic models, were consistently reinforced by rewarding messages from those in the field, leading her to accept these as normal (FeimanNemser \& Buchmann, 1985, p. 63). Without any challenge to reconsider these practices, Kristin continued to hear rewarding messages from her colleagues and administrators when messages at Monroe mirrored those from her student teaching experiences. For Kristin, her field experiences were her university experience, and because the norms of Monroe were so similar, to her, they mirrored her university experience. Living in the "two-worlds pitfall" brought her little stress and seemed like a normal place to be, which Feiman-Nemser and Buchmann (1983) caution as one of the main problem of pitfalls in teacher preparation because it perpetuates the status quo without critical reflection. Without a strong background in classroom management or a consistent focus on questioning classroom management practices during student teaching, she simply accepted the messages of the field as her norm, and this carried over into her first year.

The impact of outside contexts. The reason for the big variation in outcomes for each participant was because, more than the impact of their teacher preparation or the nuances of the PBIS framework within their schools, or even the interplay of these two, in their first-year experience, other contexts seemed to have a much stronger effect on their classroom management practices and their abilities to establish a sense of community with their classrooms. Similar to the narrow-focus that most teacher candidates have on classroom management (Kaufman \& Moss, 2010), I naively entered these classrooms believing that I could isolate 
discoveries related to specific classroom management practices, and the impact PBIS had on these. However, I quickly realized that a multitude of other contexts were having just as strong of an impact, if not stronger, on the classroom management beliefs and practices of these new teachers, including their personalities and personal backgrounds, their roles as early childhood educators, their roles as new teachers within their buildings, the contexts of their larger school communities, and the confluence of all of these, amongst others.

The contexts of their personalities and personal backgrounds played a big part in affecting whether their classroom management beliefs and practices aligned with PBIS and whether they felt the push and pull of being in the "two-worlds pitfall." Although all three case study participants had graduated from the same program that placed a heavy emphasis on reflection and introspection, so much that Molly complained that it had been too much of a focus at the university, they varied in how reflective their daily practice was. The context of reflection greatly impacted their classroom management decisions and their overall feelings of teacher selfefficacy. Consistently, Molly and Vanessa displayed behaviors in action, or in later discussion, that demonstrated that they were thinking critically about their practice as new teachers. Throughout the year, they mentioned connections between their classroom management and other teaching practices and their teacher preparation, and this made them pause. Although Molly failed to put consistently these reflections into action, Vanessa did. In contrast, especially in the beginning of the year, Kristin displayed a level of confidence that seemed to stop her from thinking more critically about her practice, and with no mentor or coach to guide her, this selfassurance contributed to her quick acceptance of classroom management practices that may not have been her own (Feiman-Nemser \& Buchmann, 1985). 
In addition, each participant operated within the world of early childhood education, which in many ways influenced their classroom management and overall experiences within their schools. Each of the participants felt that teaching at the youngest grades impacted what they could do in their classrooms because it allowed them freedoms that other grade levels did not receive, but at times this also made them feel isolated. With classroom management, Vanessa explained that, "kindergarten does its own thing," and each participant cited similar reasons for teaching in ways that were dissimilar from the rest of the school. Molly, whose preschool practices were very different from those used at other grade levels, often felt isolated because she and her class were often not included in the functioning of the rest of the school. An example of this was Molly's experience with securing services for her preschool students with challenging behavior.

Other contexts related to the adult facets of the school community. This included the context of their positions. Molly as the "sub," Kristin as the "newbie," and Vanessa, both as a lead and assistant teacher, each of these roles impacted their classroom management beliefs and practices. For Kristin, being the newest member of the team meant she coalesced with team decisions even when she did not want to, such as with her classroom rules or the structure of indoor recess. For Vanessa, her dual roles highlighted ways that she had to both establish her own classroom management decisions and negotiate following along with someone else's. For Molly, the label of the "substitute" dramatically impacted her feelings of teacher self-efficacy and self-worth, because within this role, she felt wholly incapable of changing classroom management practices with which she disagreed.

The additional outside contexts of administrative, collegial, and mentorship support, and their roles as co-teachers, also played dramatic roles in impacting these three participants' first- 
year experience, as well as their classroom management beliefs and practices. Amazingly, within these contexts, each case contrasted with the next, highlighting how one aspect of a new teachers' experience dramatically impacts every aspect of their practice, including their classroom management (Emmer \& Stough, 2001). Whether these participants were able to build their classroom communities was not as much dependent on the specific classroom management approaches or components of PBIS in their settings, but more on the confluence of these contextual aspects. Isolating the impact of any one context without consideration of the others was difficult; these participants' classroom management beliefs and practices existed within these larger contexts encircling them. Realizing this is what led me to use metaphors (Miles et al., 2014) to capture the essence of their practices, and the chapter titles and subheadings within the year-in-life sections of their chapters highlighted the phrases that best illustrated these shifting perceptions of self and practice throughout the year.

In establishing the norms of a school, the role of administrators at their schools dramatically influenced each of the participant's first-year experience. The contexts of Kristin's background experiences with the clip chart and the pressure of school-wide norms, regardless of PBIS, seemed to have a stronger impact on her classroom management decisions than anything else. Her practices were bolstered by Monroe's school-wide norms established by the administration and her colleagues, and her personality conveyed surprising self-assurance and less reflective properties than the other two participants. Kristin used the behavioristic classroom management practices that closely aligned with the PBIS framework at Monroe, but these practices did not always lead to positive outcomes for her students, and because of this, her ability to establish a sense of community was compromised. However, her commitment to her 
students as individuals seemed to alternatively contribute to a sense of togetherness and acceptance.

In sharp contrast, Molly described varying perspectives about her classroom community throughout the year, from feeling like her community was less-than because of "high-fliers," referring to her students with challenging behaviors, to an end-of-year reflection that there had not been a sense of community within her classroom because she had not had a hand in creating it. For Molly, part of the reasons her classroom management practice did not line up with PBIS at Field was due to the seemingly spotty implementation of the framework there. With this low level of implementation, a total lack of administrative or collegial support, and figuratively and literally, "no drawer in the teacher desk" for Molly by mid-year, it seemed that there was no clear space for her to create a new teacher identity. Overall, it seemed she relied on behavioristic practices because she did not feel efficacious in her teaching. Like Kristin, she had little to no support either to analyze her experiences or give her the boost of confidence she needed to push back. Additionally, her sad acceptance of her role as a substitute seemed to aid in making it easy to accept the status quo, even if it was not appropriate for children, and she disliked it. Despite her firecracker personality seen in teacher preparation, and despite any PBIS pieces at Field, the biggest challenge of Molly's first-year experience related to the contexts of the larger adult community. The many stressors she experienced in her first year prevented her from attending to her classroom management and community-building.

The third perspective from this study revealed another new-teacher reality. The schoolwide norms at Smith established by administration and faculty, as well as the tremendous collaborative support Vanessa received in reflecting upon and analyzing her practice, seemed to have more influence on her practice than anything else. Influenced by the PBIS- and non-PBIS 
related school-wide norms and her own personality traits, Vanessa was the only participant who received constant feedback about her practice. With this, her teaching identity and sense of teacher self-efficacy grew, and her classroom management practices seemed to support this. For Vanessa, her team was one of the most important aspects of her first year. Throughout my interactions with her, she consistently described herself in a "we" mentality. Unlike Molly, who felt so alone, and whose language was often "I" and "them," and Kristin who described practices that she did to and for the students, Vanessa consistently used the terms, "we" and "us" when talking about both her students and her team members. Although it appeared at times that she used her Kindergarten team as her voice, I observed the individuality they each brought to the team, and the consensus-driven ways in which they interacted. I posit that her use of "we" versus "I" was because she saw herself as a part of the many layers of community at Smith, including within her classroom, her grade level, and within the larger school. Additionally, the "culture of learning" mindset at Smith, supported by the Smith administration, seemed to have been strongly instilled in her and contributed to her feeling a sense of community at the school.

Considering these additional contexts for these first-year teachers, big questions have surfaced. How can teacher educators and administrators expect new teachers to focus on classroom management if other contextual influences overwhelm them, such as a lack of administrative support, a lack of mentorship, or a lack of a supportive teaching team? From these bigger themes of administrative support and mentorship, amongst others, how can teacher educators and administrators expect new teachers to navigate and bridge the "two-worlds pitfall" in relation to classroom management? How can teacher educators and administrators expect first-year teachers to build democratic classroom communities, if they do not feel a part of a 
community themselves? These questions drive how I reflect on the work of this study and my next steps.

\section{Reflection: My Dissertation Within the "Two-Worlds Pitfall"}

I conducted this study within these varied contexts and amid these rising questions. The role that my background played presented moments of happiness and pride, and tensions and disappointments. To me, classroom management is an integral part of every teacher's practice, and it felt rewarding to see the impact that these participants' management decisions had on so many aspects of their practice. I naively entered this research singularly focused on classroom management, PBIS, and feelings of community. However, through the prolonged engagement, my prior relationships with the participants, and my analyses and interpretations of what I was learning across this yearlong study, I walked away feeling overwhelmed and challenged by the magnitude of what I had experienced as a researcher. Because of my all-encompassing view of classroom management, as well as the countless other side stories that were revealed, it has been very challenging to narrow my focus in order to write up these findings, and I know that there have been stories and angles left untouched. Through working with each participant, my understandings of classroom management, PBIS, and school-wide functioning were tremendously enhanced, and this is what I have attempted to portray in this dissertation. Yet, these side stories, especially related to the various adult contexts impacting these participants' first-year experiences, have not been forgotten. They help to inform my next steps.

The previous relationships which I had with each participant played critical roles in the study. As I wrote in Chapter III, the relationships I had with all of the participants and specifically Molly, Kristin, and Vanessa, fostered entrée into classroom worlds and information about first-year experiences in ways that an outsider could not have accessed, but this also 
created tensions. Having known me as their professor and known that my classroom management beliefs tended to be more humanistic, Vanessa and Molly both displayed discomfort, especially in the beginning of the year, with sharing some of their behavioristic practices with me. Even when I worked to be expressionless and put my beliefs to the side, I sensed that they believed that I disapproved of their behavioristic practices, especially their behavior monitoring systems. Kristin, whom I had not taught in a course nor supervised in the field, seemed less inhibited by these feelings. Additionally, all three seemed to defer to me as their professor or consider me as a coach when I came to observe, as they regularly asked for my feedback and analysis after observations, which I had predicted would be the case.

Although many of the teaching practices I observed in their classrooms made my teacher heart happy from both a teacher educator and an ECE teacher perspective, there were just as many that made me uncomfortable. Sitting next to Molly as she sat crying in my office, observing Kristin publicly shaming students by announcing their clips' placement on the chart, and feeling attacked by Vanessa's co-teacher, Allie, when she wanted my input on a student's cheating behavior, these were all experiences that made me uncomfortable in the moment, and even after, in writing about them. However, in the moment, it was not appropriate for me to share this feedback with my participants, even when they asked for it, because I was hesitant to influence the results of the study. I was very cautious because I felt passionately about telling their stories as they were seeing it (Stake, 1995), and yet I recognize that with each decision I made in telling their stories, I revealed a bit about them and a bit about me as the ethnographer (Wolcott, 1994). As a qualitative researcher, I cannot separate myself from the interpretations I share (Glesne, 2011). 
I struggled with my researcher role throughout the study because more than anything, and especially in the moments of success and discomfort, I wanted to jump into the classroom happenings, yet, I sat on the sidelines with my researcher notebook. Because of my worry about role, I carry a tremendous guilt that throughout the year of the study, I left Molly, Kristin, and Vanessa without the guidance they were seeking. I carry with me that I played a hand in Molly securing her first-year teaching position that turned out to be less than ideal, that I left Vanessa's pleas for how to remove her clip chart hanging in the air, and that I never revealed true and honest responses to Kristin's questions for analysis of her classroom practices, especially related to her reliance on worksheets, whole group instruction, and her clip chart.

Through my discomfort, along with the length of time that I have worked on this manuscript, new learning about classroom management, PBIS, classroom communities and myself have emerged. I entered the study with a very singular focus, with an outlook that was influenced by my past, and through watching each of these participants' triumphs and struggles and negotiating my own reactions to them in telling their stories, I have left the work a different person. To quote Ruth Behar, I have become a researcher, "who has come to know others by knowing herself and who has come to know herself by knowing others" (1996, p. 33). In the beginning, with the simmer of a slow-burning fire underneath, I intended to take the role of an advocate (Stake, 1995) in order to reveal issues and problems with the PBIS framework and classroom communities. Yet, I have left this work with less intensity to do this. I have come to a place of understanding and acceptance that realities of early childhood classrooms and classroom communities can include more of a balance between humanistic and behavioristic classroom management approaches, including PBIS. Growing with my participants helped this to happen. 
Regardless of the discomfort or remorse I felt at times during this study, a hope from the start has been that through participating, each participant would feel a sense of support and mentorship that could have lasting impacts on their senses of teaching self-efficacy and create positive student outcomes. Ultimately, across the year, I believe that this was achieved. I formed a stronger relationship with all three of these new teachers that persists today (Emerson et al., 2011; Glesne, 2011), and each demonstrated in the year of the study that our conversations were helpful in some way. From being a sounding board for Molly's first-year struggles, to providing a counter perspective related to her use of the clip chart for Vanessa, to sharing ideas with Kristin that she put into practice, it seemed that my relationship with each provided them with something they needed in their first year of teaching.

\section{Next Steps}

In conclusion, I end my dissertation with the final research question, and I consider the direction that this work will take me in my years to come.

\section{Into the Future, the Third Research Question}

What are the implications for policy and practice both in PreK-12 settings and teacher preparation programs?

In reflecting on the process of this research, I have realized that my words have provided a representation of the lived experiences of these teacher candidates and new teachers, but my writing can never illustrate the fullness of their experiences. The sociologist, Ken Plummer once wrote, "All social science — including life stories — are only partial selections of realities. There is always much going on behind the scenes that are not told. Here we have the inevitable bias, the partiality, the limits, the selectivity of all stories told" (as cited in Wolcott, 2010). While these are only the stories of twelve total participants, three quite in-depth, it is my hope that they 
will resonate amongst many audiences, including those of teacher educators, district administrators, teacher candidates, new teachers, and the larger research field.

Implications for teacher preparation. Exploring the perspectives of these teacher candidates and new teachers illuminates areas of strength and weakness within early childhood teacher preparation. The findings of this study point to a persistent and critical need for better preparation for classroom management in line with a continued call from others in the field (Blum, 1994; Clement, 2002; Hammerness, 2011; Liston et al., 2006; Tal, 2010; Stough et. al, 2015). While teacher education programs cannot control the settings in which their graduates are hired, they can control the content embedded in their preparatory sequences and ensure that all graduates have a stronger foundation in classroom management. There are many models for the delivery of this content (Eisenman, Edwards, \& Cushman, 2015; Liston et al., 2006), but ideally, an embedded course or coursework that aligns with concurrent field experiences, along with consistent and persistent discussions about classroom management, can do much to bring the theoretical and practical together (Putman, 2009; Tal, 2010). When teacher candidates can confidently analyze and describe classroom management that they are observing in the field, the easier it is for them to develop their own classroom management beliefs and practices (Stoughton, 2007; Tal, 2010), as well as negotiate potential pitfalls that exist (Feiman-Nemser \& Buchmann, 1983/ 1985).

Coursework must acknowledge the multitude of theories underlying classroom management, instead of focusing on just one (Landau, 2001), and PBIS should be amongst the frameworks, approaches, and strategies that are covered (Hemmeter et al., 2006). Teacher preparation must awake to the reality that, at least in the state of Illinois, teacher candidates and new teachers are working within PBIS settings. If the values and practices of PBIS are not in 
line with beliefs that early childhood programs hold of inclusive classrooms built on democratic beliefs (NAEYC, 2009), then teacher education programs should become more intentional with what they are teaching about classroom management. More robust teaching of past and current classroom management approaches, including PBIS, means less time for a teacher candidate or new teacher to figure out these critical decisions in the moment. Much of these participants' time in student teaching and in the fall of their first year was spent trying to figure out the various systems of their settings and how this aligned with their own classroom management beliefs. Having a better understanding from the start can help. Additionally, more training and support for working with students with challenging behaviors is warranted (Tillery et al. 2010), especially in the early childhood years (Hemmeter et. al, 2006). More experience with students who exhibit challenging behaviors and learning how to support these students can and should be built into general education field experiences and concurrent coursework (Hemmeter et. al, 2006) to improve new teacher classroom management practices and outcomes for students.

This study's findings point to additional areas of teacher preparation that can and should be enhanced, especially those related to the professional educator aspects of becoming a teacher. Teacher preparation sequences should include explicit coursework and field experiences that focus on working with co-teachers, teaching teams, and administrators (Holland, Eckert, \& Allen, 2014), especially those at the early childhood levels, including how classroom management impacts these relationships. Again, these are areas over which the university has little control once candidates graduate. Yet, engaging in scenarios, role-playing, and critical analysis of these aspects of being a teacher can do much to prepare teacher candidates for these experiences once graduated. A continued focus on developing the traits of a reflective 
practitioner and guiding teacher candidates to know how to problem-solve their own professional issues can also do much to support new graduates once in the field (Holland, 2014).

Implications for the field. Multiple findings in this study provide insights into areas in which districts and schools can do a better job of supporting teacher candidates and new teachers, as well as in-service teachers, while using the PBIS framework. The first implication relates to support for teacher candidates who are in schools annually for field placements. None of the teacher candidates in this study received formal training about the PBIS frameworks of their schools, even though the framework and its related practices played such an important role in their student teaching experiences. While workshops or trainings may not be feasible each semester for teacher candidates, a single-page handout, handbook, or website could do much to help inform teacher candidates about this important facet of the school, making candidates stronger team members and enhancing their teacher preparation experiences.

Additionally, districts and schools must find ways to better support new teachers, especially related to classroom management. The findings from this study point to inconsistencies that new teachers experience. Stronger preparation for administrators that focuses on the needs of new teachers, including those teachers in substitute roles, especially about support and feedback, is critical in helping address teacher burnout and more positive outcomes for students. A more concerted focus on mentorship, whether paid or unpaid, for new teachers is essential, and opportunities for mentorship abound (Clement, 2002; Feiman-Nemser, 2003; Teague \& Swan, 2013). At so many points across the year, Vanessa's classroom management and overall teaching were enhanced because of the support and mentorship she received, while Kristin struggled at times without having someone who consistently provided feedback, and Molly floundered with a lack of mentorship and support. The positive outcomes 
from mentoring that Vanessa and Kristin experienced align with those findings found by Ingersoll and Strong (2012) in their empirical review of studies about new teacher induction and mentoring. Vanessa's experience of having a paid, district mentor may be unrealistic within some districts because of budgetary constraints. However, the use of an in-house mentor, like Danielle was for Kristin, but set up in a more formal way, such as how Sarah was for Vanessa, could do wonders to support all new teachers. No new teacher, whether in a substitute role or a permanent role, should be left without some sort of mentorship or coaching support within their first year, as Molly was in her first year, and has been documented as the reality of countless other new teachers in the literature since the 1970's with work of Lortie and others (Ingersoll \& Smith, 2012).

A final implication for districts and schools relates to the increased use of the PBIS framework as a school-wide approach to classroom and behavior management. The work of others has revealed areas of weakness in in-service teacher and administrator knowledge of classroom management (Clement, 2002; Stough et al., 2015). Because many school administrators may likely have had spotty classroom management preparation themselves, it is critical that administrator preparation programs also attend to classroom management coursework that focuses on school-wide approaches. This type of classroom management preparation should include information about the PBIS framework, but not be limited to this one model. When administrators have a better understanding of classroom management themselves, they can do much to support all teachers, including new teachers (Clement, 2002).

In addition, administrators should consider the types of classroom communities they are fostering within their schools through their use of various classroom management approaches (Clement, 2002). If using the PBIS framework, then care should be taken to use it with fidelity 
and with proper training and support for all teachers (Molloy et. al, 2013). However, a critical analysis of use of the framework should also be encouraged. In the case of these participants, the school-wide aspect of the reward-violations systems of PBIS pulled them away from dynamic and meaningful instruction that each was trying to implement, especially as it related to how much instructional time was spent monitoring behavior, passing out rewards, and allowing use of the school's rewards cart. Related to this, principal preparation programs and continued principal professional development should include a critical analysis of the ways that students are included and excluded by practices within any specific approach, such as those used within the PBIS framework. Administrators should also be prepared for and then supported in searching for school-wide alternatives that focus on building classroom communities without punishment and exclusion (Clement, 2002; Lawrence \& Hinds, 2016).

Implications for research. Because there has been a lack of research acknowledging the voices of teacher candidates and new teachers in the growing use of PBIS frameworks, this research should add significant new information to the research literature. Reading the tensions, frustrations, successes, and disappointments of teacher candidates and new teachers using the framework of PBIS and describing their classroom management does much to add to the dominance of quantitative studies on the topic (e.g. Horner et al., 2009; Miramontes et al. 2011; Molloy et al., 2013; Ross et al., 2012; Spaulding et al., 2008; Sugai et al., 2000). This work also contributes to the growing body of data that points to inconsistencies in school-wide and classwide PBIS implementation, as well as issues within the framework connected to training, support, and overall usability concerns (Handler et al., 2007; Fallon, McCarthy, \& Hagermoser Sanetti, 2014; Molloy et al., 2013). Additionally, following graduates into their first year of teaching has provided new insights into what happens to the classroom management practices of 
teacher candidates as they become first-year teachers and reveals changes in classroom management beliefs and practices that are more deeply affected by external contexts, of which teacher preparation has only so much control. The stories of these new teachers can do much to encourage further research from the perspectives of the users of PBIS, such as practicing teachers and students.

\section{My Next Steps}

After conducting this study, I am left with additional questions and areas of related research that most interest me. I plan to continue working to tell the many stories of this study's new teachers, including those of the various contextual influences on their first year. Subsequently, following up with Molly, Kristin, and Vanessa to see where they are today, after their third year since graduation, in their beliefs and practices about classroom management is very intriguing to me. On a personal level, I have grown to care about each of them deeply, and on an academic level, there are no longitudinal studies examining teacher beliefs and practices regarding classroom management for this length of time. Finding out whether Molly left the field of teaching or moved to a new school and whether she put her beliefs into practice...or whether Kristin moved away from her dependence on the clip chart with stronger teaching methods... or whether Vanessa put her clip chart away for good or became a new-teacher mentor, my curiosity is piqued. In addition, knowing that early childhood graduates from my institution now have much more preparation for classroom management embedded across clinical seminars and in courses that I have led, I would be intrigued to replicate parts of the study to see if the outcomes change with stronger classroom management preparation.

As a researcher, I plan to continue investigating user perspectives of the PBIS framework. I am intrigued by the work of Farmer and her colleagues (2016) related to 
investigating student perceptions of classroom community using drawings. Linking up their model of investigation with students in schools implementing the PBIS framework could do much to illustrate student perspectives about classroom community in these settings.

Additionally, the topic of how teacher candidates and new teachers negotiate family-professional collaborations, as they relate to their classroom management approaches also intrigues me. The theme of family-professional collaborations surrounding classroom management concerns arose within this study, and I would like to explore this more deeply in subsequent work.

Molly's cry that the university had not prepared her for the professional aspects of working in the school, versus the easy way that Kristin seemed to navigate these aspects, as compared to the very adept ways that Vanessa navigated them in her practice have also piqued my interest. What role did their teacher preparation play in affecting these important first-year outcomes? Subsequent research into teacher candidate attitudes and feelings of preparedness related to working with adults in schools is an area I would be interested in exploring as well.

The one aspect of PBIS that is most connected to a balance of humanistic and behavioristic classroom management strategies relates to the teaching of prosocial skills. However, this was an area that Molly and Kristin rarely addressed. In Vanessa's practice, her focus on building self-regulation and self-reliance led to numerous positive outcomes for both her students and her. Preparation for addressing social-emotional needs and the teaching of prosocial skills, including problem-solving and conflict resolution are topics that I am also interested in continuing to pursue. How can teacher preparation programs better prepare teacher candidates to be focused on this critical component to aid in their building of classroom communities? 
In my soul, I am an educator, and as such, my immediate next steps relate to my practice as a preparer of early childhood and elementary teachers. I plan to continue to seek out ways to make learning about classroom management and the PBIS framework, and how to fuse these aspects together in building classroom communities meaningful, practical, realistic, manageable, and concurrent with experiences my teacher candidates are having in the field. Adding in how to do this within the contexts of working with other adults will also be what I bring into my work. Discussing critical discourses related to classroom management, the blending of classroom management theory, covering the basics, and thinking about student perspectives, do much to inform a course or series of experiences that I would like to create for my early childhood department.

\section{In Conclusion}

The stories of these teacher candidates and new teachers reveal that classroom management continues to be one of the murkiest in concept, most difficult to describe, and often least-taught aspects of teacher preparation, and yet it continues to impact whether a new teacher's day will be fraught with smiles and engagement or frustrations and lack of learning. When new teachers are poorly prepared in classroom management concepts, and are then confronted with a framework in the field that mandates components of their management as a part of a school-wide effort, they can feel supported when these components align with what they have learned or if they have a guide by their side. However, if these mandates contradict the little bit of learning that these new teachers had related to classroom management in their teacher preparation, and no one helps them to process their questions, it can be difficult for them to know what to do. PBIS is one such framework that consists of a school-wide effort towards addressing classroom practices, including a new teacher's classroom management. 
After spending time with these new teachers, it seems evident that the framework does not guarantee that new teachers will have strong classroom management or feel able to build a sense of classroom community within their spaces, just as it does not guarantee that new teachers, themselves, will feel that they are a part of a community. On its own, the framework offers components that should help in establishing a sense of community within classrooms. However, individual classroom communities and the new teachers building them are impacted by any number of contexts that are related and unrelated to what new teachers learned in their teacher preparation and the framework of PBIS, in which they are teaching. In many ways, these contexts can have a stronger impact on a new teacher's classroom management than either her teacher preparation or the various components of the PBIS framework. Additionally, the question must be asked, for these three participants and all teachers using PBIS, whether the framework, itself, positively impacts practices, or whether having a school-wide approach does. Ultimately, the benefits that this study's new teachers experienced by teaching in schools using the framework seemed to come from the school-wide aspect of it, specifically. Importantly, this indicates that any school-wide approach where there is administrative, teacher, student, and parent buy-in can help create feelings of community, significance, and belonging within a school. When specific teaching practices related to PBIS still encourage traditional behaviors that include the teacher as a "manager" and punitive, top-down, exclusionary practices, and when these measures do not seem to produce gains for all students, distract from teaching, and prevent teachers from building a sense of community, then for the benefit of all parties, especially new teachers, hopefully, these new teachers' stories can provide insights into alternatives. 


\section{REFERENCES}

Adams, D. (2011). Positivism goes to School: Positive behavior supports from a disability studies lens. Paper session presented at the annual conference of the Society of Disability Studies. San Jose, CA.

Alderman, M. K., \& MacDonald, S. (2015). A self-regulatory approach to classroom management: Empowering students and teachers. Kappa Delta Pi Record, 51(2), 52-56.

Anagnostopoulos, D., Smith, E., \& Basmadjian, K. (2007). Bridging the school/ university divide: Horizontal expertise and the "two-worlds pitfall." Journal of Teacher Education, $58(2), 138-152$.

Ashton, P. T., \& Webb, R. B. (1986). Making a difference: Teachers' sense of efficacy and student achievement. New York: Longman.

A Blog About School. (2009, October 8). Behavioral, yes. Positive and supporting? Maybe not [Blog post]. Retrieved from http://ablogaboutschool.blogspot.com/2009/10/what-followsis-text-of-letter-i-am.html

Bandura, A. (1997). Self-efficacy: The exercise of control. New York: W. H. Freeman.

Battistich, V., \& Hom, A. (1997). The relationship between students' sense of their schools as a community and their involvement in problem behaviors. American Journal of Public Health, 87(12), 1997-2001.

Behar, R. (1996). The vulnerable observer: Anthropology that breaks your heart. Boston: Beacon Press.

Bigham, S. G., Hively, D. E., \& Toole. G. H. (2014). Principals' and cooperating teachers' expectations of teacher candidates. Education, 135(2), 211-229.

Blank, J., \& Schneider, J. (2011). "Use your words": Reconsidering the language of conflict in 
the early years. Contemporary Issues in Early Childhood, 12(3), 198-211.

Blum, M. H. (1994). The preservice teacher's educational training in classroom discipline: A national survey of teacher education programs. (Unpublished doctoral dissertation). Temple University, Pennsylvania.

Bornstein, J. (2015). "If they're on Tier 1, there are really no concerns that we can see": PBIS medicalizes compliant behavior. Journal of Ethnographic and Qualitative Research, 9(4), 247-267.

Boutte, G. (2008). Beyond the illusion of diversity: How early childhood teachers can promote social justice. The Social Studies, 99(4), 165-173.

Bower, J. (2010, October 21). Primitive moral development: PBIS [Blog post]. Retrieved from http://www.joebower.org/2010/10/primitive-moral-development-pbis.html

Brophy, J. (1999). Perspectives of classroom management: Yesterday, today, and tomorrow. In J. H. Freiburg (Ed.), Beyond behaviorism: Changing the classroom management paradigm (pp. 43-55). Boston: Allyn-Bacon.

Brophy, J. (2006). History of research on classroom management. In C. M. Evertson \& C. S. Weinstein (Eds.), Handbook of classroom management: Research, practice, and contemporary issues (pp. 17-43). Mahwah, NJ: Lawrence Erlbaum Associates.

Bruning, R. H., Schraw, G. J., \& Norby, M. M. (2011). Cognitive psychology and instruction. 5th Ed. Boston: Pearson.

Cakmak, M. (2008, March). Concerns about teaching process: Student teachers' perspective. Educational Research Quarterly, 31(3), 57-77.

Calkins, L. M. (2003). Units of study for primary writing: A yearlong curriculum. Portsmouth, NH: Heinemann. 
Capizzi, A. M. (2009, November). Start the year off right: designing and evaluating a supportive classroom management plan. Focus on Exceptional Children, 42(3), 1-12.

Center for Mental Health in Schools at UCLA. (2011, February). Moving beyond the three tier intervention pyramid toward a comprehensive framework for student and learning supports. (Center Policy Brief). Retrieved from http://smhp.psych.ucla.edu/pdfdocs/briefs/threetier.pdf

Chesley, G. M., \& Jordan, J. (2012). What's missing from teacher prep. Educational Leadership, $69(8), 41-45$.

Chitiyo, M., May, M. E., \& Chitiyo, G. (2012). An assessment of the evidence-base for schoolwide positive behavior support. Education and Treatment of Children, 35(1), 1-24.

Christofferson, M., \& Sullivan, A. L. (2015). Preservice teachers' classroom management training: A survey of self-reported training experiences, content coverage, and preparedness. Psychology in the Schools, 52(3), 248-264.

Clement, M. C. (2002). What cooperating teachers are teaching student teachers about classroom management. The Teacher Educator, 38(1), 47-62.

Clement, M. C. (2010, Fall). Preparing teachers for classroom management: The teacher educator's role. The Kappa Delta Bulletin, 77(1), 41-44.

Coffey, J. H., \& Horner, R. H. (2012). The sustainability of school wide positive behavior interventions and supports. Exceptional Children, 78(4), 407-422.

Committee for Children. (2017). Second Step SEL Program suite. Retrieved from http://www.cfchildren.org/second-step/second-step-suite.

Cook, L., \& Friend, M. (1995). Co-teaching: Guidelines for creating effective practices. Focus on Exceptional Children, 28(3), 1-16. 
Cramer, E. (2010). Co-teaching. International Encyclopedia of Education (Third Edition). Oxford: Elsevier.

Creswell, J. W. (2012). Educational research: Planning, conducting, and evaluating quantitative and qualitative research (4th ed.). Upper Salle River, NJ: Pearson.

Creswell, J. W. \& Miller, D. L. (2000). Determining validity in qualitative research. Theory into Practice, 39(3), 124-130.

Critchfield, T. S. (2015). PBIS may not qualify as classical applied behavior analysis. So what? Behavior Analysis in Practice, 8(1), 99-100.

Croake, J. W. (2011, October-December). A review of 'children: the challenge.' American Journal of Family Therapy, 39(5), 456-457.

Crotty, M. (1998). The foundations of social research: Meaning and perspective in the research process. England: Sage Publications.

Denzin, N. K., \& Lincoln, Y. S. (2011). The SAGE handbook of qualitative research. Los Angeles: SAGE.

Dolittle, P. E., \& Camp, W. G. (1999, Fall). Constructivism: The career and technical education perspective. Journal of Vocational and Technical Education, 16(1), 23-46.

Doyle, W. (2009, Spring). Situated practice: A reflection on person-centered classroom management. Theory into Practice, 48(2), 156-159.

Dreikurs, R. (1987). Children the challenge. New York: Dutton.

Eisenman, G., Edwards, S., \& Cushman, C. A. (2015). Bringing reality to classroom management in teacher education. The Professional Educator, 39(1), 1-12.

Eisner, E. W. (1997). The new frontier in qualitative research methodology. Qualitative Inquiry, 3(3), 259-273. 
Emerson, R. M., Fretz, R. I., \& Shaw, L. L. (2011). Writing ethnographic fieldnotes. Chicago: University of Chicago Press.

Emmer, E. T., \& Stough, L. M. (2001). Classroom management: A critical part of educational psychology, with implications for teacher education. Educational Psychologist, 36(2), 103-112.

Ertmer, P. A., \& Newby, T. J. (1993). Behaviorism, cognitivism, constructivism: Comparing critical features from an instructional design perspective. Performance Improvement Quarterly, 6(4), 50-72.

Evertson, C. M., Emmer, E. T., Clements, B. S., \& Worsham, M. E. (1996). Classroom management for elementary teachers. Allyn \& Bacon: Needham Heights, MA.

Evertson, C. M., \& Harris, A. H. (1992). What we know about managing classrooms. Educational Leadership, 49(7), 74-78.

Fallon, L. M., McCarthy, S. R., Hagermoser Sanetti, L. M. (2014). School-wide Positive Behavior Support (SWPBS) in the classroom: Assessing perceived challenges to consistent implementation in Connecticut schools. Education and Treatment of Children, $37(1), 1-24$.

Farkas, S., \& Duffett, A. (2010). Cracks in the ivory tower. The views of education professors circa 2010. Dayton, Ohio: Thomas B. Fordham Institute and Foundation. Retrieved from http://www.edexcellence.net/assets/docs/cracks-ivory-tower-full.pdf

Farmer, J. L., Leonard, A. E., Spearman, M., Qian, M., \& Rosenblith, S. (2016). Picturing a classroom community: Student drawings as a pedagogical tool to assess features of community in a classroom. Action in Teacher Education, 38(4), 299-314.

Feiman-Nemser, S. (2003). What new teachers need to learn. Educational Leadership, 60(8), 25- 
29.

Feiman-Nemser, S. (2012). Teachers as learners. Cambridge, MA: Harvard Education Press.

Feiman-Nemser, S., \& Buchmann, M. (1983). Pitfalls of experience in teacher preparation. Occasional Paper No. 65. East Lansing, MI: Michigan State University Institute for Research on Teaching.

Feiman-Nemser, S., \& Buchmann, M. (1985). Pitfalls of experience in teacher preparation. Teachers College Record, 87(1), 53-65.

Fowler, D. (2011, October). School discipline feeds the "pipeline to prison." Phi Delta Kappan, 93(2), 14-19.

Furman, G. (2012). School as community: From promise to practice. New York: SUNY Press.

Freeman, J., Simonsen, B., Briere, D. E., MacSuga-Gage, A. S. (2014). Pre-service teacher training in classroom management: A review of state accreditation policy and teacher education programs. Teacher Education and Special Education, 37(2), 106-120.

Freiberg, H. J. (1999). Beyond behaviorism: Changing the classroom management paradigm. Boston: Allyn \& Bacon.

Fuentes, A. (2011-2012, Winter). Arresting development: Zero tolerance and the criminalization of children. Rethinking Schools, 26(2), 18-23.

Ganser, T. (1999). Reconsidering the relevance of Veenman's (1984) meta-analysis of the perceived problems of beginning teachers. Paper presented at the Annual Meeting of the American Educational Research Association, (Montreal, Quebec, April 19-23, 1999).

Garfinkel, H. (1967). Studies in ethnomethodology. Englewood Cliffs, NJ: Prentice-Hall.

Gartrell, D. (2001). Replacing time-out: Part 1- using guidance to build an encouraging classroom. Young Children, 56(6), 1-8. 
Gebbie, D. H., Ceglowski, D., Taylor, L. K., \& Miels, J. (2010). The role of teacher efficacy in strengthening classroom support for preschool children with disabilities who exhibit challenging behaviors. Early Childhood Education Journal, 40(1), 35-46.

Gibson, S., \& Dembo, M. (1984). Teacher efficacy: A construct validation. Journal of Educational Psychology, 76, 569-582.

Geertz, C. (1973). Thick description: Toward an interpretive theory of culture. In The Interpretation of Cultures. New York: Basic Books.

Glazer, M. (1982). The threat of the stranger. The Hastings Center Report, 10(5), 25-31.

Glesne, C. (2011). Becoming qualitative researchers: An introduction. Boston: Pearson.

Glickman, C. D., \& Tamashiro, R. T. (1980, March). Clarifying teachers’ beliefs about discipline. Educational Leadership, 37(6), 459-465.

Goldstein, L. S. (1997). Between a rock and a hard place in the primary grades: The challenge of providing developmentally-appropriate early childhood education in an elementary school setting. Early Childhood Research Quarterly, 12(1), 3-27.

Gonzalez, L., Brown, M. S., \& Slate, J. R. (2008, March). Teachers who left the teaching profession: A qualitative understanding. The Qualitative Report, 13(1), 1-11.

Hammerness, K. (2011). Classroom management in the United States: a view from New York City. Teaching Education, 22(2), 151-167.

Handler, M. W., Rey, J., Connell, J., Thier, K., Feinberg, A., \& Putnam, R. (2007). Practical considerations in creating school-wide positive behavior support in public schools. Psychology in the Schools, 44(1), 29-39.

Hemmeter, M. L., Santos, R. M., \& Ostrosky, M. M. (2006). Preparing early childhood educators 
to address young children's social-emotional development and challenging behaviors. Journal of Early Intervention, 30(4), 321-340.

Holland, J. M., Eckert, J., \& Allen, M. M. (2014). From preservice to teacher leadership: Meeting the future in educator preparation. Action in Teacher Education, 36(5/6), 433445.

Hollway, W., \& Jefferson, T. (1997). Eliciting narrative through the in-depth interview. Qualitative Inquiry, 3(1), 53-70.

Horner, R. H., Sugai, G., \& Anderson, C. M. (2010). Examining the evidence base for schoolwide positive behavior support. Focus on Exceptional Children, 42(8), 1-14.

Horner, R. H., Sugai, G., Smolkowski, K., Eber, L., Nakasato, J., Todd, A. W., et al. (2009). A randomized, wait-list controlled effectiveness trial assessing school-wide positive behavior support in elementary schools. Journal of Positive Behavior Interventions, 11(3), 133-144.

Hoy, W. K., \& Woolfolk, A. E. (1990). Socialization of student teachers. American Educational Research Journal, 27(2), 279-300.

Illinois PBIS Network. (2013). List of PBIS implementing schools. Illinois PBIS Network. Retrieved February 14, 2014 from http://www.pbisillinois.org/schools/Implementingschools

Ingersoll, R. M., \& Strong, M. (2012). The impact of induction and mentoring programs for beginning teachers: A critical review of the research. Review of Educational Research, 81(2), 201-233.

Johnston, J. M., Foxx, R. M., Jacobson, J. W., Green, G., \& Mulick, J. A. (2006). Positive behavior support and applied behavior analysis. The Behavior Analyst, 29(1), 51-74. 
Kaufman, D., \& Moss, D. M. (2010). A new look at pre-service teachers' conceptions of classroom management and organization: Uncovering complexity and dissonance. The Teacher Educator, 45(2), 118-136.

Kee, A. N. (2011). Feelings of preparedness among alternatively certified teachers: What is the role of program features? Journal of Teacher Education, 63(1), 23-38.

Kirylo, J. D. (2012). Issues in education: The power of relationship and behavior management. Childhood Education, 86(1), 33-34.

Kliebard, H. M. (2004). The struggle for the American curriculum 1893-1958. New York: RoutledgeFalmer.

Klonsky, M. (2011, May 11). An interview with Deborah Meier on the small-schools movement [Blog post]. Retrieved from http://www.huffingtonpost.com/michael-klonskyphd/deborah-meier-small-schools_b_859362.html

Knoblauch, D., \& Hoy, A. W. (2008). "Maybe I can teach those kids.” The influence of contextual factors on student teachers' efficacy beliefs. Teaching and Teacher Education, 24(1), 166-179.

Kukla-Acevado, S. (2009). Leavers, movers, and stayers: The role of workplace conditions in teacher mobility decisions. Journal of Educational Research, 102(6), 443-452.

Lagerwerff, K. (2016, Spring). Prizes as curriculum. Rethinking Schools, 30(3), 54-57.

Landau, B. E. (2001). Teaching classroom management: A stand-alone necessity for preparing new teachers. Paper presented at the Annual Meeting of the American Educational Research Association (Seattle, WA, April 10-14, 2001).

Lawrence, E., \& Hinds, T. (2016, November/ December). From punish and discipline to repair and restore. Principal, 96(2), 23-34. 
Liston, D., Whitcomb, J., \& Borko, H. (2006). Too little or too much: Teacher preparation and the first years of teaching. Journal of Teacher Education, 57(4), 351-358.

Lortie, D. C. (1975). Schoolteacher: A sociological study. University of Chicago Press: Chicago.

Luekens, M. T., Lyter, D. M., \& Fox, E. E. (2004). Teacher attrition and mobility: Results from the Teacher Follow-up Survey, 2000-01 (NCES Publication No. 2004-301). Washington, DC: National Center for Education Statistics, U.S. Department of Education.

Marshall, J. C., Caldwell, S. D., \& Foster, J. (2011). Moral education the CHARACTERPlus Way®. Journal of Moral Education, 40(1), 51-72.

Martin, N. K., Yin, Z. \& Baldwin, B. (1998, April). Classroom management training, class size and graduate study: Do these variables impact teachers' beliefs regarding classroom management style? Paper presented at the meeting of the American Educational Research Association, San Diego, CA.

Martin, N. K., Yin, Z., Mayall, H. (2006). Classroom management training, teaching experience and gender: Do these variables impact teachers' attitudes and beliefs toward classroom management style. Paper presented at the Annual Conference of the Southwest Educational Research Association (Austin, TX, February 2006).

Martin, N. K., Yin, Z., Mayall, H. (2007-2008). The attitudes \& beliefs on classroom control inventory-revised and revisited: A continuation of construct validation. Journal of Classroom Interaction, 42(2), 11-20.

Marvel, J., Lyter, D. M., Peltola, P., Strizek, G. A., \& Morton, B. A. (2006). Teacher attrition and mobility: Results from the 2004-05 teacher follow-up survey (NCES 2007-307). Washington, DC: National Center for Education Statistics.

Marzano, R. J., Marzano, J. S., \& Pickering J. (2003). Classroom management that works: 
Research-based strategies for every teacher. Association for Supervision and Curriculum Development: Alexandria, VA.

Meier, D. (2009, May). Democracy at risk. Educational Leadership, 66(8), 45-48.

Meier, D. (2011a, Fall). What's democracy got to do with teaching. Kappa Delta Pi Record, 48(1), 19-21.

Miles, M. M., Huberman, A. M., \& Saldaña, J. (2014). Qualitative data analysis: A methods sourcebook. Thousand Oaks, CA: Sage.

Miramontes, N. Y., Marchant, M., Heath, M. A., \& Fischer, L. (2011). Social validity of a positive behavior interventions and support model. Education and Treatment of Children, 34(4), 445-468.

Molloy, L. E., Moore, J. E., Trail, J., Van Epps, J. J., \& Hopfer, S. (2013, December). Understanding real-world implementation quality and "active ingredients" of PBIS. Prevention Science, 14(6), 593-605.

Mosier, W. (2009). Developmentally appropriate child guidance: Helping children gain selfcontrol. Texas Child Care, 32(4), 2-5.

National Association for the Education of Young Children. (2005/ 2011). Code of ethical conduct and statement of commitment. Retrieved from http://www.naeyc.org/files/naeyc/image/public_policy/Ethics\%20Position\%20Statement 2011_09202013update.pdf

National Association for the Education of Young Children. (2009). Developmentally appropriate practice in early childhood programs serving children from birth through age 8. Retrieved from http://www.naeyc.org/files/naeyc/file/positions/PSDAP.pdf National Center for Mental Health Protection \& Youth Violence Prevention. (n.d.). 
Positive behavioral interventions and support (PBIS). Retrieved from http://www.promoteprevent.org/publications/ebi-factsheets/positive-behavioralinterventions-and-supports-pbis

Nelson, J., Lott, L., Glenn, H. S. (2000). Positive discipline in the classroom: Developing mutual respect, cooperation, and responsibility in your classroom. New York: Three Rivers Press.

Northeast Foundation for Children, Inc. (2009). PBIS and the Responsive Classroom approach. (White paper). Responsive Classroom. Retrieved from http://www.responsiveclassroom.org/sites/default/files/pdf_files/PBIS_whitepaper.pdf

O’Neill, S., \& Stephenson, J. (2012). Does classroom management coursework influence preservice teachers perceived preparedness or confidence? Teaching and Teacher Education, 28(8), 1131-1143.

Oakes, J., Lipton, M., Anderson, L., Stillman, J. (2013). Teaching to change the world. Boulder, CO: Paradigm Publishers.

Oliver, R. M., \& Reschly, D. J. (2007). Effective classroom management: Teacher preparation and professional development. TQ Connection Issue Paper on improving student outcomes in general and special education. Washington: National Comprehensive Center for Teacher Quality. Retrieved from http://www.tqsource.org/topics/effectiveClassroomManagement.pdf

Oliver, R. M., \& Reschly, D. J. (2010). Special education teacher preparation in classroom management: Implications for students with emotional and behavioral disorders. Behavioral Disorders, 35(3), 188-199.

Ornstein, A. C. (2011). Philosophy as a basis for curriculum decisions. In A. C. Ornstein, E. F. 
Pajak, \& S. B. Ornstein (Eds.), Contemporary issues in curriculum (pp. 2-9). Boston: Pearson.

Palmer, P. J. (2011). The heart of a teacher. In A. C. Ornstein, E. F. Pajak, \& S. B. Ornstein (Eds.), Contemporary issues in curriculum (pp. 62-74). Boston: Pearson.

Peshkin, A. (1988). In search of subjectivity—one's own. Educational Researcher, 17(7), 17-21.

Pink, D. H. (2005). A whole new mind: Moving from the information age to the conceptual age. New York: Riverhead Books.

Positive Behavioral Intervention \& Supports. (2012). What is school-wide positive behavioral interventions \& supports. Retrieved from http://www.pbis.org/school/what_is_swpbs.aspx

Powell, D., Fixsen, D., Dunlap, G., Smith, B., \& Fox, L. (2007). A synthesis of knowledge relevant to pathways of service delivery for young children with or at risk of challenging behavior. Journal of Early Intervention, 29(2), 81-106.

Putman, S. M. (2009). Grappling with classroom management: The orientations of preservice teachers and impact of student learning. The Teacher Educator, 44(4), 232-247.

Quinn, B. (2011). The school as a democratic community. Applied Developmental Science, 15(2), 94-97.

Rajuan, M., Beijaard, D., \& Verloop, N. (2007, August). The role of the cooperating teacher: bridging the gap between the expectations of cooperating teachers and student teachers. Mentoring \& Tutoring, 15(3), 223-242.

Rajuan, M., Beijaard, D., \& Verloop, N. (2010, June). The match and mismatch between expectations of student teachers and cooperating teachers: Exploring different opportunities for learning to teach in the mentor relationship. Research Papers in 
Education, 25(2), 201-223.

Rimm-Kaufman, S., \& Chiu, Y-J. I. (2007). Promoting social and academic competence in the classroom: An intervention study examining the contribution of the "Responsive Classroom" approach. Psychology in the Schools, 44(4), 397-413.

Rogers, C. R. (1961). On becoming a person: A therapist's view of psychotherapy. New York: Houghton Mifflin.

Ross, J. A., Cousins, J., \& Gadalla, T. (1996). Within teacher predictors of teacher efficacy. Teaching and Teacher Education, 12(4), 385-400.

Ross, S. W., Romer, N., \& Horner, R. H. (2012). Teacher well-being and the implementation of school-wide Positive Behavior Interventions \& Supports. Journal of Positive Behavior Interventions, 14(2), 118-128.

Rubin, R. (2011). Autonomy, self-determination and discipline in our public schools. Retrieved from http://smhp.psych.ucla.edu/pdfdocs/rubin(2011).pdf

Samuels, C. A. (2013, August 27). Tensions accompany growth of PBIS discipline model. Education Week, 33(2), 1, 16.

Schaps, E. (2003). Creating a school community. Educational Leadership, 60(6), 31-33.

Scherer, M. (1994, September). On schools where students want to be: A conversation with Deborah Meier. Educational Leadership, 52(1), 4-8.

Schiro, M. S. (2008). Curriculum theory: Conflicting visions and enduring concerns. Thousand Oaks, CA: SAGE Publications.

Seidman, I. E. (1991). Interviewing as qualitative research: A guide for researchers in education and the social sciences. New York: Teachers College Press.

Serriere, S. (2010). Carpet-time democracy: Digital photography and social consciousness in the 
early childhood classroom. The Social Studies, 101(2), 60-68.

Shulman, B. H. \& Dreikurs, S. G. (1978, November). The contributions of Rudolf Dreikurs to the theory and practice of individual psychology. Journal of Individual Psychology, 34(2), 153-169.

Sileo, J. M. (2011). Co-teaching: Getting to know your partner. Teaching Exceptional Children, 43(5), 32-38.

Simonsen, B., Myers, D., Everett, S., Sugai, G., Spencer, R., LaBreck, C. (2011, December). Explicitly teaching social skills school wide: Using a matrix to guide instruction. Intervention in School and Clinic, 47(5), 259-266.

Smith, E. R. (2007). Negotiating power and pedagogy in student teaching: Expanding and shifting roles in expert-novice discourse. Mentoring \& Tutoring, 15(1), 87-106.

Smith, E. R., \& Avetisian, V. (2011). Learning to teach with two mentors: Revisiting the "two world's pitfall" in student teaching. Teacher Educator, 46(4), 335-354.

Souto-Manning, M. (2014). Making a stink about the "ideal" classroom: Theorizing and storying conflict in early childhood education. Urban Education, 49(6), 607-634.

Spaulding, S. A., Horner, R. H., May, S. L., \& Vincent, C. G. (2008, November). Evaluation brief: Implementation of school-wide PBS across the United States. OSEP Technical Assistance Center on Positive Behavioral Interventions and Supports. [Web site]. Retrieved from http://pbis.org/evaluation/evaluation_briefs/default.aspx

Stake, R. E. (1995). The art of case study research. Sage Publications, Thousand Oaks, CA.

Stake, R. E. (2010). Qualitative research: Studying how things work. New York: The Guilford Press.

Stewart-Wells, G. (2000). An investigation of student teacher and teacher educator perceptions 
of their teacher education programs and the role classroom management plays or should play in preservice education. Unpublished doctoral dissertation, The Claremont Graduate University, San Diego.

Stone, J. (2001, November). Building classroom community: The early childhood teacher's role. Early Childhood Today, 16(3), 17-18.

Stough, L. M. (2006). The place of classroom management and standards in teacher education. In C. Evertson \& C. Weinstein, (Eds.), Handbook of classroom management: Research, practice, and contemporary issues (pp. 909-923). Mahwah, NJ: Erlbaum.

Stough, L. M., Montague, M. L., Landmark, L. J., \& Williams-Diehm, K. (2015). Persistent classroom management training needs of experienced teachers. Journal of the Scholarship of Teaching and Learning, 15(5), 36-48.

Stoughton, E. H. (2007). “How will I ever get them to behave?”: Pre-service teachers reflect on classroom management. Teaching and Teacher Education, 23(7), 1024-1037.

Sugai, G., \& Horner, R. (2002). The evolution of discipline practices: School-wide positive behavior supports. Child and Family Behavior Therapy, 24(1-2), 23-50.

Sugai, G., Lewis-Palmer, Todd, A. W., \& Horner, R. H. (2001). School-wide Evaluation Tool (version 2.0). Eugene, OR: Educational and Community Supports, University of Oregon.

Sugai, G., \& Simonsen, B. (2012, June 19). Positive behavioral interventions and supports: History, defining features, and misconceptions. Retrieved from http://www.pbis.org/school/pbis_revisited.aspx

Sugai, G., Sprague, J.R., Horner, R.H., Walker, H.M. (2000). Preventing school violence: The use of office discipline referrals to assess and monitor school wide-discipline interventions. Journal of Emotional and Behavioral Disorders, 8(2), 94-101. 
Tal, C. (2010, August). Case studies to deepen understanding and enhance classroom management skills in preschool teacher training. Early Childhood Education Journal, $38(2), 143-152$.

Teague, D., \& Swan, J. (2013). Enhancing the future of education by actively supporting novice teachers. The Delta Kappa Gamma Bulletin, 80(1), 41-52.

Tellez, K. (2008). What student teachers learn about multicultural education from their cooperating teachers. Teaching and Teacher Education, 24(1), 43-58.

Tillery, A. D., Varjas, K. Meyers, J., \& Collins, A. S. (2010). General education teachers' perceptions of behavior management and intervention strategies. Journal of Positive Behavior Interventions, 12(2), 86-102.

Tönnies, F. (1957). Community and society. NY: Harper \& Row Publishers.

Tschannen-Moran, M., Hoy, A. W., \& Hoy, W. K. (1998). Teacher efficacy: Its meaning and measure. Review of Educational Research, 68(2), 202-248.

U.S. Department of Education. (2016, July). The state of racial diversity in the educator workforce. Policy and Program Studies Service. Office of Planning, Evaluation, and Policy Development. Retrieved from https://www2.ed.gov/rschstat/eval/highered/racialdiversity/state-racial-diversity-workforce.pdf

Veenman, S. (1984). Perceived problems of beginning teachers. Review of Educational Research, 54(2), 143-178.

Walker, J. M. T., (2009, Spring). Situated practice: A reflection on person-centered classroom management: Viewpoint essay. Theory into Practice, 48(2), 156-149.

Wasilewski, Y., Gifford, B., Bonneau, K. (2008). Evaluation of the school-wide positive 
behavioral support program in eight North Carolina elementary schools. Center for Child and Family Policy Duke University, 1-43. Retrieved from http://files.eric.ed.gov/fulltext/ED503191.pdf

Whitebook, M. (2014, September). Building a skilled teacher workforce: Shared and divergent challenges in early care and education and in grades K-12. Retrieved from http://cscce.berkeley.edu/files/2014/Building-a-Skilled-Teacher-Workforce_September2014_9-25.pdf

Whole Brain Teaching. (n.d.). Homepage. Retrieved from http://wholebrainteaching.com.

Wilson, A. (2015). A critique of sociocultural values in PBIS. Behavior Analysis in Practice, $8(1), 92-94$.

Wisneski, D. B. (2005). Complicating classroom community in early childhood. (Unpublished doctoral dissertation). The University of Texas at Austin, Austin, TX.

Witz, D. (2011). Teacher: How to address bullying in school and how not to. [Blog post] Retrieved from http://saferschools.blogspot.com/2011/12/pbis-positive-behaviorintervention-and.html

Wolcott, H. F. (1994). Transforming qualitative data: Description, analysis, and interpretation. Thousand Oaks, CA: Sage.

Wolcott, H. F. (2002). Writing up qualitative research...better. Qualitative Health Research, 12(1), 91-103.

Wolcott H. F. (2010). Overdetermined behavior, unforeseen consequences. Qualitative Inquiry, $16(1), 10-20$.

Wolfgang, C. H. (2001). Solving discipline and classroom management problem. John Wiley \& Sons, Inc.: New York, New York. 
Zeichner, K. (2010). Rethinking the connections between campus courses and field experiences in college- and university-based teacher education. Journal of Teacher Education, 61(12), 89-99. 


\section{APPENDIX A: DATA COLLECTION SCHEDULE}

Table A-1

Focus Group Data Collection Log

\begin{tabular}{llll}
\hline $\begin{array}{l}\text { Focus Group } \\
\text { Interview }\end{array}$ & TC Participants & Month & Format \\
\hline 1. & $1,2,3,4$ & May 2014 & In-Person \\
2. & 5 & June 2014 & In-Person \\
3. & 6,7 & July 2014 & Online \\
4. & $8,9,10,11$ & July 2014 & Online \\
\hline
\end{tabular}

Table A-2

Case Study Data Collection Log

\begin{tabular}{lllll}
\hline $\begin{array}{l}\text { Case Study } \\
\text { Participant }\end{array}$ & Focus Group & Interviews & $\begin{array}{l}\text { Classroom } \\
\text { Observations }\end{array}$ & $\begin{array}{l}\text { Artifact } \\
\text { Collection }\end{array}$ \\
\hline Molly & $\# 1$ & 5 total interviews & 3 total & 2 total \\
& & $9 / 25 / 14$ (my office) & $9 / 24 / 14$ & $9 / 24 / 14$ \\
& $11 / 19 / 14$ (Skype) & $1 / 21 / 15$ & $5 / 20 / 15$ \\
& & $5 / 21 / 15$ (my office) & $5 / 20 / 15$ & \\
Kristin & $3 / 11 / 15$ (my office) & & \\
& & $5 / 20 / 15$ (my office) & & 3 total \\
& Was recruited, but & 4 total interviews & 3 total & $11 / 19 / 14$ \\
& unable to attend any & $11 / 19 / 14$ (online) & $1 / 20 / 15$ & $1 / 20 / 15$ \\
& & $1 / 20 / 15$ (her classroom) & $3 / 10 / 15$ & $3 / 10 / 15$ \\
& & $3 / 10 / 15$ (her classroom) & $5 / 21 / 15$ & \\
& & $5 / 21 / 15$ (her classroom) & & 4 total \\
Vanessa & & & $11 / 16 / 14$ \\
& Scheduled for \#2, & 4 total interviews & 3 total & $1 / 30 / 15$ \\
& but unable to attend & $11 / 16 / 14$ (online) & $1 / 30 / 15$ & $3 / 12 / 15$ \\
& at the last minute. & $1 / 30 / 15$ (her classroom) & $3 / 12 / 15$ & $6 / 9 / 15$ \\
\hline & Thus, she & $3 / 12 / 15$ (her classroom) & $6 / 9 / 15$ & \\
& participated in $\# 4$. & $6 / 9 / 15$ (her classroom) & & \\
\hline
\end{tabular}




\section{APPENDIX B: INTERVIEW PROTOCOLS}

2014 Summer Focus Group Interview Protocol with Teacher Candidates

Interview with

Date Time Location

Thank you so much for meeting with me today. The purpose of this focus group interview is to help me understand how you feel about classroom management and your university preparation. This interview will last about an hour and I will be asking you questions about your teaching, your university preparation, your student teaching and the classroom management used/ taught in each. In addition, I will be asking you specific questions about how you feel about these types of management and your future teaching.

1. Tell me about yourselves and how you all decided to become a teacher. Paint the picture; ask for examples and stories.

2. Tell me about your student teaching.

3. Is teaching what you thought it would be? In what ways?

4. In what ways did teacher prep prepare you for the classroom? In what ways, did you feel there were gaps?

5. I'm interested in classroom management for teacher candidates and new teachers. Can you tell me about the classroom management or discipline that your school had in place? Approach/ program?

a. What did that look like in your classrooms? Paint the picture. Give examples. Tell me that story.

b. So, what did you think about that program [school/ classrooms]?

6. Can you tell me about the sense of community that your school/ classroom had established? Approach/program/ components?

a. What did that look like in your classrooms? Paint the picture. Give examples. Tell me that story.

b. So, what did you think about that program [school/ classrooms]?

7. (if it hasn't already come up...) Tell me about the relationship between the two: classroom management and sense of community in your setting.

8. In an ideal world, what would you do? What would be the ideal set-up?

a. What are you basing that on? Where does this come from? [Is this out of ISU/ personal experience/ CT?]

9. How did your teacher preparation cover classroom management? Classroom community?

10. Is there anything else you want to share with me about what we talked about today? Anything I didn't ask, but you thought I would?

11. Do you have anything more you want to tell me about?

12. Do you have any questions for me?

13. Demographic information about participants will be gathered at the end of the interview. 
2014-2015 Case Studies First Interview Protocol

(Administered at the start of the school year, or when entered the study)

Interview with

Date Time Location

Thank you so much for meeting with me today. The purpose of this interview is to help me understand how you are feeling as a new teacher at the start of the school year. This interview will last about an hour and I will be asking you questions about your teaching, your university preparation, and your feelings about this upcoming year. I will be asking you specific questions about how you feel about classroom management and classroom community for this year.

1. Tell me about getting hired for this position.

a. How did the interview process go?

b. Did any questions surprise you?

c. Were there any questions related to classroom management/ community/ discipline?

2. How is the start of the school year going?

3. What are you most excited about for this year?

4. What are you most worried about?

5. Have you been assigned or found a mentor?

6. What have you learned about the school's/ grade level's approach to classroom management/ community? How has this been communicated to you?

7. What plans do you have this year related to your classroom management/ community?

8. What excites you about this plan?

9. What are you most worried about?

10. Is there anything else you want to share with me about what we talked about today? Anything I didn't ask, but you thought I would?

11. Do you have anything more you want to tell me about?

12. Do you have any questions for me? 
2014-2015 Case Studies Second-Fourth Interview Protocol

(Administered in November, January, and March 2014-2015)

Interview with

Date _ Time___ Location

Thank you so much for meeting with me today. The purpose of this interview is to help me

understand how the school year is going for you. This interview will last about an hour, and I

will be asking you questions about your teaching, your students, and your feelings about it all. I

will be asking you specific questions about your classroom management and classroom

community.

1. How is your school year going? How has it been coming back from breaks?

2. What is going well?

3. What is not going so well?

4. Tell me about your students.

5. What is the best part of working with them? What is the toughest part?

6. How is mentorship going (if going)? How is this person supporting/ not supporting you?

7. How is working in the school?

8. Tell me about your classroom management.

9. Successes? Challenges?

10. How does this mesh with what the school is doing?

11. Do you realize any influences from your teacher prep? How? In what ways?

12. Is there anything else you want to share with me about what we talked about today? Anything I didn't ask, but you thought I would?

13. Do you have anything more you want to tell me about?

14. Do you have any questions for me? 
2014-2015 Case Studies Final Interview Protocol

(Administered in May-June 2015, depending on when the school year ended)

Interview with

Date Time Location

Thank you so much for meeting with me today. The purpose of this final interview is to help me understand how the school year went for you. This interview will last about an hour, and I will be asking you questions about your teaching, your students, and your feelings about it all. I will be asking you specific questions about your classroom management and classroom community.

1. Tell me about the first year of school. What went well? What are you proud of?

2. What did not go so well?

3. Tell me about your students.

4. What was the best part of working with them? What was the toughest part?

5. Tell me about the mentorship you received this year. How did this go? How did this person support/ not support you?

6. Tell me about working in this school. How was working in the school?

7. Tell me about your classroom management.

8. Successes? Challenges?

9. How did this mesh with what the school was doing?

10. Did you realize any influences from your teacher prep? How? In what ways?

11. What are your plans for next year? What will you do the same? What will you do differently?

12. Is there anything else you want to share with me about what we talked about today? Anything I didn't ask, but you thought I would?

13. Do you have anything more you want to tell me about?

14. Do you have any questions for me? 